University of Louisville

ThinkIR: The University of Louisville's Institutional Repository

Electronic Theses and Dissertations

8-2017

\title{
Cationic surfactant modification and its impact on the engineering behaviors of montmorillonite.
}

\author{
Mohammad Ghavami \\ University of Louisville
}

Follow this and additional works at: https://ir.library.louisville.edu/etd

Part of the Environmental Engineering Commons, and the Geotechnical Engineering Commons

\section{Recommended Citation}

Ghavami, Mohammad, "Cationic surfactant modification and its impact on the engineering behaviors of montmorillonite." (2017). Electronic Theses and Dissertations. Paper 2788.

https://doi.org/10.18297/etd/2788

This Doctoral Dissertation is brought to you for free and open access by ThinkIR: The University of Louisville's Institutional Repository. It has been accepted for inclusion in Electronic Theses and Dissertations by an authorized administrator of ThinkIR: The University of Louisville's Institutional Repository. This title appears here courtesy of the author, who has retained all other copyrights. For more information, please contact thinkir@louisville.edu. 


\title{
CATIONIC SURFACTANT MODIFICATION AND ITS IMPACT ON THE ENGINEERING BEHAVIORS OF MONTMORILLONITE
}

\author{
By \\ Mohammad Ghavami

\begin{abstract}
A Dissertation
Submitted to the faculty of the

J.B. Speed School of Engineering at the University of Louisville In Partial Fulfillment of the Requirements for the Degree of
\end{abstract} \\ Doctor of Philosophy \\ In Civil Engineering \\ Department of Civil and Environmental Engineering \\ University of Louisville \\ Louisville, Kentucky
}

August, 2017 
Copyright 2017 by Mohammad Ghavami

All rights reserved 

CATIONIC SURFACTANT MODIFICATION AND ITS IMPACT ON THE ENGINEERING BEHAVIORS OF MONTMORILLONITE

By

Mohammad Ghavami

A Dissertation Approved on

May 25, 2017

by the Following Committee:

Dr. Qian Zhao, Dissertation Director

Dr. Thomas D. Rockaway

Dr. Young Hoon Kim

Dr. Li Yang 
To my beloved parents, Ali Ghavami and Maryam Mirhassannia

For their continuous love and endless support 


\section{ACKNOWLEDGMENTS}

This research would not have been completed without the help and support of so many great people in so many ways. I would like to sincerely thank my research advisor, Dr. Qian Zhao, for his excellent guidance and the countless hours of time and effort that he has dedicated to my success. He helped me to broaden my knowledge in geotechnical and geoenvironmental engineering, and his help will not be forgotten.

I would like to thank my committee members, Dr. Thomas Rockaway, Dr. Young Hoon Kim, and Dr. Li Yang, for their invaluable contributions and insightful comments throughout my dissertation. I would also like to acknowledge Dr. J. P. Mohsen, the head of Department of Civil and Environmental Engineering, for his willingness to help in many situations throughout my Ph.D. studies at the University of Louisville. His sincere help and support are very much appreciated. I would like to extend my appreciation to other CEE faculty members and staffs for their help.

I want to give special thanks to all my wonderful friends and colleagues: Sadra Javadi, Hong Shang, Mahyar Ramezani, Mahyar Ghorbanian, Bashir Hassanzadeh, Nina Saraei, Masoud derakhshani, Farhad Imani, Mehdi Farhangi, and Hossein Mirinezhad for their friendship and support. You are great friends to me and I am so blessed to have you all in my life. 
Lastly but most importantly, I would like to truly appreciate my family for their prayer and unconditional support. I would like to express my sincere gratitude to my parents, sister, and brother-in-law whom have encouraged, inspired and supported me throughout my whole life. 


\begin{abstract}
CATIONIC SURFACTANT MODIFICATION AND ITS IMPACT ON THE ENGINEERING BEHAVIORS OF MONTMORILLONITE

Mohammad Ghavami
\end{abstract}

May 25, 2017

This study focuses on the microstructure of organoclays after organic surfactant modifications and the potential use in geoenvironmental engineering applications including waste containment in earthen barrier, rheological control agents for drilling fluid and soil stabilization. Organoclays, or clays modified by organic matters, are often synthesized by exchanging the naturally occurring interlayer inorganic cations (e.g., Na+, $\mathrm{Ca}^{2+}$ ) of the clay with organic cationic surfactants. In this research, montmorillonites intercalated with two quaternary ammonium surfactants, hexadecyltrimethylammonium (HDTMA+) and bis (hydrogenated tallow alkyl) dimethyl ammonium were used as the representative organo-rich, partitioning clays.

The laboratory characterization techniques including XRD, TEM and FT-IR were employed to examine the interactions between montmorillonite minerals, surfactants, and organic sorbates. The results of XRD and TEM showed the successive interlayer expansion of montmorillonite because of intercalation of surfactants and hydrocarbons sorbates. The 
FT-IR results further confirmed the arrangement of the intercalated surfactant and the organic sorbates due to primary and secondary sorption.

To understand the engineering behaviors of organoclays in earthen barriers, the free swelling and hydraulic conductivity tests were conducted to evaluate the permeability of compacted clay and geosynthetic clay liner (GCL) amended with HDTMA-organoclay. The results suggested that the addition of organoclay (less than 10\%) in compacted clay slightly increased the permeability of the mixture to water. However, due to the interaction between the organophilic phase in organoclays and non-polar liquids, low amounts of organoclay within the compacted clay admixture significantly decreased its permeability for non-polar liquids such as gasoline. Moreover, it was observed that low weight percentages of HDTMA-bentonite (up to $20 \%$ by weight) had little or no impact on the hydraulic conductivity of the Na-bentonite or Ca-bentonite GCL. However, higher dosages of organoclay in GCLs could reduce the permeability to organic fluids such as gasoline.

The impact of the amount of organoclay additives, pressure and temperature on the rheological behavior of organoclay/oil-based drilling fluids was investigated. The obtained results from XRD test suggested that the oil molecules entered the PM199 interlayer, resulting in swelling and exfoliation of PM199. It was observed that the viscosity of 5\% PM199 suspension slightly decreased by increasing the temperature from 25 to $60{ }^{\circ} \mathrm{C}$, and then the viscosity increased when the temperature raised from 60 to $150{ }^{\circ} \mathrm{C}$. Moreover, it was found that the viscosity of 5\% PM199 suspension increased when the pressure increased from 0 to 200 bar due to physical changes on both oil and organoclay particles.

The effectiveness of organoclay and Portland cement for the solidification and stabilization (S/S) of contaminated soils was investigated in the laboratory. The results 
indicated that the addition of cement (5\% or $10 \%$ by weight) reduced the hydraulic conductivity and increased the compressive strength of the solidification and stabilization soil specimens. Additionally, the leaching test results indicated that the addition of organoclay during solidification and stabilization significantly reduced the leaching of naphthalene and phenanthrene from the stabilized soil specimen. The results suggested that organoclay particles sorbed the organic contaminates and consequently reduced the naphthalene and phenanthrene leachate concentration. Also, it was observed that the naphthalene and phenanthrene leachate concentration decreased by increasing the curing time of $\mathrm{S} / \mathrm{S}$ products.

Overall, this study performed laboratory tests to obtain information regarding the microsturcture of cationic surfactant modifed bentonties and their engineering behaviors (e.g. hydrophobicity, swelling, permeability, stability in oil suspension). The obtained results are expected to yield significant insights into their potential applications as sorbents in hydraulic and sorptive barriers for organic compounds; rheological control additives in oil-based drilling fluid; agents for stabilization and solidification of contaminated soils. 


\section{TABLE OF CONTENTS}

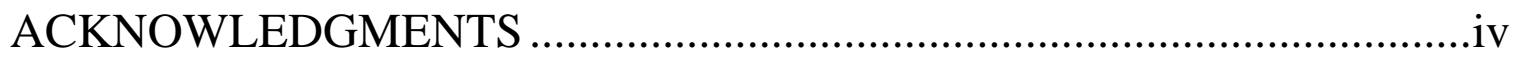

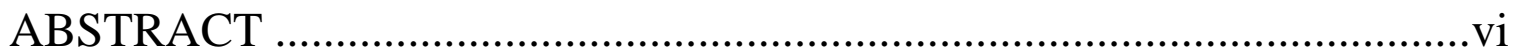

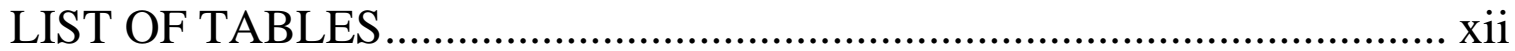

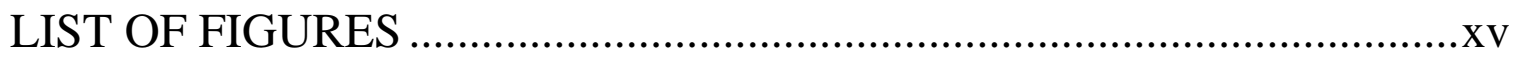

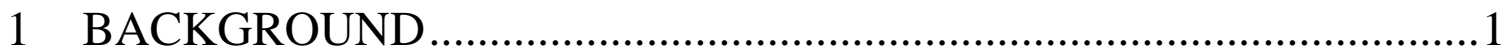

1.1 Clay minerals and montmorillonite............................................................... 1

1.2 Properties and characterizations of montmorillonite …………........................ 2

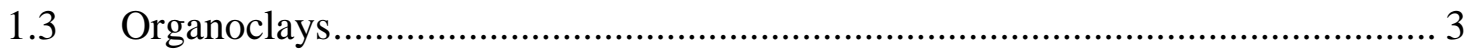

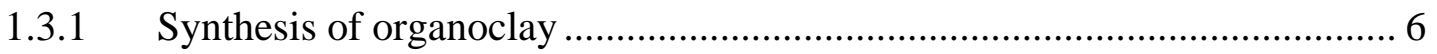

1.3.2 Organic cations arrangement in organoclays ............................................ 7

1.4 Engineering properties of organoclays........................................................... 8

1.4.1 Atterberg limit and hydrophobicity ..................................................... 9

1.4.2 Swelling behavior and hydraulic conductivity ......................................... 9

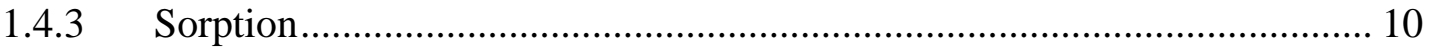

1.4.4 Shear strength and dynamic properties ................................................... 11

1.5 Engineering application of organoclays ....................................................... 12

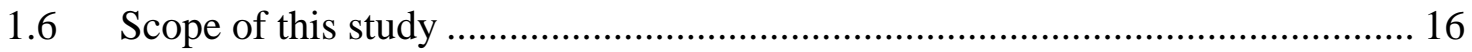

2 CHANGES OF ORGANOBENTONITE INTERLAYER

MICROSTRUCTURE INDUCED BY SORPTION OF ORGANIC

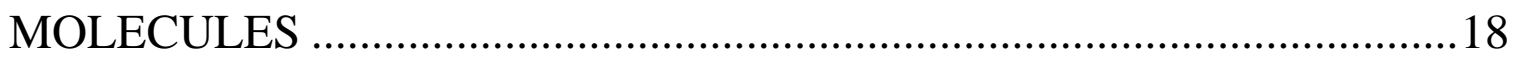

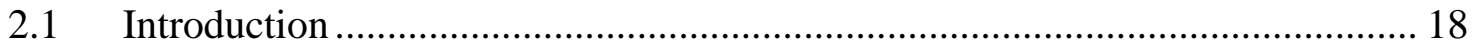

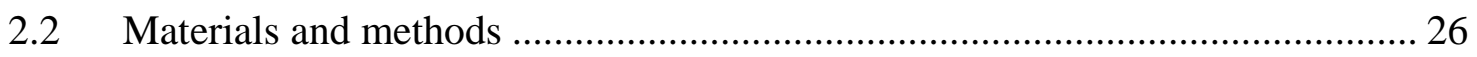

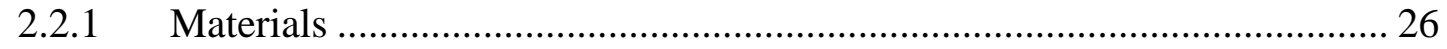

2.2.2 Experimental Methods ....................................................................... 30

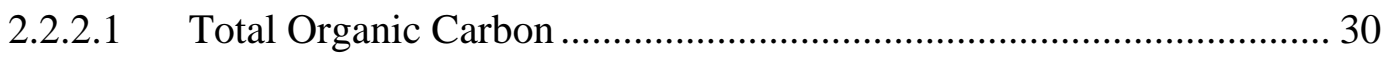


2.2.2.2 Atterberg Limits .......................................................................... 31

2.2.2.3 Specific Gravity ............................................................................. 31

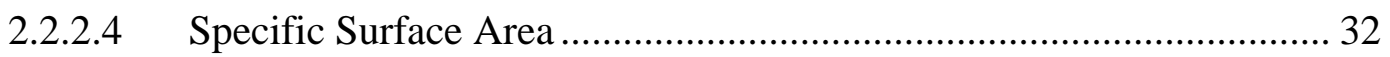

2.2.2.5 X-ray diffraction (XRD) ................................................................. 33

2.2.2.6 Scanning electron microscopy (SEM) …………………………........ 36

2.2.2.7 Transmission electron microscopy (TEM) ......................................... 38

2.2.2.8 Fourier transform infrared spectroscopy (FT-IR)................................ 40

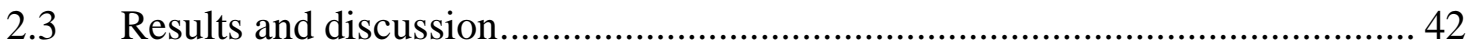

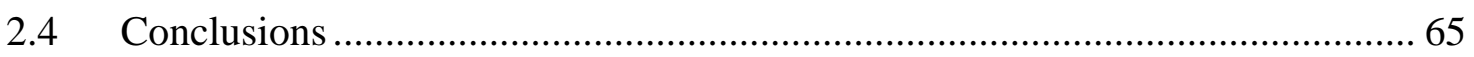

3 CONTAMINANTS FLOW IN COMPACTED CLAY LINER (CCL) AND GEOSYNTHETIC CLAY LINER (GCL) WITH ORGANOBENTONITE AMENDMENT ...................................................67

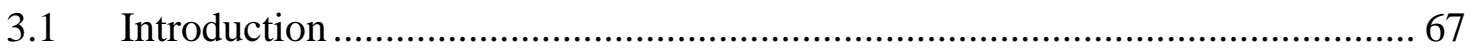

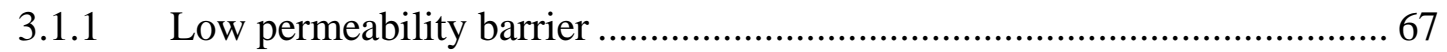

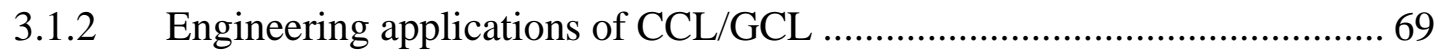

3.1.3 Problems observed in conventional CCL/GCL ........................................ 70

3.1.4 Organoclay amendment in CCL/GCL ................................................. 72

3.2 Compacted clay liner amended with organobentonite ……............................... 75

3.2.1 Materials and methods ………………………….................................. 75

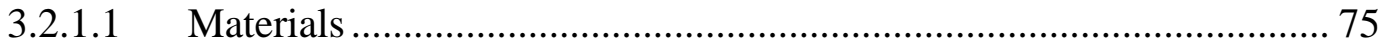

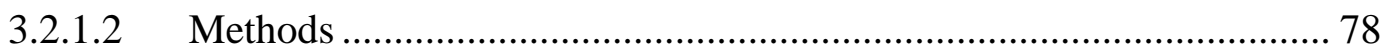

3.2.2 Results and discussion ......................................................................... 91

3.3 Geosynthetic clay liner amended with organobentonite .................................... 101

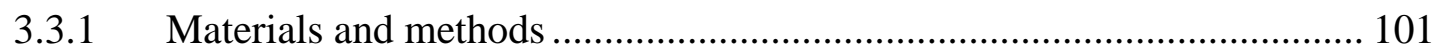

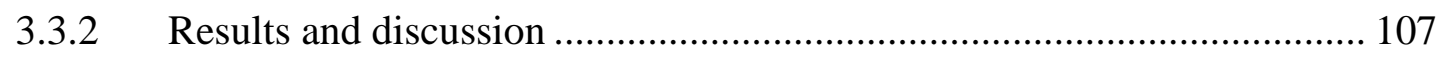

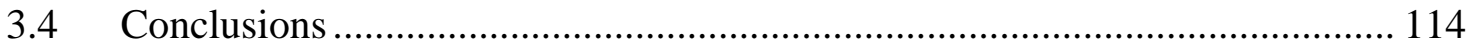

4 RHEOLOGICAL BEHAVIOR OF ORGANOBENTONITE ADDITIVE IN OIL-BASED DRILLING FLUIDS ....................................................117

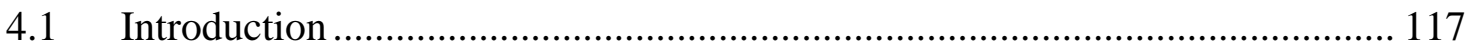

4.2 Materials and methods ...................................................................... 124

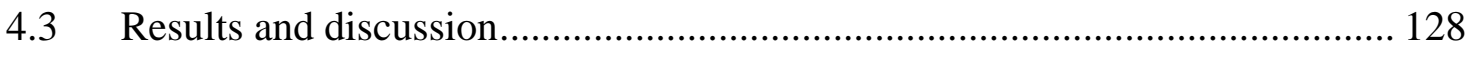




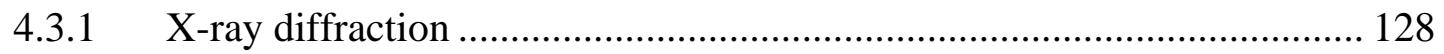

4.3.2 Gel volume (swelling volume) ............................................................... 138

4.3.3 Viscous flow measurement ................................................................. 140

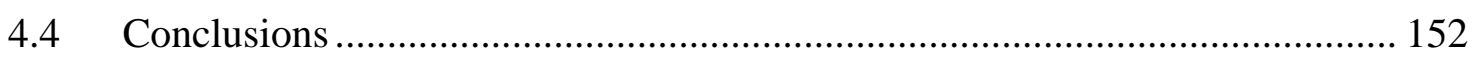

5 CEMENT-ORGANOBENTONITE ADMIXTURES FOR STABILIZATION/SOLIDIFICATION OF PAH-CONTAMINATED SOIL 155

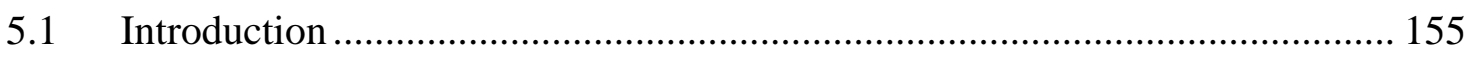

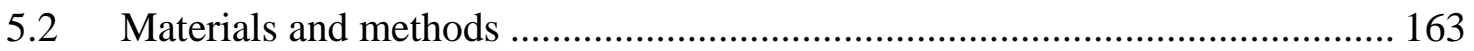

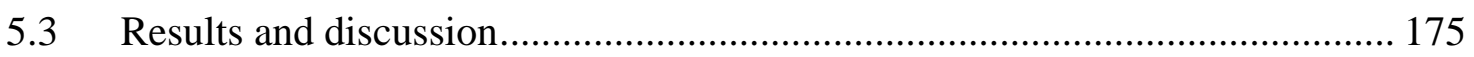

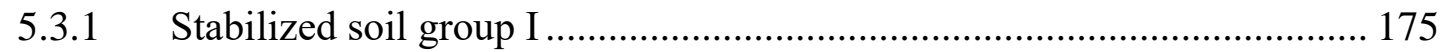

5.3.1.1 Unconfined Compressive Strength................................................. 175

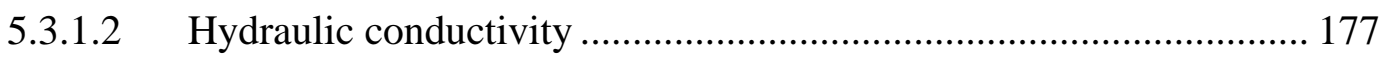

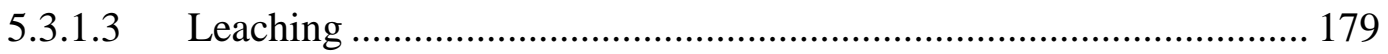

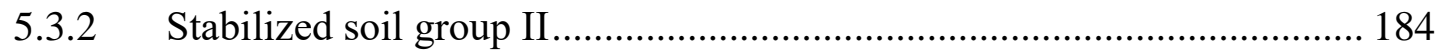

5.3.2.1 Unconfined compressive strength ................................................... 184

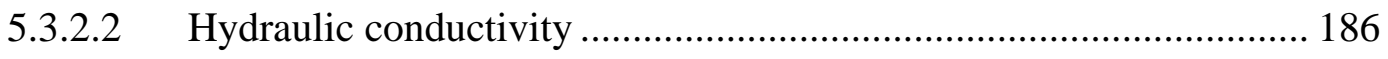

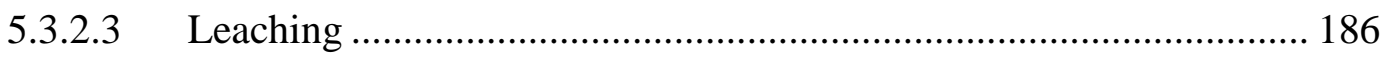

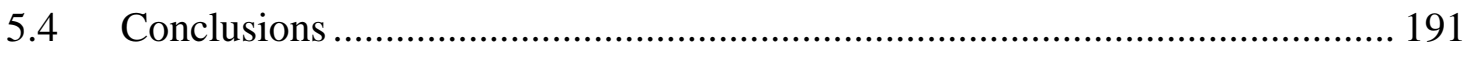

6 CONCLUSIONS AND RECOMMENDATIONS ............................194

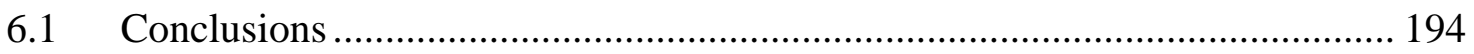

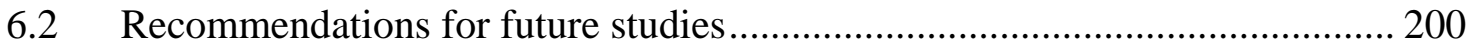

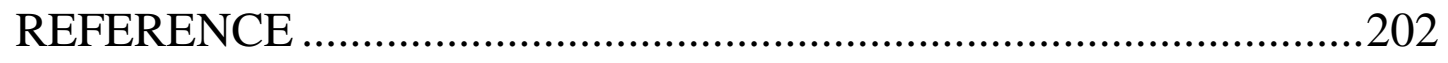

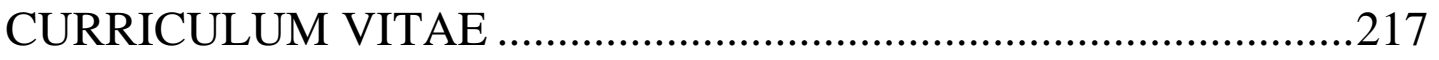




\section{LIST OF TABLES}

Table 1-1. Summary of previous studies on the application of organoclay.................... 17

Table 2-1. Comparison of the this study with previous studies ................................... 24

Table 2-2. Partitioning and hydrodynamic properties of the studied liquids................... 30

Table 2-3. Physicochemical properties of the studied soils .......................................... 43

Table 2-4. Sorbents performance of HDTMA-MMT, and PM199 ............................... 45

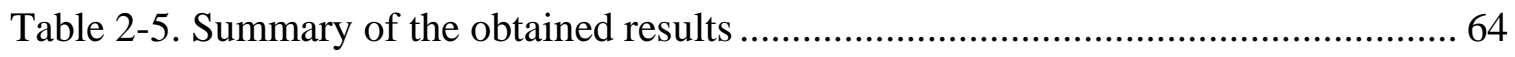

Table 3-1. Some selected difference between GCL and CCL (Sharma and Reddy 2004)70

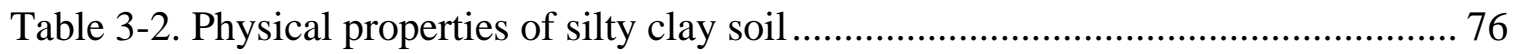

Table 3-3. Physico-chemical properties of the studied fluids ..................................... 77

Table 3-4. Hydraulic conductivity testing matrix for the admixture of silty clay and

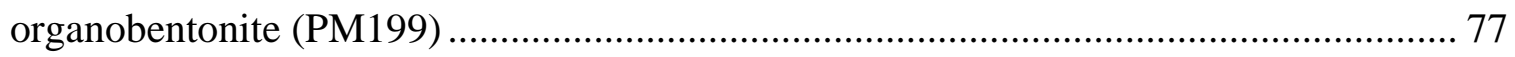

Table 3-5. Testing matrix for the admixture of silty clay, Ca-MMT, and HDTMA-MMT

Table 3-6. Swelling index for silty clay-organobentonite mixtures permeated with water, methanol and naphthalene/methanol solution...................................................... 91

Table 3-7. Hydraulic Conductivity and Intrinsic Permeability of Silty Clay-

Organobentonite Mixtures Permeated with Water ................................................. 93

Table 3-8. Conductivity and Intrinsic Permeability of 50\% Silty Clay- 50\%

Organobentonite Permeated with Water, Methanol, and Naphthalene/Methanol Solution .95

Table 3-9. Average fluid conductivities of compacted soils with varying permeants...... 99

Table 3-10. Physio-chemical properties of bentonites and organobentonite.................. 102

Table 3-11. Hydraulic conductivity of GCL (Ca-bentonite (100\%)) as a function of

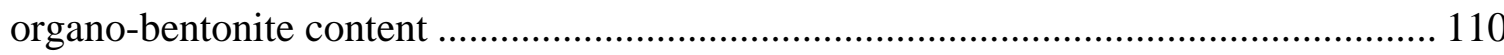

Table 3-12. Hydraulic conductivity of GCL (Na-bentonite (100\%)) as a function of organo-bentonite content 
Table 3-13. Conductivity of GCL (Na-bentonite (100\%)) permeated with water, methanol, and gasoline

Table 3-14. Conductivity of GCL (HDTMA-bentonite (100\%)) permeated with water, methanol, and gasoline

Table 3-15. Conductivity of GCL (Na-bentonite (90\%) + HDTMA-bentonite (10\%) permeated with water, methanol, and gasoline.

Table 4-1. The physiochemical properties of the studied soils.

Table 4-2. Summary of previous studies on organobentonite/oil-based drilling fluids.. 137 Table 4-3. Bingham's parameters for PM199 and HDTMA-MMT(1.0 CEC) suspensions as a function of the organobentonites concentrations

Table 4-4. Bingham's parameters for Na-bentonite suspensions as a function of $\mathrm{Na}$ bentonite concentrations

Table 4-5. Bingham's parameters for 5\% HDTMA-MMT suspension as a function of CEC loading.

Table 4-6. Bingham's parameters for 5\% PM199 suspension as a function of temperature

Table 4-7. Bingham's parameters for 5\% PM199 suspension as a function of pressure 151

Table 5-1. The physiochemical properties of the studied soils. 163

Table 5-2. Chemical composition of Portland cement............................................... 164

Table 5-3. Physicochemical properties of naphthalene and phenanthrene 165

Table 5-4. Testing matrix for stabilization and solidification for contaminated soil (a) group I (b) group II 167

Table 5-5. Unconfined compressive strength of S/S contaminated soil ....................... 175

Table 5-6. Hydraulic conductivity of S/S contaminated soil 178

Table 5-7. Initial concentration of naphthalene and phenanthrene before and after evaporation of acetone 180

Table 5-8. Summary of final concentration of (a) naphthalene and (b) phenanthrene in S/S specimens test by acetone Toxicity Characteristic Leaching Procedure. 182

Table 5-9. Unconfined compressive strength of S/S contaminated soil 185

Table 5-10. Hydraulic conductivity of S/S contaminated soil 186 
Table 5-11. Summary of final concentration of (a) naphthalene and (b) phenanthrene in S/S specimens test by acetone Toxicity Characteristic Leaching Procedure................. 188 


\section{LIST OF FIGURES}

Figure 1-1. Structure of (a) kaolinite, (b) illite and (c) smectite (montmorillonite) ........... 2 Figure 1-2. (a) Structure of quaternary ammonium cations (b) structure of hexadecyltrimethlyammonium (HDTMA), one of the QACs ....................................... 5

Figure 1-3. Structure of unmodified and modified bentonite (montmorillonite)............... 5

Figure 1-4. Interlamellar arrangements of alkylammonium ions in interlayers of space of montmorillonite (a) monolayer (b) bilayers (c) pseudotrimolecular layer (d) paraffin

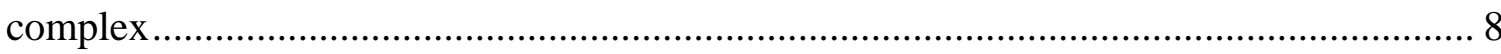

Figure 2-1. Primary and secondary sorption.................................................................. 19

Figure 2-2. Different chain arrangement: (a) trans conformation (b) gauche conformation

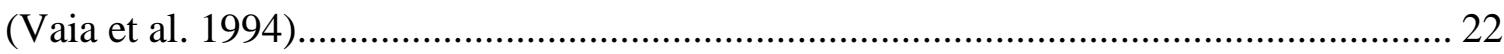

Figure 2-3. Structure of the hexadecyltrimethylammonium (HDTMA) bromide ............ 27

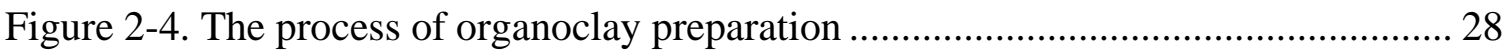

Figure 2-5. The images of the soils (a) Ca-MMT (b) HDTMA-MMT (c) PM199 ......... 29

Figure 2-6. X-Ray Diffraction (XRD) schematic pattern .......................................... 34

Figure 2-7. XRD machine and its main components (University of Kentucky) .............. 35

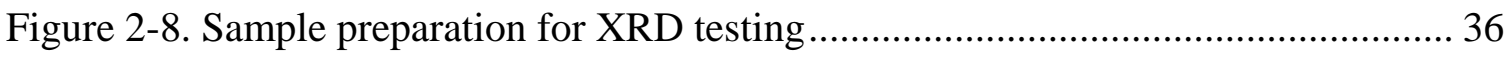

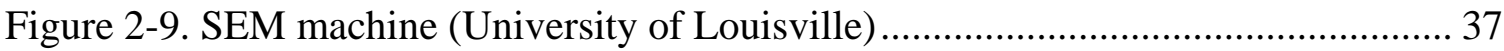

Figure 2-10. Sample preparation for SEM testing ................................................... 38

Figure 2-11. Gold sputter coating machine (University of Louisville) ......................... 38

Figure 2-12. FEI Tecnai TEM machine (University of Louisville) ............................... 39

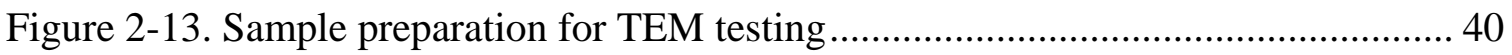

Figure 2-14. Thermo Nicolet 360 FTIR spectrometer (University of Louisville) ............ 41

Figure 2-15. XRD patterns of HDTMA-MMT and HDTMA-MMT with sorbed

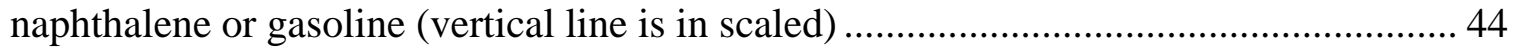

Figure 2-16. XRD patterns of PM199 before and after sorption of gasoline ................. 46 
Figure 2-17. SEM images of Ca-MMT at different magnifications ............................. 48

Figure 2-18. SEM images of HDTMA-MMT at different magnifications ...................... 49

Figure 2-19. SEM images of PM199 at different magnifications................................... 50

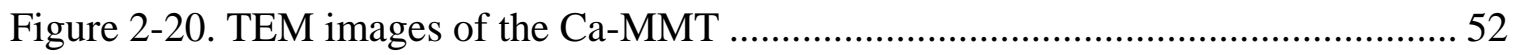

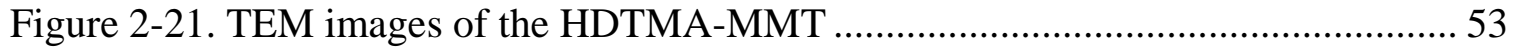

Figure 2-22. TEM images of HDTMA-MMT with sorbed naphthalene ......................... 54

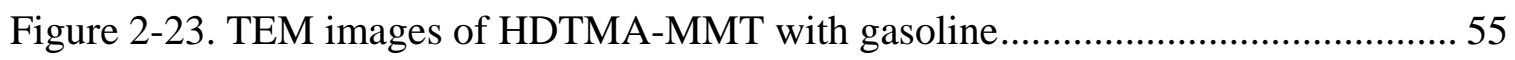

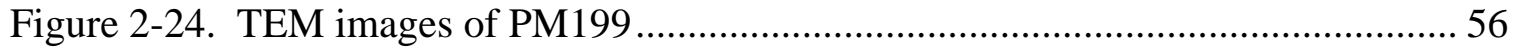

Figure 2-25. TEM images of PM199 with sorbed gasoline ......................................... 57

Figure 2-26. FT-IR spectra of: (a) Ca-MMT, HDTMA-MMT and HDTMA-Br............. 58

Figure 2-27. FT-IR spectra of HDTMA-MMT, naphthalene, HDTMA-MMT with sorbed naphthalene 60

Figure 2-28. FT-IR spectra of HDTMA-MMT, gasoline, HDTMA-MMT with sorbed gasoline 61

Figure 2-29. FT-IR spectra of PM199, gasoline, PM199 with sorbed gasoline ............... 62

Figure 2-30. FT-IR spectra of selected regions of FTIR spectra of 4 soils ..................... 63

Figure 3-1. General cross-section of geosynthetic clay liner (GCL) ............................. 69

Figure 3-2. Leaking underground storage tank.................................................... 71

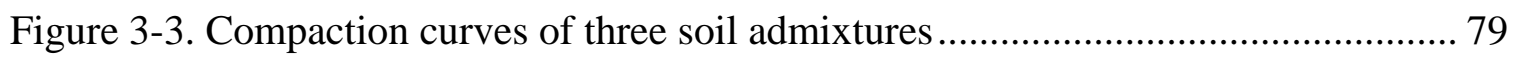

Figure 3-4. One-dimensional oedometer test setup (load device with consolidometer)... 80

Figure 3-5. A fixed oedometer (consolidation) ring ............................................. 81

Figure 3-6. Pressure control panel (Trautwein soil testing Co.) ….............................. 83

Figure 3-7. (a) the mixture of soil with water (b) compacted soil in a compaction mold 84

Figure 3-8. (a) sample trimmer (b) specimen after trimming ..................................... 85

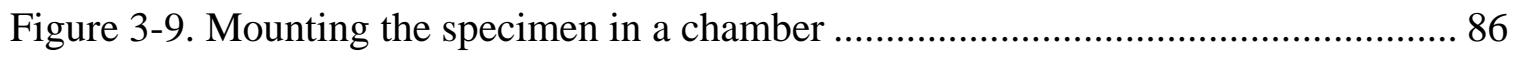

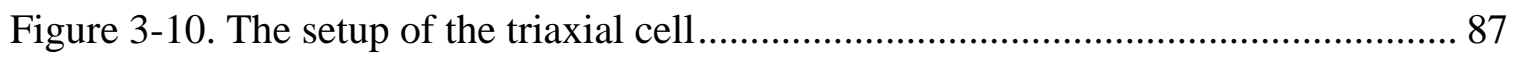

Figure 3-11. Hydraulic conductivity test setup for CCL specimen ............................... 88

Figure 3-12. Hydraulic conductivity of mixtures with two different chamber pressure .. 94

Figure 3-13. One-dimensional swelling of the studied soils in water............................ 96

Figure 3-14. One-dimensional swelling of the studied soils in gasoline ....................... 97 
Figure 3-15. (a) Roll of GCL Bentomat 200R (b) Components of GCL Bentomat 200R 103

Figure 3-16. GCL specimen preparation procedure 104

Figure 3-17. Schematic diagram of GCL specimen in permeameter cell (ASTM D6766-

12) 105

Figure 3-18. Hydraulic conductivity test setup for GCL specimen 106

Figure 3-19. Free swelling volume for Na-bentonite, Ca-bentonite, and HDTMAbentonite permeated with water, methanol, and gasoline 108

Figure 4-1. The circulation of drilling mud during the drilling of a well 118

Figure 4-2. Common drilling fluids classification 119

Figure 4-3. (a) Concentric cylinder geometry (b) Concentric cylinder-pressure cell geometry with cap

Figure 4-4. XRD patterns of untreated and treated bentonite 130

Figure 4-5. XRD patterns of (a) PM199 and (b) HDTMA-MMT (0.5 CEC) (c) HDTMAMMT (1.0 CEC) and (d) HDTMA-MMT (2.0 CEC) with various concentration of sorbed diesel oil.

Figure 4-6. (a) Microstructure of the organobentonites (HDTMA-MMT(1.0 CEC) and PM199) before and after sorption of diesel oil (b) dispersion of two organoclays in oil medium

Figure 4-7. (a) Gel volume of organobentonites as a function of organobentonite concentration (b) gel volume of 5\% HDTMA-MMT as a function of surfactant loading

Figure 4-8. Gel volume of 5\% HDTMA-MMT (1 CEC) and PM199 suspensions within 48 hours

Figure 4-9. (a) shear stress versus shear rate (b) viscosity versus shear rate of PM199 suspension as a function of PM199 concentration 142

Figure 4-10. (a) shear stress versus shear rate (b) viscosity versus shear rate of HDTMAMMT (1.0 CEC) suspension as a function of HDTMA-MMT concentration 143

Figure 4-11. The predicted viscosity of PM199 and HDTMA-MMT(1.0 CEC) as a function of organobentonite percentage. 
Figure 4-12. (a) shear stress versus shear rate (b) viscosity versus shear rate of Nabentonite suspension as a function of Na-bentonite concentration.

Figure 4-13. (a) shear stress versus shear rate (b) viscosity versus shear rate of $5 \%$

HDTMA-bentonite suspension as a function of CEC loading.

Figure 4-14. (a) shear stress versus shear rate (b) viscosity versus shear rate of $5 \%$

PM199 suspension as a function of temperature

Figure 4-15. (a) shear stress versus shear rate (b) viscosity versus shear rate of 5\%

PM199 suspension as a function of pressure.

Figure 5-1. Procedure of making S/S specimen

Figure 5-2. Detailed experimental program of $\mathrm{S} / \mathrm{S}$ treatment of naphthalene and

phenanthrene contaminated soil (a) group I (b) group II ......................................... 170

Figure 5-3. Simplified schematic of a batch equilibrium leaching procedure ............... 174

Figure 5-4. Comparison of unconfined compressive strength of S/S samples to USEPA standard 177

Figure 5-5. Reduction in (a) naphthalene and (b) phenanthrene mass leaching for each mix design......

Figure 5-6. Comparison of unconfined compressive strength of S/S samples to USEPA

standard 185

Figure 5-7. Reduction in (a) naphthalene and (b) phenanthrene mass leaching for each mix design. 190 


\section{BACKGROUND}

\subsection{Clay minerals and montmorillonite}

Clay is naturally occurring soil composed primarily of fine-grained soil minerals (Guggenheim and Martin 1995). Clays have a broad range of applications in wastewater treatment, oil spill control, drilling and other industrial activities (Bergaya and Lagaly 2013). The most common groups of crystalline minerals of clays are: kaolinite, illite and smectite. Kaolinite has a structure that consists of one silica sheet and one alumina sheet bonded together into a layer about $0.72 \mathrm{~nm}$ thick and stacked repeatedly, and the layers are held together by hydrogen bonds. Illite consists of repeated layers of one alumina sheet sandwiched by two silicate sheets with a thickness of $0.92 \mathrm{~nm}$. The layers are held together by potassium ions. The smectite group is composed of several minerals including pyrophyllite, talc, vermiculite, sauconite, saponite, nontronite and montmorillonite. The montmorillonite has a structure similar to illite, except its layers are held together by weak van der Waals forces and exchangeable ions. As the van der Waals bonds are relatively

weak, the surface sites can easily attract water and other smaller molecules, montmorillonite is typically considered a swelling clay mineral (Figure 1-1). 


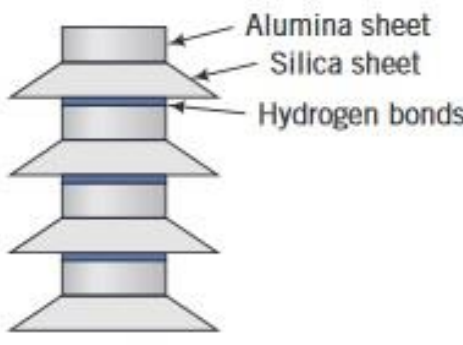

(a) Kaolinite

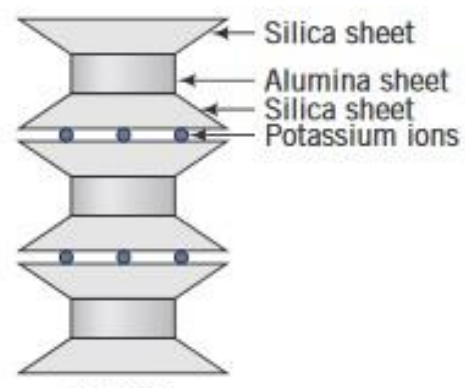

(b) Illite

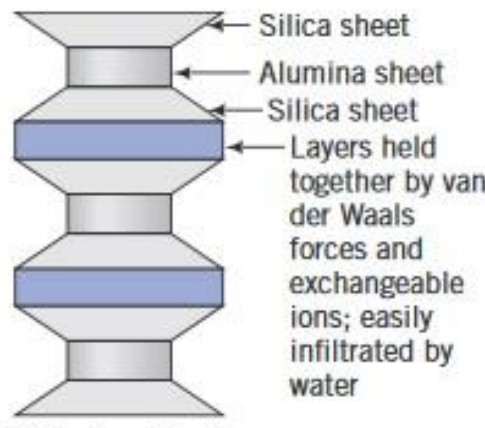

(c) Montmorillonite

Figure 1-1. Structure of (a) kaolinite, (b) illite and (c) smectite (montmorillonite)

(Budhu 2008)

\subsection{Properties and characterizations of montmorillonite}

Due to its composition, montmorillonite $\left[\mathrm{Na} 0.65(\mathrm{Al}, \mathrm{Fe})_{4}\left(\mathrm{Si}_{8} \mathrm{O}_{20}\right)(\mathrm{OH})_{2}\right]$ is one of the most interesting and important clay minerals (Xie et al. 2001). It has negative surface charges, and these negative charges are balanced by interlayer cations (e.g. $\mathrm{Na}^{+}, \mathrm{K}^{+}, \mathrm{Ca}^{2+}$, or $\left.\mathrm{Mg}^{2+}\right)$. The interlayer water molecules can be either sorbed to the montmorillonite surfaces or hydration shells around interlayer inorganic cations (Gleason et al. 1997). The ability of the montmorillonite to sorb significant amounts of water is important in that it separates its behavior from other similar materials.

Cations within the interlayers of montmorillonite are typically exchangeable. The ability of montmorillonite to exchange its naturally occurring cations with the cations in aqueous phase in referred to as the cation exchange capacity (CEC). CEC is typically expressed in centimole of positive charge per kilogram of dry clay minerals, which is numerically equal to the traditional unit of milliequivalents per $100 \mathrm{~g}$ of clay mineral 
(meq/100 g). The CEC of pure montmorillonite is generally between 80 to $150 \mathrm{meq} / 100 \mathrm{~g}$ (Bergaya and Lagaly 2013).

Montmorillonite typically has a large specific surface area as well as a large net negative charge. When these two characteristics are combined, the montmorillonite is able to sorb a large number of hydrated cations. As a result, these sorbed cations and water molecules can compose a substantial fraction of the pore space. Moreover, the tendency of montmorillonite minerals to sorb hydrated cations and water molecules results in remarkable swelling and volumetric expansion (usually 5-10 times of its dry volume).

Montmorillonite (bentonite) has been used in many engineering practices including drilling, wastewater treatment, waste containment, etc (Bergaya and Lagaly 2006). Importantly, bentonite has been widely used as a component of the hydraulic barrier systems such as geosynthetic clay liners to prevent pollutants to the subsurface (Bouazza 2002). Moreover, montmorillonite has been used for many decades in the drilling as a major constituent of drilling fluid, making the drilling fluid more viscous, and helping to keep the drill bit cool. Additionally, montmorillonite has been employed as a promising material for wastewater treatment and sludge dewatering.

\subsection{Organoclays}

Clay minerals can interact with various types of organic compounds due to its porous microstructure and layered charge characteristics. Chemical modification, especially surfactant or polymer modification of clay minerals have gained significant attention recently since it allows the creation of clay-polymer or clay-surfactant hybrids with enhanced engineering behaviors (Beall 2003; de Paiva et al. 2008; Di et al. 2005). The 
intercalated organoclays (organobentonites) can be prepared by exchanging the clay's inorganic cations with various types of organic cations. Among the naturally occurring clay minerals, montmorillonite has been widely employed to prepare the organoclay due to its promising properties including high cation exchange capacity, large surface area, high adsorption, and significant swelling behavior.

Although organoclay is a collective term to describe clay/organics hybrids, this dissertation only focused on the surfactant modified bentonites and they are all referred to as "organoclays" in the following chapters. Surfactant modified organoclays in this dissertation are synthesized by intercalating quaternary alkylammonium cations (QACs) into the interlayer of the inorganic bentonites (Park et al. 2011; Zhao and Burns 2012). QACs are composed of a nitrogen head group and four exchangeable positions that can be occupied by organic functional groups with different structures and sizes (Figure 1-2). The process of introducing quaternary alkylammonium organic cations onto bentonite surface by replacing inorganic cations can be denoted as primary sorption of organic cations (Figure 1-3). The interlayer of unmodified clay is relatively small, and the environment of the interlayer is hydrophilic due to the attendance of inorganic cations. Intercalation of organic surfactant within the clay interlayers not only changes the hydrophilic environment to hydrophobic, but also significantly increases the interlayer spacing (Lagaly 1981). The expansion of the interlayer space is expressed by basal spacing. 


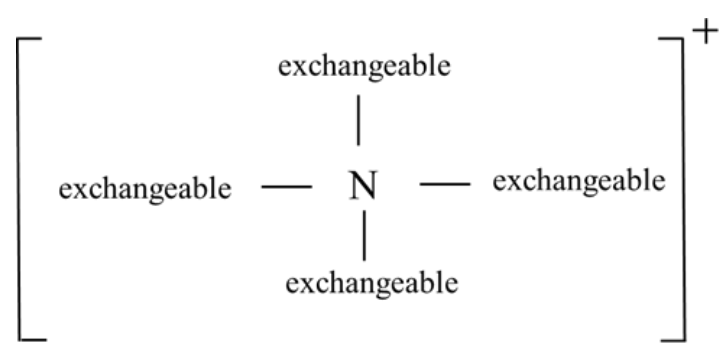

(a)

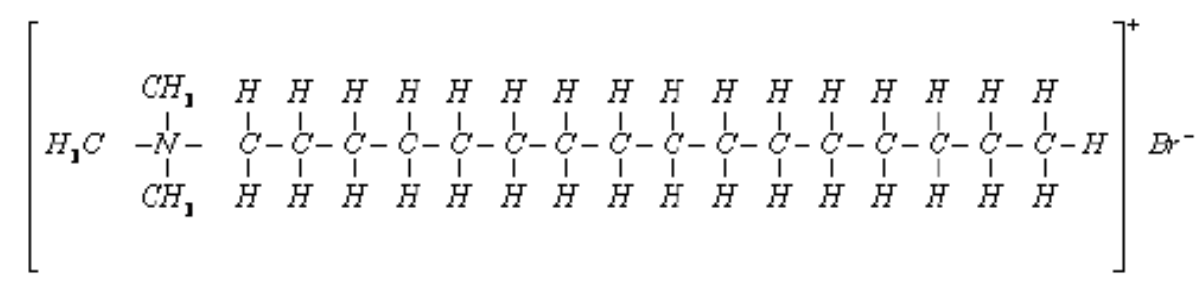

(b)

Figure 1-2. (a) Structure of quaternary ammonium cations (b) structure of hexadecyltrimethlyammonium (HDTMA), one of the QACs
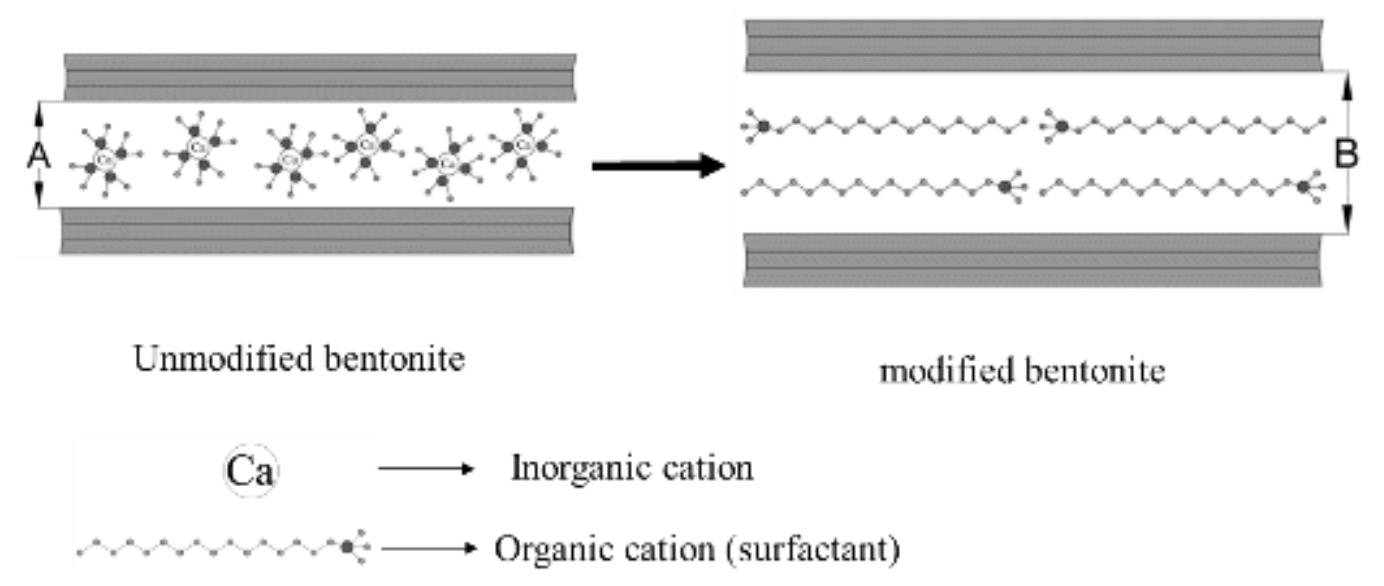

Interlayer spacing: B > A (unit: nanometer (nm) or Angstrom $(\hat{A})$ )

Figure 1-3. Structure of unmodified and modified bentonite (montmorillonite) 


\subsubsection{Synthesis of organoclay}

The organoclays are mainly prepared by two methods including cation exchange reaction or solid-state reaction (de Paiva et al. 2008). Cation exchange is a process that interlayer cations of clay mineral exchange by quaternary alkylammonium cations in aqueous solution. The solid-state reaction is a technique that organic molecules are intercalated in dried clay minerals without using any solvents. Preparing organoclay without using any solvents is an environmentally friendly method. Therefore, this process will be more appropriate for industrialization. Most solid-state reactions are based on the ion-dipole interaction in which organic molecules with polar groups are bonded to the interlayer cations of clay minerals.

Typically, the microstructure of clay/surfactant composites can be categorized into three groups: conventional, intercalated, and exfoliated (Alexandre and Dubois 2000; Esfandiari et al. 2008). The intercalated clay-surfactant hybrid is formed when alkyl chains get into the interlayers of the base clay. Thus, the basal spacing of the base clay expands to over $20 \AA$ and favors the sorption of organic compounds (de Paiva et al. 2008; Esfandiari et al. 2008). On the other hand, the exfoliated clay/surfactant hybrid is produced from the penetration of surfactant chains into clay interlayers, which caused the separation of clay tactoids, leading to a basal spacing in a range of 80 to $100 \AA$ (Wang et al. 2008). The percentage of clay particles in the exfoliated composite is lower than the conventional and intercalated composites and the physical and chemical properties of the exfoliated composite is a function of unconfined status of surfactant chains and clay platelets (Lan et al. 1995). 
Surfactant-intercalated clay minerals with enhanced sorption properties, thermal stability and compatibility with non-polar fluids are favorable for practical application including wastewater treatment, environmental remediation, soil liner construction, waste containment, and oil well drilling operation (Caenn et al. 2011; Lo and Yang 2001; Lorenzetti et al. 2005; Redding et al. 2002; Sheng and Boyd 2000). The sorptivity of the clay/surfactant hybrid is typically the highest when long carbon-chain surfactants are intercalated into the interlayer of the montmorillonites because the intercalated surfactants favor the partitioning of organic compounds (Zhao and Burns 2012).

\subsubsection{Organic cations arrangement in organoclays}

The arrangement of organic cations in the interlayer of organoclay highly depends on the layer charge of clay minerals and the chain length of organic ions. Alkylammonium ions can form different arrangements including lateral monolayers, bilayers, pseudotrimolecular layers and paraffin structure (de Paiva et al. 2008; Lagaly 1986).

In monolayers, the packing density of the chains is low, and the chains conformation is parallel to the silicate surfaces. The basal spacing of monolayer structure is typically in the range of $13-15 \AA$. For the lateral bilayers structure, two carbon layers is typically observed but the carbon chains still aligned parallel to the silicate surfaces. The typical basal spacing is approximately 17-19.8. . In the pseudotrimolecular layer structure, the head groups of the alkylammonium ions remain attached to the layers. By formation of kinks the unpolar chain ends are shifted one above the other and the interlayer separation is determined by the thickness of the three alkyl chains (Lagaly 1994). In the paraffin-type structure, the ammonium groups (the head group of alkylammonium) remain attached to the silicate layer, the chains in all-trans conformation point away from the surface. 
Typically, the basal spacing of pseudotrimolecular layer and paraffin type monolayer are greater than $22 \AA$ (Lagaly 1986). The arrangement of alkylammonium ions within the clay galleries is illustrated in Figure 1-4.

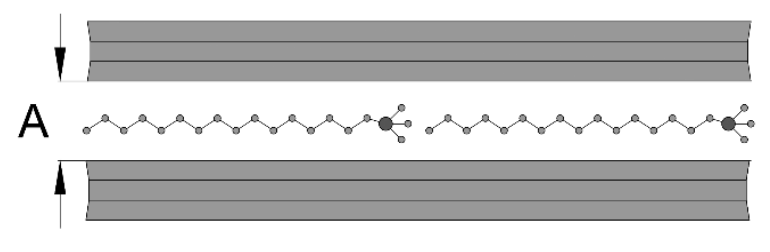

(a)

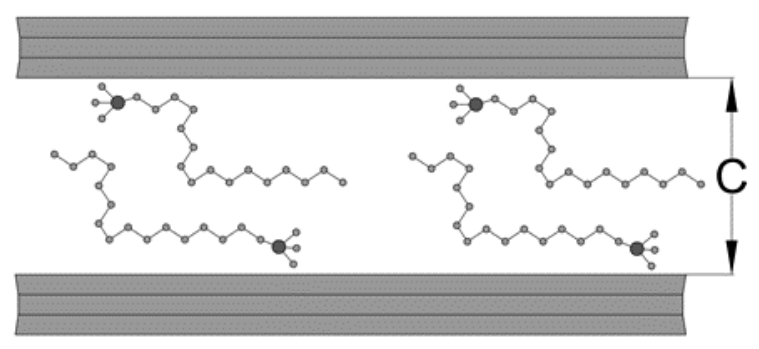

(c)

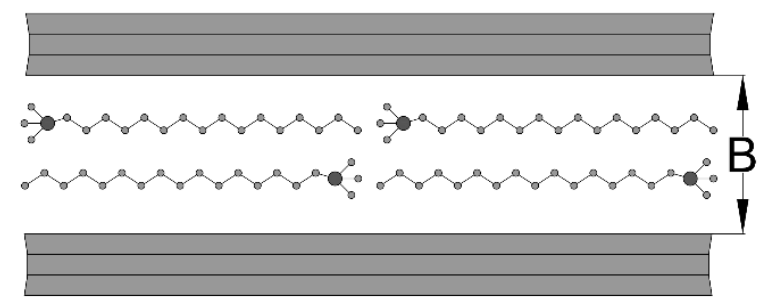

(b)

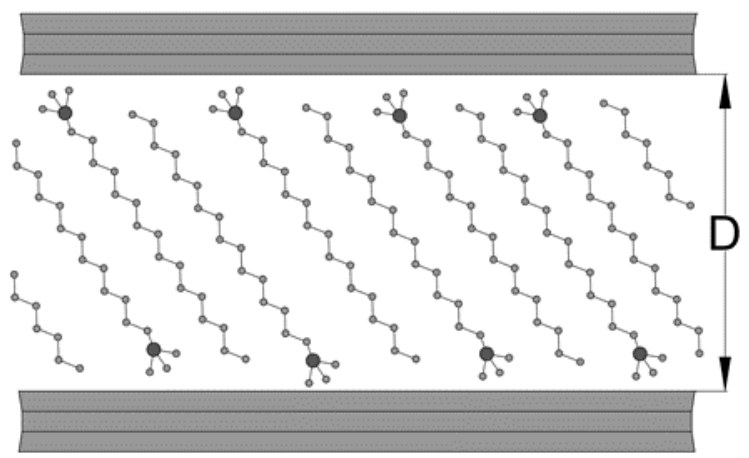

(d)

Figure 1-4. Interlamellar arrangements of alkylammonium ions in interlayers of space of montmorillonite (a) monolayer (b) bilayers (c) pseudotrimolecular layer

\section{(d) paraffin complex}

\subsection{Engineering properties of organoclays}

The geochemical, physical and mechanical properties of the clay minerals are significantly altered due to the introduction of the cationic surfactant. In the following sections, the Atterberg limits, hydrophobicity, swelling behavior, hydraulic conductivity, 
and shear strength of the organobentonites or soil admixtures containing organobentonites are discussed briefly.

\subsubsection{Atterberg limit and hydrophobicity}

The interactions between organically modified clays and the pore fluid are remarkably different from that of unmodified clays. Natural occurring bentonite presents high water content at its liquid limit. However, the exchanging of the organic cations (surfactants) onto the clay surfaces significantly reduces the liquid limit of clay minerals when they are faced with polar liquids (e.g. water). Soule and Burns (2001) reported the reduction in the liquid limit of sodium montmorillonite to water from $458 \%$ to $65 \%$ when organic surfactants were introduced to the montmorillonite minerals. However, when the pore fluid is changed from polar liquid to low or non-polar fluids (e.g. methanol and gasoline), organoclays showed consistency at a higher liquid content.

The lower liquid limit is observed for the modified clay when compared with unmodified clay, reveals that the organoclay is more hydrophobic. It can be explained as the organic surfactants (e.g. QACs) are incapable of hydration when compared with the naturally occurring inorganic cations on the surfaces of unmodified clay. The hydrophobicity of organoclay clay increases with the organic surfactant loading (or organic carbon content), and it can be distinguished by an increased contact angle, high rate of polar fluid transfer, and preferential sorptivity for non-polar organic molecules (Zhao et al. 2016).

\subsubsection{Swelling behavior and hydraulic conductivity}

In the presence of organic liquids (e.g. heptane, hexane, and gasoline), organically modified clay behaves similarly to natural occurring clay when contacted with water, i.e., 
exhibiting a high swelling tendency and low hydraulic conductivity (Bergaya and Lagaly 2013). The decreased hydraulic conductivity is related to the high swelling tendency of the organoclay in organic liquid as interlayer expansion, and particle dispersion would lead to decrease pore volume of soil under certain confining stress or with a fixed volume. However, organoclay shows relatively low swelling and high permeability when it is faced with polar liquids (e.g. water) (Lo et al. 1997; Smith et al. 2003).

It was revealed by previous studies that pure organoclays or soil/organoclay mixtures typically exhibit two to four orders of magnitude lower permeability for organic fluids with low or no polarity (Benson et al. 2015; Gates et al. 2004; Li et al. 1996; Lorenzetti et al. 2005). Gates et al. (2004) investigated the permeability of organoclay when ethanol and water were used as permanent liquids. They observed that the permeability of organoclay to ethanol decreased three orders of magnitude as compared to the permeability of organoclay to water. Furthermore, Lee et al. (2012) found that the permeability of organoclay-sand mixtures containing at least $25 \%$ organoclay to nonaqueous phase liquids (NAPLs) is seven orders of magnitude lower than its permeability to water. In another study by Benson et al. (2015), it was demonstrated that the permeability of granular organoclay to organic liquids including unleaded gasoline, fuel oils, and ethylbenzene was six or seven orders of magnitude lower than to water.

\subsubsection{Sorption}

Sorption capability of unmodified montmorillonite as a sorbent for nonpolar organic compounds is relatively low due to the hydrophilic characteristics of its surfaces and interlayer species (Park et al. 2011). Oppositely, the organically modified montmorillonite exhibits enhanced sorption capacity (i.e. secondary sorption) for the 
nonpolar organic compound in comparison with naturally occurring base calcium and sodium montmorillonite (Redding et al. 2002; Richards and Bouazza 2007; Zhao and Burns 2012; Zhu et al. 2016).

It has been demonstrated that organically modified clay exhibits varying sorptivity due to the differences in the amount of exchanged organic cations and their interlayer arrangement. There are two sorption mechanisms for organoclays based on their organic cation structure: surface adsorption and partitioning. Organoclays synthesized from small organic surfactant cations (e.g. tetramethylammonium (TMA) and trimethylphenylammonium (TMPA)) exhibits surface adsorption for organic compounds, while organoclays synthesized by long carbon chain surfactants (e.g. HDTMA and dioctodecyldimethylammonium (DODMA)) demonstrates partitioning behavior to sorb nonionic organic contaminants (Redding et al. 2002). Typically, organoclays are many times more effective than naturally occurring clays in the sorption of organic contaminants from water. The sorptivity of organoclays is influenced by several factors including nature of the sorbates, solvent, co-solvent and co-sorbates, distribution of sorbates in aqueous and in the gaseous phase and temperature, $\mathrm{pH}$ and ionic strength of the solution (Delle Site 2001; Zhao et al. 2016).

\subsubsection{Shear strength and dynamic properties}

Based on previous studies it was demonstrated that organoclays have relatively higher shear strength when compared with unmodified clays (Bate et al. 2013; Burns et al. 2006; Soule and Burns 2001). The high shear strength of organoclays is associated with the adsorption of organic surfactants within the clay interlayers that alter the structure of 
clay. This yields the strong forces between organic surfactant head groups and the clay surface by electrostatic bonding.

Soule and Burns (2001) analyzed the effects of four organic surfactants (TMA, DTMA, HDTMA, and BTEX) on the friction angle of a sodium bentonite using direct shear test. They observed that four modified organoclays had values of the direct shear friction angle, as much as five times higher when compared with unmodified bentonite (34-37 versus $7^{\circ}$ ). Bate et al. (2013) studied that triaxial shear frictional behavior of sodium bentonite particles coated with different organic surfactants varying in chain length and structure (e.g. TMA, TEA, TBA, DTMA, and HDTMA) using consolidated undrained (CU) triaxial tests. They verified that in all the cases, the critical state friction angle of organoclays was higher than the critical state friction angle measured for unmodified bentonite. Furthermore, they observed that the critical friction angle of organoclays increases by increasing the total organic loading and cation size.

\subsection{Engineering application of organoclays}

Organoclays with unique characterization including high strength, low compressibility, and excellent sorption capacity for organic compounds, can be employed for a variety of engineering applications in waste containment, water purification, soil stabilization, drilling and contaminated site remediation.

\section{Waste containment}

Compacted clay liner (CCL) and geosynthetic clay liner (GCL) are primarily used as hydraulic barriers in landfills, underground storage tanks, lagoons, etc, to prevent the transport of contaminants into surrounding environment (Sharma and Reddy 2004). 
Although it has been proven by many researchers that CCL and GCL are effective barriers at waste containment facilities due to long term stability, low permeability, and deformability, they are not compatible when they faced with organic compounds (Bowders and Daniel 1987; Broderick and Daniel 1990; Lake and Rowe 2005). Several studies suggested that hydraulic conductivity of CCL and GCL increases when it contacts with organic liquids (Shackelford et al. 2000).

Because of this behavior, many researchers have suggested several additives such as fly ash, organo-zeolite, polymer treated bentonite, coated sand and organoclay to CCL and GCL to improve the performance of the barrier system against certain organic contaminants. (Benson et al. 2015; de Paiva et al. 2008). Organoclays show low conductivity, high swelling tendency, and high plasticity when they are in contact with organic liquids or petroleum products. The organic surfactants in organoclays provide strong binding to the organic molecules in the interlayer spaces. It was demonstrated by Smith et al. (2003) that the hydraulic conductivity of organoclays for unleaded gasoline decreased two to four orders of magnitude compared to that for water. Moreover, Benson et al. (2015) observed that hydraulic conductivity of organoclay varied by six orders of magnitude $\left(10^{-5}\right.$ to $\left.10^{-11} \mathrm{~m} / \mathrm{s}\right)$ when different permeation fluids (e.g. water, methanol, phenol, fuel oil, and unleaded gasoline) were used. Although organoclays may have higher hydraulic conductivities for water, their impact on the overall conductivity of compacted soils might be negligible due to low dosage. Consequently, organoclay modified clay can be used as an excellent amendment in barrier systems to prevent the transport of organic contaminants. 


\section{Drilling}

Most worldwide drilling operations use water-based drilling fluids, because of their reduced cost and lower environmental impact (Caenn and Chillingar 1996). However, water-based drilling fluids have certain undesirable properties such as low boiling pint, high tendency for dissolving salts and high interference with the flow of oil and gas through porous rocks. Therefore, oil-based drilling fluids have been proposed for drilling under high pressure and high temperature. Based on previous studies, oil-based drilling fluids are well-known for their outstanding lubricity, excellent thermal stability, and high rate of penetration (Caenn et al. 2011).

In the recent years, organoclays have been introduced as an important rheological control additive for oil-based drilling fluids. The intercalation of organic surfactant within clay interlayers can change the clay surface from hydrophilic to hydrophobic (organophilic). Due to this phenomenal property, organoclay can be dispersed into a predominate hydrocarbon medium, such as diesel and mineral oils to produce the oil-based drilling fluids. The ease of dispersion is highly affected by the type and concentration of organic surfactant and the polarity of the solvent (Cassagnau 2008; King Jr et al. 2007). In past years, a few researchers have studied the rheological behavior of oil-based drilling fluids containing organoclay in severe borehole conditions. They have recommended that organoclay with outstanding features (e.g. high adsorption capacity and high thermal stability) can be used as a rheological control agent in oil-based drilling fluids when they are subjected to the high temperature and pressure conditions of the wellbore (Hermoso et al. 2014; King Jr et al. 2007; Zhuang et al. 2016). 


\section{Contaminated site remediation}

There is growing public concern regarding the widespread contamination of surface water, groundwater, and soil by different organic compounds due to the rapid development of chemical and petroleum industries over the past several decades (Zhu et al. 2015). Therefore, the removal of organic pollutants from contaminated sites has become a significant task. Numerous studies have been conducted to suggest innovative and effective materials for the treatment of contaminated sites. The researchers proposed that organoclays with their outstanding sorption capacity can be an effective and excellent sorbent for the removal of hydrophobic organic contaminants from contaminated water (Alkaram et al. 2009; Upson and Burns 2006; Zhou et al. 2015). The organoclays are highly able to remove or immobilize several pollutants such as organic compounds, anionic compounds, heavy metals, pesticide, and herbicides, etc.

Recently, several researchers showed that organoclay could be used as an effective binder or stabilizer for waste materials or contaminated soils. Stabilization is the result of chemical alteration in contaminants and their environment, which cause the contaminants to be less toxic or less mobile. According to previous studies, organoclays are an efficient intermediate in the immobilization of dangerous contaminants such as polycyclic aromatic hydrocarbons (PAH) and non-aqueous phase liquid (NAPL) (Abood et al. 2007; Belarbi and Al-Malack 2010; Dotelli et al. 2008; Gitipour et al. 1997; Mohebbi et al. 2013). They have proved that organoclays with outstanding properties can sorb great amounts of organic contaminants by either partition mechanism or mixed mechanisms, depending on the nature of the organoclay and contaminants. Table 1-1 briefly presents the current state of the art on the application organoclay. 


\subsection{Scope of this study}

Although some engineering properties of organoclay have been studied in the past, there is still a lack of fundamental understanding of the microstructure of organobentonites and how it controls their properties. Therefore, this study aims to provide significant insights into the engineering behaviors of organoclays based on the interpretations from their microstructures and their interactions with organic compounds. Two organoclays, laboratory synthesized organoclay (HDTMA-bentonite) and commercial organoclay (PM199) were used in this study. Three well-established experimental tests including Xray diffraction (XRD), transmission electron microscopy (TEM) and Fourier transform infrared spectroscopy (FTIR) were conducted to examine the changes in the microstructure of montmorillonite after primary and secondary sorption. Hydraulic conductivity and swelling tests were performed to investigate the hydraulic behavior of organoclays as an amendment in CCL and GCL when faced with polar and non-polar fluids (e.g. water, methanol, gasoline). Moreover, the viscosity test was conducted on oil-based drilling fluid with organoclay additive under different temperature and pressure. Shear strength and toxicity characteristic leaching procedure (TCLP) tests were performed on solidified and stabilized polycyclic aromatic hydrocarbon (PAH) contaminated soil.

This dissertation includes five chapters. Chapter 2 summarizes the effect of primary and secondary sorption on the microstructure of unmodified bentonite. Chapter 3 focuses on the use of organoclay as a promising amendment in hydraulic barrier systems (CCL and GCL) to reduce the transport of organic compounds. Chapter 4 provides information regarding the rheological behavior of organoclay-oil as drilling fluids. Chapter 5 presents the feasibility of organoclay as a stabilizer agent for PAH contaminated soil. 
Table 1-1. Summary of previous studies on the application of organoclay

\begin{tabular}{|c|c|c|c|c|}
\hline Reference & Base clay & Surfactant type & Contaminants & Application \\
\hline $\begin{array}{l}\text { Lo and } \\
\text { Yang } \\
(2001)\end{array}$ & Na-bentonite & $\begin{array}{l}\text { Dicetyldimethyl- } \\
\text { ammonium chloride }\end{array}$ & $\begin{array}{l}\text { Leachate, gasoline, } \\
\text { diesel, 2,4,5-TCP }\end{array}$ & $\begin{array}{c}\text { Earthen barrier } \\
\text { system }\end{array}$ \\
\hline $\begin{array}{l}\text { Smith et al. } \\
\text { (2003) }\end{array}$ & $\begin{array}{l}\text { Wyoming } \\
\text { bentonite }\end{array}$ & HDTMA and BTEA & Gasoline & $\begin{array}{c}\text { Earthen barrier } \\
\text { system }\end{array}$ \\
\hline $\begin{array}{l}\text { Moon et al. } \\
\quad(2007)\end{array}$ & $\begin{array}{l}\text { Kaoline and } \mathrm{Ca}- \\
\text { bentonite }\end{array}$ & HDTMA & $\begin{array}{l}\text { Benzene, toluene, } \\
\text { ethylbenzene, } \\
\text { xylene and gasoline }\end{array}$ & $\begin{array}{c}\text { Earthen barrier } \\
\text { system }\end{array}$ \\
\hline $\begin{array}{l}\text { Lorenzetti } \\
\text { et al. } \\
(2005) \\
\end{array}$ & $\begin{array}{l}\text { Wyoming } \\
\text { bentonite }\end{array}$ & HDTMA and BTEA & Benzene & $\begin{array}{c}\text { Earthen barrier } \\
\text { system }\end{array}$ \\
\hline $\begin{array}{l}\text { Zhuang et } \\
\text { al. (2015) }\end{array}$ & $\begin{array}{l}\mathrm{Na}- \\
\text { montmorillonite }\end{array}$ & CTAB & - & $\begin{array}{l}\text { Oil well } \\
\text { drilling } \\
\text { industry }\end{array}$ \\
\hline $\begin{array}{l}\text { Hermoso et } \\
\text { al. (2014) }\end{array}$ & Bentonite & DHTDMAC & - & $\begin{array}{l}\text { Oil well } \\
\text { drilling } \\
\text { industry }\end{array}$ \\
\hline $\begin{array}{l}\text { King Jr et } \\
\text { al. }(2007)\end{array}$ & Montmorillonite & DTDM & - & $\begin{array}{l}\text { Oil well } \\
\text { drilling } \\
\text { industry }\end{array}$ \\
\hline $\begin{array}{l}\text { Mohebbi et } \\
\text { al. (2013) }\end{array}$ & Bentonite & HDTMA & Cresol & $\begin{array}{c}\text { Stabilization of } \\
\text { contaminated } \\
\text { soil }\end{array}$ \\
\hline $\begin{array}{l}\text { Gitipour et } \\
\text { al. (1997) }\end{array}$ & Montmorillonite & $\begin{array}{c}\text { Dimethyl di } \\
\text { (hydrogenated) tallow }\end{array}$ & $\begin{array}{l}\text { benzene, toluene, } \\
\text { ethylbenzene, } \\
\text { xylene }\end{array}$ & $\begin{array}{l}\text { Stabilization of } \\
\text { contaminated } \\
\text { soil }\end{array}$ \\
\hline $\begin{array}{l}\text { Gentry et } \\
\text { al. (2014) }\end{array}$ & Montmorillonite & Commercial organoclay & $\begin{array}{c}\text { Naphthalene, } \\
\text { benzene, toluene, } \\
\text { ethylbenzene, } \\
\text { xylene }\end{array}$ & $\begin{array}{l}\text { Stabilization of } \\
\text { contaminated } \\
\text { soil }\end{array}$ \\
\hline $\begin{array}{l}\text { Dotelli et } \\
\text { al. }(2008)\end{array}$ & Montmorillonite & $\begin{array}{c}\text { Commercial organoclay } \\
\text { (modified with phenolic } \\
\text { resin) }\end{array}$ & 2-chloroaniline & $\begin{array}{c}\text { Stabilization of } \\
\text { contaminated } \\
\text { soil } \\
\end{array}$ \\
\hline $\begin{array}{l}\text { Redding et } \\
\text { al. }(2002)\end{array}$ & Montmorillonite & HDTMA and BTEA & Benzene & $\begin{array}{c}\text { Remediation of } \\
\text { contaminated } \\
\text { water }\end{array}$ \\
\hline $\begin{array}{l}\text { Sanchez- } \\
\text { Martin et } \\
\text { al. (2006) }\end{array}$ & $\begin{array}{l}\text { Montmorillonite } \\
\text { and kaolinite }\end{array}$ & ODTMA & Pesticide & $\begin{array}{c}\text { Remediation of } \\
\text { contaminated } \\
\text { water }\end{array}$ \\
\hline $\begin{array}{l}\text { Alkaram et } \\
\text { al. }(2009)\end{array}$ & $\begin{array}{l}\text { Bentonite } \\
\text { kaolinite }\end{array}$ & HDTMA and PTMA & Phenol & $\begin{array}{c}\text { Remediation of } \\
\text { contaminated } \\
\text { water } \\
\text { remediation }\end{array}$ \\
\hline
\end{tabular}




\section{CHANGES OF ORGANOBENTONITE INTERLAYER MICROSTRUCTURE INDUCED BY SORPTION OF ORGANIC MOLECULES}

\subsection{Introduction}

Previous studies demonstrated that the intercalation of organic surfactant into aluminosilicates such as montmorillonite occurs through cation exchange, and this process can be called primary adsorption (Yariv and Cross 2001). The secondary sorption in organoclays is the process when non-polar organic compounds are sorbed within the interlayers of organoclays (Figure 2-1). The secondary sorption in organoclays leads to the further modification of organoclays microstructures and consequently, engineering properties such as sorptivity, permeability, and strength. At the micro scale, organoclays synthesized from long-chain surfactants (e.g. HDTMA) have decreased the surface area as the large organic surfactant molecules may block the surface sites of clays (Soule and Burns 2001; Xi et al. 2010). However, the increased loading of surfactants can increase the interlayer space and create an organophilic phase for the secondary sorption of non-polar molecules (Zhao and Burns 2012). Therefore, the sorbed sorbates (in addition to the surfactants) may further increase the interlayer spacing (Lee and Kim 2002; Zhou et al. 2007) and facilitate the sorption of even larger sorbates. The slightly enhanced sorptivity 
or increased soil-water distribution coefficient was observed for organoclays after secondary sorption and was explained as due to the increased organic partitioning phase and an interlayer spacing (Sheng and Boyd 2000).

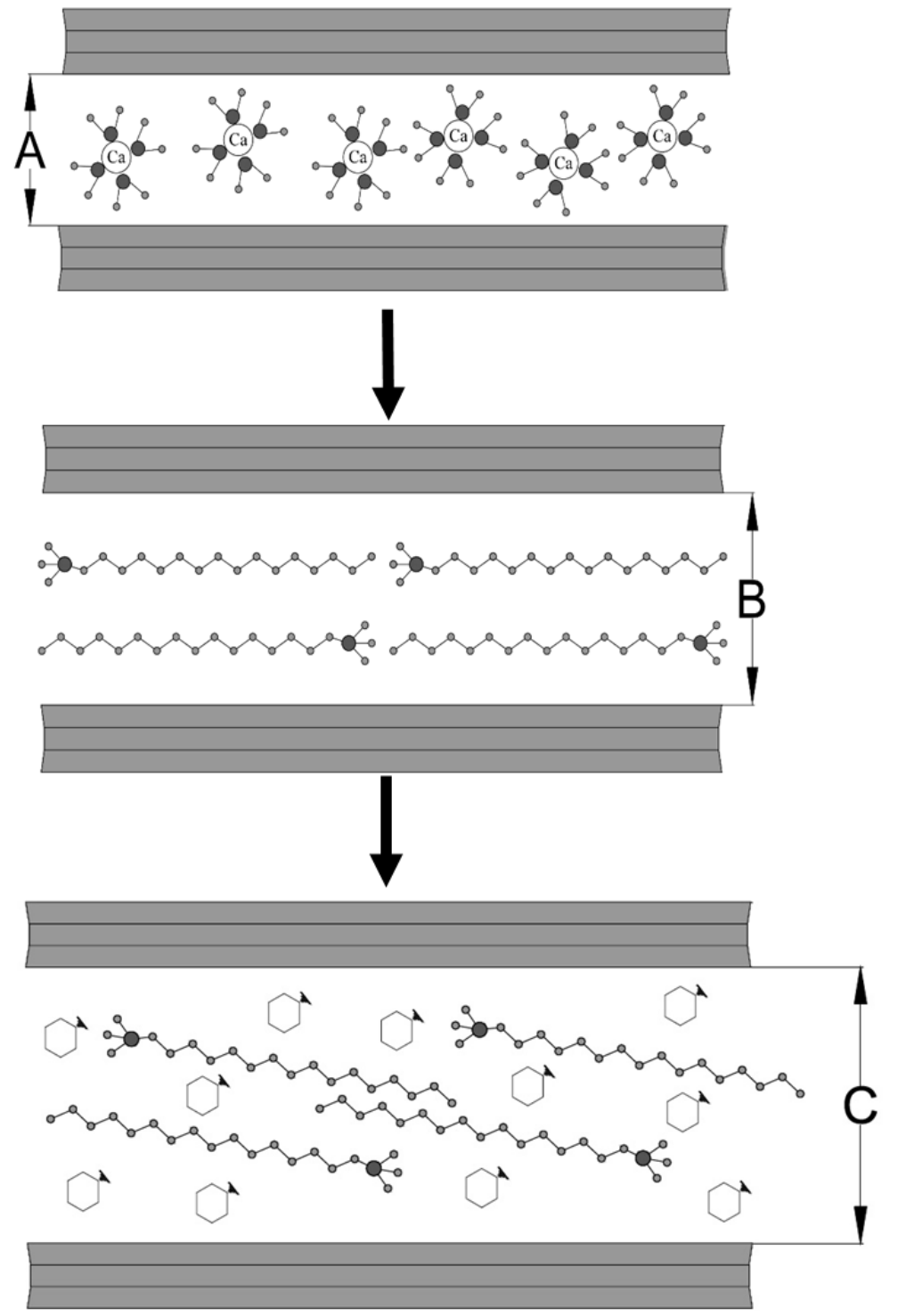

Organic sorbate

Interlayer spacing: $\mathrm{A}<\mathrm{B}<\mathrm{C}$

Figure 2-1. Primary and secondary sorption 
Several studies indicated that the interlayer expansion and swelling of the bulk volume of organoclays were observed when interlayer sorption of hydrocarbon molecules of diesel oil, gasoline, and kerosene occurred (Jaynes and Vance 1999; Lee and Kim 2002; Zhu et al. 1997). The study by Benson et al. (2015) demonstrated that the permeability of organoclay could be lowered by six orders of magnitude when permeated with fuels. The decreased permeability was related to the high swelling tendency of the organoclay in fuels. In another research study by Lo and Yang (2001), it was observed that organoclays exposed to hydrocarbon or fuels exhibited much-improved self-healing ability under freeze-thaw and dry-wet cycles and less susceptibility to volumetric deformations and cracking.

The interlayer microstructure of intercalated organic surfactant within montmorillonite (primary sorption) and interaction between organoclay and a non-polar organic sorbate (secondary sorption) can be directly or indirectly examined at the microscale by various modern characterization tools such as X-ray diffraction (XRD), Fourier Transform Infrared spectroscopy (FT-IR), Raman Spectroscopy, Transmission Electron Microscopy (TEM) and Scanning Electron Microscopy (SEM). These most advanced techniques can help engineers to measure the basal spacing of clays and organoclays platelets, to visualize the particle aggregates, and to distinguish the functional groups of organic surfactants or sorbed molecules present in the soil.

$\mathrm{XRD}$ is one of the most widely used techniques to determine the basal spacing of clays and organoclays. The results of XRD can also provide useful information on the molecular configuration of the surfactant intercalated within the interlayers of clay by comparing with arrangement patterns proposed by Lagaly (1986). Previous studies have used the XRD to determine the basal spacing of clay after consecutive interaction between 
mineral phase, surfactants, and organic sorbates (Bonczek et al. 2002; Burstein et al. 2008; Lagaly and Dékany 2005; Zhou et al. 2007). They observed that surfactant and further organic sorbate entered and expanded the interlayer space of clay.

TEM and SEM techniques are employed to make a direct observation of microstructural features on organoclays. TEM demonstrates the packing density of organoclays within the clay interlayer space at the nano scale and also yields to determine the interlayer spacing of organoclays. SEM micrographs show surface morphology of clay and organoclay samples. Due to the novelty and costly procedure expenses of TEM, only a few researchers have employed the TEM to study the changes in clay microstructure due to intercalation of organic surfactant within the montmorillonite interlayers, and then interaction between the organoclay and a nonpolar organic sorbate (He et al. 2006; Schampera et al. 2016; Zhou et al. 2007; Zhou et al. 2007).

FT-IR can confirm the presence of organics in the clay and organoclay (Vaia et al. 1994). It can also provide the evidence of evolved surfactant conformation before and after the sorption of organic molecules. The intercalated organic molecules can be proved by FT-IR when the frequency shifts of the $\mathrm{CH}_{2}$ stretching and scissoring vibrations happen. Vaia et al. (1994) have mentioned that conformation of the intercalated surfactants may exist either in disordered conformation (gauche conformation), or in ordered conformation (all-trans conformation) (Figure 2-2). The presence of gauche conformation is more ubiquitous, while a trans conformation is present only under special circumstances. When the interlayer packing density or the surfactant chain length decreases, the intercalated surfactant chains adopt a more disordered structure resulting from an increase in the gauche/trans conformer ratio (de Paiva et al. 2008). 


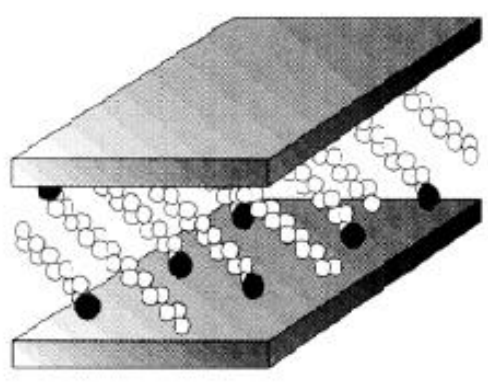

(a)

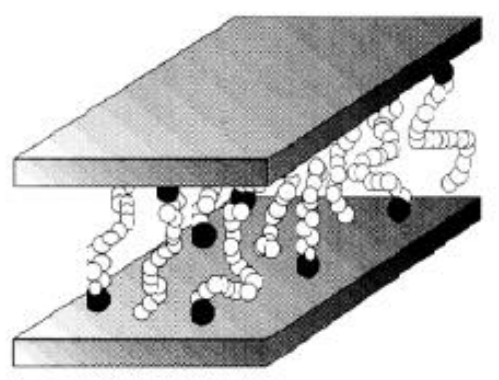

(b)

Figure 2-2. Different chain arrangement: (a) trans conformation (b) gauche conformation (Vaia et al. 1994)

Only a few studies employed FT-IR to investigate the changes in the surfactant conformation upon adsorption of organic sorbates (He et al. 2006; Zhou et al. 2007). They observed that organic sorbates penetrated into clay interlayers had a significant influence on the clay interlayer structure (i.e. the arrangement of the intercalated surfactant). Therefore; it is worth mentioning that FT-IR is a well-established tool to analyze the surfactant chain conformation while, the XRD and TEM provide very limited information on the carbon chain morphology.

Many studies were conducted to investigate the transition of interlayer microstructure from natural bentonite to surfactant-modified bentonite (He et al. 2006; Lee and Kim 2002; Masooleh et al. 2010; Zhou et al. 2007). However, limited information regarding the impact of organic sorbates on the organoclays interlayer morphology is available. Thus, the fundamental understanding of the impact of secondary sorption of organic sorbates on the interlayer microstructure and resultant bulk properties of organoclays merits examination. Table 1-1 summarizes the comparison between some significant related journal papers and this study. 
The main purposes of this chapter were to systematically quantify: (1) the interactions between mineral phase (alluminosillicates), surfactants and hydrocarbon sorbates, (2) the interlayer expansion of montmorillonite due to consecutive intercalation of surfactant and hydrocarbons, (3) the surfactant arrangement and re-arrangement before and after hydrocarbon sorption. Two organoclays, laboratory made (HDTMA-MMT) and commercially bought (PM199) were chosen as sorbents. Aromatic hydrocarbons and gasoline hydrocarbons were chosen as the organic sorbates. Laboratory characterization tests including the XRD, SEM, TEM, FT-IR were conducted to quantify the impact of the primary sorption (intercalated of organic surfactant within montmorillonite) and the secondary sorption (interaction between the organoclay and a nonpolar organic sorbate) on the organoclay microstructure. 
Table 2-1. Comparison of the this study with previous studies

\begin{tabular}{|c|c|c|c|c|}
\hline Source & Sorbent & Sorbate & Conclusion & Novelty in our work \\
\hline $\begin{array}{l}\text { Burstein et } \\
\text { al. (2008) }\end{array}$ & $\begin{array}{l}\text { HDTMA- } \\
\text { MMT }\end{array}$ & $\begin{array}{l}\text { Nitrobenzene } \\
\text { m-nitrophenol }\end{array}$ & $\begin{array}{l}\text {-Sorbed nitrobenzene } \\
\text { and m-nitrophenol can } \\
\text { increase the basal } \\
\text { spacing of the } \\
\text { organoclay (XRD) } \\
\text {-Increasing temperature } \\
\text { can reduce the basal } \\
\text { spacing of organoclay } \\
\text { with sorbed organic } \\
\text { compounds }\end{array}$ & \multirow{2}{*}{$\begin{array}{l}\text { - The details of the } \\
\text { surfactant arrangement are } \\
\text { discussed, and its effect on } \\
\text { the secondary sorption is } \\
\text { demonstrated } \\
\text {-Single sorbate and multi- } \\
\text { component sorbate are used. } \\
\text {-The re-arrangement of } \\
\text { surfactant due to sorption } \\
\text { are discussed }\end{array}$} \\
\hline $\begin{array}{l}\text { Nourmoradi } \\
\text { et al. (2012) }\end{array}$ & $\begin{array}{l}\text { PEG- } \\
\text { MMT }\end{array}$ & $\begin{array}{l}\text { Benzene } \\
\text { Toluene } \\
\text { Ethylbenzene } \\
\text { Xylene }\end{array}$ & $\begin{array}{l}\text {-Increasing the } \\
\text { surfactant loading (up to } \\
200 \% \text { CEC) can } \\
\text { increase the adsorption } \\
\text { capacity of organoclay } \\
\text { - Increasing the contact } \\
\text { time up to } 24 \mathrm{hr} \text { can } \\
\text { increase the adsorption } \\
\text { of BTEX in the } \\
\text { organoclay interlayers }\end{array}$ & \\
\hline $\begin{array}{l}\text { Zhou et al. } \\
\text { (2007) }\end{array}$ & $\begin{array}{l}\text { HDTMA- } \\
\text { MMT }\end{array}$ & $\begin{array}{l}\text { para- } \\
\text { nitrophenol }\end{array}$ & $\begin{array}{l}\text {-Increased the } \\
\text { surfactant loading can } \\
\text { increase the basal } \\
\text { spacing, and in result } \\
\text { increase the adsorption } \\
\text { capacity of organoclay } \\
\text { (XRD and TEM } \\
\text { studies) } \\
\text {-Para-nitrophenol } \\
\text { sorbed within } \\
\text { organoclay interlayers } \\
\text { (FT-IR) }\end{array}$ & $\begin{array}{l}\text {-The re-arrangement of } \\
\text { surfactant due to sorption } \\
\text { are discussed }\end{array}$ \\
\hline $\begin{array}{l}\text { Schampera } \\
\text { et al. (2016) }\end{array}$ & $\begin{array}{l}\text { HDTMA- } \\
\text { MMT } \\
\text { HDPY- } \\
\text { MMT }\end{array}$ & $\begin{array}{l}\text { No sorbate } \\
\text { studied }\end{array}$ & $\begin{array}{lr}\begin{array}{l}\text {-Interlayer } \\
\text { organoclay } \\
\text { with }\end{array} & \begin{array}{r}\text { spacing of } \\
\text { increased } \\
\text { increased } \\
\text { surfactants } \\
\text { loading }\end{array} \\
\begin{array}{l}\text {-increasing } \\
\text { surfactant }\end{array} \\
\begin{array}{l}\text { loading exhibited high } \\
\text { surface packing density, }\end{array}\end{array}$ & $\begin{array}{l}\text {-The secondary sorption in } \\
\text { organoclays, in addition to } \\
\text { the primary adsorption, are } \\
\text { examined } \\
\text { - The surfactant chain } \\
\text { arrangement in addition to } \\
\text { the interlayer expansion are } \\
\text { discussed }\end{array}$ \\
\hline
\end{tabular}




\begin{tabular}{|c|c|c|l|l|}
\hline & & $\begin{array}{l}\text { and consequently higher } \\
\text { stability (MD) }\end{array}$ & $\begin{array}{l}\text {-Aromatic and petroleum } \\
\text { hydrocarbons are used as } \\
\text { sorbates, and the interaction } \\
\text { between surfactants and } \\
\text { these organic compounds is } \\
\text { comprehensively studied }\end{array}$ \\
\hline $\begin{array}{c}\text { Wen et al. } \\
\text { (2006) }\end{array}$ & $\begin{array}{c}\text { DDTMA- } \\
\text { MMT }\end{array}$ & $\begin{array}{c}\text { No sorbate } \\
\text { studied }\end{array}$ & $\begin{array}{l}\text {-increased the surfactant } \\
\text { loading, increased the } \\
\text { basal spacing (XRD) } \\
\text {-DDTMA alkyl chains } \\
\text { at different } \\
\text { concentrations } \\
\text { exhibited a disordered } \\
\text { conformation (mixture } \\
\text { of trans and gauche) }\end{array}$ & \\
\hline
\end{tabular}




\subsection{Materials and methods}

\subsubsection{Materials}

Different types of soil: calcium bentonite which mainly consists of calcium montmorillonite (Ca-MMT), HDTMA modified calcium montmorillonite (HDTMAMMT), commercial organoclay PM199, and organobentonites with sorbed aromatic and petroleum hydrocarbons were used in this study.

\section{Calcium montmorillonite (Ca-MMT)}

Powdered with a chemical formula of $(\mathrm{Na}, \mathrm{Ca})_{0.33}\left(\mathrm{Al}_{1.67} \mathrm{Mg}_{0.33}\right) \mathrm{Si}_{4} \mathrm{O}_{10}(\mathrm{OH})_{2} \mathrm{nH}_{2} \mathrm{O}$ was obtained from the American Colloid Company with high quality, and it was used as a base clay to produce the organoclay. The chemical composition of Ca-MMT was $60.5 \% \mathrm{SiO}_{2}, 18.20 \% \mathrm{Al}_{2} \mathrm{O}_{3}, 5.25 \% \mathrm{FeO}_{3}, 4.58 \%$ LOI, $3.26 \% \mathrm{MgO}, 3.14 \% \mathrm{CaO}, 0.2 \% \mathrm{Na}_{2} \mathrm{O}, 0.14 \% \mathrm{~K}_{2} \mathrm{O}$. All Ca-MMT particles were passed through \#200 sieve size. Clay minerals are composed of approximately $85 \%$ of montmorillonite and $15 \%$ of feldspar, calcite, and quartz. The $\mathrm{pH}$ of the soil was in the range of 6 to 10 as received. The cation exchange capacity (CEC) of the soil was 103 meq/100g.

\section{PM199 (Commercial organoclay)}

The commercial powdered organoclay PM199 was provided by the CETCO Company. PM199 was montmorillonite modified with an amine bis(hydrogenated tallow alkyl)dimethyl ammonium surfactant. The main application of the PM199 is to remove 
oils, greases, non-aqueous phase liquids (NAPL), and other dissolved high molecular weight organic contaminants from environmental systems.

\section{HDTMA-Montmorillonite (HDTMA-MMT)}

HDTMA-MMT was synthesized from the Ca-MMT by exchanging $\mathrm{Ca}^{2+}$ cation with hexadecyltrimethylammonium (HDTMA+) bromide cation. The HDTMA bromide was obtained from Fisher Scientific company with $99 \%$ purity, and it was used as received. The chemical formula of HDTMA bromide was $\left(\mathrm{CH}_{3}\right)_{3} \mathrm{NC}_{16} \mathrm{H}_{33} \mathrm{Br}$ and its structure was illustrated in Figure 2-3. It is worth mentioning that the shape of the perfect straight-chain quaternary ammonium cation (HDTMA-Br), has the appearance of a nail where the long alkyl chain is the body of the nail and the carbon chain end containing three methyl groups is the nail-head. The length of HDTMA cation is around $25 \AA$, the height of alky-chain and the nail-head are $4 \AA$ and $5 \AA$, respectively (Zhu et al. 2003).

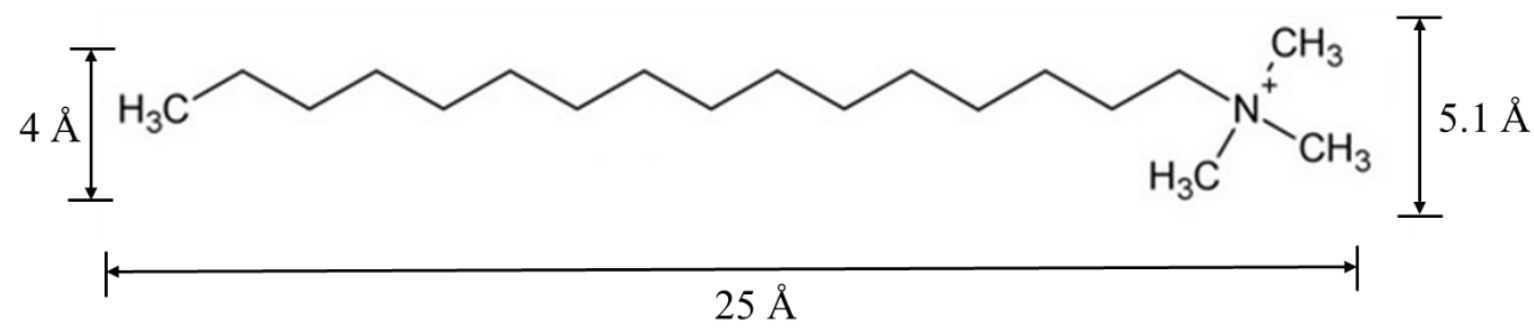

\section{Figure 2-3. Structure of the hexadecyltrimethylammonium (HDTMA) bromide}

The HDTMA-MMT was prepared in the laboratory by exposing the bentonite particles to an aqueous solution containing HDTMA bromide at $100 \%$ of the cation exchange capacity of the base clay (Ca-MMT). First, 100 grams of the dried Ca-MMT (passed through \#200 mesh) was weighted and also the amount of HDTMA bromide salt was measured which was equal to $100 \%$ CEC of the Ca-MMT. To prepare an aqueous 
solution, $500 \mathrm{ml}$ of deionized water was heated to $60{ }^{\circ} \mathrm{C}$, and the weighted HDTMA-Br was added to hot water, and the solution was continuously stirred for around 10 minutes until all HDTMA-Br particles were dissolved in water.

Afterwards, the weighted Ca-MMT was slowly added to the aqueous solution, and the new suspension was stirred for 30 minutes using a Hamilton mixer. Then, the resulting suspension was poured into a bowl, covered with plastic wrap, and let to rest for 24 hours. After 24 hours, the supernatant objects were removed from the surface of the dispersion. The resulting soil was washed and rinsed at least three times with deionized water until the soil was free of chloride ions. The outcoming soil was dried at oven at $110{ }^{\circ} \mathrm{C}$ for 24 hours until the water was completely evaporated. In the last step, the dried soil was grounded with mortar and pestle, and then sieved through \#200 mesh. The schematic procedure of making organoclay is shown in Figure 2-4. The images of three studied soils are presented in Figure 2-5.

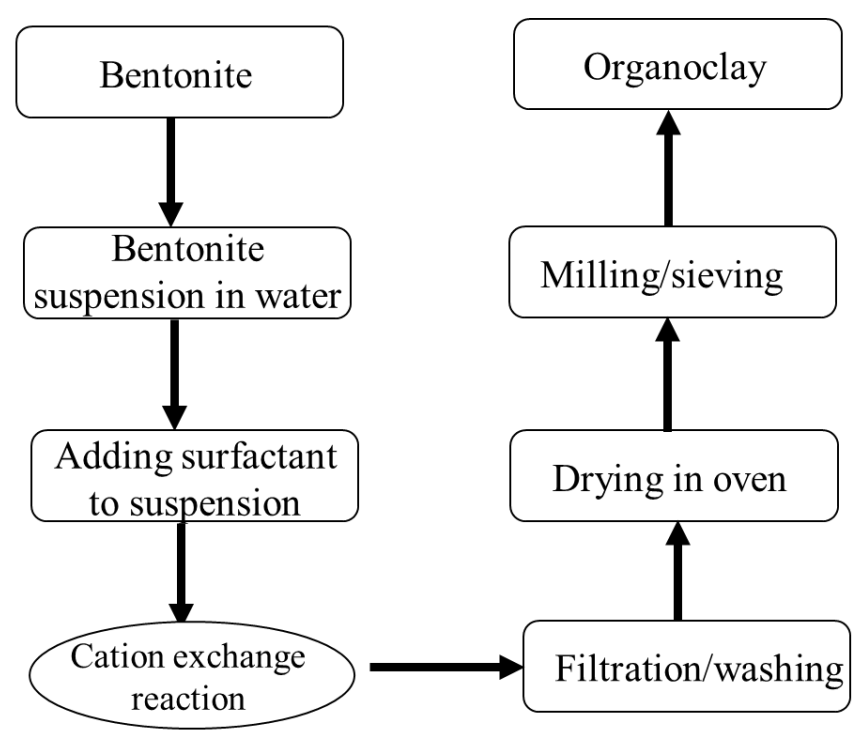

Figure 2-4. The process of organoclay preparation 


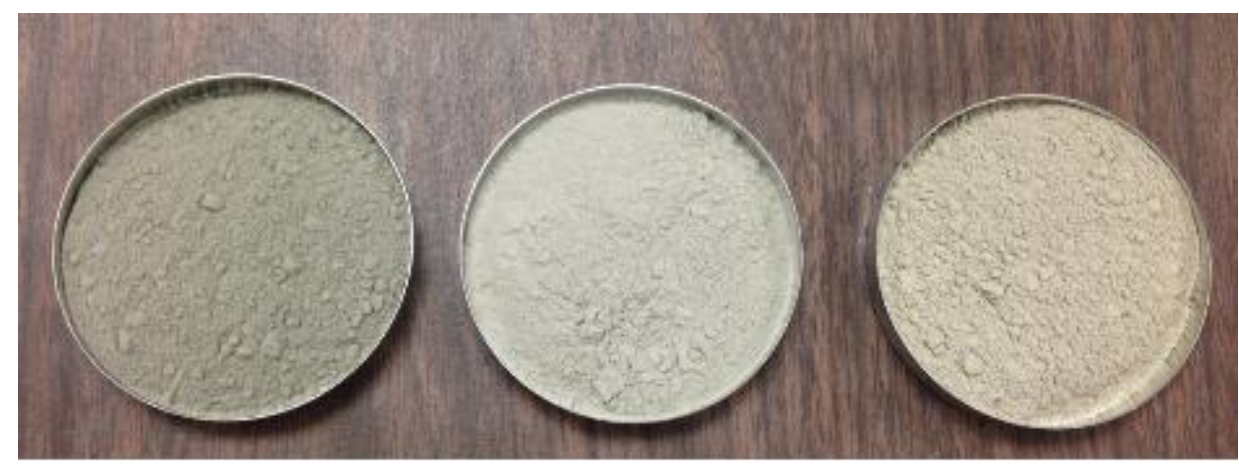

(a)

(b)

(c)

Figure 2-5. The images of the soils (a) Ca-MMT (b) HDTMA-MMT (c) PM199

\section{Organo-bentonites with sorbed hydrocarbons}

HDTMA-MMT samples with an initial mass of $2 \mathrm{~g}$ were soaked in gasoline and naphthalene solution $(200 \mu \mathrm{g} / \mathrm{mL}$ in $30 \%$ of methanol and $70 \%$ of water) separately for 48 hours. PM199 was soaked in gasoline for 48 hours. All soils were dried at the room temperature for five days; then they were placed in the oven at the temperature of $60{ }^{\circ} \mathrm{C}$ for 2 hours before they were crushed into particles finer than $75 \mu \mathrm{m}$. Note that the mass of sorbed hydrocarbons and naphthalene were measured before the soils were crushed into the particles finer than $75 \mu \mathrm{m}$.

\section{Organic liquids}

Gasoline is a refined product of petroleum including a mixture of hydrocarbons, blending agents and additives. The assumed composition of gasoline hydrocarbons (\%volume) is as follows: $20 \%$ of n-alkanes, $30 \%$ of branched alkanes, $30 \%$ of aromatics, and $20 \%$ of cycloalkanes. The studied unleaded gasoline was a commercial grade of 85 . 
Naphthalene was selected as a representative dissolved organic contaminant or nonaqueous phase liquid (NAPL) component because of its simple structure and frequent presence in leachate/wastewater of the landfills and industrial facilities. Naphthalene was purchased from Fisher Scientific Co. in crystal form. The solubility of naphthalene in water is as low as $31.6 \mathrm{mg} / \mathrm{L}$ in $25^{\circ} \mathrm{C}$. To prevent naphthalene dissolution/precipitation reaction in soils; it was diluted in the methanol and water matrix to the designed concentration. The stock solution consisted of $70 \%$ deionized water (DI) and 30\% methanol with naphthalene concentrations of $200 \mu \mathrm{g} / \mathrm{ml}$. The chemical and hydrodynamic properties of the studied organic and inorganic liquids are shown in Table 2-2.

Table 2-2. Partitioning and hydrodynamic properties of the studied liquids

\begin{tabular}{|l|c|c|c|}
\hline \multicolumn{1}{|c|}{ Liquid } & $\begin{array}{c}\text { Density }(\mathbf{K g} / \mathbf{L}) \text { at } \\
\mathbf{2 0} \mathbf{~}^{\mathbf{0}} \mathbf{C}\end{array}$ & Polarity Index & $\begin{array}{c}\text { Kinematic viscosity } \\
\left(\mathbf{m}^{\mathbf{2}} / \mathbf{s}\right) \times \mathbf{1 0}^{-\mathbf{6}} \text { at 20 }\end{array}$
\end{tabular}

\subsubsection{Experimental Methods}

\subsubsection{Total Organic Carbon}

Total organic carbon (TOC) refers to the amount of organic carbon in soil. The TOC of each soil sample was measured by an organic carbon analyzer. Each soil sample was dried at room temperature before running the TOC test. The sample was placed inside the chamber in the organic carbon analyzer. Then the sample was combusted at a high 
temperature, and all carbon was converted to carbon dioxide $\left(\mathrm{CO}_{2}\right)$. The resulting carbon dioxide was measured by a gas analyzer to determine the total organic carbon.

\subsubsection{Atterberg Limits}

The liquid limit of each type of soil was determined according to two methods: Fall cone (British Standard 1377 (1990)) and Casagrande cup (ASTM D4318-05). For the fall cone method, approximately 300 to 400 grams of dry soil was mixed with adequate water, and then the mixture was placed in the cup. Afterwards, the cup was placed on the fall cone apparatus, exactly below the tip of the cone. The fall cone tip was dropped, and the penetration (travel distance) was recorded. The liquid limit of the specimen could be determined when the tip traveled $20 \mathrm{~mm}$ inside the soil specimen. For the Casagrande cup method, the dry soil was mixed with adequate water and placed in the Casagrande cup. The soil specimen was split up by a groove to create a gap. When the gap was closed by exactly 25 counts of the blow, the moisture content of the specimen could be recorded as a liquid limit of the soil. Note that each soil should be mixed with different water contents to obtain several data points. Moreover, the plastic limit of each type of soil was determined according to the procedure outlined in ASTM D4318-05. The soil was mixed with water, and it was rolled into a $1 / 8$ in diameter thread. When the rolling sample crumbled at a thread of $1 / 8$ in diameter, the obtained water content was the plastic limit.

\subsubsection{Specific Gravity}

Specific gravity testing was performed on each type of soil in accordance with ASTM D854 (2012) following Method B, the liquid pycnometer. The soil sample was placed in the oven for 24 hours to get fully dry. A pycnometer with a capacity of $100 \mathrm{ml}$ was selected to run the specific gravity test. The mass of pycnometer was weighted when 
it was full of de-aired water. Afterwards, half of the water was discharged from the pycnometer. 10 grams of the dried soil were added to the pycnometer, and then the pycnometer was filled with water until it reached the calibration mark. The vacuum was applied to each pycnometer to remove air from the water inside the pycnometer. Finally, the specific gravity of each soil was calculated according to the following equation:

$G_{s}=\frac{M_{s}}{\left(M_{p w}-\left(M_{p w s}-M_{s}\right)\right)}$

$\mathrm{M}_{\mathrm{s}}$ : mass of the oven-dried soil (gr)

$\mathrm{M}_{\mathrm{pw}}$ : mass of the pycnometer full of water (gr)

$\mathrm{M}_{\mathrm{pws}}$ : Mass of pycnometer full of water and soil solids (gr)

\subsubsection{Specific Surface Area}

The specific surface area of the studied soils was determined by the spot test (methylene blue) procedure, in according to Santamarina et al. (2002) and Kandhal and Parker (1998). First, the methylene blue solution was prepared by mixing 1 gr of dry methylene blue powder with $200 \mathrm{ml}$ of deionized water until all the particles dissolved into the water. The soil suspension was prepared by adding $10 \mathrm{gr}$ of oven-dried soil to $30 \mathrm{ml}$ of deionized water, and the suspension was mechanically stirred until all the sediments were suspended. Then, methylene blue solution was added to the soil suspension at an increment of $0.5 \mathrm{ml}$, and the suspension was mixed for 1 minute. After each addition of methylene blue solution into the soil suspension, a small drop of the resulting suspension was removed by a drop-pipette and placed on a filter paper. The number of addition of methylene blue solution increment was counted until a permeant light blue halo around the wet soil spot 
on the filter paper appeared. After this, the specific surface area was determined by the following equation:

$S_{S}=\frac{1}{M_{W}} \frac{1}{V}(0.5 N) A_{v} A_{M B} \frac{1}{M_{S}}$

Where:

Mw: molecular weight of the methylene blue ( $\mathrm{g} / \mathrm{mol})$

$\mathrm{V}$ : volume of deionized water to dissolve methylene blue (ml)

$\mathrm{N}$ : number of methylene blue increment

Av: Avogadro number $\left(6.02 \times 10^{23} \mathrm{~mol}^{-1}\right)$

Амв: area occupied by one methylene blue molecular $\left(1.3 \mathrm{~nm}^{2}\right)$

Ms: total mass of soil in the soil solution (gr)

\subsubsection{X-ray diffraction (XRD)}

X-ray diffraction (XRD) analysis is a well-known method which is designed to provide significant information regarding the quantification and identification of crystalline compounds and the atomic and molecular structure of substances. X-rays are scattered when faced with atoms of a crystalline solid which is made of lattice planes separated by the interplanar distance d (i.e., basal spacing). By employing the Bragg's law, the crystal structure (e.g., basal spacing) can be determined.

$2 d \sin (\theta)=n \lambda$, where $d$ is the spacing between the diffracting planes and sometimes called basal spacing, $\theta$ is the diffraction angle (the angle between the diffraction 
waves and the surface of the atoms), $n$ is an integer $(\mathrm{n}=1.5406 \AA)$, and $\lambda$ is the wavelength of the beam. Figure 2-6 illustrates a schematic diagram of the diffraction process in XRD analysis, where the x-ray waves are detoured upon striking the atoms within the lattice structure. The diffraction pattern of each sample is recorded by measuring the intensity of scattered waves at each scattering angle.

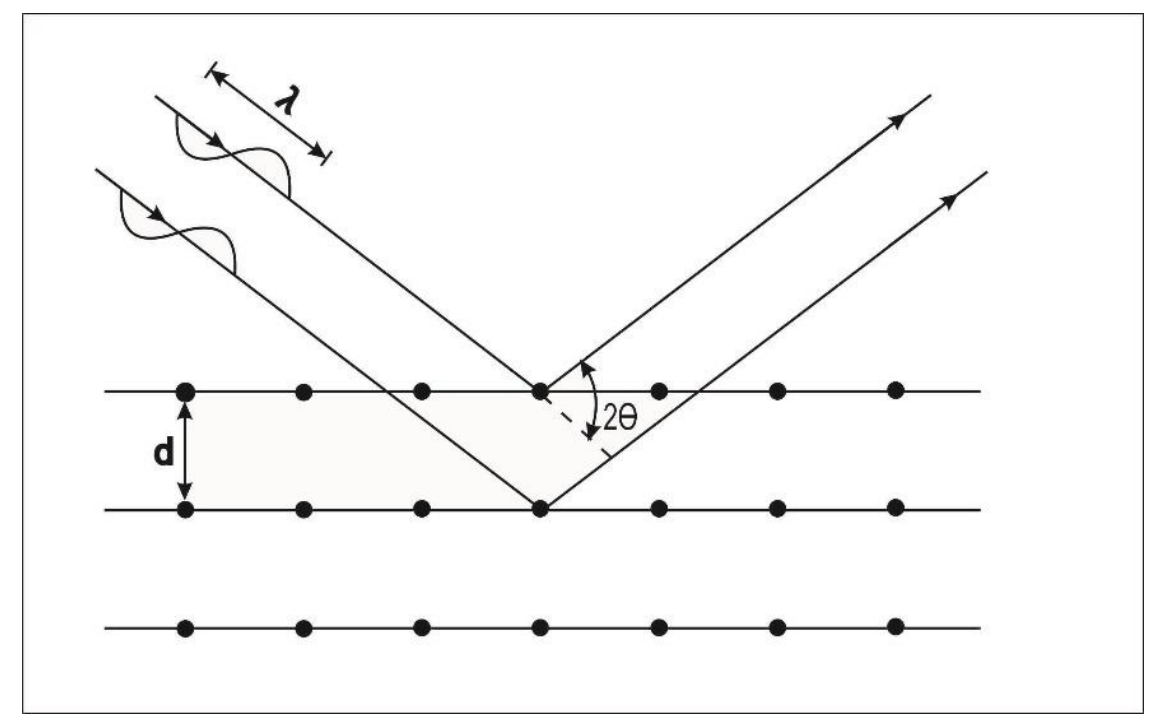

Figure 2-6. X-Ray Diffraction (XRD) schematic pattern

The Bruker-AXS D8 DISCOVER Diffractometer was employed to perform the XRD analysis (Figure 2-7). An X-ray diffractometer machine commonly consists of an Xray source and an $\mathrm{x}$-ray detector, which is resposible for receiving and recording the incident waves (Figure 2-7). The XRD system was equipped with EVA software to analyze the XRD patterns of the samples. The scanning rate was set at $2 \theta /$ min over the $2 \theta$ range between 2 to 20 degrees to ensure the complete investigation on the basal spacing of the soil samples. Note that the scanning angles $(2 \theta)$ from 3 to 6 degrees covers the common range of organoclay basal spacing. 

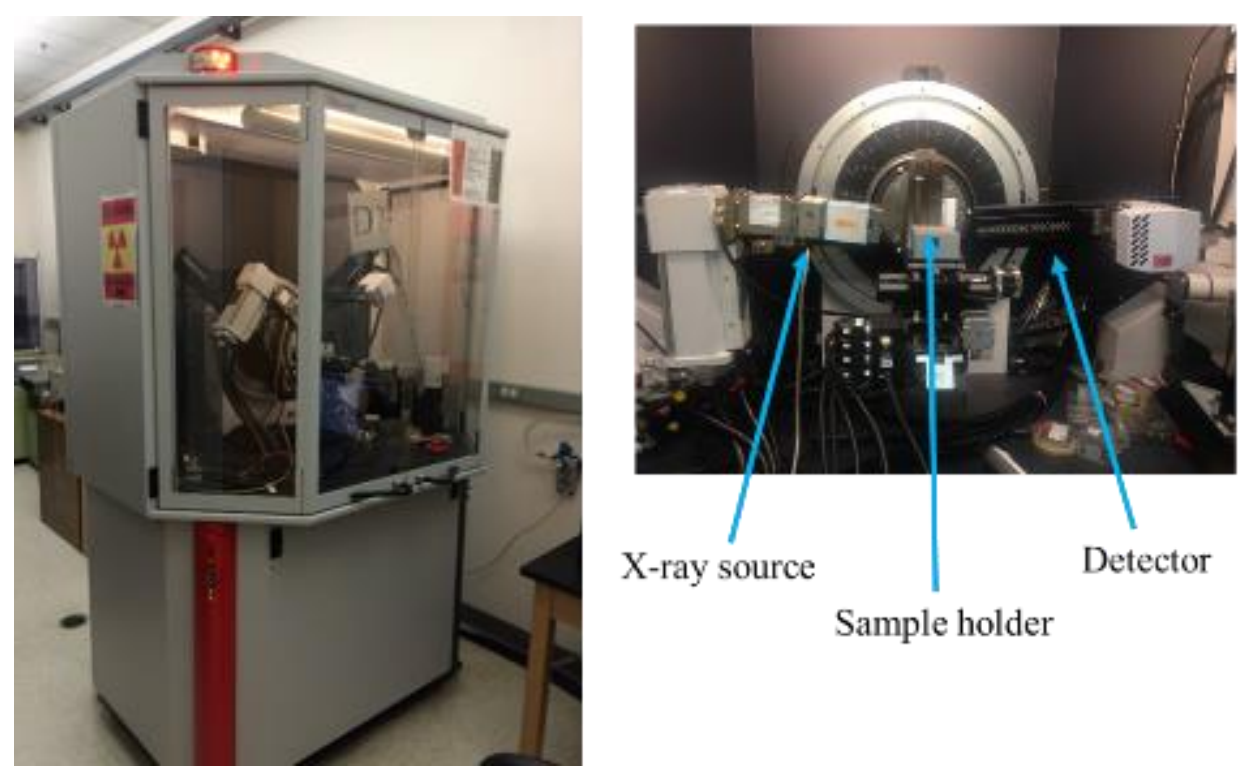

\section{Figure 2-7. XRD machine and its main components (University of Kentucky)}

Since the coarse soil particles may produce the "defected" diffraction data, very fine soil particles were used to run the XRD test. Note that fine powders should contain sufficient soil particles to provide the adequate number of diffraction when they are bombarded with the incident x-rays. To achieve the fine soil particles, the soil sample was crushed by pestle and mortar and then sieved through the No. 200 mesh size. Afterwards, the sieved soil particles were placed on a glass sample holder with a smooth surface, and then the excess soil from the glass holder was removed by a soft brush. The prepared sample was securely located in the XRD machine. The detailed sample preparation procedure is illustrated in Figure 2-8. 

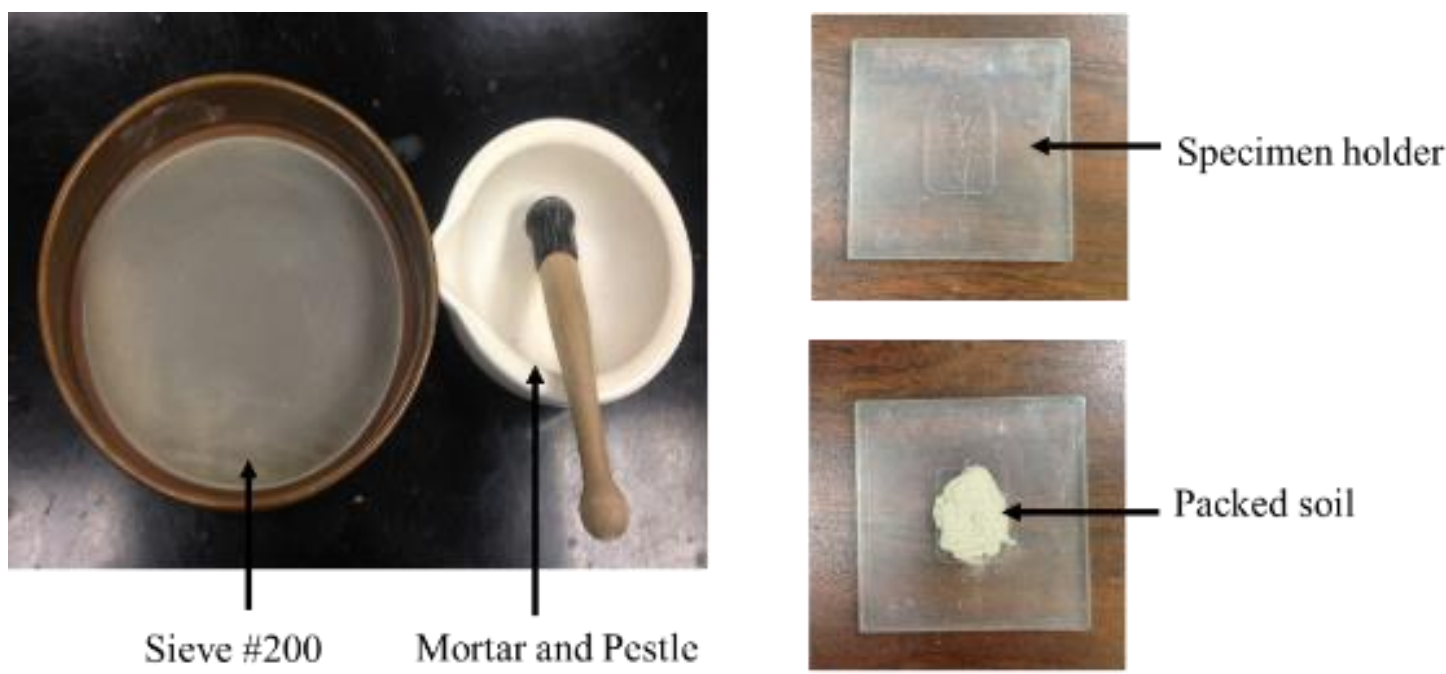

Figure 2-8. Sample preparation for XRD testing

\subsubsection{Scanning electron microscopy (SEM)}

A scanning electron microscopy (SEM) is a non-destructive and well-established technique that generates images of a soil sample in microscale by scanning the sample with an adjusted beam of electrons. When the electrons are faced with atoms in a soil sample, they produce many signals that have information regarding the soil's surface topography, structure, and composition. Under different magnifications (resolutions), many images on different areas of a soil sample can be captured. The morphology of each soil sample was examined using an FEI Nova nanoSEM 600 with an accelerating voltage of 2-3 kV (Figure 2-9). The SEM machine was equipped with backscattered electron detectors and a vacuum pump. 


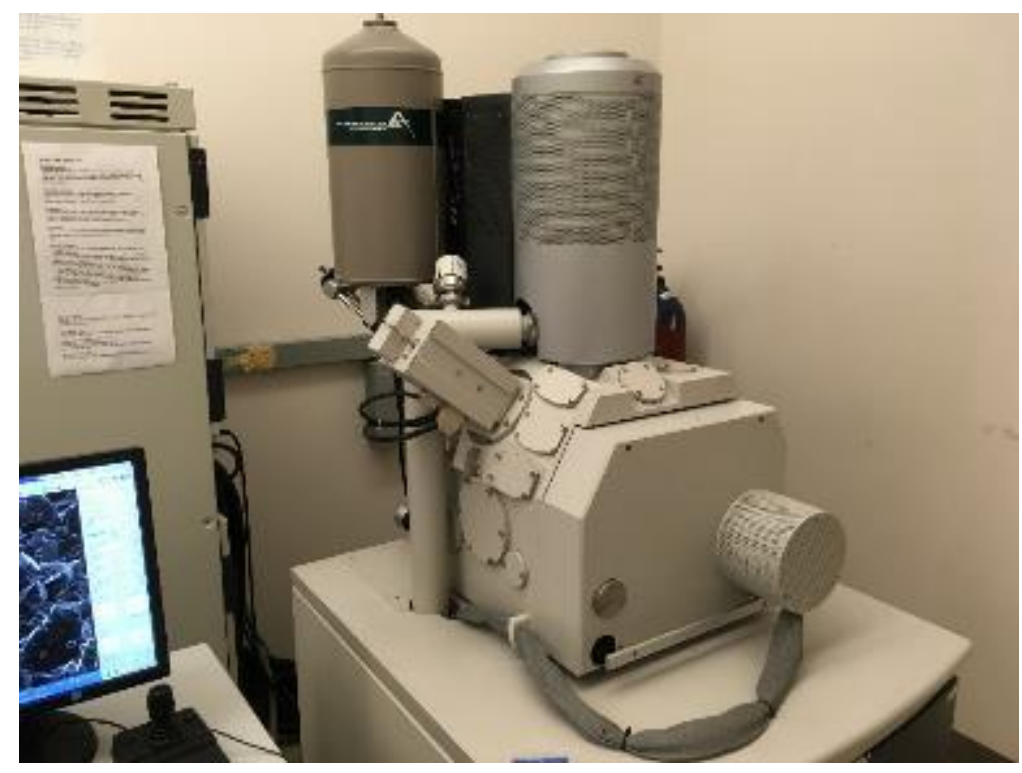

Figure 2-9. SEM machine (University of Louisville)

Oven-dried powdered soil that passed through sieve \#200 was selected for the SEM imaging. A small portion of soil was spread out on a sample holder (aluminum pin stub) which was already mounted by a strip of double-sided carbon tape. The soil was stuck on the tape, and the extra soil was gently removed by a brush (Figure 2-10). The specimen was then placed in the chamber inside a gold sputter coating machine in order to make a thin gold layer on the surface of the specimen (Figure 2-11). The main function of the surface coating is to make the sample conductive to avoid a charging problem during the imaging process. After finishing the coating process, the specimen was securely placed inside the SEM machine. 


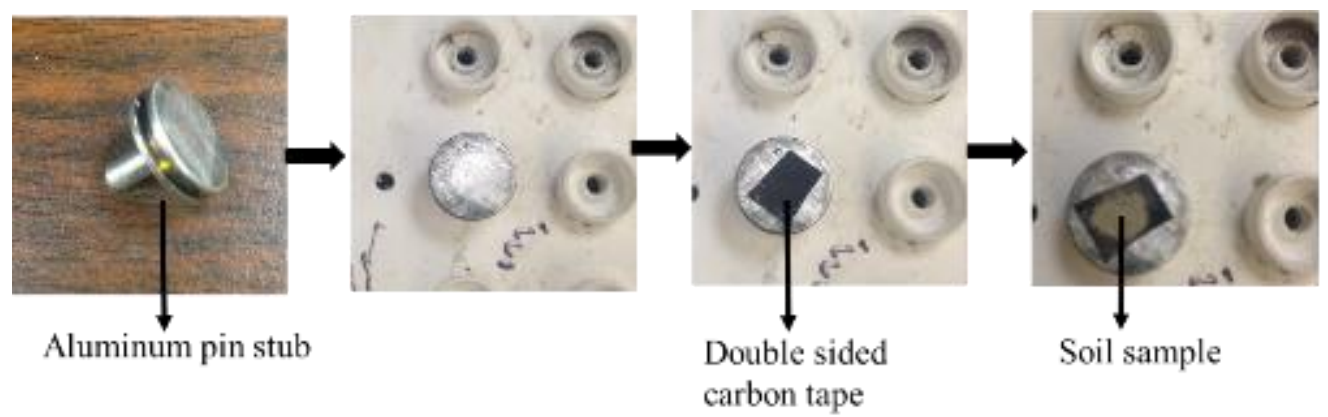

Figure 2-10. Sample preparation for SEM testing

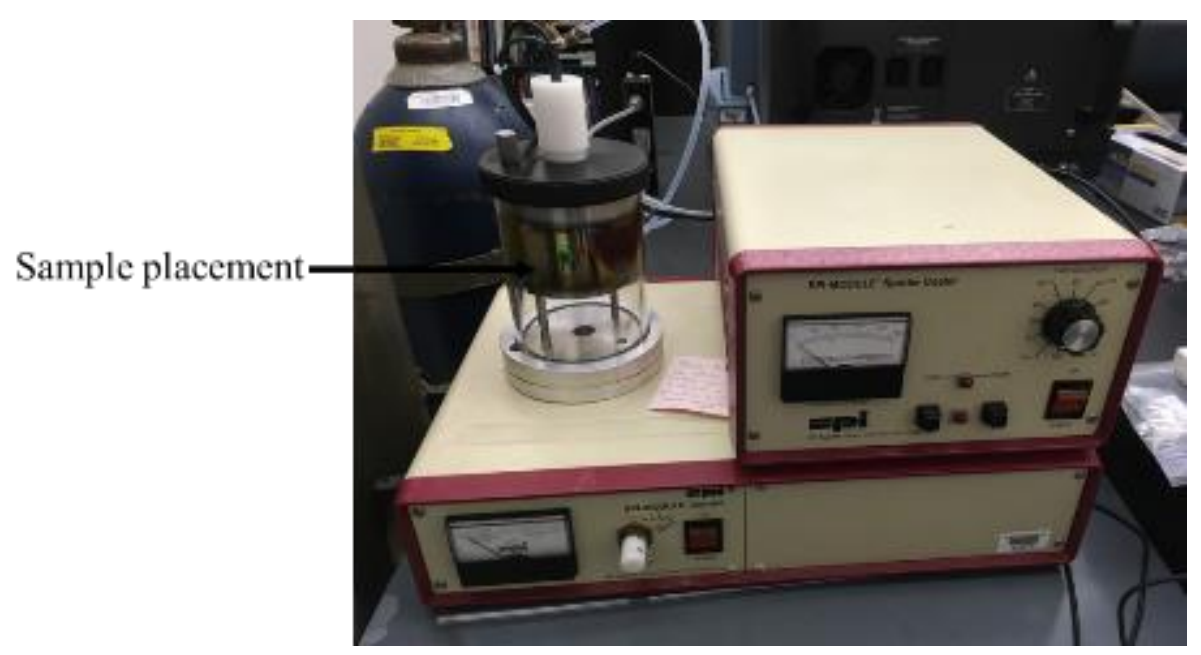

Figure 2-11. Gold sputter coating machine (University of Louisville)

Each specimen was initially examined at a lower magnification, and then step-bystep the magnification was increased. The specimens were imaged at many different magnifications including 500X, 1000X, 2000X, 5000X, 10,000X, 20,000X, 30,000X and $50,000 X$. For each specimen, nearly 20-30 images were taken to represent different views of the specimen's microstructure, but only a few images were presented in the results part.

\subsubsection{Transmission electron microscopy (TEM)}

Transmission electron microscopy (TEM) is a non-destructive technique to record high-resolution images of materials in nanoscale $(0.5-50 \mathrm{~nm})$. A TEM machine has several 
components including a vacuum system, an electron emission source to generate the electron wave, a few electromagnetic lenses and electrostatic plates. A TEM image is formed when a beam of electrons transmits through a very thin layer of a specimen, and interacts with the specimen particles as it passes through. The image can be magnified and focused at nanoscale onto an imaging device.

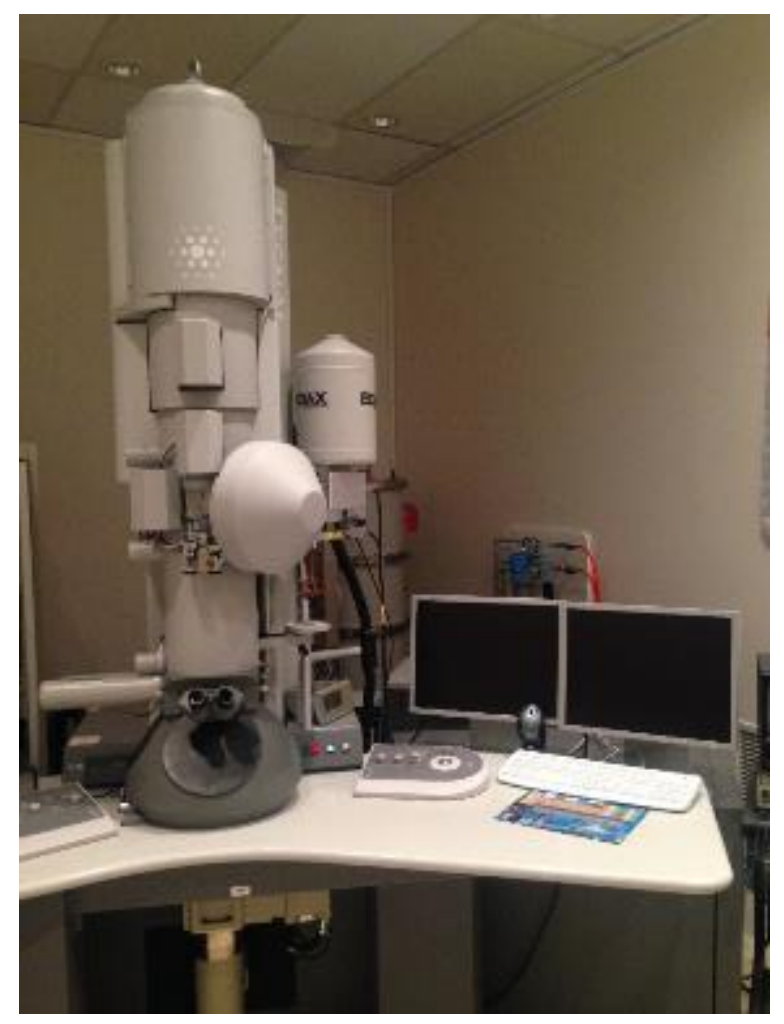

Figure 2-12. FEI Tecnai TEM machine (University of Louisville)

The FEI Tecnai F20 FEG-TEM/STEM with an accelerating voltage of $200 \mathrm{Kv}$ was used to record the image of the soil samples in nanoscale (Figure 2-12). The density of the soil specimen should be low enough to permit the easy traveling of electrons through the layers of the specimen. To prepare the specimen, around $0.1 \mathrm{gr}$ of very fine soil particles that passed through sieve \#200 was measured. The measured soil was placed on a mesh grid and coated with a thin carbon film. The carbon film helped the soil particles to remain 
stable when the electrons traveled through the soil interlayers. The detailed sample preparation procedure for TEM testing is illustrated in Figure 2-13. The prepared specimen was gently placed in the single tilt TEM sample holder, and then the sample holder was inserted into the chamber inside the TEM machine. Many images at different resolutions were taken to inspect the basal/interlayer spacing of each soil sample. The "ImageJ" software was employed to measure the basal spacing of each soil sample.

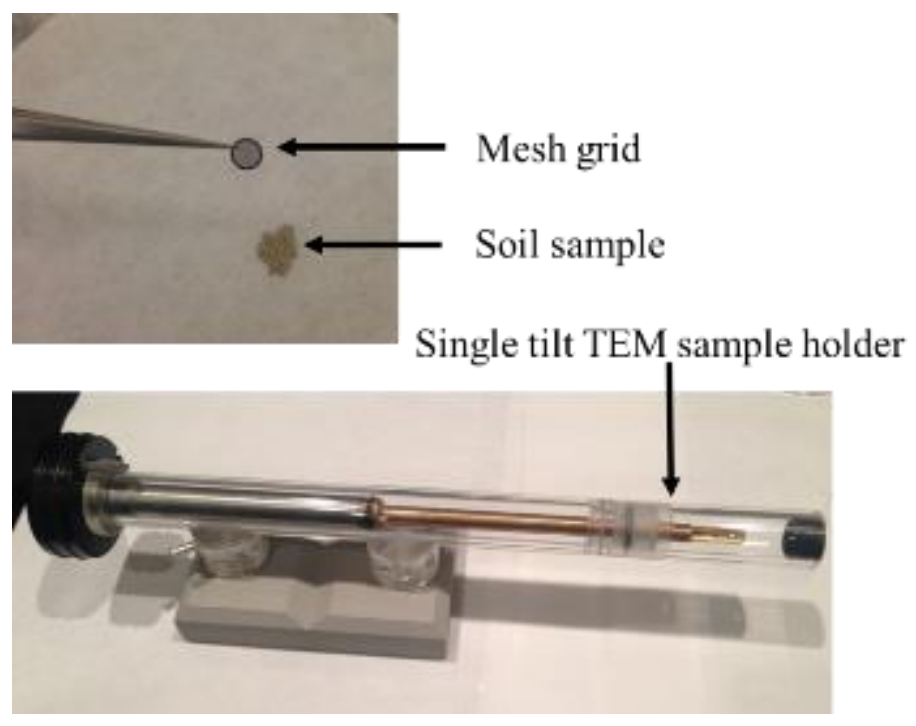

Figure 2-13. Sample preparation for TEM testing

\subsubsection{Fourier transform infrared spectroscopy (FT-IR)}

Infrared spectroscopy is a proven technique to verify the existence of surfactants or sorbate phases in aluminosilicates and their interactions with the siloxane surfaces. Molecular vibrations can be estimated by bonds absorbing radiation of the same frequency and shown in the spectrum. FT-IR spectra were acquired on a Thermo Nicolet 360 FTIR spectrometer (AVATAR) (see Figure 2-14). Around $0.1 \mathrm{~g}$ of the soil was placed in the IR machine, and then the soil sample was squeezed to yield a specimen with a flat surface and even thickness. The transmission method was employed to run the test with a scanning 
speed of $0.762 \mathrm{scan} / \mathrm{sec}(16$ scans per $21 \mathrm{sec})$. The range of the FT-IR spectra was between 500 to $3800 \mathrm{~cm}^{-1}$. The OMNIC software was used to normalize and smooth off the FT-IR spectrums and also to omit noise peaks.

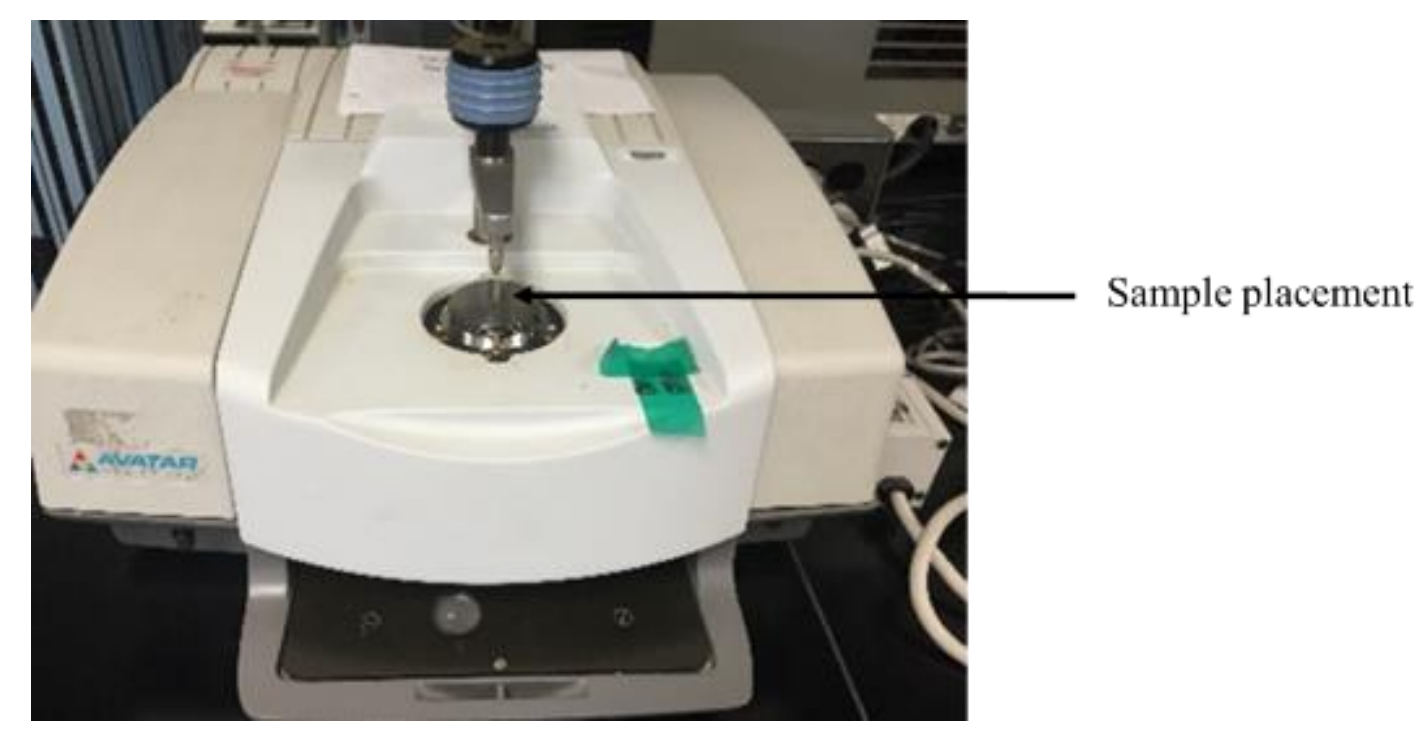

Figure 2-14. Thermo Nicolet 360 FTIR spectrometer (University of Louisville) 


\subsection{Results and discussion}

\section{Engineered properties of the studied soils}

The physiochemical properties of the studied soils are presented in Table 2-3. The unmodified bentonite (Ca-MMT) showed the highest liquid limit (88.3\%) and plasticity index $(37.3 \%)$ when compared with the two organobentonites. According to previous studies, the addition of organic cation onto clay particles can cause the reduction of liquid limit (Burns et al. 2006; Soule and Burns 2001). This phenomenon can be related to the size and carbon chain length of the surfactant. The reduction of the liquid limit of organoclays can cause organoclays to retain less water. The Atterberg limits results of the modified clays are in accordance with the results of the previous study (Burns et al. 2006).

The two organobentonites showed lower specific gravity in comparison with the unmodified bentonite. This is because the introduction of organic surfactant within clay interlayers causes the clay to become hydrophobic and displace a lower quantity of water. The hydrophobicity of the organoclays gives them a higher apparent volume during the specific gravity testing. The specific surface area of natural occurring clay (Ca-MMT) and the two organobentonites (HDTMA-MMT and PM199) were measured by the methylene blue test method. It was observed that Ca-MMT exhibited high specific surface area (276.3 $\mathrm{m}^{2} / \mathrm{g}$ ). This suggested that methylene blue penetrated the interlayer surface area of the CaMMT. On the other hand, the two organobentonites showed a lower specific surface area in comparison with the unmodified bentonite. This revealed that methylene blue could not completely penetrate within the organobentonites interlayers due to the hydrophobic characteristics of the organoclays. Besides that, the surfactants within the organoclay 
interlayers are expected to cover some/all of the mineral surface and decrease the apparent surface area of the surfactant/clay hybrid. Overall, it can be concluded that by introducing organic cations within clay interlayers, the specific surface area decreases, and the decreased surface area of organoclay is accompanied by increasing the organic carbon content (Table 2-3).

Table 2-3. Physicochemical properties of the studied soils

\begin{tabular}{|l|c|c|c|}
\hline Soil & Ca-MMT & HDTMA-MMT & PM199 \\
\hline Liquid limit (\%) & 88.3 & 74.9 & 60 \\
\hline Plastic limit (\%) & 51 & 58.6 & 47.6 \\
\hline Plasticity index (\%) & 37.3 & 16.3 & 12.4 \\
\hline $\begin{array}{l}\text { Fraction passed through No. 200 } \\
\text { sieve }\end{array}$ & 85.5 & 100 & 100 \\
\hline Specific gravity & 2.58 & 1.73 & 1.75 \\
\hline Specific surface area (m) $\mathbf{2})$ & 276.28 & 162.21 & 60.7 \\
\hline Total organic carbon $\mathbf{( \% )}$ & 2.73 & 21.44 & 21.7 \\
\hline
\end{tabular}

\section{X-ray diffraction}

The XRD patterns of Ca-MMT, HDTMA-MMT, and HDTMA-MMT with sorbed hydrocarbons are illustrated in Figure 2-15. The d-001 or basal spacing of Ca-MMT was 15.06 $\AA$, which corresponds to $2 \theta$ of $5.84^{\circ}$. Introducing the HDTMA cationic surfactant into Ca-MMT interlayers caused interlayer expansion (4.38 $)$ to a measured basal spacing of $19.44 \AA$.

It is important to mention that the basal spacing of montmorillonite is highly dependent on the type and amount of exchanged cationic surfactants (Lee et al. 2005). The results of 
our study revealed that the hydrated interlayer inorganic cations were replaced by HDTMA cations, and the intercalated HDTMA cations formed a lateral bilayers structure (with basal spacing less than $20 \AA$ ), as explained in a previous study by Lagaly (1986). This type of HDTMA cation arrangement between the structural layers of montmorillonite appears at the concentration of the HDTMA cationic surfactant near 1.0 CEC.

Note that the shape of the perfect straight-chain quaternary ammonium cation (HDTMA-Br) has the appearance of a nail where the long alkyl carbon chain is the body of the nail and the carbon chain end containing three methyl groups is the nail-head. The theoretical length of the HDTMA cation is $25 \AA$, and the theoretical height of alkyl chain and nail-head are $4.0 \AA$ and $5.1 \AA$, respectively (Refer to Figure 2-3). As a result, it can be hypothesized that the HDTMA cations lied flat within the montmorillonite interlayers (Ikhtiyarova et al. 2012; Zhu et al. 2003).

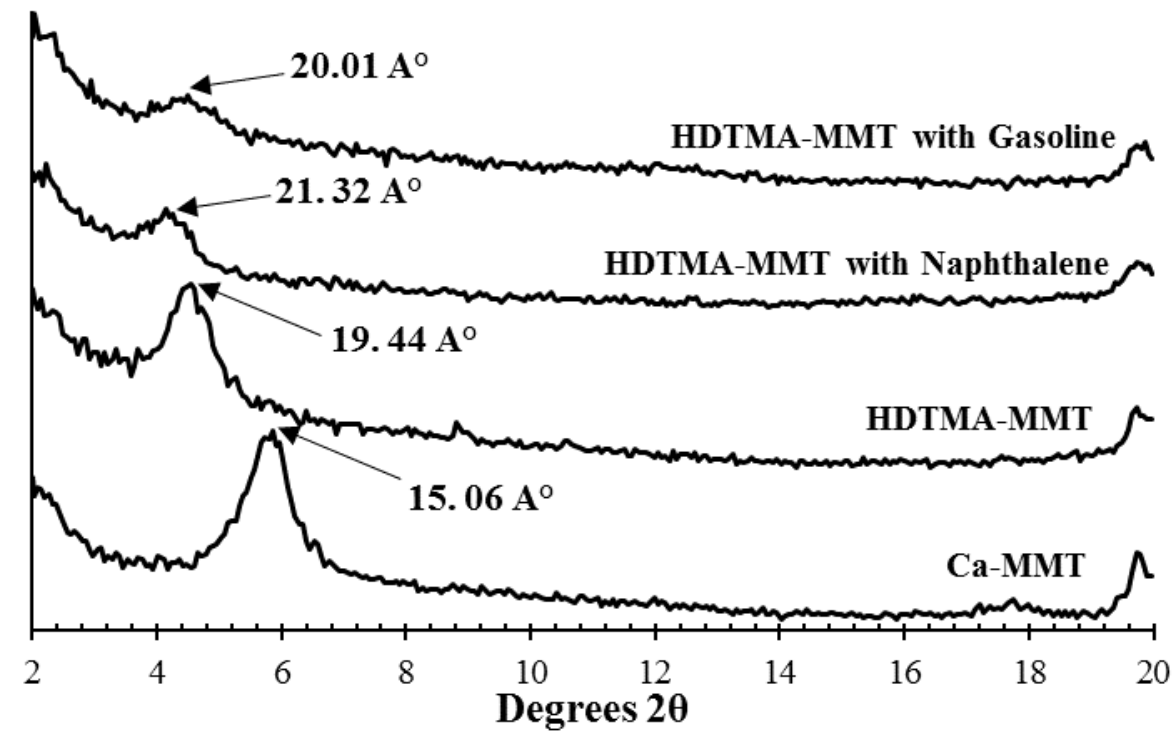

Figure 2-15. XRD patterns of HDTMA-MMT and HDTMA-MMT with sorbed naphthalene or gasoline (vertical line is in scaled) 
The sorption of aromatic or gasoline hydrocarbons onto organophilic clays is driven by the short range forces between sorbates and surfactant sorbents (Zhao and Burns 2012). When the HDTMA-MMT sorbed the naphthalene from the aqueous solution, the basal spacing of HDTMA-MMT increased to $21.32 \AA$. The approximately $2 \AA$ of interlayer expansion (19.44 $\AA$ to 21.32 $\AA$ ) of HDTMA-MMT soaked in naphthalene solution revealed that naphthalene molecules penetrated into and remained in the HDTMA-MMT interlayers (even though some escaped during sample drying). This suggests that the uptake of naphthalene by surfactants was predominantly a process which occurred in the interlayers of the organoclay. Additionally, the intercalated naphthalene (3.5\% by weight, Table $2-4$ ) caused the interlayer expansion of approximately $2 \AA$. The XRD pattern of HDTMA-MMT with adsorbed gasoline showed the basal spacing increased to $20.1 \AA$. The less pronounced interlayer expansion $(0.66 \AA)$ suggests that sorption of gasoline hydrocarbon molecules into the HDTMA-MMT interlayer (with initial interlayer spacing $<13 \AA$ ) was less favored due to the larger size of the alkane molecules (up to $10.5 \AA$ ).

Table 2-4. Sorbents performance of HDTMA-MMT, and PM199

\begin{tabular}{|c|c|c|}
\hline Soils & $\begin{array}{c}\text { Sorbed hydrocarbons } \\
(\text { weight } \%)\end{array}$ & $\begin{array}{c}\text { Specific surface area } \\
\left(\mathbf{m}^{\mathbf{2}} \mathbf{g}\right)\end{array}$ \\
\hline $\begin{array}{c}\text { HDTMA-MMT with } \\
\text { naphthalene }\end{array}$ & 3.5 & 153.8 \\
\hline $\begin{array}{c}\text { HDTMA-MMT with } \\
\text { gasoline }\end{array}$ & 6.9 & 141.3 \\
\hline PM199 with gasoline & 21.8 & 28.3 \\
\hline
\end{tabular}

Figure 2-16 shows the XRD patterns for PM199 with and without sorbed gasoline hydrocarbons. For commercial organobentonite, PM199 with higher sorption capacity of hydrocarbons of larger sizes, the X-ray diffraction pattern indicated that the initial basal 
spacing of the PM199 was $35.58 \AA$. This suggests a possible paraffin-bilayers surfactant arrangement pattern according to a study by Lagaly (1986). Upon the sorption of gasoline hydrocarbon, the significant amounts of sorbate molecules (21.8\%, Table 2-4) in PM199 interlayer lead to an increased basal spacing of $38.66 \AA$ A. This noticeable increase in basal spacing proves that gasoline hydrocarbon easily penetrated into the PM199 interlayers, bonded to the surfactant molecules within the organoclay layers and expanded the interlayer spacing. Moreover, upon adsorption of gasoline hydrocarbon molecules on the organoclay, PM199 surfaces, structural re-arrangement of the surfactant molecules between organoclay layers occurred.

The results suggest that sorption of gasoline hydrocarbon molecules (especially C6 and C8 alkanes) by PM199 was favored as a result of large initial interlayer spacing (> $29 \AA$, compared with HDTMA-MMT with a similar amount of organic carbon). It is also expected that other organoclays with larger basal spacing are more effective sorbents when exposed to petroleum hydrocarbons or large organic sorbates.

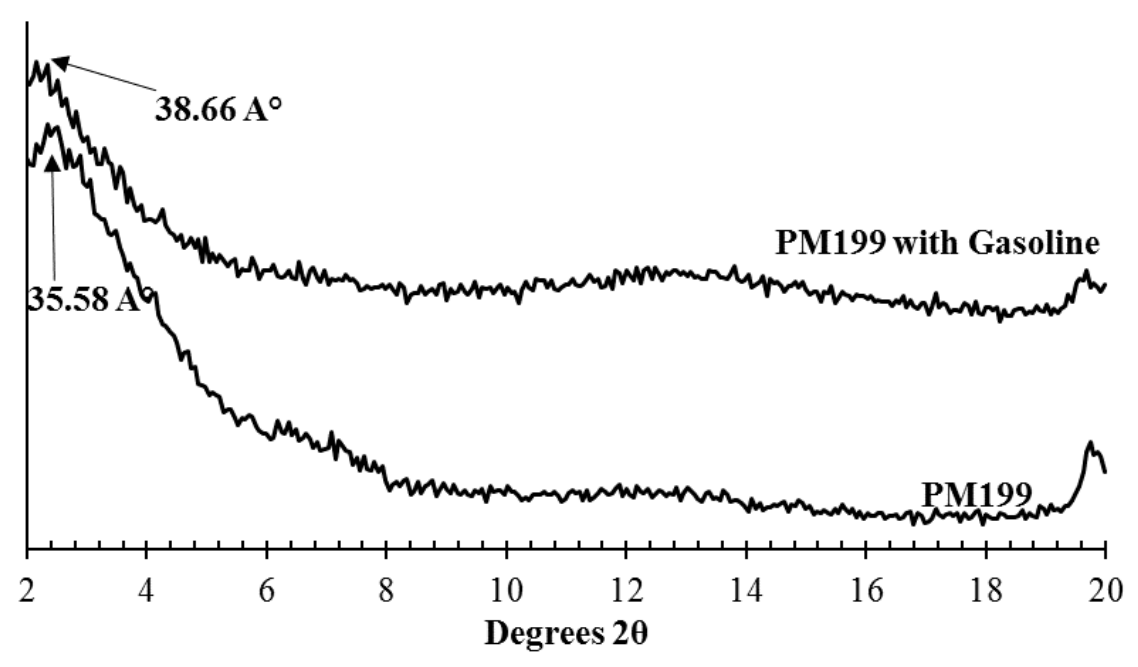

Figure 2-16. XRD patterns of PM199 before and after sorption of gasoline 


\section{Scanning Electron Microscopy (SEM)}

The SEM micrographs of Ca-MMT, HDTMA-MMT, and PM199 are illustrated in Figures 2-17, 2-18 and 2-19. The SEM was used to investigate the morphologic differences between the untreated and treated bentonite. It was observed that Ca-MMT had large aggregated particles with curved edges, and in some areas, there were some large flakes. However, it was observed that after the modification of Ca-MMT with HDTMA organic surfactant, the particles of HDTMA-MMT showed a less foliated structure with rough edges, as well as large number of small flakes (Mallakpour and Dinari 2011; Xi et al. 2005; Zhou et al. 2009). The SEM images of PM199 showed mostly flat and aggregated morphology that can be related to high surfactant packing density within the interlayer of clay, which makes the curved plates in clay transform to flat layers (He et al. 2006). 

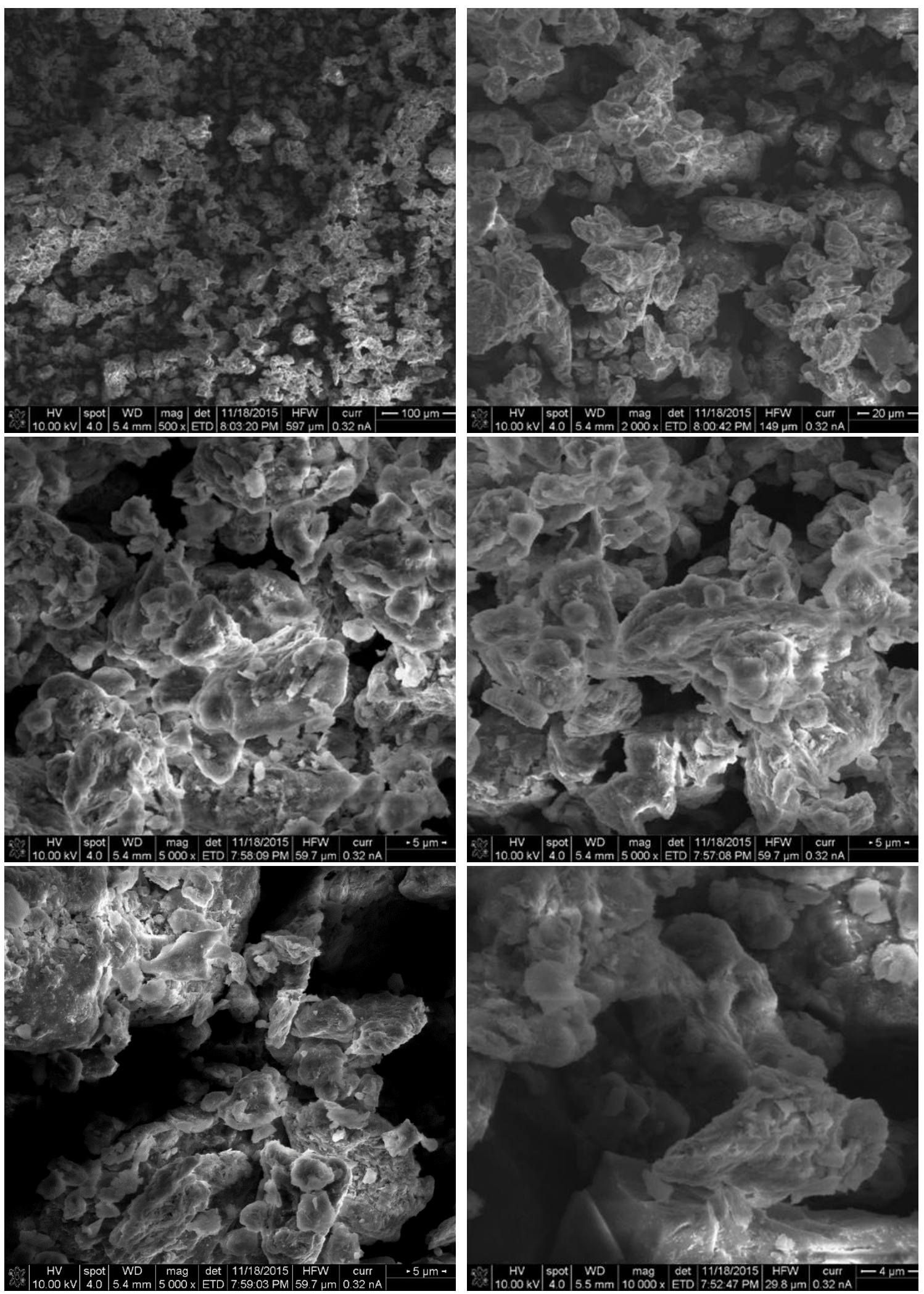

Figure 2-17. SEM images of Ca-MMT at different magnifications 

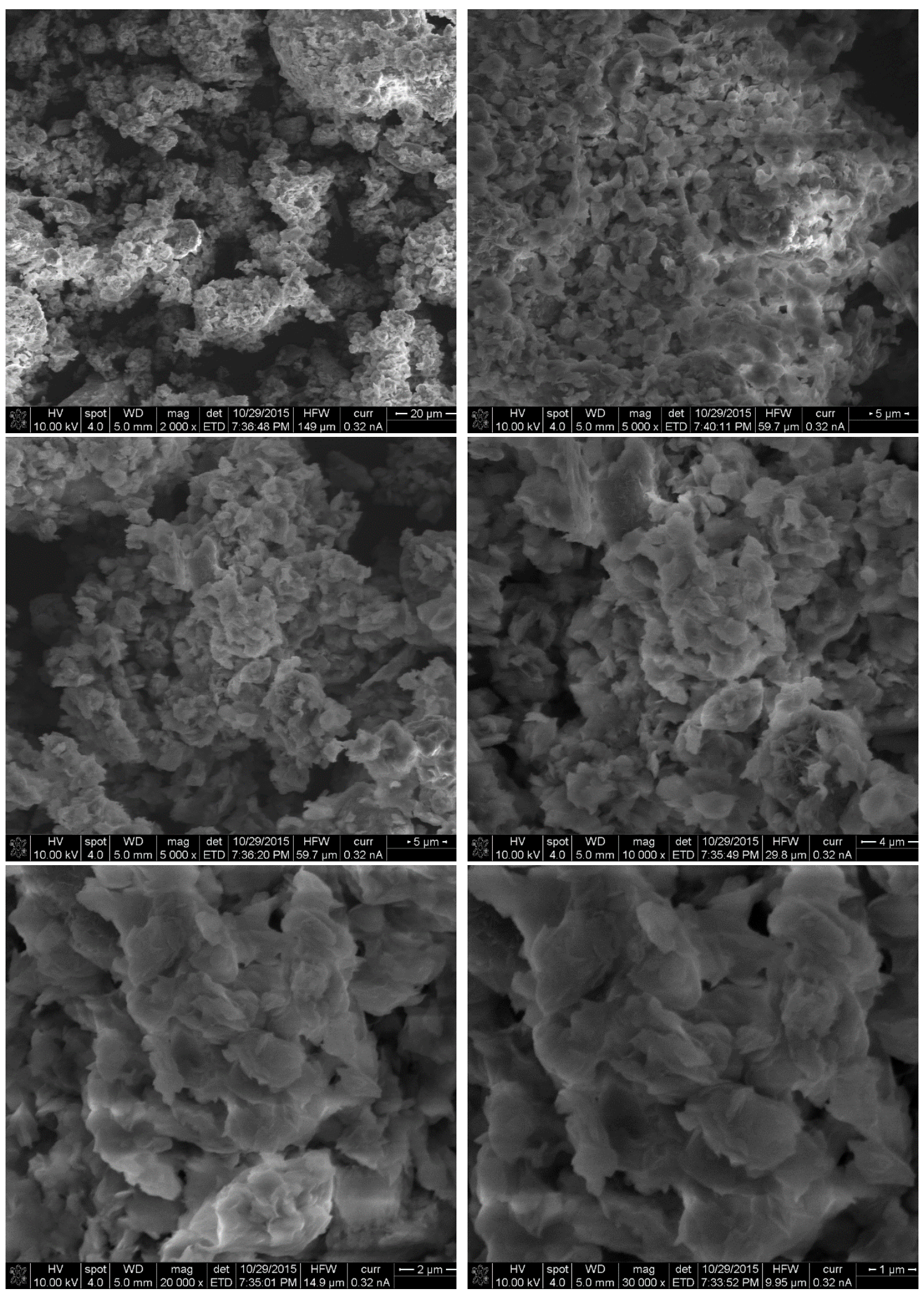

Figure 2-18. SEM images of HDTMA-MMT at different magnifications 


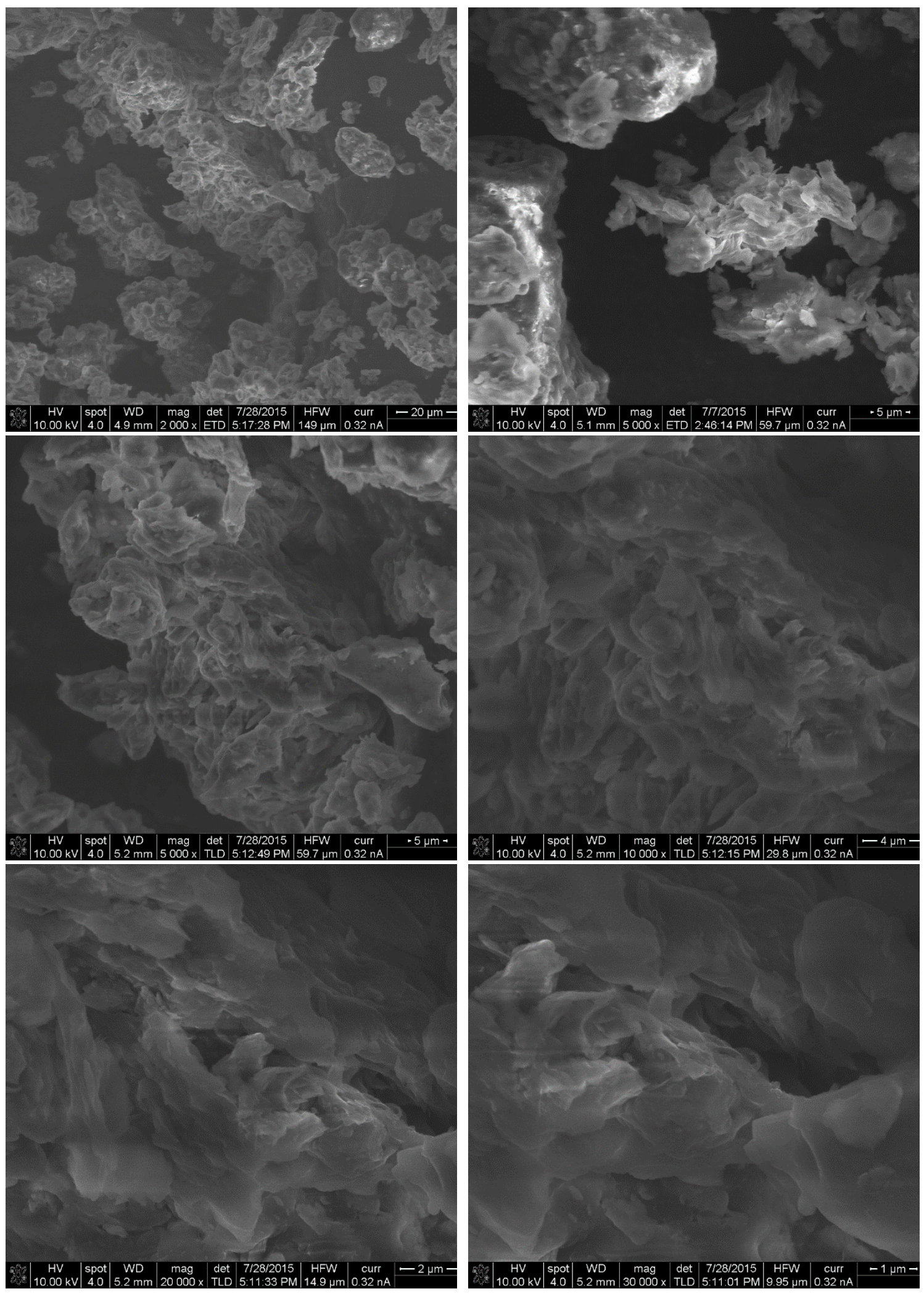

Figure 2-19. SEM images of PM199 at different magnifications 


\section{Transmission electron microscopy (TEM)}

TEM tests were conducted to compare the basal spacing of the six studied soils. The uniformity of interlayer expansion was also examined by random sampling across the obtained snapshots. For each snapshot, more than 20 measurements of basal spacing were obtained and compared. It was observed that all measured basal spacings had a standard deviation of less than $0.3 \AA$, indicating that the predominant basal spacing in the samples was well represented by the obtained TEM results.

A selection of TEM micrographs of Ca-MMT and HDTMA-MMT are presented in Figures 2-20 and 2-2, respectively. The obtained snapshots of Ca-MMT indicated that the soil was composed of a layered structure with a difference in the layer-to-layer distance. The most measurable basal spacing of Ca-MMT was in the range of 15.1 to $15.6 \AA$ (with the exception of some irregular-shaped aluminosilicate layers), which is slightly different from the value of $15.06 \AA$ obtained from the XRD analysis. It should be mentioned that the XRD measurement is an average value, while the TEM results are based upon the spacing of individual layers. The basal spacing of HDTMA-MMT was in the range of 18.8 to 20.5 $\AA$. The increased basal spacing indicated that the interlayers in Ca-MMT were intercalated by HDTMA surfactant. The majority of layers in HDTMA-MMT appeared flat with similar interlayer spacings. The obtained results from TEM images are in accordance with those of previous studies (Sun et al. 2013; Zhou et al. 2007). 

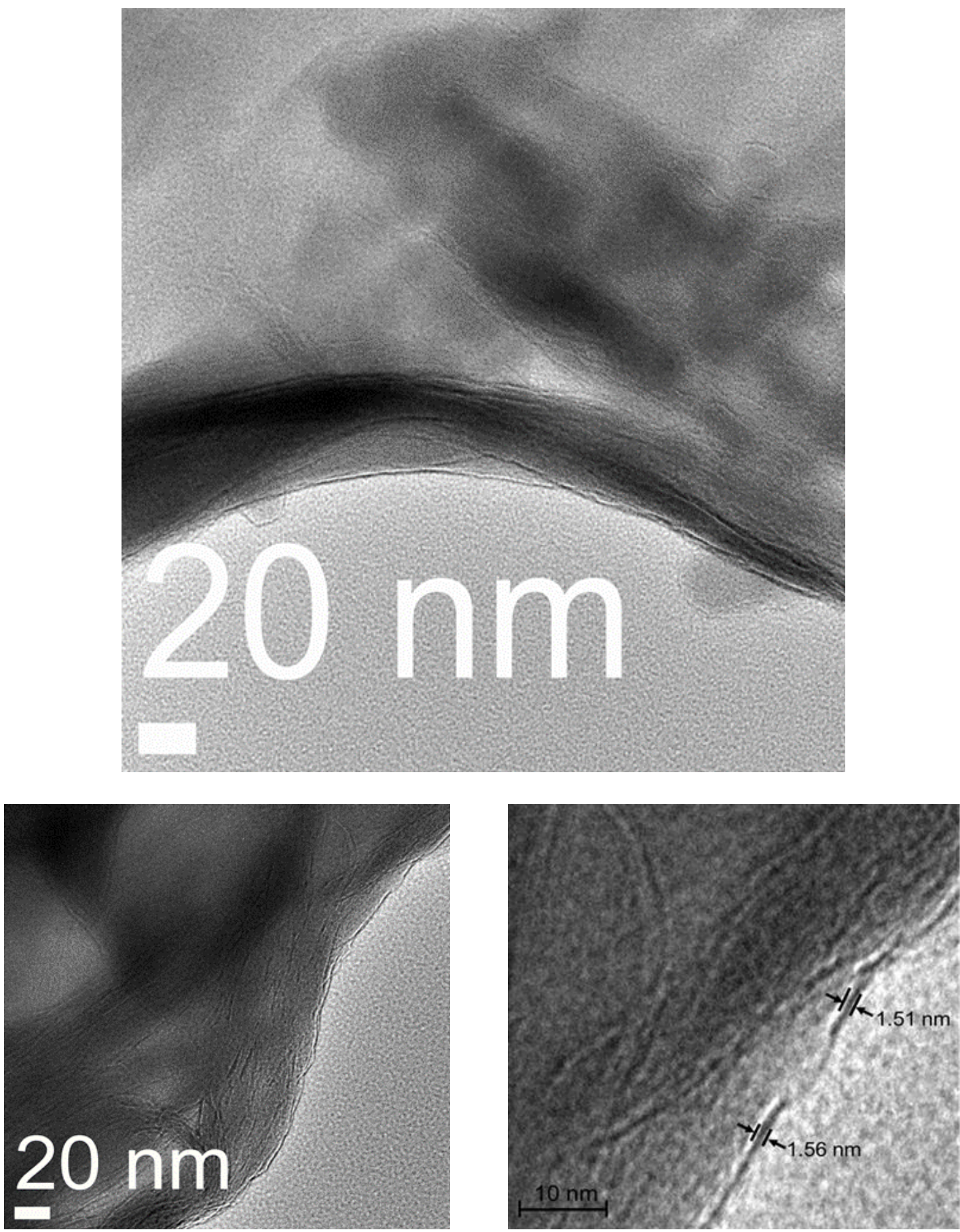

Figure 2-20. TEM images of the Ca-MMT 

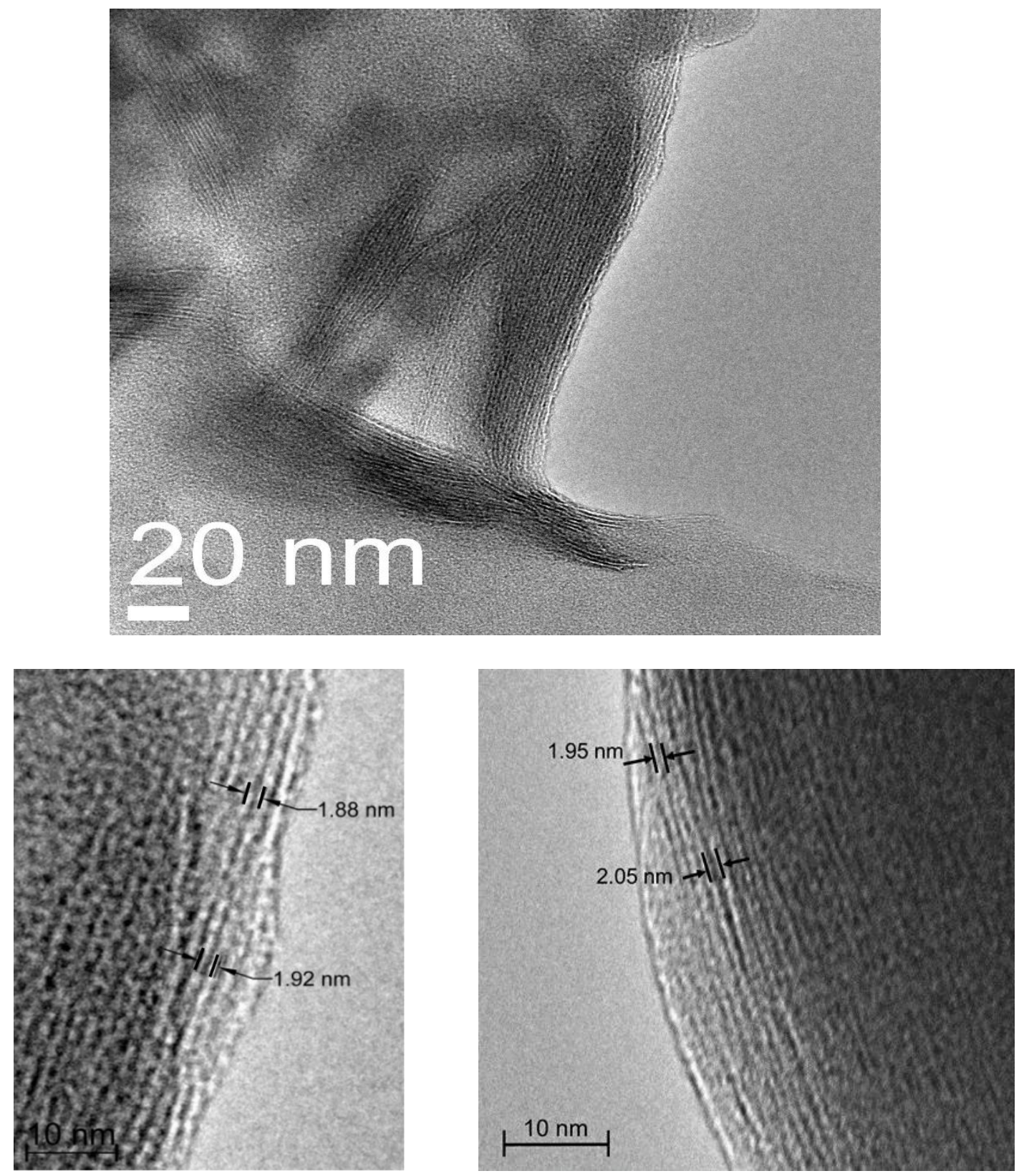

Figure 2-21. TEM images of the HDTMA-MMT

The basal spacing of HDTMA-MMT was slightly increased (20.8 21.4 A) after sorption of naphthalene from the aqueous phase (Figure 2-22). The observed interlayer expansion, due to sorption of aromatic hydrocarbons, confirms the similar trend in previous studies on HDTMA-MMT with sorbed para-nitrophenol (Park et al. 2011; Zhou et al. 2007). The TEM images of HDTMA-MMT with sorbed gasoline also showed slightly 
increased basal spacing (20.6 21.8 ̊, Figure 2-23). TEM images showed that the layers' structure of HDTMA-MMT with sorbed naphthalene and gasoline hydrocarbon were flat and regular.
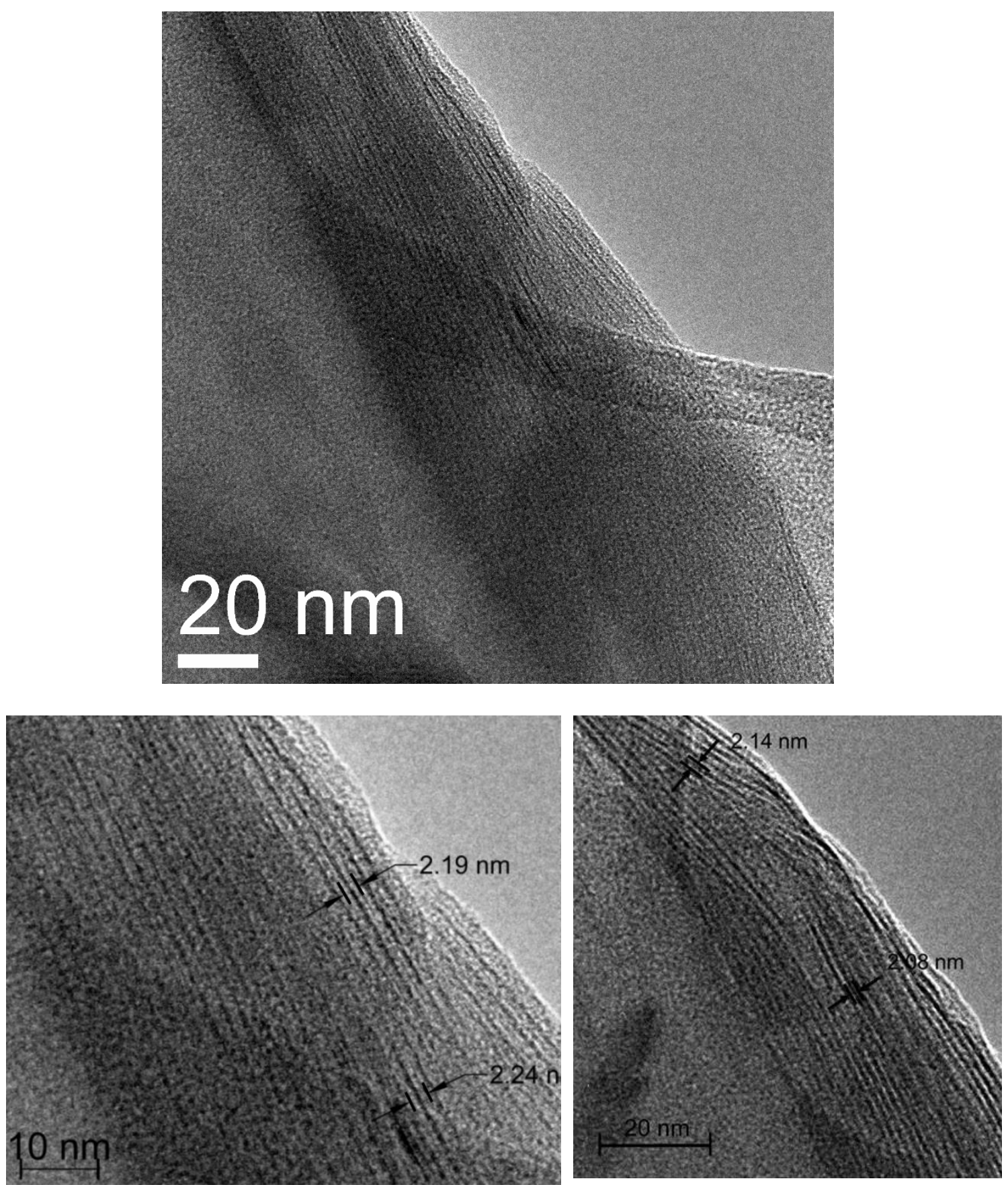

Figure 2-22. TEM images of HDTMA-MMT with sorbed naphthalene 

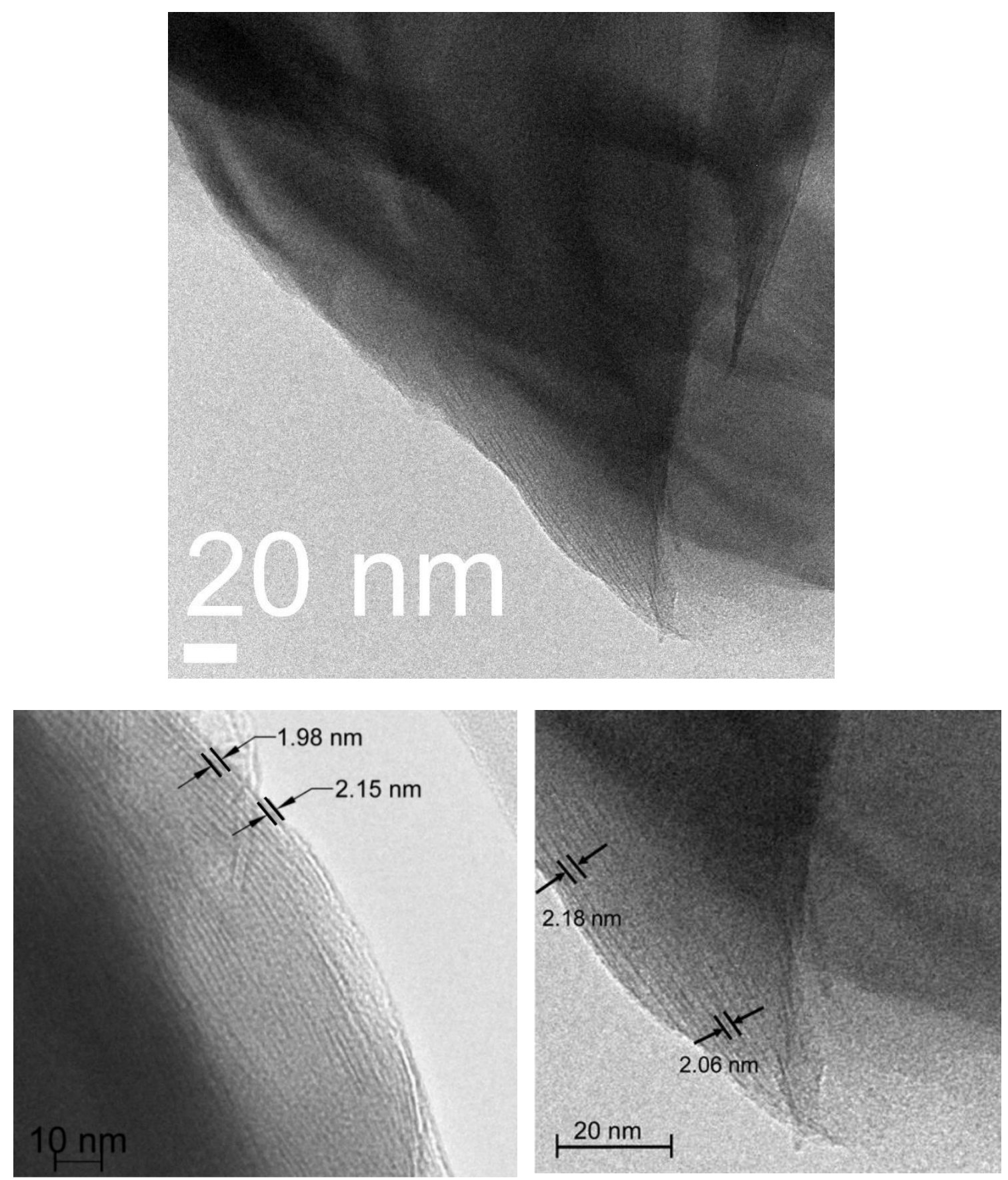

Figure 2-23. TEM images of HDTMA-MMT with gasoline

TEM images of PM199 organoclay with and without sorbed gasoline hydrocarbons are shown in Figures 2-24 and 2-25. The measured basal spacings for PM199 organoclay were in the range of 35.4 to $36.3 \AA$. Compared with HDTMA-MMT, the higher interlayer volume but relatively same carbon content (Table 2-3) in PM199 indicated that the 
interlayer surfactant carbons were likely to be loosely packed. It was assumed that the loosely packed surfactants facilitated further intercalation of gasoline hydrocarbons, as PM199 gained 20\% of gasoline by weight (see Table 2-4) and its basal spacing increased up to approximately $38.4 \AA$. Although the measured basal spacing using the TEM test was obtained from selected areas, and the obtained basal spacing from XRD test was inferred from scattering of the entire sample, the obtained results from the both methods were in good agreement. Figure 2-24 shows the obtained basal spacing of the six studied soils from XRD and TEM tests.
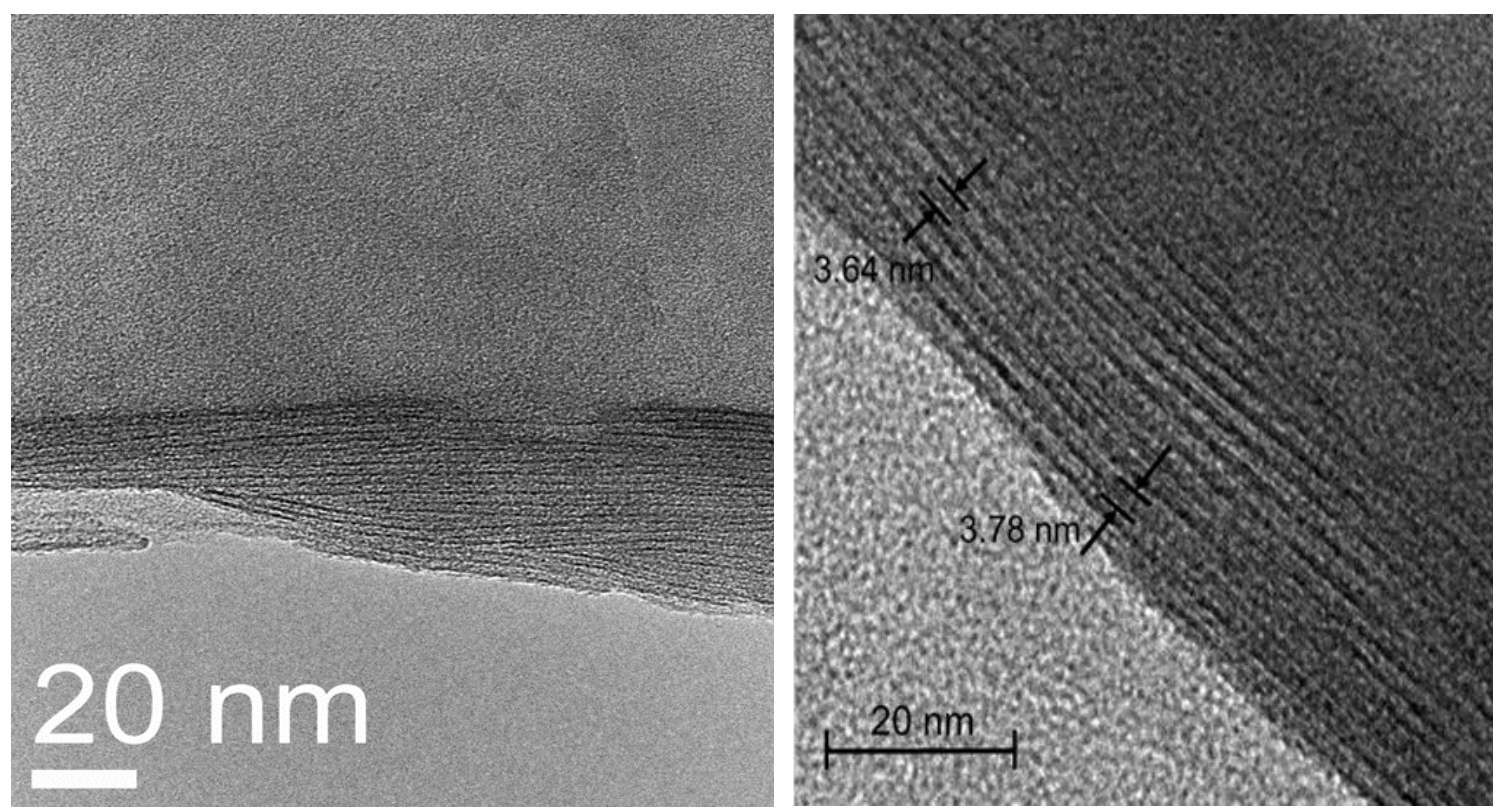

Figure 2-24. TEM images of PM199 

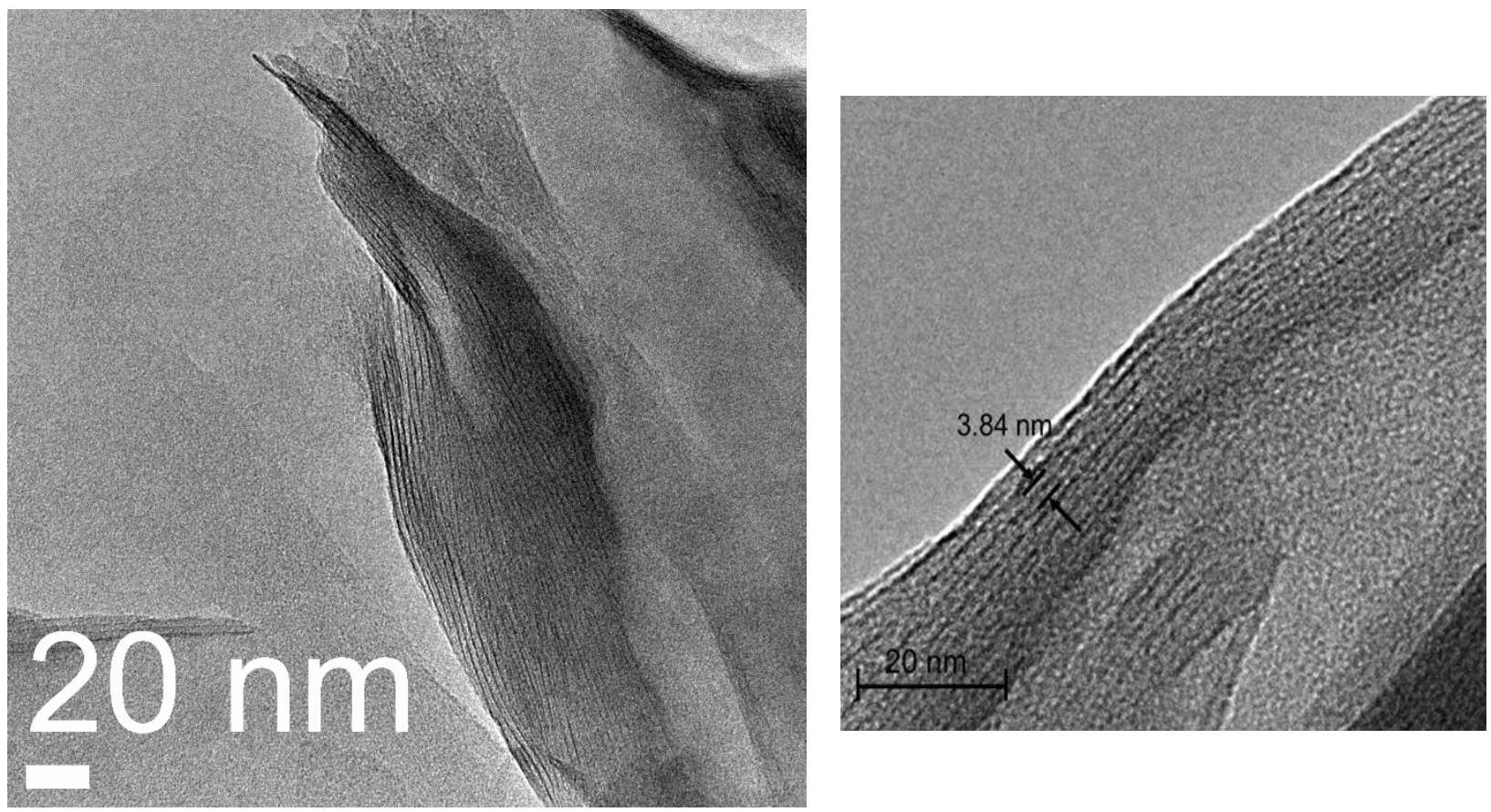

Figure 2-25. TEM images of PM199 with sorbed gasoline

\section{Infrared spectroscopy}

The FT-IR absorbance spectra were divided into several significant regions to identify the predominant vibrations of bond stretching and angle bending in clay/surfactant hybrids: Si-O stretching and bending vibrations region $\left(800-1000 \mathrm{~cm}^{-1}\right), \mathrm{HOH}$ bending vibration region $\left(1600-1700 \mathrm{~cm}^{-1}\right), \mathrm{CH}$ stretching region $\left(2800-3000 \mathrm{~cm}^{-1}\right)$, and $\mathrm{OH}$ stretching region (3000-3700 $\left.\mathrm{cm}^{-1}\right)$ (He et al. 2006; Pavia et al. 2008). 


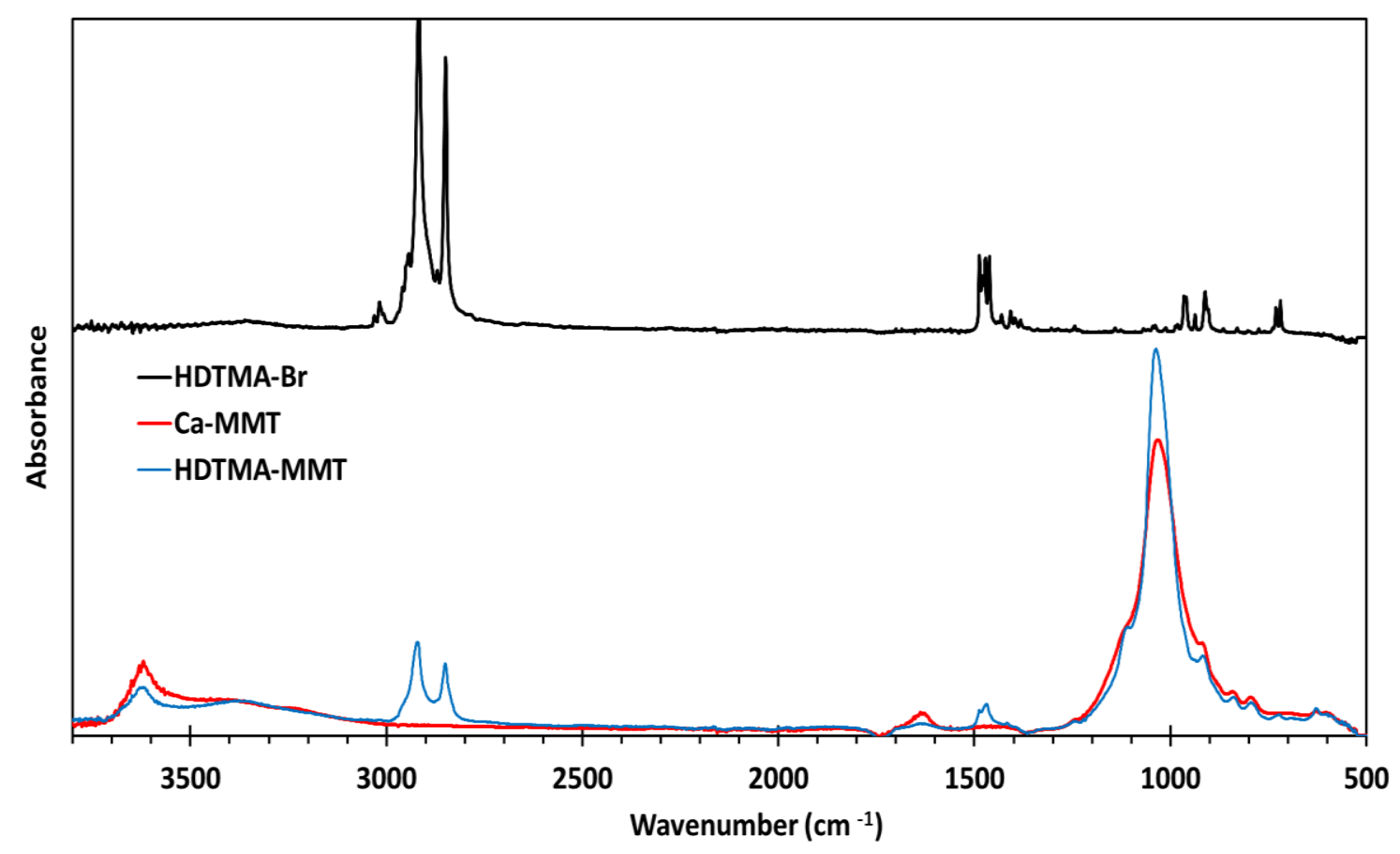

Figure 2-26. FT-IR spectra of: (a) Ca-MMT, HDTMA-MMT and HDTMA-Br

The FT-IR spectra of the Ca-MMT, HDTMA-MMT, and HDTMA-Br (surfactant salt) were carried out over the range of 500 to $3800 \mathrm{~cm}^{-1}$ and were compared with each other to obtain information on the modification of Ca-MMT with HDTMA functional groups (Figure 2-26). The FT-IR spectra of clay minerals show Si-O stretching and bending, and $\mathrm{OH}$ bending absorptions in the 500 to $1300 \mathrm{~cm}^{-1}$ range. Ca-MMT and HDTMA-MMT displayed a deep band between 1032.694 and $1036.551 \mathrm{~cm}^{-1}$, respectively, due to the $\mathrm{Si}-\mathrm{O}$ stretching and $\mathrm{Si}-\mathrm{O}-\mathrm{Si}$ bending on the siloxane surfaces of montmorillonite. The results also indicated that the introduction of HDTMA surfactants into montmorillonite minerals had a stronger interaction with the siloxane surfaces when compared with the water molecules and hydrated cations in unmodified montmorillonite. 
Moreover, the FT-IR spectrum of HDTMA-MMT showed bands of $\mathrm{CH}_{2}$ bending and $\mathrm{CH}$ stretching between 1400 to $1500 \mathrm{~cm}^{-1}$ and 2800 to $3000 \mathrm{~cm}^{-1}$, respectively. This supports the modification of natural bentonite with HDTMA surfactant cations (Hongping et al. 2004; Ikhtiyarova et al. 2012). In comparison, Ca-MMT displayed no such bands but one at $1637.268 \mathrm{~cm}^{-1}$, which was attributed to the $-\mathrm{OH}$ deformation of water in Ca-MMT. It should be noted that the intensity of this band, which is related to the amount of interlayer water molecules, decreased with the introduction of the HDTMA surfactants. The observed shift of bands from $\mathrm{HOH}$ bending to $\mathrm{CH}_{2}$ bending verified the replacement of hydrated cations by the intercalated surfactants and indicated the hydrophobic characteristics of the resultant organoclay (He et al. 2006). The FT-IR spectrum of HDTMA-MMT displayed peaks at 2850.274 and $2920.663 \mathrm{~cm}^{-1}$ and can be assigned to the symmetric and asymmetric stretching vibration of the $\mathrm{CH}$ bond. This proves that a significant amount of HDTMA surfactants was intercalated into the interlayer space of HDTMA-MMT. A group of absorption peaks was observed between 3350 and $3650 \mathrm{~cm}^{-1}$, which is related to the inner $\mathrm{OH}$ unit within the clay structure and adsorbed water, and the intensity of these bands (especially at $3650 \mathrm{~cm}^{-1}$ ) decreased with the surfactant modification. 


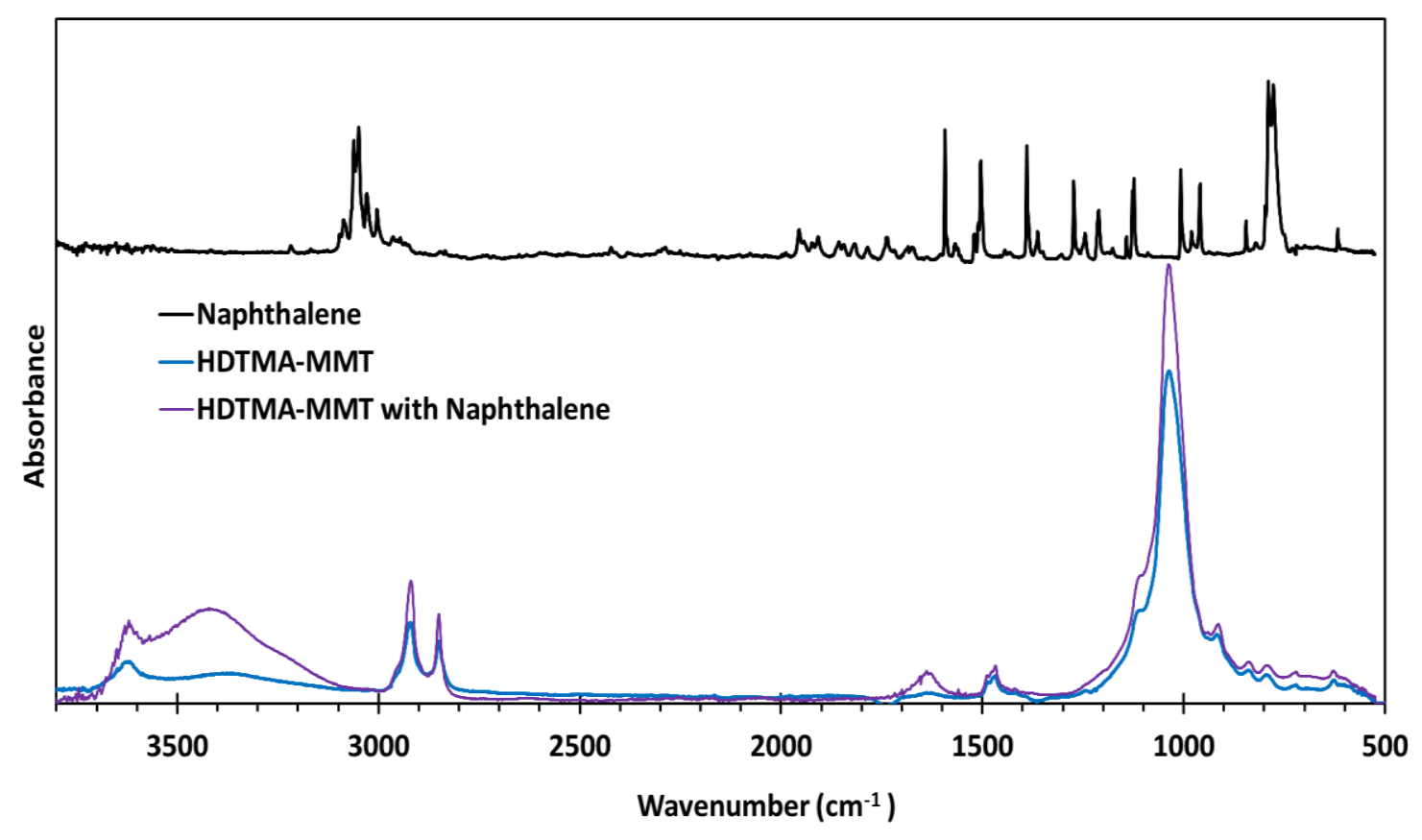

Figure 2-27. FT-IR spectra of HDTMA-MMT, naphthalene, HDTMA-MMT with sorbed naphthalene

The FT-IR spectrum of HDTMA-MMT soaked in naphthalene solution is shown in Figure 2-27. The intensity of the Si-O stretching band of HDTMA-MMT increased as a result of naphthalene sorption. The peaks of asymmetric $\mathrm{CH}$ stretching band also shifted from $2920.663 \mathrm{~cm}^{-1}$ to $2919.699 \mathrm{~cm}^{-1}$ after the sorption of naphthalene within HDTMAMMT interlayers, indicating an increased packing density of interlayer species and less gauche conformation near the clay surfaces. This was expected as naphthalene molecules were able to interact with the clay and the available surface area for gauche conformers of the surfactants decreased. Although induced by sorbate intercalation, the increased basal spacing and decreased gauche conformation was in good agreement with previous studies (Vaia et al. 1994). Overall, the increased interlayer organic carbon per unit surface area was considered as the reason for interlayer expansion and increased hydrophobic 
interactions (Chuang et al. 2010; Lee and Kim 2002; Park et al. 2011). The observed $\mathrm{OH}$ bond stretching and $\mathrm{HOH}$ bending were expected to be from sorbed water and methanol by the HDTMA-MMT.

The FT-IR spectra of the HDTMA-MMT and PM199 with and without sorbed gasoline are shown in Figures 2-28 and 2-29, respectively. Si-O stretching bands showed peaks at 1035.578 and $1043.301 \mathrm{~cm}^{-1}$ for HDTMA-MMT and PM199 with sorbed gasoline, respectively. Figure 2-29 exhibited that PM199 had a much higher intensity of Si-O stretching band after sorption of gasoline. This can be verified as the result of interaction with sorbed gasoline hydrocarbons with the siloxane surfaces.

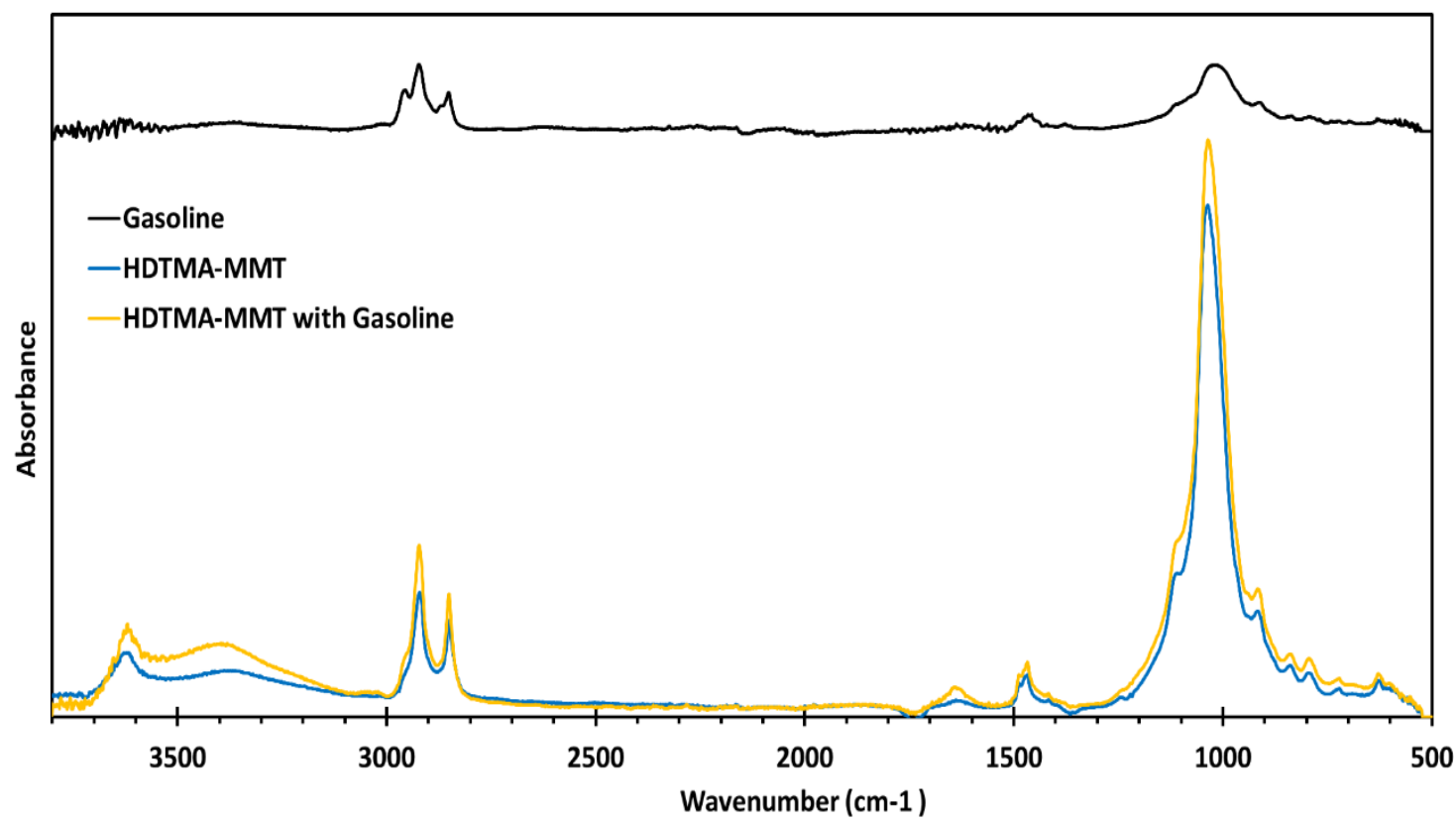

Figure 2-28. FT-IR spectra of HDTMA-MMT, gasoline, HDTMA-MMT with sorbed gasoline 


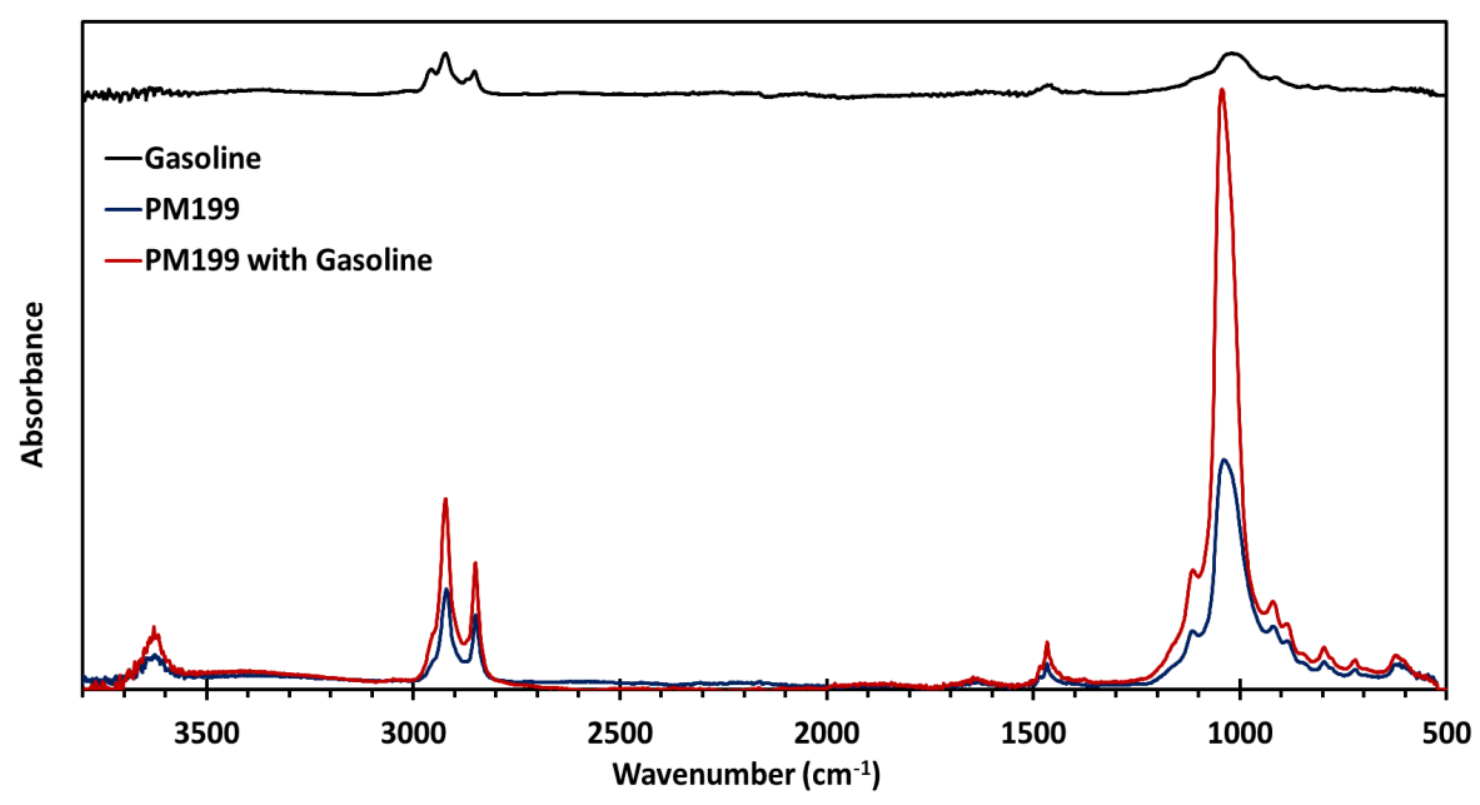

Figure 2-29. FT-IR spectra of PM199, gasoline, PM199 with sorbed gasoline

Moreover, the $\mathrm{CH}$ stretching region was highlighted in Figure 2-30 to compare the chain conformation within HDTMA-MMT, HDTMA-MMT with naphthalene, PM199, and PM199 with gasoline. It was observed that the peaks of symmetric $\mathrm{CH}$ stretch remained the same for HDTMA-MMT and PM199 after sorption of hydrocarbons. However, for HDTMA-MMT, the asymmetric $\mathrm{CH}$ bond stretch shifted to the lower frequency after sorption of naphthalene, while in PM199, the asymmetric $\mathrm{CH}$ bond stretch shifted to the higher frequency after sorption of gasoline. Although the frequency shifts appeared to be relatively small, they are significant considering that they are reproducible to a least \pm 0.1 $\mathrm{cm}^{-1}$. Generally, the frequency and width of asymmetric $\mathrm{CH}$ bond are sensitive to the "gauche/trans" conformer ratio. 


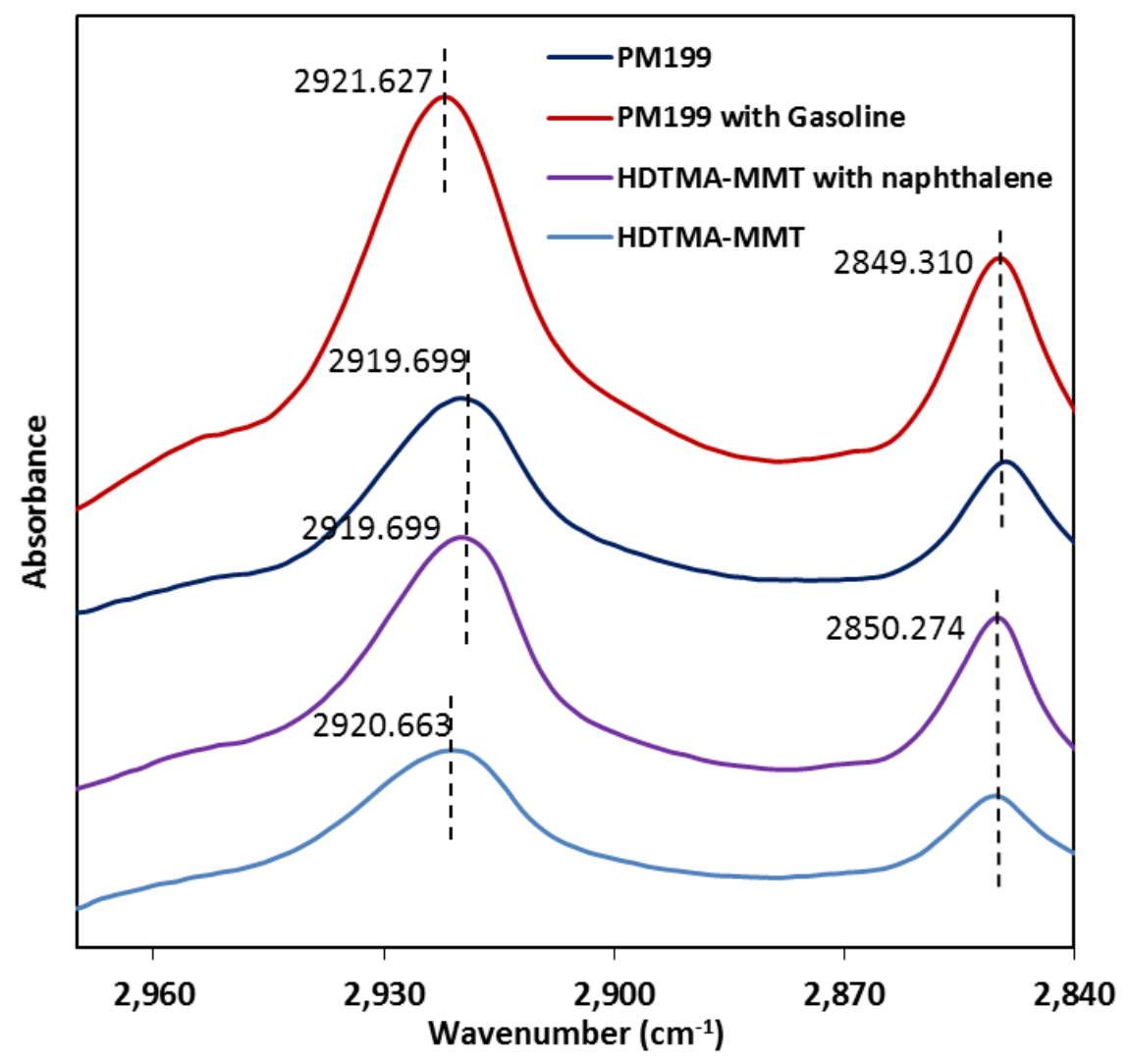

Figure 2-30. FT-IR spectra of selected regions of FTIR spectra of 4 soils

This proposed that in HDTMA-MMT with bilayers structure of surfactants, the effect of secondary sorption was reduced by the chain conformation of HDTMA within the montmorillonite interlayers. While in PM199, sorption of gasoline hydrocarbons led to a less ordered arrangement of surfactant chains (gauche conformation) and increased bending and torsion of the chains. As a result, stronger interactions were observed between the more "liquidlike" surfactants and organic sorbate molecules in PM199. This explains the ease of sorbate intercalation in PM 199 from a perspective at the molecular level. Also, it suggests that further twisting and bending of surfactant chains due to secondary intercalation. 
Table 2-5. Summary of the obtained results

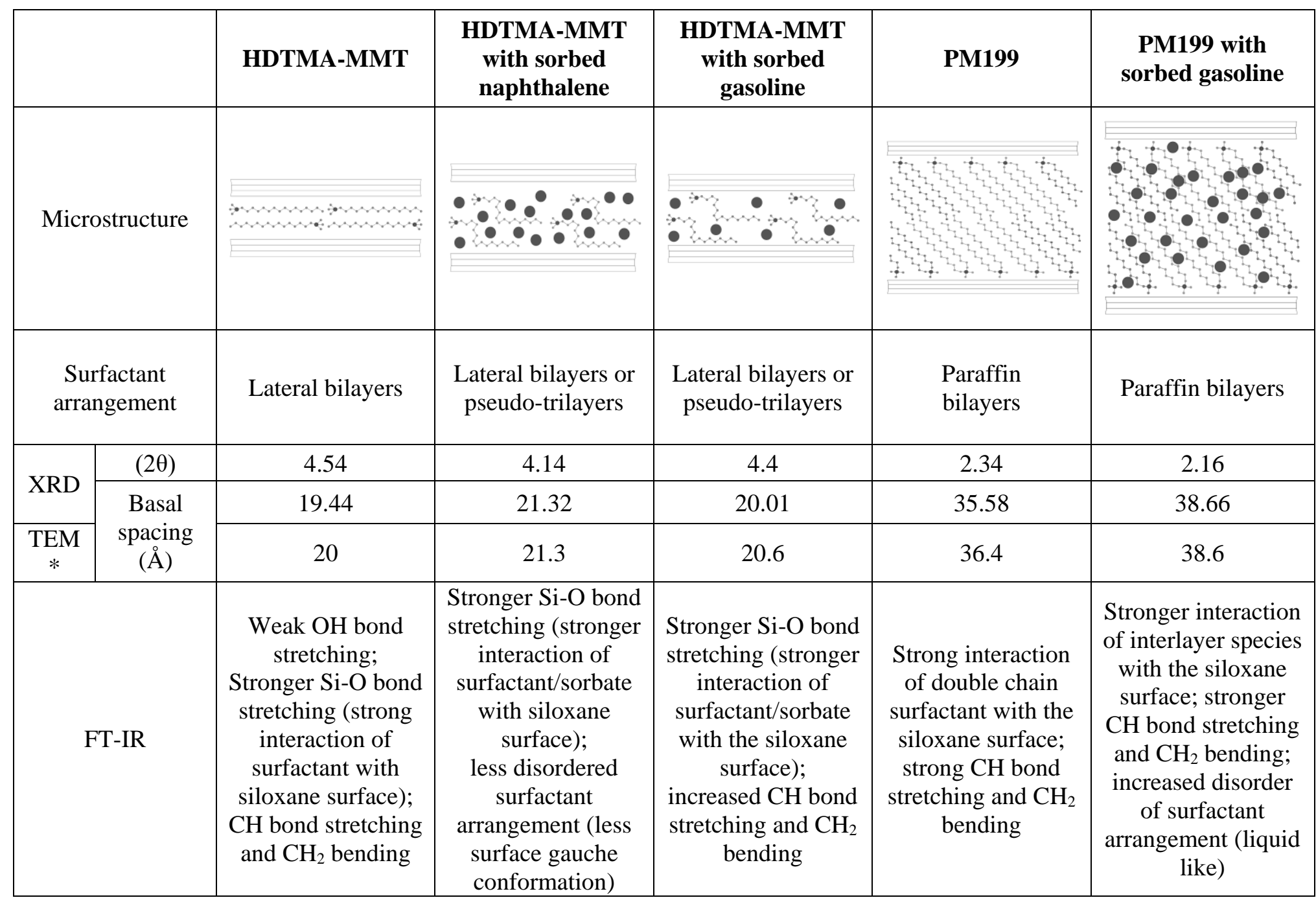




\subsection{Conclusions}

The microstructure of montmorillonite due to the primary sorption (intercalated of organic surfactant within montmorillonite) and the secondary sorption (interaction between the organoclay and a nonpolar organic sorbate) were studied with XRD, TEM, SEM, and FT-IR in this chapter. The obtained information on the microstructures were interpreted to understand several geotechnical laboratory test results. The following conclusions can be drawn from the study:

1. The XRD and TEM results indicated that interlayer spacing of organoclays increased when the organic compounds such as naphthalene and gasoline hydrocarbons were introduced

2. The XRD and TEM results suggested a lateral bilayers surfactant arrangement for HDTMA-MMT and a paraffin-bilayers surfactant arrangement for PM199

3. The XRD results showed that interlayer expansion was more pronounced for PM199 (an organoclay with larger initial interlayer spacing) in compared with HDTMA-MMT.

4. TEM results showed a good uniformity of intercalation and interlayer expansion of the organoclays upon interaction with the organic compounds

5. A good correlation between TEM and XRD results was observed for both basal spacing of Ca-MMT and organoclays

6. FT-IR spectra of the organoclays demonstrated that the intensity of two bands (SiO stretching, C-H stretching) increased upon interaction of organic compounds with organoclays, indicating increased interlayer organic carbon content and stronger stretching of siloxane surfaces 
7. FT-IR results suggested new evidence that in PM199, sorption of gasoline hydrocarbons led to less-ordered arrangement of surfactant (gauche conformation) chains and increased bending and torsion of the chains

8. The obtained results provide significant insights into the modified engineering properties (e.g. swelling, permeability, strength and compressibility) of intercalated organoclays and their applications as soil sorbent and barrier materials for NAPLs and fuels. 


\section{CONTAMINANTS FLOW IN COMPACTED CLAY LINER (CCL) AND GEOSYNTHETIC CLAY LINER (GCL) WITH ORGANOBENTONITE AMENDMENT}

\subsection{Introduction}

\subsubsection{Low permeability barrier}

Barrier systems are designed to prevent contamination of the subsurface soil and water by minimizing the migration of contaminant flow (Rowe 2001). The typical applications of barrier systems include the use of liners for waste disposal facilities, dams, canals, ponds, dams, and spill protection around underground storage tanks. Theses liquids can be water (e.g. in dams, canals, and ponds), contaminated water (e.g. in landfills and sewage lagoons), and pure chemicals or hydrocarbons (e.g. in underground storage tanks). Generally, barrier systems control the movement of fluids by providing an effective liner component with a low permeability (Sharma and Reddy 2004). There are two main types of soil liner: compacted clay liners (CCLs) and geosynthetic clay liners (GCLs).

Compacted clay liners (CCLs) are essential components of hydraulic barrier systems that have been used for several decades. CCLs are commonly composed of soils that are classified as $\mathrm{CL}, \mathrm{CH}$ or $\mathrm{SC}$ in the unified classification system. The clayey soils are placed and compacted in thin 0.1 to $0.3 \mathrm{~m}$ layers called lifts (Rowe et al. 1996). 
Typically, CCLs have a high dry density, low void ratio and low permeability, all of which contribute to the low advection rate of fluid flow through the CCLs.

According to the Resources Conservation and Recovery Act (RCRA) and the United States Environmental Protection Agency (USEPA), the hydraulic conductivity of the barrier systems (CCLs and GCLs) should be equal or less than $1 \times 10^{-7} \mathrm{~cm} / \mathrm{s}$. Generally, the hydraulic conductivity of CCLs is determined by a flexible or fixed permeameter tests in the laboratory; or large scale lysimeters and large fixed ring infiltrometers on the field. The quality of a CCL depends on (a) the characteristics and properties of the clayey soil (e.g. mineralogy and grain size distribution) (b) the method of compaction (the compaction water content) and (c) the protection against desiccation after construction (Rowe et al. 2004).

During the past few decades, geosynthetic clay liners (GCLs) have been commonly used as a soil-based barrier for geotechnical applications. GCLs are consisting of a thin layer of dry bentonite (e.g. calcium or sodium bentonite) sandwiched between two geotextiles which are fastened together by needle-punching, stitching, or gluing with an adhesive (Figure 3-1) (Koerner 2012). Typically, the thickness of GCLs is in the range of 5 to $10 \mathrm{~mm}$. There are many types of GCLs with varying geotextiles, bentonites and attaching methods. Na-bentonite is preferred in GCLs, because of its fine particle size, high surface charges and high swelling tendency. The hydraulic conductivity of GCLs depends on the type of bentonite, the mass of bentonite per unit area, swelling index, moisture content and confining stress (Rowe et al. 2004). 


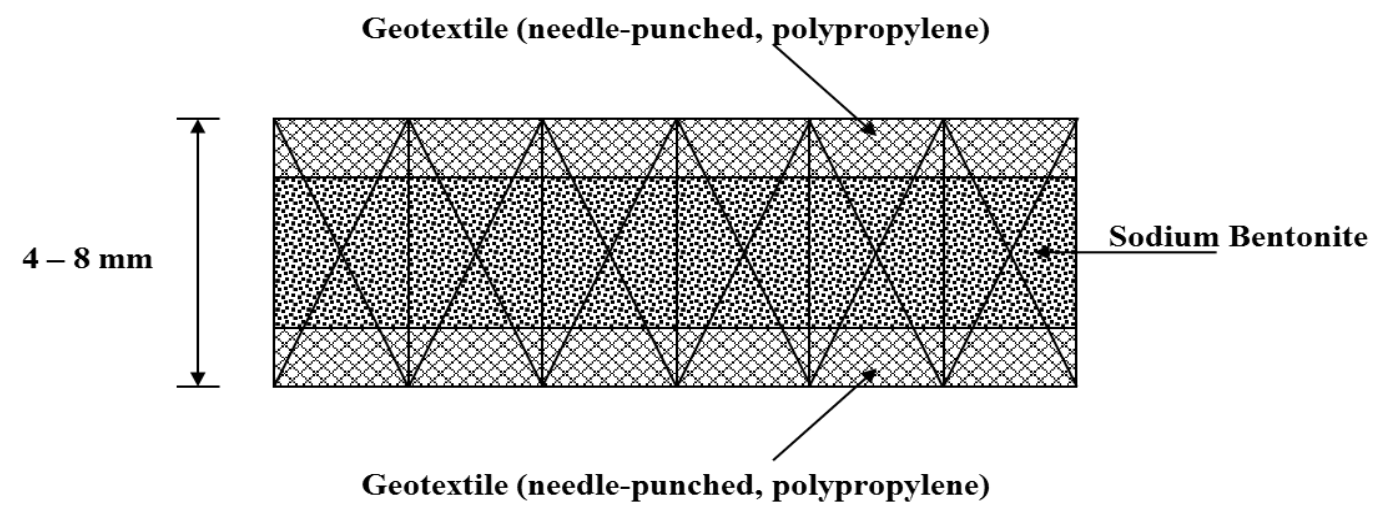

Figure 3-1. General cross-section of geosynthetic clay liner (GCL)

\subsubsection{Engineering applications of CCL/GCL}

The CCLs and GCLs have been used in soil liner or composite liner in landfills and surface impoundments (Shackelford et al. 2010). Some of the properties of CCLs and GCLs were compared in details (Table 3-1). The GCLs are flexible, easy to install, and somewhat self-healing. In places where low permeability clayey soils are not readily available, GCLs may offer substantial cost savings (Sharma and Lewis 1994). 
Table 3-1. Some selected difference between GCL and CCL (Sharma and Reddy

2004)

\begin{tabular}{|c|c|c|}
\hline Characteristic & $\begin{array}{l}\text { Geosynthetic Clay Liner } \\
\text { (GCL) }\end{array}$ & Compacted Clay Liner (CCL) \\
\hline Materials & $\begin{array}{l}\text { Bentonite clay, adhesives, } \\
\text { geotextiles, and } \\
\text { geomembranes }\end{array}$ & $\begin{array}{l}\text { Native soil or blend of soil and } \\
\text { bentonite }\end{array}$ \\
\hline Construction & $\begin{array}{l}\text { Manufactured and then } \\
\text { installed in the field }\end{array}$ & Constructed in the field \\
\hline Thickness & Less than $10 \mathrm{~mm}$ & Approximately 0.6 to $1.2 \mathrm{~m}$ \\
\hline Permeability & $10^{-10}$ to $10^{-8} \mathrm{~cm} / \mathrm{s}$ & $10^{-8}$ to $10^{-7} \mathrm{~cm} / \mathrm{s}$ \\
\hline $\begin{array}{l}\text { Speed and ease } \\
\text { of construction }\end{array}$ & Rapid, simple construction & Slow, complicated construction \\
\hline Cost & $\$ 5$ to $\$ 11$ per square meter & $\begin{array}{l}\text { Highly variable: } \$ 8 \text { to } \$ 35 \text { per } \\
\text { square meter }\end{array}$ \\
\hline Experience level & $\begin{array}{l}\text { Limited due to newness and } \\
\text { nonfamiliarity }\end{array}$ & $\begin{array}{l}\text { Has been used for many decades } \\
\text { with great confidence as a liner } \\
\text { system }\end{array}$ \\
\hline
\end{tabular}

\subsubsection{Problems observed in conventional CCL/GCL}

It was proved by many researchers that CCLs and GCLs have low permeability when they faced with inorganic fluids (e.g. water). However, recently several field applications raised some concerns regarding the chemical compatibility of CCLs and GCLs to certain organic contaminants (Bowders and Daniel 1987; Hamdi and Srasra 2013; Lake and Rowe 2005; Gheibi et al. 2016; Khabiri et al. 2017). Organic pollutants such as petroleum-related products and non-aqueous-phase liquids (NAPLs) from point and nonpoint sources are of great concerns regarding their impact to the soil-based barriers 
(Figure 3-2). These organic contaminants can cause the clayey soils in CCLs and GCLs to shrink and crack with an increase in permeability.

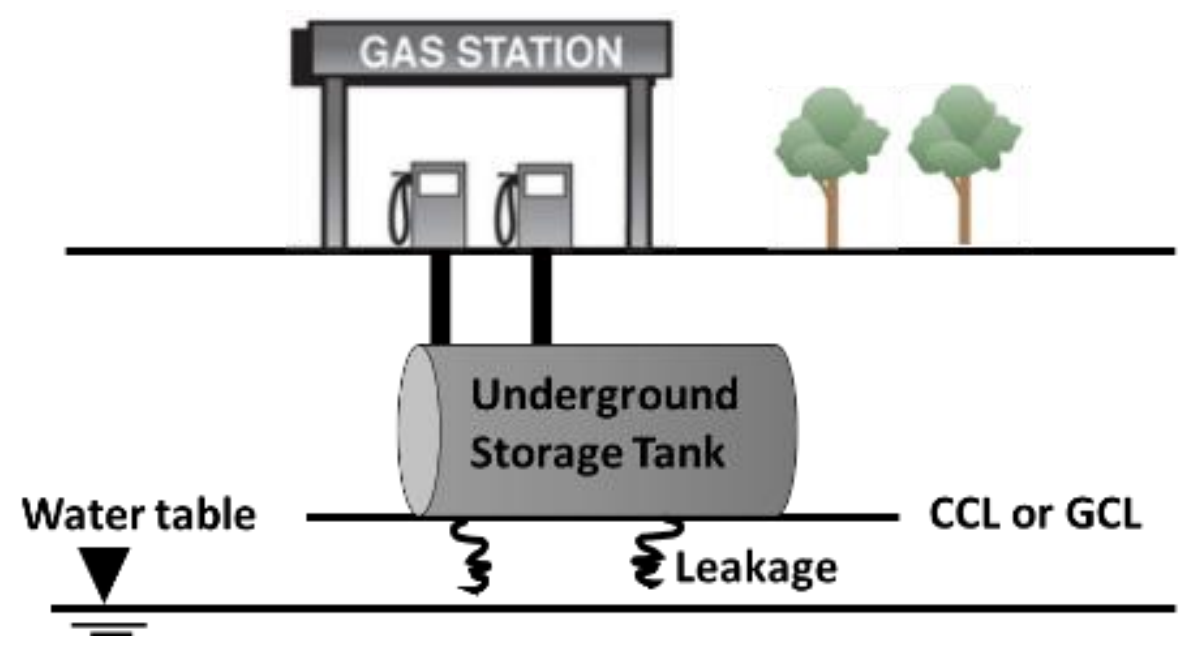

Figure 3-2. Leaking underground storage tank

Numerous studies have been conducted to distinguish the chemical compatibility of CCLs and GCLs when faced with inorganic salts or organic chemical solutions. Brown et al. (1983) and (Fernandez and Quigley 1985) have investigated on permeability of compacted clayey soil to pure hydrocarbons (e.g. gasoline). They have observed that permeability of compacted clayey soil increased four orders of magnitude $\left(5 \times 10^{-9}\right.$ to $1 \times$ $10^{-4} \mathrm{~cm} / \mathrm{s}$ ). Bowders and Daniel (1987) have studied the effect of organic contaminants such as methanol, acetic acid, heptane, and trichloroethylene on permeability of compacted clay. They proved that these organic chemicals increased the permeability of the compacted soil since these organic liquids can replace the original pore water in the soil, and make the soil particle's double layer shrink which may produce several cracks and lead to higher permeability.

Ruhl and Daniel (1997) have comprehensively conducted permeability tests on GCLs using a simulated municipal solid waste (MSW). They found out that permeability 
of GCLs permeated with MSW was approximately four orders of magnitude higher than those permeated with tap water. Moreover, Daniel et al. (1993) and Shan and Daniel (1991) permeated GCL with water, and then with various chemicals such as methanol, pure heptane, sulfuric acid, and gasoline. They have observed that permeability of GCLs increased up to $10^{-5} \mathrm{~cm} / \mathrm{s}$, when permeated with organic liquids. Furthermore, Jo et al. (2001), Jo et al. (2005), Kolstad (2000), Shackelford et al. (2000), and Shackelford et al. (2010) have studied the impact of inorganic solutions (e.g. $\mathrm{NaCl}, \mathrm{KCL}, \mathrm{CaCl}_{2}$ ) on the saturated permeability of GCLs. They have observed that permeability of prehydrated GCLs increased two to three orders of magnitude when they were faced with inorganic solutions. Therefore, improvement of the barrier performance of CCLs and GCLs against certain contaminant flows still requires further examination.

\subsubsection{Organoclay amendment in CCL/GCL}

Recently, many researchers proposed that the chemically reactive geo-materials are able to play an important role to enhance the barrier performance of CCL and GCL. The soil amendments in the barriers (e.g. CCLs and GCLs) are capable of uptaking, immobilizing and/or degrading the pollutants actively while maintaining a satisfactory hydraulic performance.

Several types of natural and engineered materials have been proposed as CCLs and GCLs amendments to enhance the chemical barrier performance of the liners. The proposed amendments include fly ash, zeolite, organo-zeolite, coated sand, and organoclays. Among the suggested additives, organoclays have been proven to be very effective sorbents for organic pollutants (Benson et al. 2015; de Paiva et al. 2008). Organoclays are produced by the exchange of organic cations (e.g. quaternary ammonium) 
for the inorganic cations (e.g. $\mathrm{Na}^{+}, \mathrm{Ca}^{2+}$ ) that naturally occur on the internal and external mineral surfaces of clay. Organic cations bound to the clay surfaces can facilitate the binding of organic molecules to the clay mineral via adsorption and partitioning (Zhao and Burns 2012). Organoclays exhibit low conductivity, high swelling tendency, and high plasticity in organic liquids (Benson et al. 2015; Zhao et al. 2016). Therefore, organoclays can be used as an amendment in barrier systems such as CCLs and GCLs to improve their hydraulic performance when faced with non-polar organic liquids.

Previous studies showed that organoclay amendment could improve the efficiency of CCLs and GCLs when facing organic liquids or petroleum products (Lo and Yang 2001; Smith et al. 2003; Yang and Lo 2004). They observed that permeability of organoclays decreased as the polarity of the permeant decreases. Benson et al. (2015) demonstrated that permeability of granular organoclay varied by six orders of magnitude $\left(10^{-5}\right.$ to $\left.10^{-11} \mathrm{~m} / \mathrm{s}\right)$ when different permeation fluids (e.g. water, methanol, phenol, fuel oil, and unleaded gasoline) were used. Furthermore, Lee et al. (2012) found that the permeability of organoclay-sand mixtures containing at least $25 \%$ organoclay to NAPL is seven orders of magnitude lower than its hydraulic conductivity to water. Lo and Yang (2001) proposed to use compacted organoclay as the secondary barrier liner for underground storage tanks against petroleum products. They observed that the permeability of compacted organoclay decreased two orders of magnitude when permeant liquid changed from water $\left(3.5 \times 10^{-7}\right.$ $\mathrm{cm} / \mathrm{s})$ to gasoline $\left(6 \times 10^{-9} \mathrm{~cm} / \mathrm{s}\right)$. They also concluded that compacted organoclay had enhanced hydraulic performance against the advection of gasoline. It was observed by all previous studies that low permeability of organoclay is often associated with a high swelling tendency for the permeating fluids. 
Yang and Lo (2004) have examined the feasibility of using organoclay and HDPE membrane as a composite barrier for gasoline storage tanks. The permeability test results indicated that the combination of organoclay and HDPE membrane are effective and reliable in reducing the permeation of gasoline and to prevent the surrounding soils and ground water from being contaminated by petroleum products. Recently, Lorenzetti et al. (2005) examined the hydraulic conductivities of GCLs amended with organoclays. They found that the hydraulic conductivity of the amended GCL increases with an increased percentage of organoclay amendment. However, they observed that adding up to $20 \%$ organoclay did not have a significant impact on the conductivity of amended GCL to water $\left(4.3 \times 10^{-9}\right.$ to $\left.6.9 \times 10^{-9} \mathrm{~cm} / \mathrm{s}\right)$. Therefore, a low amount of organoclay amendment $(10-$ $20 \%$ by mass) holds promising applications in GCL and other composite barriers (e.g. CCL).

However, a few studies investigated the applicability of using organoclays as an amendment in barrier systems for waste containment; further investigation is still needed to conduct on hydraulic performance of amended organoclays in CCLs and GCLs when faced with non-polar organic liquids. In this section, the permeability and swelling behavior of organoclay amendment in CCL and GCL when faced with varying inorganic and organic liquids (e.g. water, methanol, and methanol) were comprehensively examined. Two organoclays (HDTMA-MMT and PM199) with defined microstructure and properties were chosen as representative CCL and GCL amendments in this research. Three wellestablished experiments including free swelling, one-dimensional swelling, and permeability were performed to quantify the hydraulic behavior of organoclay amendment in barrier systems. 


\subsection{Compacted clay liner amended with organobentonite}

\subsubsection{Materials and methods}

\subsubsection{Materials}

Soils

Four different types of soils including calcium montmorillonite (Ca-MMT), HDTMA modified calcium montmorillonite (HDTMA-MMT), commercial organoclay PM199, and natural occurring silty clay were used in this study. The physical properties of Ca-MMT, HDTMA-MMT, and PM199 were elaborated in Chapter 1. In this chapter, only the physical properties of natural silty clay as a base soil for compacted clay liner is presented.

The silty clay soil was obtained from Nugent Sand Company, Louisville. According to the ASTM D 422, the soil contained 1\% gravel, 12\% sand, and $87 \%$ fine particles. Based on ASTM D2487, the soil can be classified as low plasticity silty clay. Atterberg limits and specific gravity of soil were determined in accordance with ASTM D 4318 and ASTM D 854, respectively. The procedure of each method was explained in the methods part in chapter 1 . The physical properties of silty clay soil are presented in Table $3-2$. 
Table 3-2. Physical properties of silty clay soil

\begin{tabular}{|l|c|c|}
\hline Properties & $\begin{array}{c}\text { Natural Silty } \\
\text { Clay }\end{array}$ & Methods \\
\hline Liquid limit (\%) & 25.9 & ASTM D4318 - 10 \\
\hline Plastic limit (\%) & 21.5 & ASTM D4318 - 10 \\
\hline Plasticity index (\%) & 4.4 & ASTM D4318 - 10 \\
\hline $\begin{array}{l}\text { Fraction passed through No. } \\
200 \text { sieve (\%) }\end{array}$ & 87 & ASTM D6913 - 04 \\
\hline Specific gravity & 2.62 & ASTM D854 - 14 \\
\hline Specific Surface Area $\left(\mathrm{m}^{2} / \mathrm{g}\right)$ & 33.5 & Refer to chapter 1 \\
\hline Total organic carbon $(\%)$ & $<1$ & - \\
\hline
\end{tabular}

\section{Permeant Liquids}

Water, methanol and a naphthalene/methanol solution and gasoline were used in this research to study how different types of organic liquids can affect the swelling index and the hydraulic conductivity of silty clay- organobentonite mixtures. Methanol with a chemical purity of 97\% was purchased from Carolina Biological Supply Company. Naphthalene was purchased from Fisher Scientific Co. in crystal form with a specified purity of $99 \%$. Naphthalene was diluted in the methanol with a concentration of $0.05 \mathrm{~g} / \mathrm{ml}$. Unleaded gasoline with a commercial grade of $\# 87$ and a density of $0.76 \mathrm{gr} / \mathrm{cm}^{3}$ was provided from a Speedway gas station, in Louisville. It is worth noting that the permeant liquids were selected based on a different range of polarity index (approximately 2 to 10). The physicochemical properties of the studied liquids are shown in Table 3-3. 
Table 3-3. Physico-chemical properties of the studied fluids

\begin{tabular}{|c|c|c|c|c|}
\hline Liquid & Formula & $\begin{array}{c}\text { Polarity } \\
\text { Index }\end{array}$ & $\begin{array}{c}\text { Density } \\
(\mathrm{kg} / \mathrm{L}) \text { at } \\
20^{\circ} \mathrm{C}\end{array}$ & $\begin{array}{l}\text { Kinematic viscosity } \\
\left(\mathrm{m}^{2} / \mathrm{s}\right) \times 10^{-6} \text { at } 20^{\circ} \mathrm{C}\end{array}$ \\
\hline Water & $\mathrm{H}_{2} \mathrm{O}$ & 10.2 & 1 & 1.004 \\
\hline Methanol & $\mathrm{CH}_{4} \mathrm{O}$ & 5.1 & 0.793 & 0.731 \\
\hline $\begin{array}{l}\text { Naphthalene/Methanol } \\
\text { Solution }\end{array}$ & $\begin{array}{l}\mathrm{C}_{10} \mathrm{H}_{8} / \\
\mathrm{CH}_{4} \mathrm{O}\end{array}$ & NA & 0.801 & 0.811 \\
\hline Unleaded gasoline & - & $<2$ & 0.76 & 0.5 \\
\hline
\end{tabular}

\section{Test matrix}

Since many tests (e.g. hydraulic conductivity, free swelling index, one-dimensional swelling) were conducted on different soils with various permeant liquids. This section clearly explained the testing matrix.

1- The hydraulic conductivities of compacted low plasticity silty clay and PM199 mixtures as a function of varying PM199 fractions under two different confining pressures were studied (Table 3-4).

Table 3-4. Hydraulic conductivity testing matrix for the admixture of silty clay and organobentonite (PM199)

\begin{tabular}{|c|c|c|}
\hline $\begin{array}{c}\text { Sample } \\
\text { Number }\end{array}$ & $\begin{array}{c}\text { Silty Clay } \\
\text { content \% }\end{array}$ & $\begin{array}{c}\text { PM199 } \\
\text { Content } \%\end{array}$ \\
\hline 1 & 100 & 0 \\
\hline 2 & 70 & 30 \\
\hline 3 & 50 & 50 \\
\hline 4 & 30 & 70 \\
\hline 5 & 0 & 100 \\
\hline
\end{tabular}


2- The free swelling and hydraulic conductivity of silty clay (50\%) + PM199 (50\%) mixture sample, when faced with varying liquids including water, methanol, naphthalene solution, was investigated.

3- The one-dimensional swelling and hydraulic conductivity of silty clay (100\%), silty clay $(90 \%)+$ Ca-MMT (10\%), and silty clay (90\%) + HDTMA-MMT (10\%) to water and gasoline were examined (Table 3-5).

Table 3-5. Testing matrix for the admixture of silty clay, Ca-MMT, and HDTMAMMT

\begin{tabular}{|c|c|c|c|c|}
\hline \multirow{2}{*}{ Materials } & \multicolumn{2}{|c|}{$\begin{array}{c}\text { One-dimensional } \\
\text { swelling }\end{array}$} & \multicolumn{2}{|c|}{ Fluid conductivity } \\
\cline { 2 - 5 } & water & gasoline & water & gasoline \\
\hline Silty clay (100\%) & $\checkmark$ & $\checkmark$ & $\checkmark$ & - \\
\hline $\begin{array}{c}\text { Silty clay (90\%) + Ca-MMT } \\
(10 \%)\end{array}$ & $\checkmark$ & $\checkmark$ & $\checkmark$ & - \\
\hline $\begin{array}{c}\text { Silty clay (90\%) + HDTMA- } \\
\text { MMT (10\%) }\end{array}$ & $\checkmark$ & $\checkmark$ & $\checkmark$ & $\checkmark$ \\
\hline
\end{tabular}

\subsubsection{Methods}

Free swelling test

The free swelling test was performed following the methods in ASTM D5890. Three different fluids including water, methanol, and a naphthalene solution were used as liquids to measure the free swelling index of silty clay-PM199 samples. All samples were oven-dried and passed through sieve No. 200. A graduated cylinder of $90 \mathrm{ml}$ was filled with the studied liquid, and two grams of the mixture was added gradually with increments 
of $0.1 \mathrm{~g}$. The liquid was then added to the cylinder until the $100 \mathrm{~mL}$ mark was reached. Finally, the volume of swollen soils was measured (in milliliters) after 24 hours of exposure.

\section{Compaction test}

Synthesized HDTMA bentonite, calcium bentonite, and silty clay soil were ovendried for 24 hours. The standard compaction test was performed on three soil admixtures of: silty clay (100\%), silty clay $(90 \%)+$ Ca-MMT (10\%), and silty clay (90\%) + HDTMAMMT (10\%) (by weight), following the ASTM D698, Method A. The relationship between water content and dry density of each compacted specimen were obtained with sufficient numbers of repeated tests. The maximum dry density and the optimum water content of each admixture were determined (Figure 3-3). It was observed that the optimum water content and dry unit weight of the samples were in the range of $13.5-15.5 \%$ and $1.81-1.85$ $\mathrm{g} / \mathrm{cm} 3$, respectively.

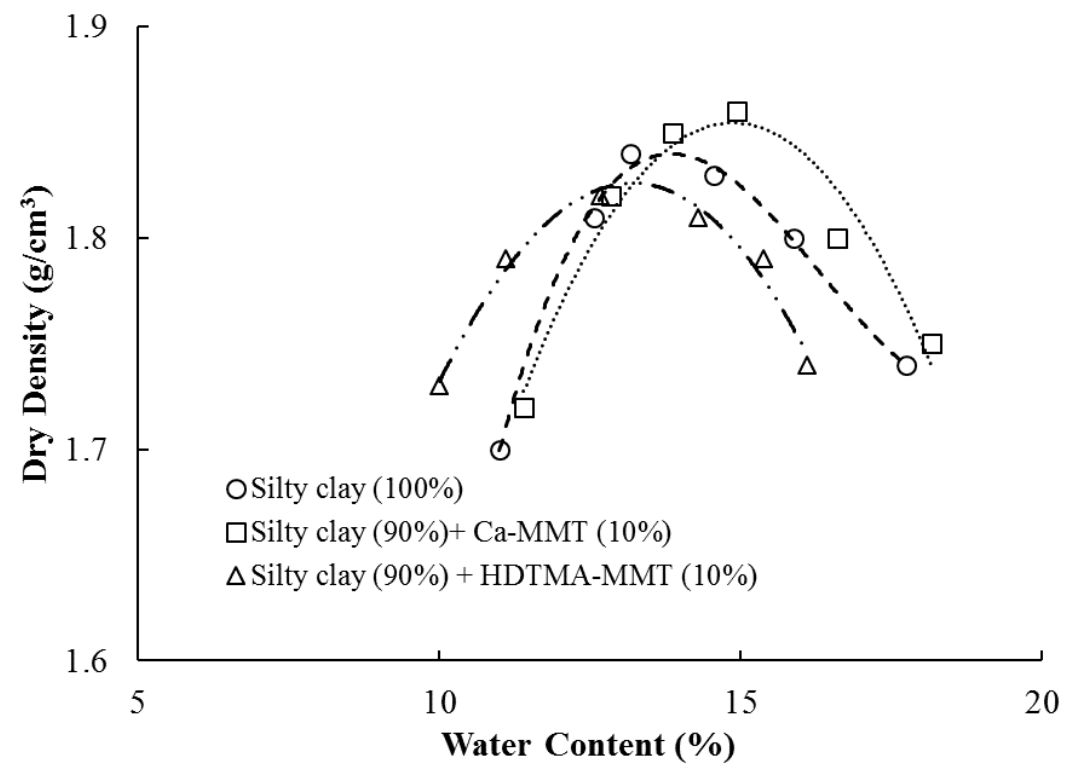

Figure 3-3. Compaction curves of three soil admixtures 


\section{One-Dimensional swelling test}

The one-dimensional oedometer was used to measure the magnitude of onedimensional wetting induced swell of the compacted soils when faced with water and unleaded gasoline, following ASTM D4546 (Figure 3-4). In the one-dimensional swelling test, a soil specimen was placed in the fixed ring consolidation cell, and a small seating load $1 \mathrm{kPa}$ was applied. Then, the changes of the specimen height were monitored for 24 hours. The one-dimensional swelling tests were conducted on three specimens: silty clay (100\%), silty clay (90\%) + Ca-MMT (10\%), and silty clay (90\%) + HDTMA-MMT (10\%) when exposed to water and unleaded gasoline. The procedure of the one-dimensional swelling test is described below:

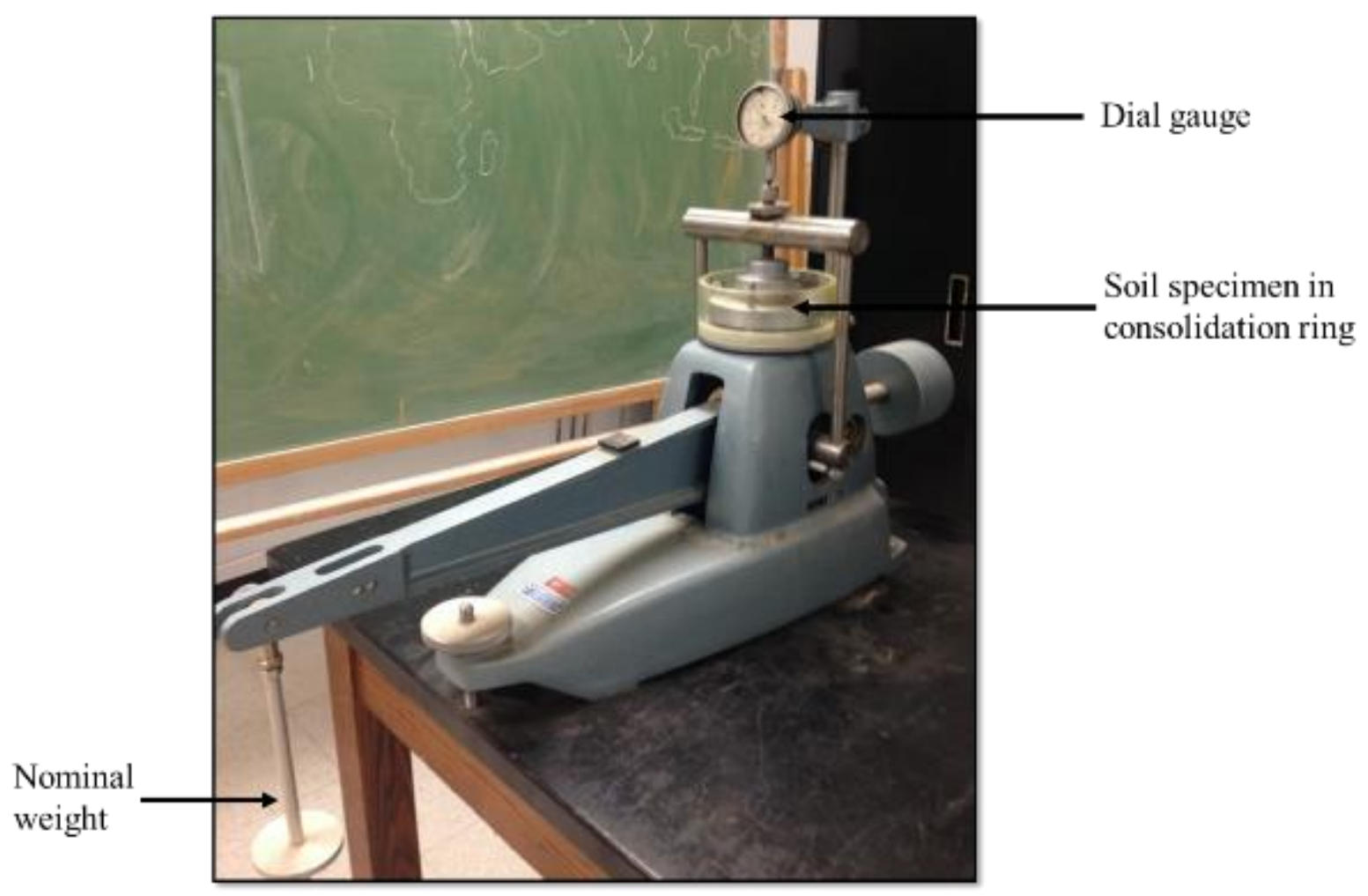

Figure 3-4. One-dimensional oedometer test setup (load device with consolidometer) 
200 grams of each oven-dried soil mixture was weighted and moistened with its corresponding water content. Each moistened mixture was poured in a fixed oedometer ring with a diameter of $66 \mathrm{~mm}$ and height of $20 \mathrm{~mm}$ (Figure 3-5). Note that there were a porous stone and filter paper at the bottom of the ring to allow the drainage. A hammer was used to compact the soil until the desired density was reached by measuring the mass and volume of the compacted soil. The surface of each specimen was trimmed to be smooth, and the height of each specimen was measured to the nearest 0.001 inch by taking the average of three measurements.

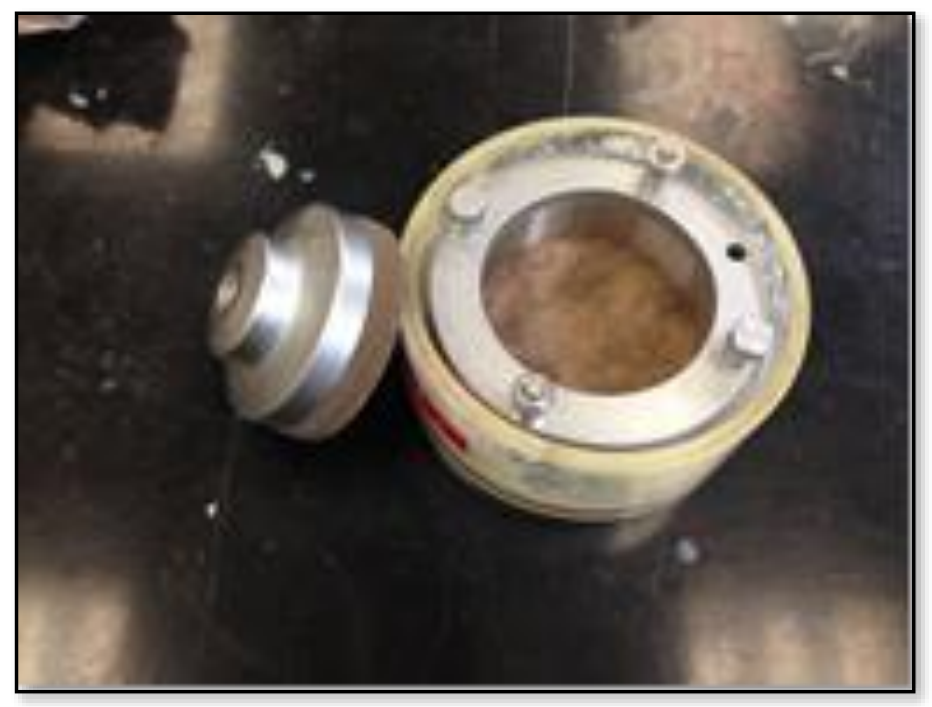

\section{Figure 3-5. A fixed oedometer (consolidation) ring}

Each specimen was placed in an oedometer frame, and a seating pressure of $1 \mathrm{kPa}$ including the mass of the top porous stone and load plate was applied. The dial indicator was placed on top of the sample to measure the changes in the height of the specimen. The dial indicator was set to zero for the initial reading. Then, each specimen was inundated with water and gasoline to the oedometer cell to measure the increasing height of the sample by a vertical deformation gauge. Deformation was immediately recorded at the 
intervals of $0.5,1,2,4,8,15$, and 30 minutes, $1,2,4,8$, and 24 hours. The measurement of one-dimensional swelling potential for each specimen was almost completed in 24 hours. Consequently, the swelling (vertical deformation) of each specimen over 24 hours was calculated by the following equations:

$h_{1}=h-\Delta h_{1}$

$h_{2}=h_{1}+\Delta h_{2}$

$\varepsilon=\left(100 \Delta h_{2}\right) / h_{1}$

where: $h=$ initial height of specimen (in)

$\Delta h_{l}=$ specimen compression after applying load prior wetting (in)

$h_{l}=$ specimen height after applying load prior wetting (in)

$\Delta h_{2}=$ change in specimen height by wetting at each time interval (in)

$h_{2}=$ final specimen height at each time interval (in)

$\varepsilon=$ swell strain (vertical deformation) at each interval (\%)

\section{Hydraulic conductivity test}

In this section, the tools and procedures that were used to measure the hydraulic conductivity of soil specimens are described. The main tools are a pressure control board (Figure 3-6) (Trautwein Soil Testing Company, Houston, Texas); air compressor; vacuum pump; water storage tank; data acquisition system; computer and a flexible wall permeameter. 


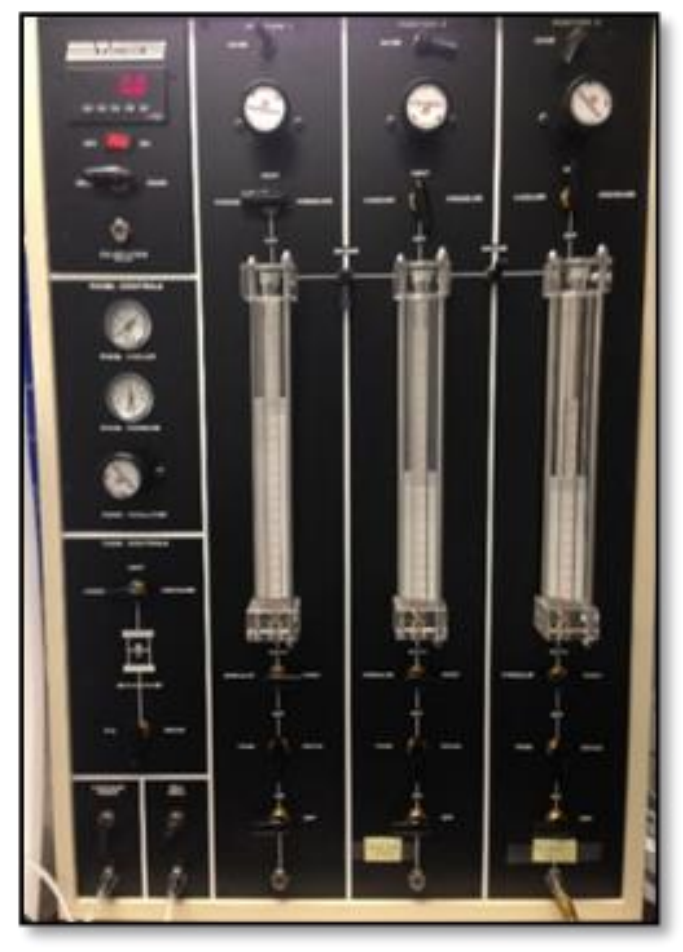

Figure 3-6. Pressure control panel (Trautwein soil testing Co.)

\section{Making the samples}

$2 \mathrm{~kg}$ of dry soil was weighted and spread on the pan. The optimum water content was added slowly to the soil and mixed together for 20 minutes (Figure 3-7, a). Then the mixture was poured into a compaction mold (diameter: 4 in and height: 4.6 in) in three layers and each layer was compacted 25 times by $5.5 \mathrm{lbs}$ rammer. After compacting the third layer, the surface of the soil sample was trimmed off very well to be level with the top of the mold (Figure 3-7, b). 


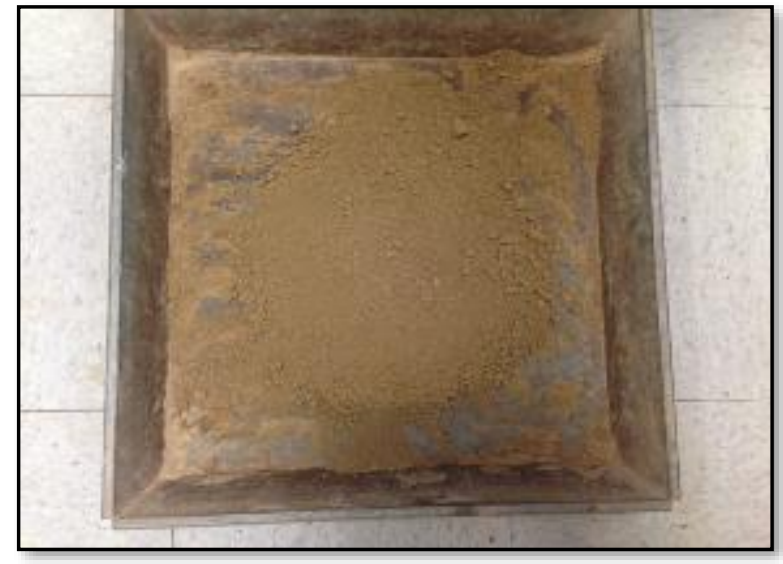

(a)

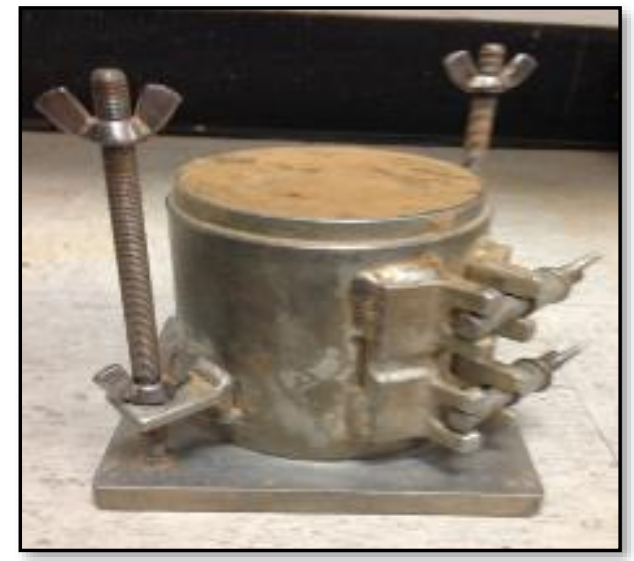

(b)

Figure 3-7. (a) the mixture of soil with water (b) compacted soil in a compaction

\section{mold}

Then the soil sample was extracted from the compaction mold by a hydraulic jack. The process of extracting the sample should be done very gently as not to disturb the structure soil sample. Trimming mold with a diameter and height of 2 and 4 inches respectively was used to get the desirable specimen from the compacted soil sample (Figure 3-8). The trimming mold was gently pushed into the soil sample, and after reaching the end of the compacted sample, the specimen was slowly removed from the trimming mold. It should be noted that the surface of the top and bottom of the specimen was smoothed by a plastic saw and wire brush. Finally, the height and diameter of the specimen were measured with an accuracy of 0.001 in. 


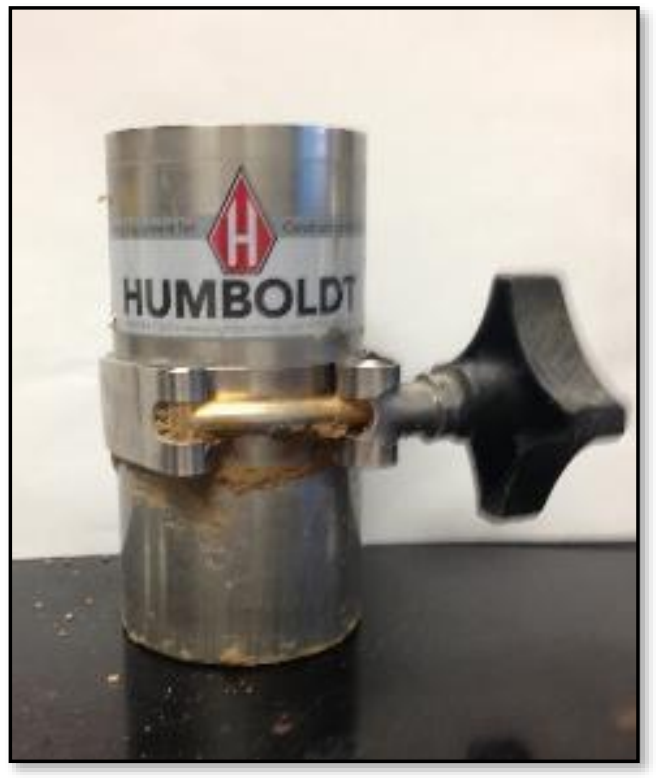

(a)

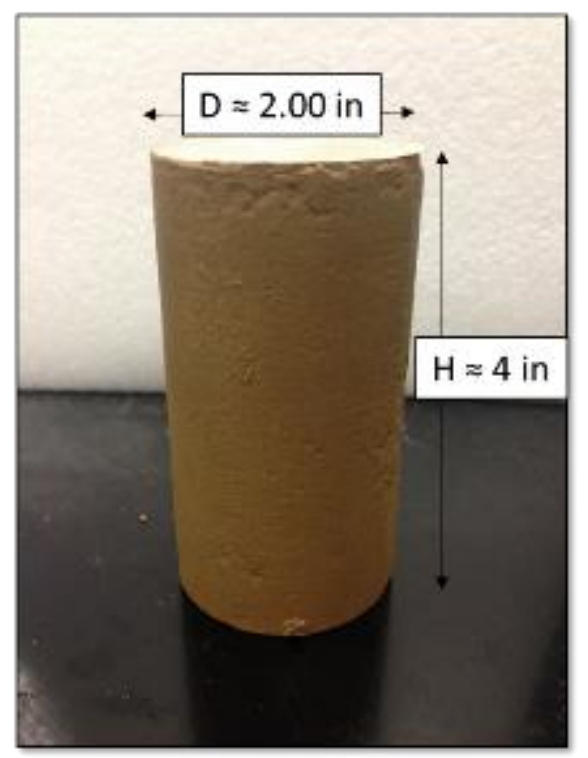

(b)

Figure 3-8. (a) sample trimmer (b) specimen after trimming

\section{Placing the specimen in the chamber}

For mounting the specimen in a chamber, two porous stones and two filter papers were soaked in water for 5 minutes to be fully saturated. One porous stone and filter paper were placed on the base cap in the chamber, respectively. Then the specimen was placed on top of them (Figure 3-9, a). A membrane stretcher was used to stretch the membrane by applying the vacuum to a mold and then, the mold was lowered on the specimen very carefully till the specimen was covered by the membrane. By disconnecting the vacuum tube on the mold, the membrane was released and stuck tightly to the sample (Figure 3-9, b). Two O-rings were rolled down to place at the bottom of the specimen. On top of the sample, a filter paper, a porous stone, and a top cap were placed respectively, and two Oring were placed around the top of the specimen to seal it very well (Figure 3-9, c). Note that the specimen should stand straight on the platform. After connecting all the inflow and 
outflow tubes, a small vacuum was applied to the top and bottom of the specimen to get the extra air out of the specimen. Note that this process can facilitate the saturation step.

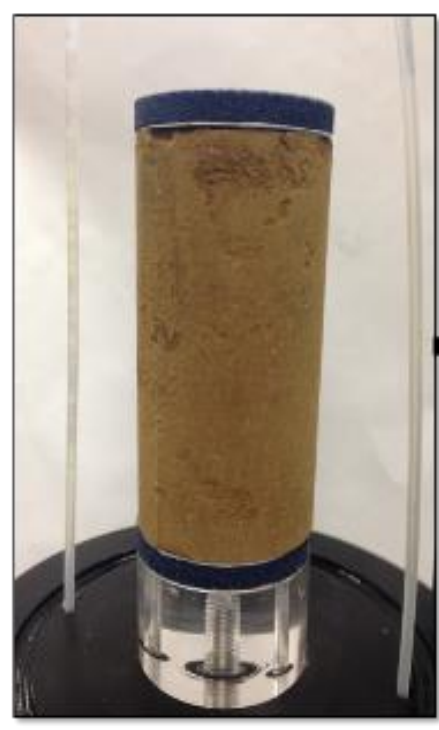

(a)

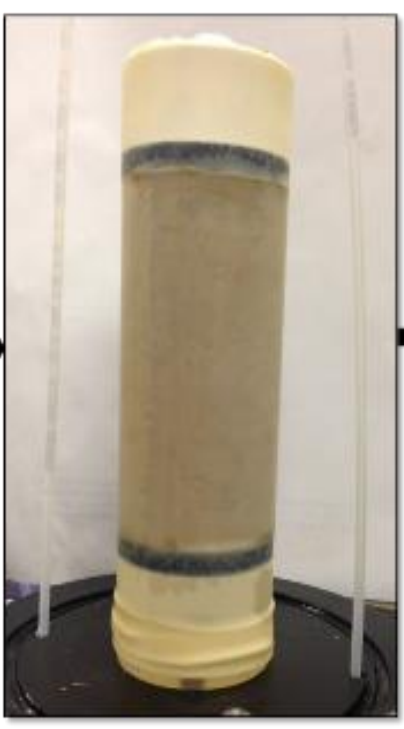

(b)

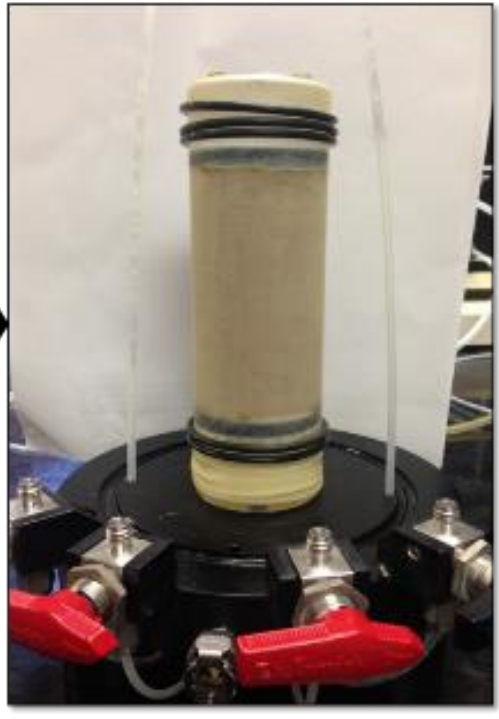

(c)

Figure 3-9. Mounting the specimen in a chamber

The vacuum grease was applied at the bottom and top caps of the chamber, and the cell wall was placed very gently on the platform. It is important to ensure that the loading rod slides into the fitting of the top cap without applying any pressure to the specimen. Three rods were placed around the chamber, and they were tightened very gently to seal and secure the cell as shown in Figure 3-10. 


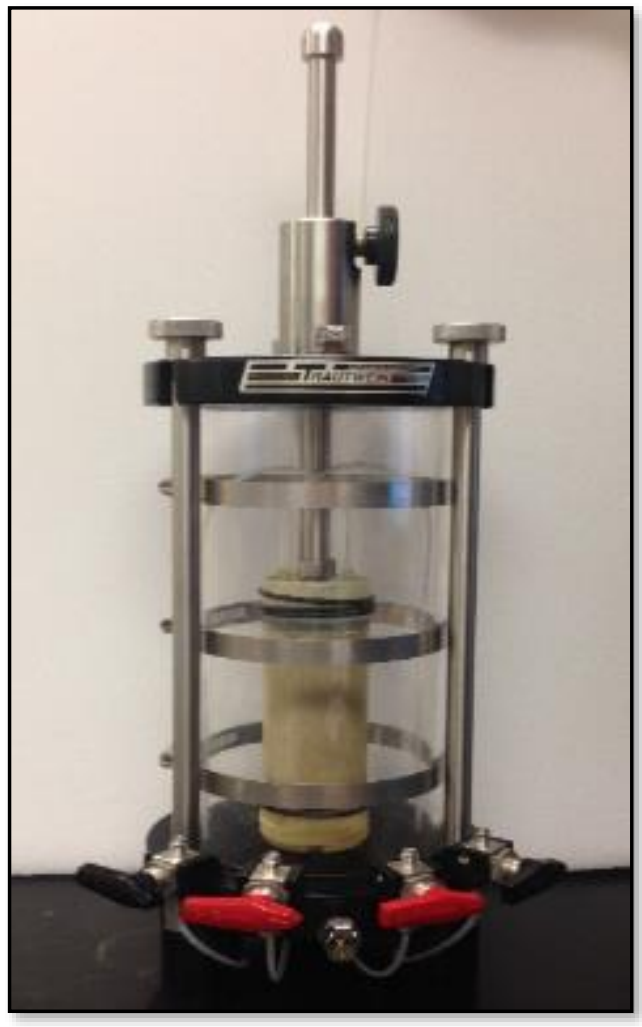

Figure 3-10. The setup of the triaxial cell

Filling the cell, applying the seat pressure, saturating the sample

After assembling the chamber (triaxial cell), the cell was filled with water by attaching a quick connector to the pressure control panel. By switching "ON" the cell valve on the panel, water began to enter the cell. Note that there was a quick connector on top of the cell, which was opened, so the air cloud escapes from the cell as water entered the cell. When the cell filled with water, and there was no air trap inside the cell, then the quick connectors at the top and bottom were disconnected simultaneously. 


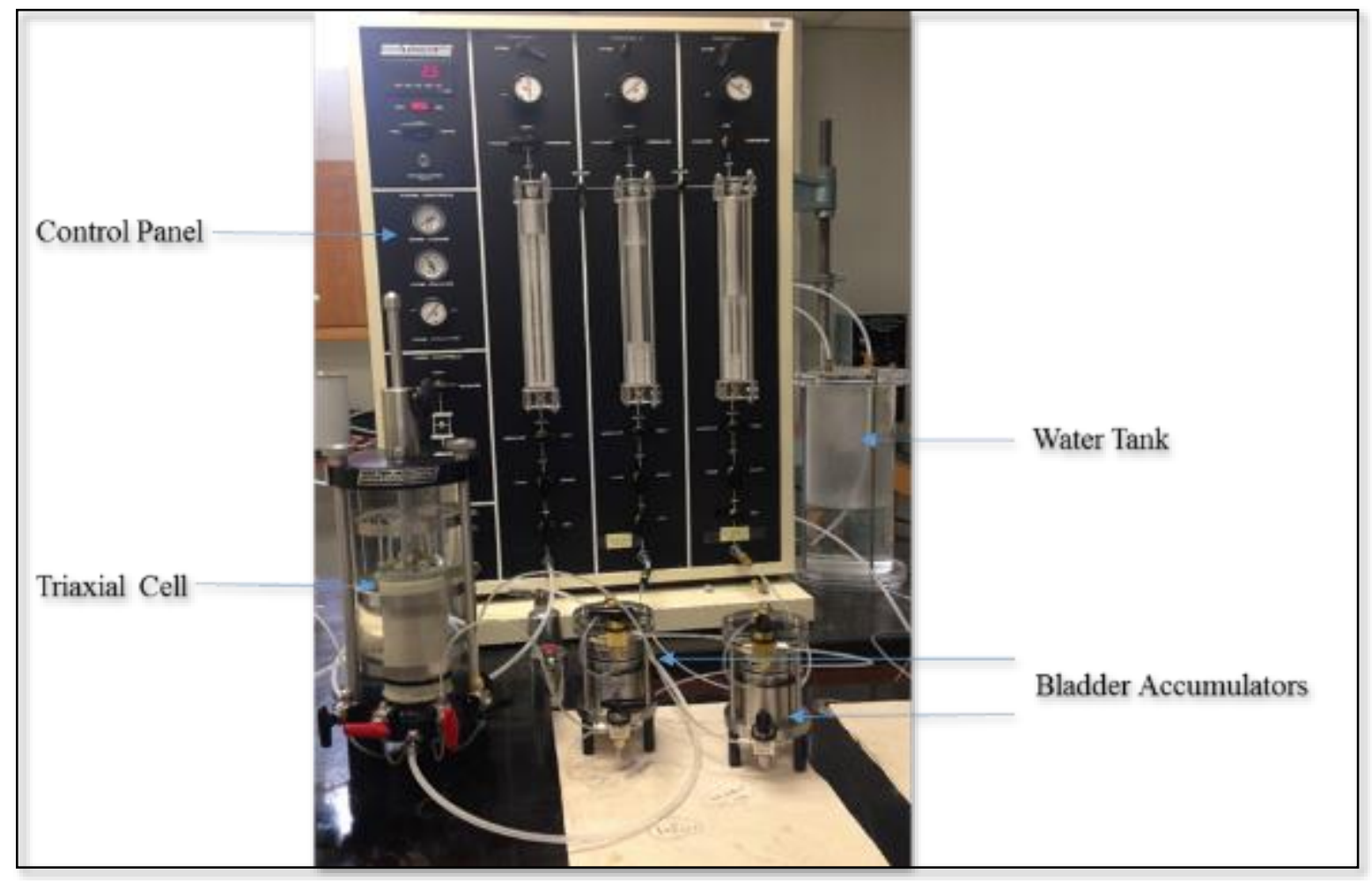

Figure 3-11. Hydraulic conductivity test setup for CCL specimen

After filling the cell with water, the quick connector at the bottom of the cell was connected to the control panel. Then, the cell pressure was set to $13.8 \mathrm{kPa}$ (2 psi) to confine the membrane against the specimen. In the next step, the de-aired water was flushed through the specimen, and this was completed within 3 days. It is important to mention that water should be pushed into the specimen from bottom to top. Finally, the pore pressure sensor was connected to the top of the specimen, which can be used to measure the pore pressure during the saturation process. The saturation process was initiated by increasing the cell pressure and backpressure with 2 psi increments simultaneously. The completion of saturation was verified by measuring the B-value (Skempton's parameter). Based on ASTM D5084, the B-value can be defined as a change in the pore pressure of the specimen that occurred as a result of a change in the chamber pressure when the permeameter 
drainage valves are closed. The B value should be greater than 0.95 until the sample can be accepted as a nearly fully saturated sample. The B value of 0.97 was reached when the cell pressure, back pressure, and pore pressure were $380,365.4$, and $362.4 \mathrm{kPa}(54,52$, and 51.5 psi) respectively, for approximately 3 days. For investigating the effect of confining pressure on hydraulic conductivity of the specimens, cell pressure and back pressure were reduced to 220 and $207 \mathrm{kPa}$ (32 and $30 \mathrm{psi}$ ), respectively.

\section{Measuring the hydraulic conductivity}

The falling Head, rising tailwater elevation method (D5084- Method C) with a hydraulic gradient of 5 was used to measure the hydraulic conductivity of the specimens. The equation used to calculate hydraulic conductivity was:

$K=\frac{a_{\text {in }} a_{\text {out }} \times L}{\left(a_{\text {in }}+a_{\text {out }}\right) \times A \times \Delta t} \ln \left(\frac{h_{1}}{h_{2}}\right)$

Where $\mathrm{K}=$ hydraulic conductivity $(\mathrm{m} / \mathrm{s})$

$\mathrm{L}=$ length of specimen (m)

$\mathrm{a}=$ cross-sectional area of the reservoir containing the inflow ( $\left.\mathrm{a}_{\mathrm{in}}\right)$ and outflow $\left(\mathrm{a}_{\mathrm{out}}\right)\left(\mathrm{m}^{2}\right)$

$A=$ cross-sectional area of specimen $\left(\mathrm{m}^{2}\right)$

$\Delta \mathrm{t}=$ interval time $(\mathrm{s})$

$\mathrm{h}_{1}=$ head loss across the permeameter/specimen at $\mathrm{t}_{1},(\mathrm{~m})$

$\mathrm{h}_{2}=$ head loss across the permeameter/specimen at $\mathrm{t}_{2},(\mathrm{~m})$

Moreover, the intrinsic permeability of some specimens was calculated by the following equation: 
$K=k \frac{g}{v}$

$\mathrm{K}=$ hydraulic conductivity $(\mathrm{m} / \mathrm{s})$

$\mathrm{k}=$ intrinsic permeability $\left(\mathrm{m}^{2}\right)$

$v=$ kinematic viscosity of the permeant liquid $\left(\mathrm{m}^{2} / \mathrm{s}\right)$

$\mathrm{g}=$ gravitational acceleration $\left(\mathrm{m} \cdot \mathrm{s}^{-2}\right)$

Hydraulic conductivity tests were completed when three criteria were fulfilled: (1) results of four successive hydraulic conductivities were within $\pm 25 \%$ of their mean; (2) the ratio of inflow to outflow rates for the specimen was between 0.75 and 1.25 ; and (3) a plot of hydraulic conductivity versus time exhibited no obvious rising or falling trend. When these conditions were met, the mean of the final four permeability measurements was recorded as a hydraulic conductivity of the specimen. For the specimens tested in this study, these criteria were met in a period of 4 days. 


\subsubsection{Results and discussion}

\section{Free Swelling Index}

The swelling index of three admixtures of silty clay and PM199 in different liquids is summarized in Table 3-6. Typically, the swelling index can affect the hydraulic conductivities of the silty clay- organobentonite (PM199) mixtures (Gates et al. 2004; Jo et al. 2001). From the obtained results, it was observed that the swelling index for each tested liquid increased when the organobentonite percentage in the soil sample increased. This was due to a higher specific surface area of organobentonite as compared with natural, low-plasticity silty clay. Therefore, increasing the percentage of organobentonite content in soil samples increased the available absorption area, and higher swelling index was observed. The soil samples with different percentages of organobentonite had similar swelling tendencies in methanol and naphthalene/methanol solution. However, it was demonstrated that the PM199 had much higher swelling tendencies in fuels and other nonpolar organic liquids (Benson et al. 2015).

Table 3-6. Swelling index for silty clay-organobentonite mixtures permeated with water, methanol and naphthalene/methanol solution

\begin{tabular}{|c|c|c|c|}
\hline \multirow{2}{*}{$\begin{array}{c}\text { PM199 content in } \\
\text { mixture \% }\end{array}$} & \multicolumn{3}{|c|}{ Swell Index (mL/2g) } \\
\cline { 2 - 4 } & Water & Methanol & $\begin{array}{c}\text { Naphthalene /Methanol } \\
\text { Solution }\end{array}$ \\
\hline 0 & 1.5 & 1.1 & 1.3 \\
\hline 50 & 4.2 & 2.3 & 2.7 \\
\hline 100 & 6.2 & 4.8 & 5.1 \\
\hline
\end{tabular}


The hydraulic conductivity and intrinsic permeability of the silty clay and organobentonite (PM199) mixtures are summarized in Table 3-7. All five prepared samples are permeated with de-aired water to measure their hydraulic conductivity and intrinsic permeability.

The hydraulic conductivities measurement was repeated three times for each soil sample to ensure reliable results. The results showed that the hydraulic conductivity and intrinsic permeability of the mixtures increased as the organobentonite content increased. Moreover, it was observed that the difference between the hydraulic conductivities of compacted natural silty clay and compacted organobentonite was only 1 order of magnitude. The hydraulic conductivity and intrinsic permeability vary about six orders of magnitude depending on the fluids used for permeation (Benson et al. 2015). It is worth noting that the intrinsic permeability exhibits the influence of the geometry of the pore space (i.e. shape, size and connectivity of the pores) on the rate of fluid flow through a porous material, while the hydraulic conductivity reflects for the geometry of the pore space and the hydrodynamic properties of the fluid flowing in the pores (Sharma and Reddy 2004). 
Table 3-7. Hydraulic Conductivity and Intrinsic Permeability of Silty Clay-

Organobentonite Mixtures Permeated with Water

\begin{tabular}{|c|c|c|c|c|}
\hline \multirow{2}{*}{$\begin{array}{c}\text { Organobentonite } \\
\text { content (\%) }\end{array}$} & \multicolumn{2}{|c|}{$\begin{array}{c}\text { Chamber pressure 220 kPa } \\
\text { Effective Confining Pressure } \\
\mathbf{1 3 . 8 ~ k P a}\end{array}$} & $\begin{array}{c}\text { Chamber Pressure 380 kPa } \\
\text { Effective Confining Pressure } \\
\mathbf{1 3 . 8 ~ k P a}\end{array}$ \\
\cline { 2 - 5 } & $\begin{array}{c}\text { Hydraulic } \\
\text { Conductivity } \\
\mathbf{m} / \mathbf{s}\end{array}$ & $\begin{array}{c}\text { Intrinsic } \\
\text { Permeability } \\
\left(\mathbf{m}^{2}\right)\end{array}$ & $\begin{array}{c}\text { Hydraulic } \\
\text { Conductivity } \\
\mathbf{m} / \mathbf{s}\end{array}$ & $\begin{array}{c}\text { Intrinsic } \\
\text { Permeability } \\
\left(\mathbf{m}^{2}\right)\end{array}$ \\
\hline 0 & $4.6 \times 10^{-9}$ & $4.7 \times 10^{-16}$ & $5.5 \times 10^{-9}$ & $5.6 \times 10^{-16}$ \\
\hline 30 & $1.6 \times 10^{-8}$ & $1.7 \times 10^{-15}$ & $1.5 \times 10^{-8}$ & $1.6 \times 10^{-15}$ \\
\hline 50 & $1.4 \times 10^{-8}$ & $1.5 \times 0^{-15}$ & $1.9 \times 10^{-8}$ & $2.0 \times 0^{-15}$ \\
\hline 70 & $5.5 \times 10^{-8}$ & $5.6 \times 10^{-15}$ & $5.9 \times 10^{-8}$ & $6.0 \times 10^{-15}$ \\
\hline 100 & $7.5 \times 10^{-8}$ & $7.6 \times 10^{-15}$ & $8.3 \times 10^{-8}$ & $8.4 \times 10^{-15}$ \\
\hline
\end{tabular}

In Figure 3-12, the hydraulic conductivity versus different organobentonite fractions was plotted for varying confining pressure. Based on the result, it was concluded that increasing the organobentonite fraction in the mixtures increased the hydraulic conductivities of the compacted silty clay-organobentonite mixtures. Lorenzetti et al. (2005) have reported that increasing the organobentonite fraction from $10 \%$ to $80 \%$ in the GCL can increase the hydraulic conductivity to water as much as three orders of magnitude. This was due to the hydrophobic surfactants exchanged onto the organobentonite surface, which was able to increase the hydrophobicity of the soils and facilitate the water conduction in soil pores, and this prevailed as the organobentonite fraction increased. However, this study indicated that increased organobentonite fractions had a much less significant impact on the hydraulic conductivity of compacted clays when compared to GCL and uncompacted clays. This could be attributed to the fact that low porosity of the compacted soil dominated the advection in the soil specimens while the hydrophobicity of 
the specimens imposed less impact.

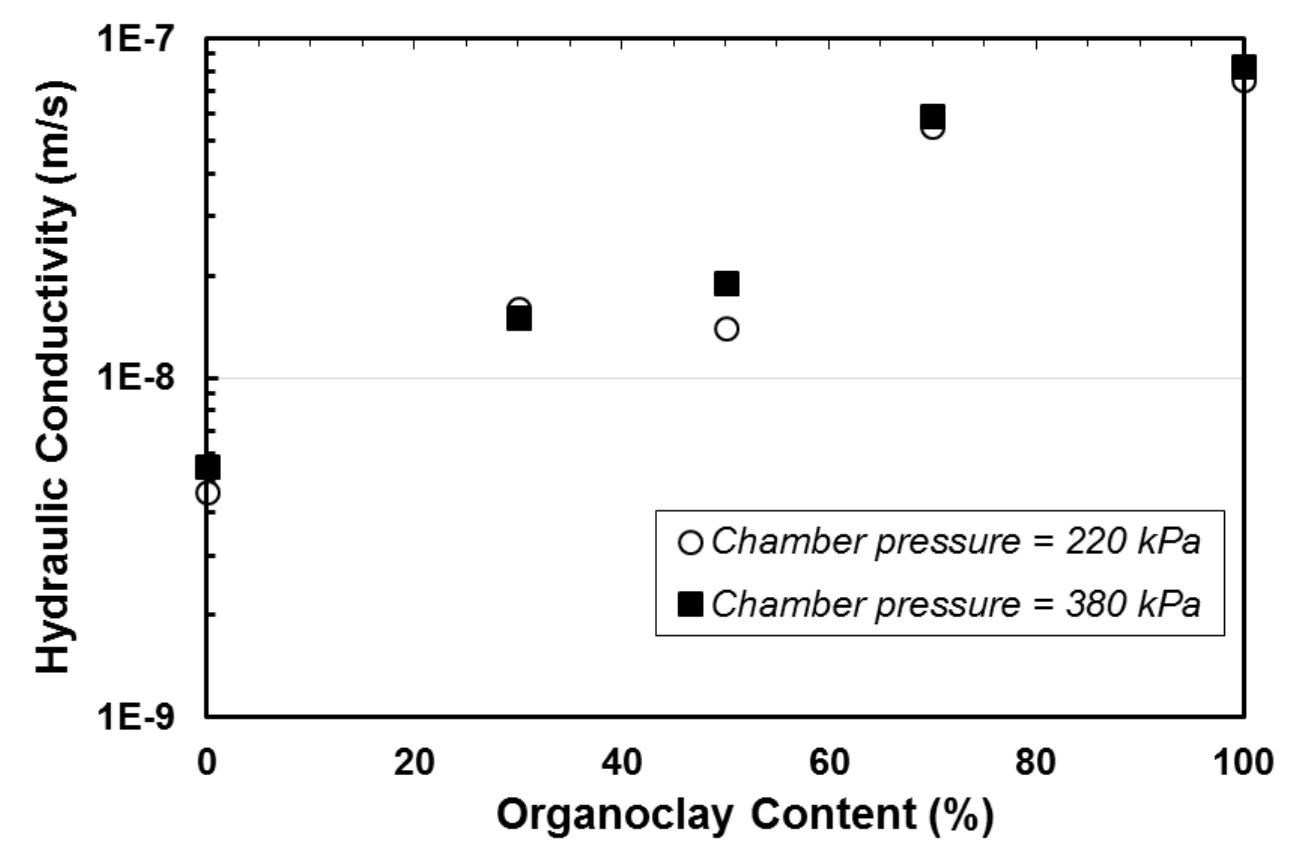

Figure 3-12. Hydraulic conductivity of mixtures with two different chamber pressure

The hydraulic conductivity of samples was measured when the confining pressure was $380 \mathrm{kPa}$ and $220 \mathrm{kPa}$. The results have shown that the confining pressure had a negligible effect on the measured hydraulic conductivity as long as the effective confining pressure was kept constant.

The silty clay $(50 \%)+$ organobentonite $(50 \%)$ compacted samples were used to test for permeabilities and intrinsic permeabilities with low polarity permeant fluids (Table 3-8). It was suggested that the permeabilities of organobentonites tend to be lower with low polarity or non-polar liquids, as a result of intercalated hydrophilic surfactants ( $\mathrm{Li}$ et al. 1996; Moon et al. 2007; Smith et al. 2003). 
Table 3-8. Conductivity and Intrinsic Permeability of 50\% Silty Clay- 50\% Organobentonite Permeated with Water, Methanol, and Naphthalene/Methanol Solution

\begin{tabular}{|c|c|c|}
\hline Liquid & Conductivity $(\mathbf{m} / \mathbf{s})$ & Intrinsic Permeability $\left(\mathbf{m}^{\mathbf{2}}\right)$ \\
\hline Water & $1.4 \times 10^{-8}$ & $1.5 \times 10^{-15}$ \\
\hline Methanol & $5.7 \times 10^{-9}$ & $4.2 \times 10^{-16}$ \\
\hline $\begin{array}{c}\text { Naphthalene/Methanol } \\
\text { Solution }\end{array}$ & $6.5 \times 10^{-9}$ & $5.3 \times 10^{-16}$ \\
\hline
\end{tabular}

The permeabilities of the mixtures to water are approximately 2.5 times higher than the permeabilities to the methanol and naphthalene/methanol solution. The intrinsic permeabilities of all specimens were similar as they reflect the low-porous structures of compacted soil mixtures. The permeability and intrinsic permeability of the mixture to the methanol and naphthalene/methanol solution were almost equal since the kinematic viscosities of liquids were approximately same. Liquids that alter the intrinsic permeability alter the pore network in a soil.

Benson et al. (2015) have reported that the permeability of organobentonite (granular PM199) to water is 68 times higher compared to methanol. Similarly, it was concluded from permeability test results that permeability of organobentonite decreases when the permeant fluid changes from water to a low polarity organic liquid such as methanol. However, the differences were not significant for the compacted soil samples in this study. In addition, further investigation is needed regarding the long-term conduction of varying liquids in compacted silty clay-organobentonite mixtures. 


\section{One-dimensional Free swelling}

In another study, the one-dimensional swelling and permeability of three specimens: silty clay (100\%), silty clay $(90 \%)+$ Ca-MMT $(10 \%)$, silty clay $(90 \%)+$ HDTMA-MMT (10\%) to water and gasoline were studied. Figure 3-13 presents the results of the one-dimensional swelling tests of the three studied soils. The free swelling of siltyclay in water increased significantly as $10 \%$ of calcium bentonite (Ca-MMT) was added. Previous studies proved that this was due to the hydration of bentonite soil (Rao et al. 2006; Sun et al. 2009). When the silty clay soil was mixed with $10 \%$ HDTMA-MMT, the onedimensional swelling to the water showed similar behavior as $100 \%$ silty clay soil. This was due to the inhibited swelling tendency of HDTMA-MMT in water, as the HDTMA coating tended to be hydrophobic and did not hydrate in the water.

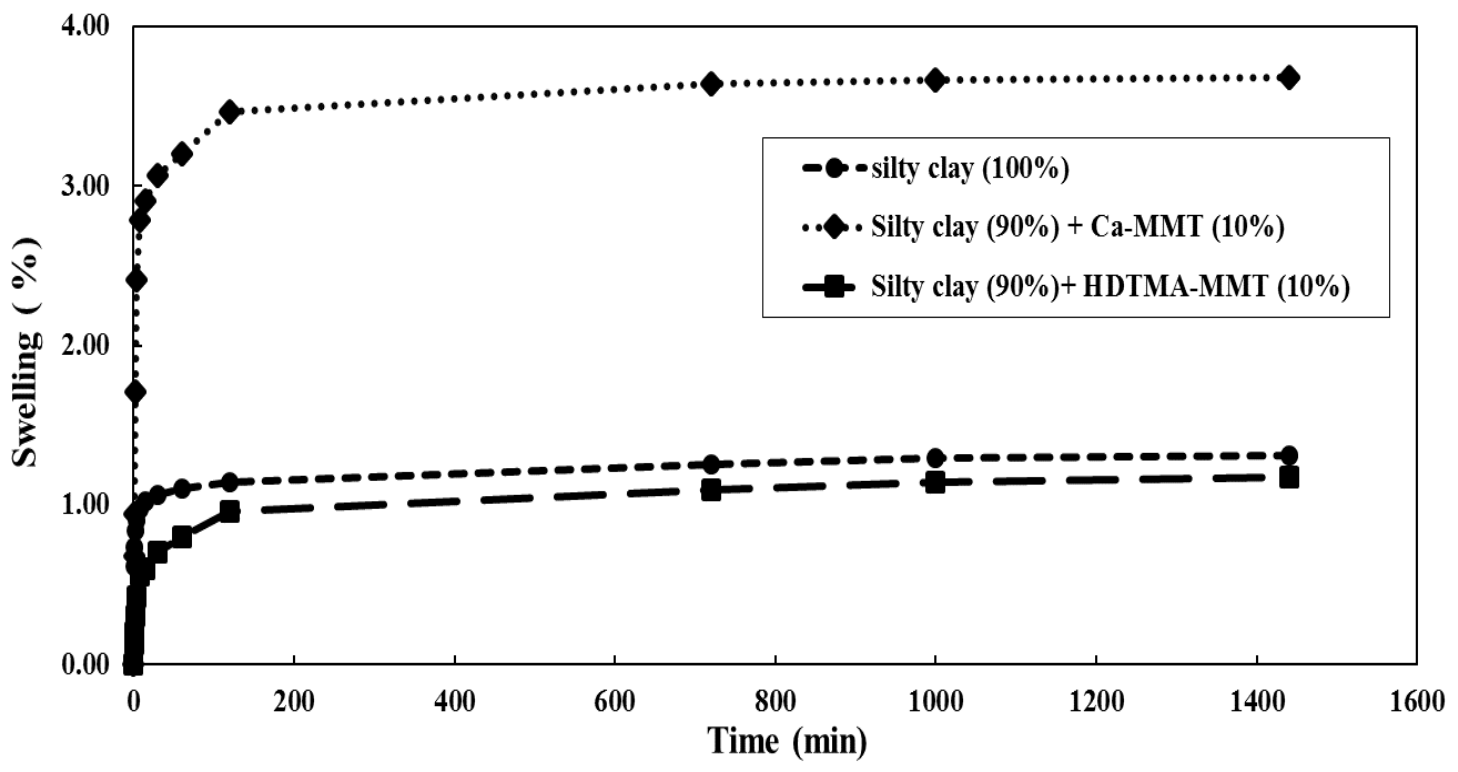

Figure 3-13. One-dimensional swelling of the studied soils in water

However, when a mixture of silty clay and HDTMA-MMT interacted with nonpolar organic liquids such as gasoline, it swelled much more than in the water. A 
detailed comparison suggested that $10 \%$ of HDTMA-MMT additive may increase the free swelling tendency of the mixture soil by approximately ten times in gasoline (Figure 3-14). It was assumed that the non-polar organic species could cause the interlayer expansion of the HDTMA-MMT due to their interaction with the intercalated aliphatic carbon chains. In contrast, natural silty clay soil alone or mixed with Ca-MMT had little or no volume change in gasoline. It can be derived that when exposing with petroleum products, organoclay may be a superior and effective material than natural clay soil in soil barriers. It should be mentioned that this study represented the case of soil swelling under low confining stress. While the hydraulic conductivities of these mixtures can be affected by their swelling potential, the overburden stress may reduce swelling potential.

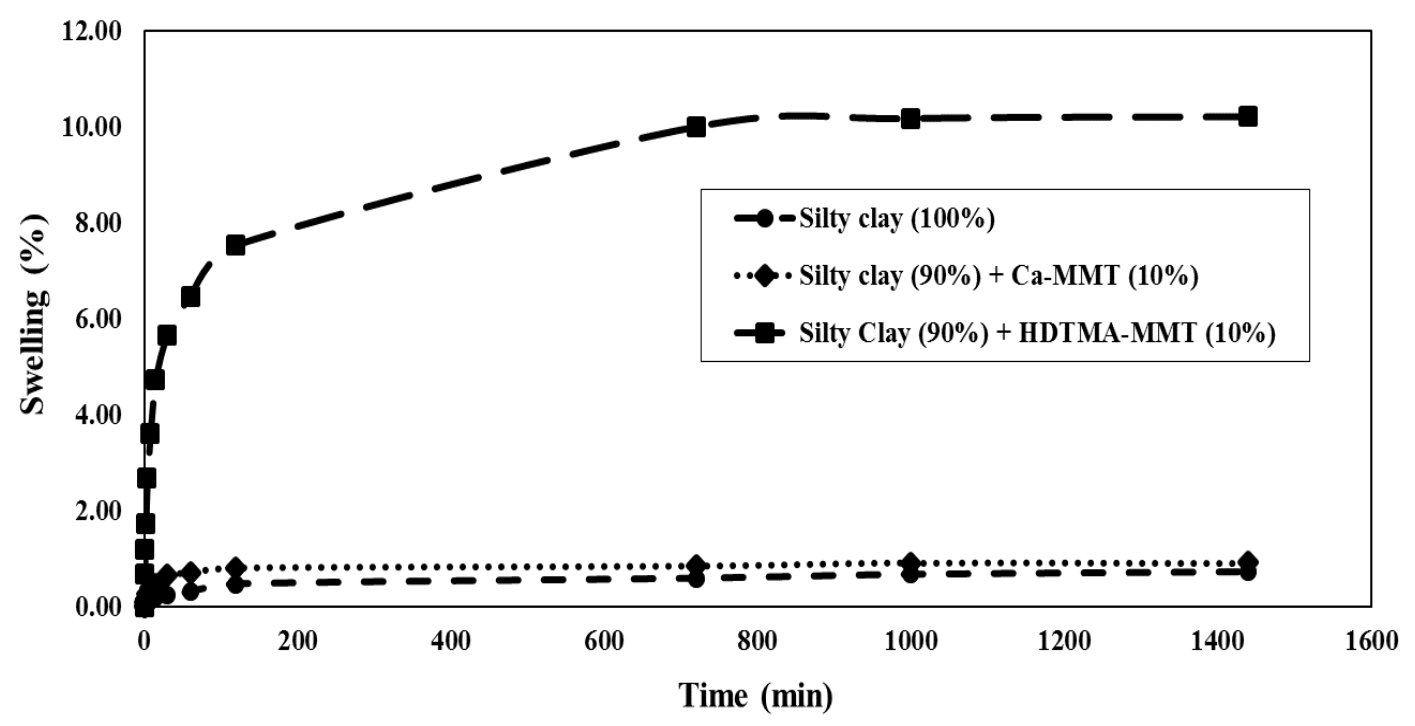

Figure 3-14. One-dimensional swelling of the studied soils in gasoline 


\section{Hydraulic conductivity}

The permeability of silty clay (100\%), silty clay (90\%) + Ca-MMT (10\%), silty clay $(90 \%)+$ HDTMA-MMT $(10 \%)$ are presented in Table 3-9. The permeability of natural silty clay mixed with $10 \%$ HDMTA-MMT to gasoline was also examined. When the natural silty clay was mixed with $10 \%$ bentonite (Ca-MMT), the hydraulic conductivity decreased around one order of magnitude compared to the hydraulic conductivity of natural silty clay due to increasing the plasticity index of the specimen from 4.4 to 10 . It should be mentioned that increasing the plasticity index of the specimen could reduce the hydraulic conductivity when water is used as a permeant liquid (Benson 1994; Lo and Yang 2001). Furthermore, the "plasticity index" of organobentonite may increase when the pore fluid is non-polar organic liquid (Soule and Burns, 2001). When HDTMA-MMT was added to natural silty clay, the conductivity to water increased approximately 1 order of magnitude compared to $100 \%$ natural silty clay. This phenomenon can be correlated to increasing the hydrophobicity as 10\% HDTMA-MMT was added to the specimen. It was proved that hydrophobicity of the soil could facilitate water conduction through soil pores. 
Table 3-9. Average fluid conductivities of compacted soils with varying permeants

\begin{tabular}{|c|c|c|c|c|c|c|}
\hline Materials & $\begin{array}{c}\text { Void } \\
\text { ratio }\end{array}$ & $\begin{array}{c}\text { Permeant } \\
\text { Liquid }\end{array}$ & $\begin{array}{c}\text { Liquid } \\
\text { limit }\end{array}$ & $\begin{array}{c}\text { Plasticity } \\
\text { index }\end{array}$ & $\begin{array}{c}\text { Fluid } \\
\text { conductivity } \\
(\mathbf{m} / \mathbf{s})\end{array}$ & $\begin{array}{c}\text { Intrinsic } \\
\text { permeability } \\
\left(\mathbf{m}^{\mathbf{2}}\right)\end{array}$ \\
\hline Silty clay (100\%) & 0.42 & Water & 26 & 4.4 & $5.04 \times 10^{-9}$ & $5.16 \times 10^{-16}$ \\
\hline $\begin{array}{c}\text { Silty clay (90\%)+ } \\
\text { Ca-MMT (10\%) }\end{array}$ & 0.43 & water & 32 & 10 & $7.70 \times 10^{-10}$ & $7.78 \times 10^{-17}$ \\
\hline $\begin{array}{c}\text { Silty clay (90\%)+ } \\
\text { HDTMA-MMT }\end{array}$ & 0.42 & water & 30 & 6.6 & $1.57 \times 10^{-8}$ & $1.61 \times 10^{-15}$ \\
\cline { 2 - 7 }$(10 \%)$ & 0.42 & Gasoline & - & - & $9.20 \times 10^{-10}$ & $6.7 \times 10^{-17}$ \\
\hline
\end{tabular}

The permeability of the natural silty clay and HDTMA-MMT mixture to gasoline was approximately 1.5 orders of magnitude lower than the permeability to water. This can be related to the organophilicity of HDTMA-MMT when permeated with a non-polar organic liquid. The results were in agreement with previous studies (Moon et al. 2007; Smith et al. 2003; Yang and Lo 2004). Smith et al. (2003) investigated on the intrinsic permeability of the two types of compacted organoclays, HDTMA-bentonite and BTEAbentonite to water and unleaded gasoline. They observed that the permeability of both types of organobentonite decreased around two orders of magnitude as the permeant liquid was altered from water to unleaded gasoline. Moreover, Moon et al. (2007) studied on the permeability of compacted conventional clay and HDTMA-modified bentonite to water and unleaded commercial gasoline. They also exhibited that the HDMTA modified bentonite had a higher hydraulic conductivity for water but much lower permeability when 
exposed to petroleum related products like unleaded gasoline. It worth mentioning that in our study, we examined the effect of polar and non-polar liquid on the permeability of organobentonite in combination with natural clay while the previous studies focused on the pure organobentonite as the studied sorbent matrix.

It was anticipated that the gasoline hydrocarbons entered the interlamellar space of HDTMA-MMT due to the hydrophobic characteristic of organoclay (refer to chapter 2), and wet the external surface of HDTMA-MMT more efficiently than water. Previous studies indicated that organoclays swell in non-polar organic liquids (e.g. fuels, gasoline) like bentonites swell in water (Benson et al. 2015). Consequently, the swelling of HDTMAMMT and the increased drag force on the gasoline were expected to be the main reasons for the decreased permeability of organoclays-amended natural clay when exposed to gasoline. Although it was not examined in this study, it was demonstrated that organoclays tend to have lower conductivities for non-polar or low-polarity fluids (Benson et al. 2015; Li et al. 1996). Overall, the conductivities of all compacted soils with varying fluids were low, due to their reduced pore voids and increased dry densities. This suggests that organobentonites amendments can be used in the compacted soils to lower the advection of contaminant flow. 


\subsection{Geosynthetic clay liner amended with organobentonite}

\subsubsection{Materials and methods}

\section{Materials}

\section{Soils}

The calcium and sodium bentonites used in this study were obtained from American Colloid Co and CETCO Co., respectively. The average initial gravimetric water content of the two bentonites was approximately 6\%. HDTMA-bentonite (HDTMA-MMT) was chosen as an organoclay amendment in GCL because of its enhanced sorptivity for organic contaminants. HDTMA-MMT was synthesized from the calcium bentonite by exchanging $\mathrm{Ca}^{2+}$ cation with hexadecyltrimethylammonium cation (HDTMA+). The preparation of HDTMA-MMT was presented in chapter 2. Both conventional bentonites and organobentonite were in powdered form. The physio-chemical properties of both bentonites and organobentonite are shown in Table 3-10. Note that the description of each method was comprehensively explained in chapter 2 . 
Table 3-10. Physio-chemical properties of bentonites and organobentonite

\begin{tabular}{|l|c|c|c|c|}
\hline Properties & Ca-bentonite & Na-bentonite & $\begin{array}{c}\text { HDTMA- } \\
\text { bentonite }\end{array}$ & Methods \\
\hline Liquid limit (\%) & 88.3 & 282.5 & 74.9 & $\begin{array}{c}\text { ASTM D4318 - } \\
10\end{array}$ \\
\hline Plastic limit (\%) & 51 & 60.9 & 58.6 & $\begin{array}{c}\text { ASTM D4318 - } \\
10\end{array}$ \\
\hline Plasticity index (\%) & 37.3 & 221.6 & 16.3 & $\begin{array}{c}\text { ASTM D4318 - } \\
10\end{array}$ \\
\hline $\begin{array}{l}\text { Fraction passed through } \\
\text { No. 200 sieve (\%) }\end{array}$ & 85.5 & 100 & 100 & $\begin{array}{c}\text { ASTM D6913 - } \\
04\end{array}$ \\
\hline Specific gravity & 2.58 & 2.63 & 1.73 & ASTM D854 - 14 \\
\hline $\begin{array}{l}\text { Specific Surface Area } \\
\left(\mathrm{m}^{2} / g\right)\end{array}$ & 276.28 & 608 & 162.21 & See Chapter 2 \\
\hline $\begin{array}{l}\text { Total organic carbon } \\
(\%)\end{array}$ & 2.58 & $<2$ & 21.44 & - \\
\hline Basal spacing & 15.06 & 12.57 & 19.44 & XRD result \\
\hline
\end{tabular}

\section{Permeant liquid}

Water, methanol and unleaded gasoline were used in this study to evaluate how different types of inorganic and organic liquids can affect the conductivity of organobentonite amended GCL. The physiochemical properties of each fluid were already presented in Table 3-3.

\section{Preparation of organobentonite amended GCLs}

The organobentonite amended GCLs were modified from a commercial GCL, Bentomat 200R (CETCO Company) (Figure 3-15, a). Bentomat 200R is a GCL composed of a layer of granular sodium bentonite between a woven geotextile layer and a nonwoven geotextile layer. Note that the thickness of the GCL was around $0.6 \mathrm{~cm}$. Several specimens with diameters of 4 inches $(10.16 \mathrm{~cm})$ were carved out from a roll of Bentomat 200R by a 
sharp knife. The top geotextile was gently removed, and the sodium bentonite was lightly scraped out ( Figure 3-15, b).

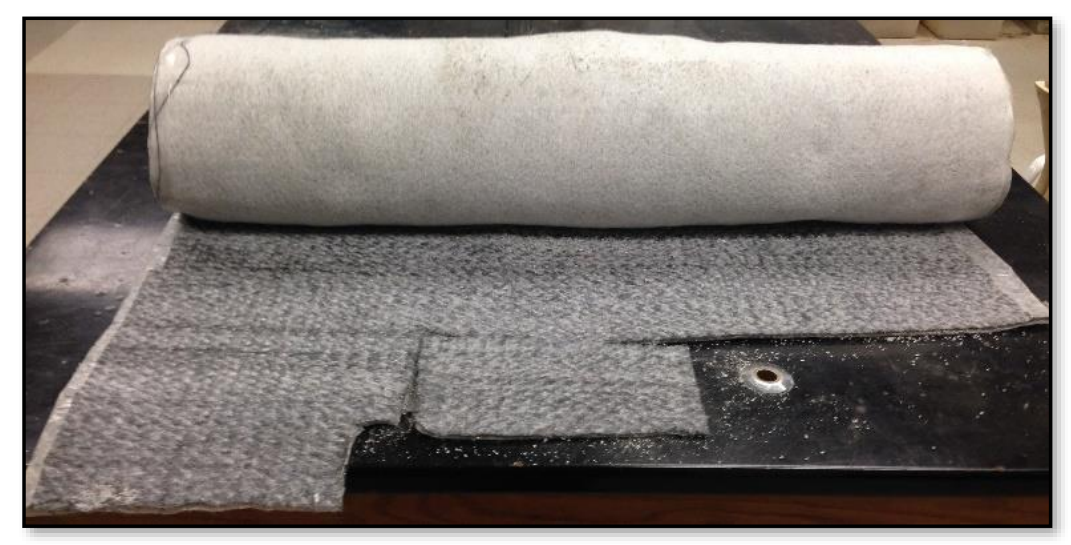

(a)

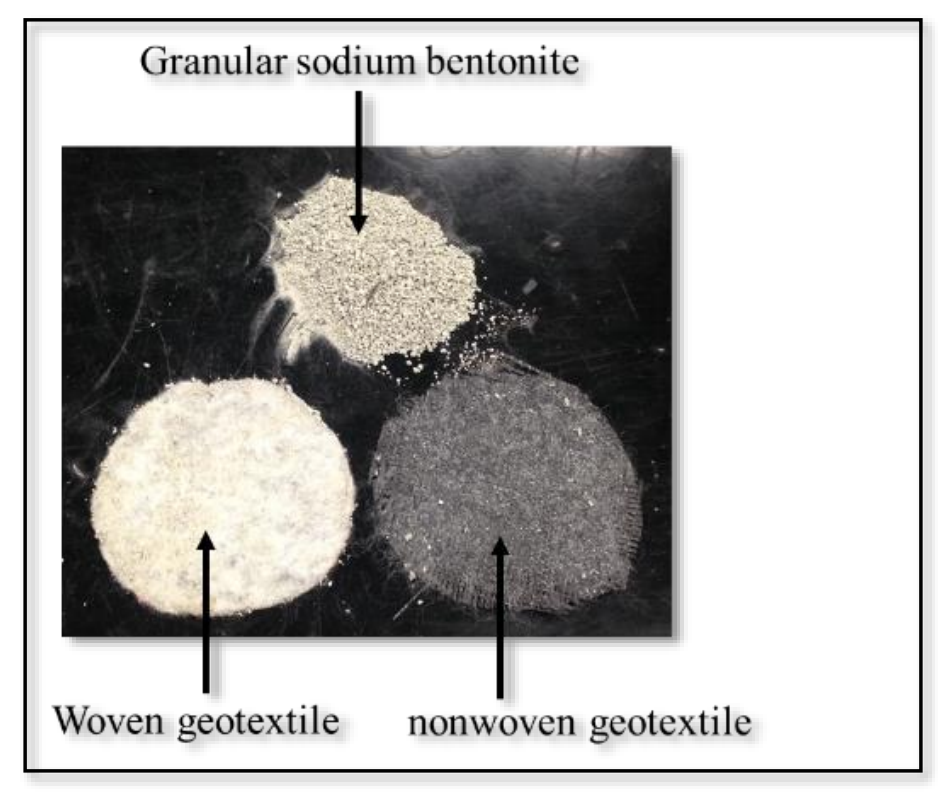

(b)

Figure 3-15. (a) Roll of GCL Bentomat 200R (b) Components of GCL Bentomat

\section{R}

To prepare the amended GCLs, either powered Ca-bentonite or Na-bentonite alone or with HDTMA-bentonite (10\% and $20 \%$ by weight) as the new fillings were completely mixed in a bowl. Nonwoven geotextile was placed on the bottom cap in a triaxial cell. The 
mixture was spread out on the nonwoven geotextile (diameter of 4 in), so that the thickness was approximately 0.6 to $0.7 \mathrm{~cm}$. The surface of the filled materials was smoothed, and another nonwoven geotextile was placed on the top of the bentonite layer. The edges of the GCL specimens were inspected for any possible flaws; if any flaws were detected, they were treated by a bentonite slurry. Several GCLs specimens were prepared using this technique. The construction procedure of GCL was illustrated in Figure 3-16.
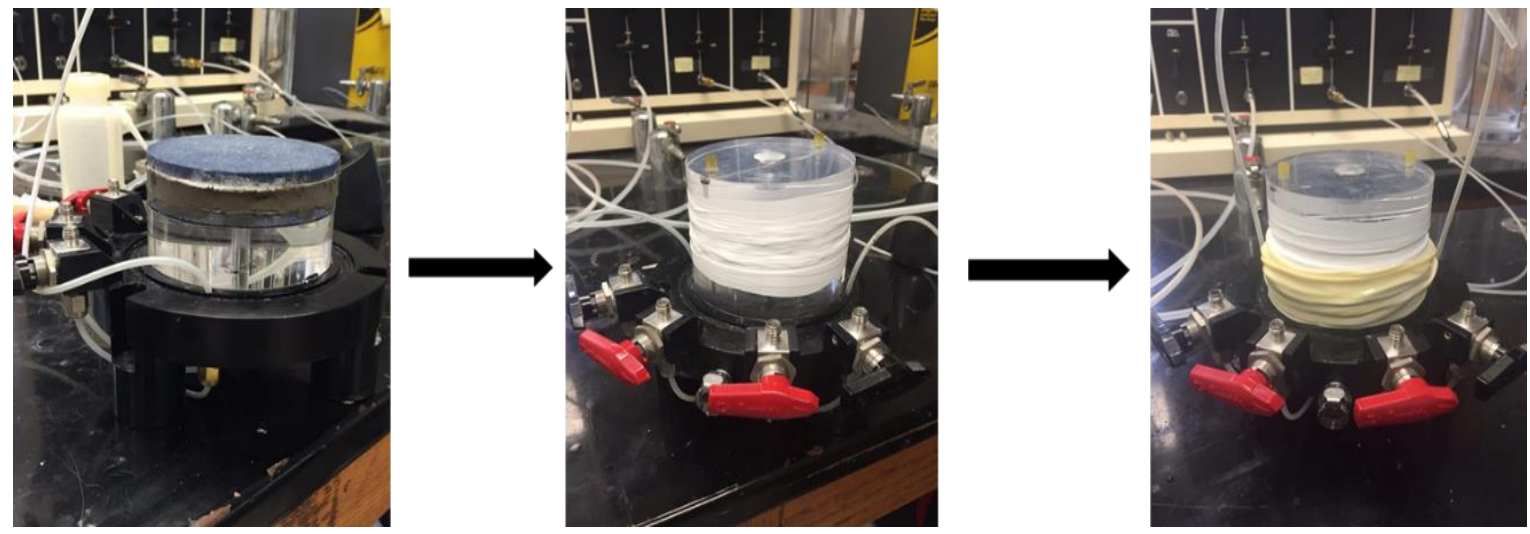

Figure 3-16. GCL specimen preparation procedure

\section{Methods}

\section{Free swelling}

The free swelling tests were performed according to ASTM D5890 on Cabentonite, Na-bentonite, and HDTMA-bentonite when exposed to water, methanol, and gasoline. The complete procedure of the free swelling test was explained in chapter 2 .

\section{Hydraulic conductivity}

In this study, the flexible wall permeameter was used to conduct the hydraulic conductivity tests according to ASTM D5084-10 and ASTM D6766-12. The falling head, constant tail water elevation method with a hydraulic gradient of 100 was used to determine 
the hydraulic conductivity of the GCL specimens. The GCL specimens were sandwiched between two porous stones and filter papers in the triaxial permeameter chamber. The specimens were then covered with a top cap and wrapped by Teflon tape. Teflon tape was used to protect the latex membrane from being exposed to organic liquids. Then the specimens were surrounded by a latex membrane, which was sealed to a base and top cap. The schematic diagram of GCL specimen in the flexible wall permeameter was illustrated in Figure 3-17. Afterward, the triaxial cell was assembled, and all valves were connected to the control panel (see Figure 3-18). Note, a bladder accumulator was employed as an interface for methanol and gasoline inflow. Bladder accumulator helps to avoid contamination of the control panel board and also prevents the volatilization of methanol and gasoline.

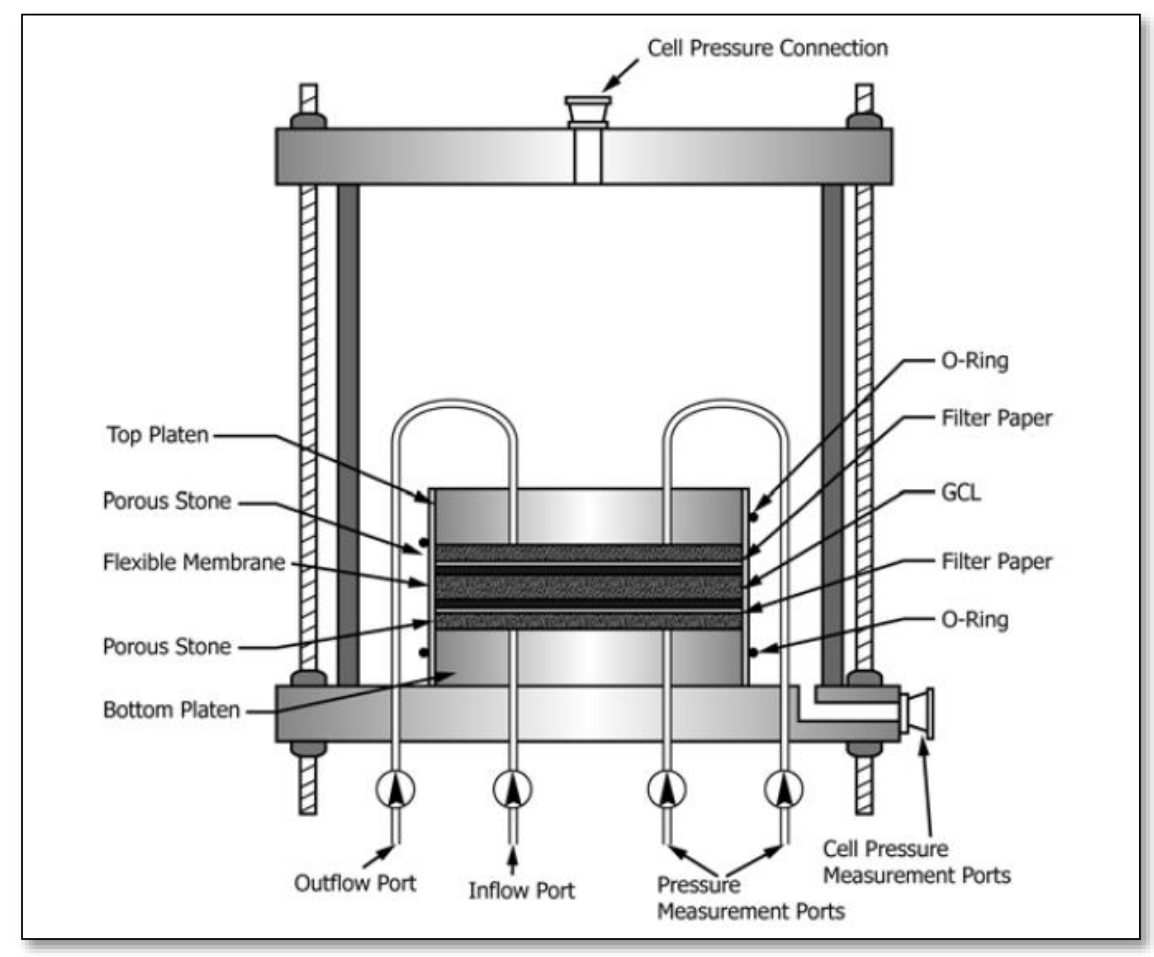

Figure 3-17. Schematic diagram of GCL specimen in permeameter cell (ASTM D6766-12) 


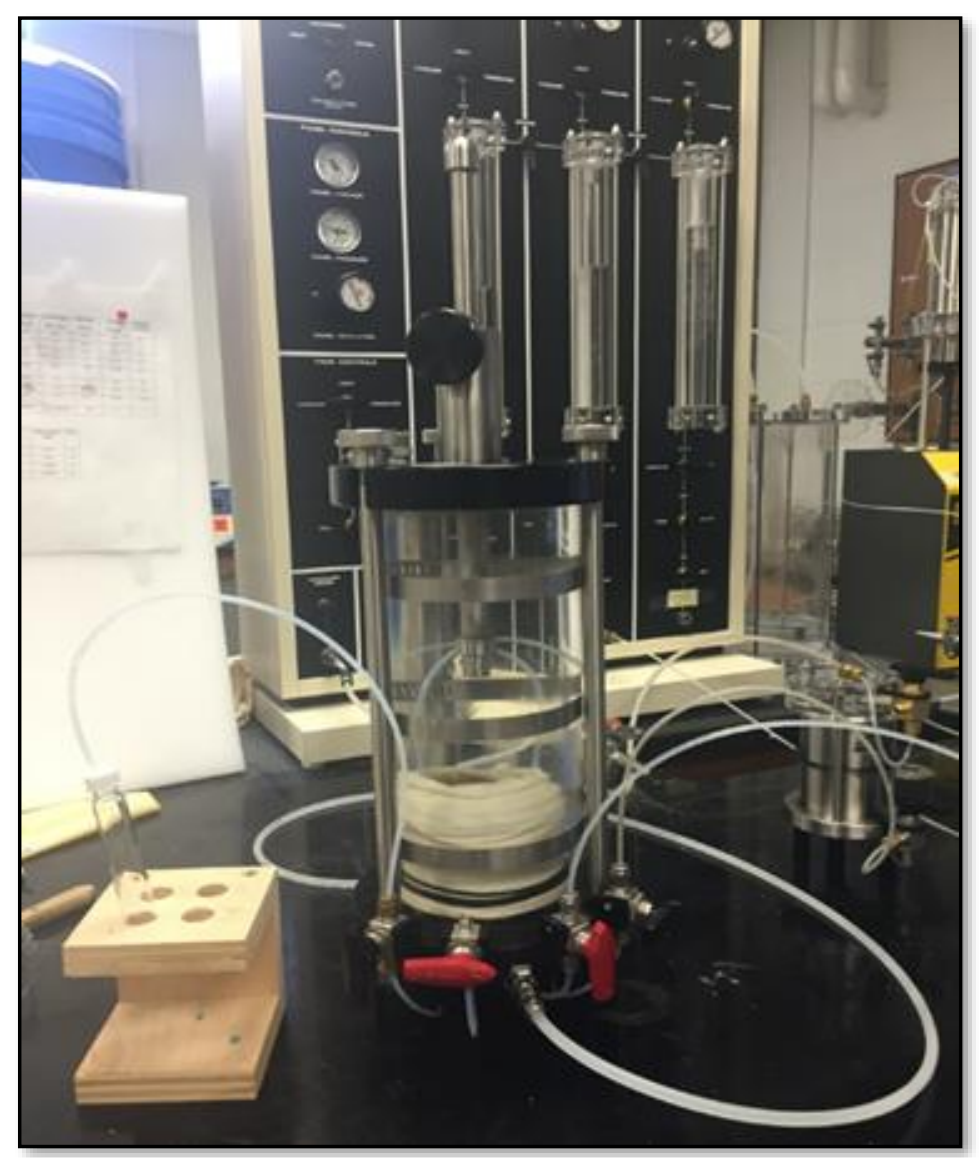

Figure 3-18. Hydraulic conductivity test setup for GCL specimen

The triaxial cell was filled with de-aired water, and the cell pressure was set to 5 psi to confine the membrane against the GCL specimens. The de-aired water was flushed through the specimen for 48 hours to hydrate the GCL specimens. Then the studied liquid was introduced to the specimen, and the hydraulic conductivity was measured when the flow was reached to the steady state condition. Afterwards, several hydraulic conductivity measurements were recorded, and the mean value was used as a hydraulic conductivity of the specimen. The hydraulic conductivity of GCL specimens was measured by the following equation: 
$K=\frac{a \cdot L}{A \cdot \Delta t} \cdot \ln \left(\frac{h_{1}}{h_{2}}\right)$

$\mathrm{K}=$ hydraulic conductivity $(\mathrm{m} / \mathrm{s})$

$\mathrm{L}=$ length of specimen (m)

$\mathrm{a}=$ cross-sectional area of the reservoir containing the influent liquid $\left(\mathrm{m}^{2}\right)$

$A=$ cross-sectional area of specimen $\left(\mathrm{m}^{2}\right)$

$\Delta \mathrm{t}=$ interval time $(\mathrm{s})$

$\mathrm{h}_{1}=$ head loss across the permeameter/specimen at $\mathrm{t}_{1},(\mathrm{~m})$

$\mathrm{h}_{2}=$ head loss across the permeameter/specimen at $\mathrm{t}_{2},(\mathrm{~m})$

\subsubsection{Results and discussion}

\section{Free swelling}

The results of the free swelling index of Na-bentonite, Ca-bentonite, and HDTMAbentonite when faced with water, methanol and gasoline are shown in Table 3. It was observed that two natural bentonites, especially sodium bentonite, had the more swelling capacity with water as a polar liquid due to the hydration behavior of natural bentonite. The large swelling tendency of Na-bentonite is related to the bond (van der Waals force and exchangeable cations $\mathrm{Na}^{+}$) holding the mineral sheets. These kinds of bonds are very weak and easily broken by water or other polar liquids entering between the sheets. The absorbed water within the interlayers of Na-bentonite can build up many discrete layers and expand the interlayer. However, it was observed that both Ca-bentonite and Na- 
bentonite exhibit no tendency to swell when faced with non-polar (organic) liquid like methanol and gasoline due to organophobic characteristic of the minerals.

The swelling volume of HDTMA-bentonite increased when it was faced with organic liquids such as gasoline. With the replacement of exchangeable cations by quaternary amines, the surface of the modified bentonite became organophilic, which enhanced its tendency for organics. The swelling capacity of HDTMA-bentonite was dramatically reduced in water due to a lack of hydration of exchangeable cations, whereas the aliphatic carbon chains caused the organobentonite to swell in organic liquids. Thus, the organophilic characteristics of HDTMA-bentonite can account for its swelling potential in nonpolar organic liquids.

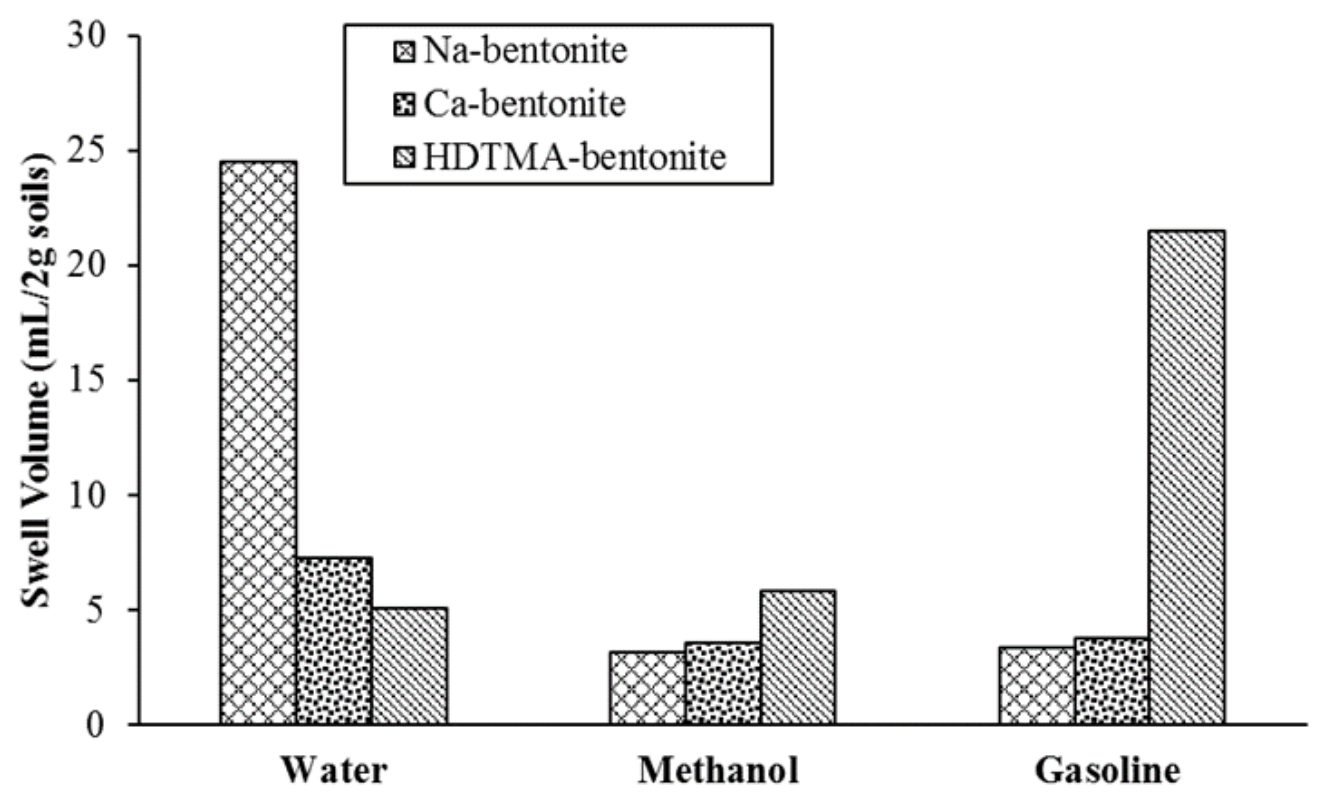

Figure 3-19. Free swelling volume for Na-bentonite, Ca-bentonite, and HDTMAbentonite permeated with water, methanol, and gasoline

Overall, the volumetric swelling of bentonite and organobentonite is highly dependent on the polarity of the permeating liquids. The swelling capacity of natural 
occurring bentonite increases with the polarity of the test liquids, whereas the swelling capacity of organo-bentonite increases with the non-polarity of the test liquids. The results of this study imply that organobentonite has a greater compatibility with petrochemicals (e.g. gasoline) due to its large swelling capacity in petroleum products and will have a higher tendency to self-heal cracks than natural occurring bentonite.

\section{Hydraulic conductivity}

The hydraulic conductivity of Ca-bentonite and Na-bentonite GCL as a function of organo-bentonite are shown in Table 3-11 Table 3-12. It was observed that Na-bentonite GCL $\left(1.7 \times 10^{-11} \mathrm{~m} / \mathrm{s}\right)$ showed a lower hydraulic conductivity, approximately 1 order of magnitude compared to Ca-bentonite GCL $\left(3 \times 10^{-10} \mathrm{~m} / \mathrm{s}\right)$ due to the greater diffuse double layer (DDL) length. The greater DDL is attributed to a greater resistance to the liquid. Sodium bentonite with a valence of +1 has a lower ionic strength in comparison with calcium bentonite with a valence of +2 , which leads to a greater DDL. Therefore, sodium bentonite has a lower hydraulic conductivity when compared to calcium bentonite.

Moreover, it was suggested that there was a strong correlation between hydraulic conductivity and the swelling volume of bentonites. This correlation is attributed to the volume of water molecules that are attached to the bentonite surface. Overall, at the macroscale structure, an increase in the volume of bound water is proved as an increase in the swelling volume and a reduction in hydraulic conductivity. The obtained results confirmed in the previous studies that calcium bentonite has a smaller swelling potential and a higher hydraulic conductivity to water than sodium bentonite (Lee and Shackelford 2005; Shackelford et al. 2000). 
Table 3-11. Hydraulic conductivity of GCL (Ca-bentonite (100\%)) as a function of organo-bentonite content

\begin{tabular}{|c|c|c|}
\hline Specimen & $\begin{array}{c}\text { Hydraulic } \\
\text { conductivity (m/s) }\end{array}$ & Porosity \\
\hline Ca-bentonite (100\%) & $3 \times 10^{-10}$ & 0.64 \\
\hline $\begin{array}{c}\text { Ca-bentonite (90\%) + } \\
\text { HDTMA-bentonite (10\%) }\end{array}$ & $4.6 \times 10^{-10}$ & 0.69 \\
\hline $\begin{array}{c}\text { Ca-bentonite (80\%)+ } \\
\text { HDTMA-bentonite (20\%) }\end{array}$ & $8.6 \times 10^{-10}$ & 0.67 \\
\hline HDTMA-bentonite & $4.5 \times 10^{-8}$ & 0.5 \\
\hline
\end{tabular}

Hydraulic conductivity of both amended GCLs slightly increased when the amount of organo-bentonite amendment increased up to $20 \%$ in the soil matrix. This is due to the hydrophobic surface characteristics of organoclays and decreased drag forces in their pores when permeated with water. The hydraulic conductivity of 100\% HDTMA-bentonite in GCL matrix to water was $4.5 \times 10^{-8} \mathrm{~m} / \mathrm{s}$, which was higher than the hydraulic conductivity of $100 \%$ Na-bentonite $\left(1.7 \times 10^{-11} \mathrm{~m} / \mathrm{s}\right)$ and Ca-bentonite $\left(3 \times 10^{-10} \mathrm{~m} / \mathrm{s}\right)$, probably due to its lowest plasticity index (see Table 3-10). Typically, a higher plasticity index (higher liquid limit) is associated with the soils that have a higher quantity of clay particles which exhibit a higher surface activity (Lo and Yang 2001). The low plasticity index of HDTMAbentonite is due to the less hydrophilic properties of the particles, rather than the lack of clay-size particles. Overall, this study suggests that a low concentration of organobentonite amendment (up to $20 \%$ ) has little or no impact on the permeability of both Nabentonite and Ca-bentonite GCLs. 
Table 3-12. Hydraulic conductivity of GCL (Na-bentonite (100\%)) as a function of organo-bentonite content

\begin{tabular}{|c|c|c|}
\hline Specimen & $\begin{array}{c}\text { Hydraulic } \\
\text { conductivity (m/s) }\end{array}$ & Porosity \\
\hline Na-bentonite (100\%) & $1.7 \times 10^{-11}$ & 0.68 \\
\hline $\begin{array}{c}\text { Na-bentonite (90\%) + } \\
\text { HDTMA-bentonite (10\%) }\end{array}$ & $2.8 \times 10^{-11}$ & 0.67 \\
\hline $\begin{array}{c}\text { Na-bentonite (80\%) + } \\
\text { HDTMA-bentonite (20\%) }\end{array}$ & $5.7 \times 10^{-11}$ & 0.64 \\
\hline HDTMA-bentonite & $4.5 \times 10^{-8}$ & 0.5 \\
\hline
\end{tabular}

Table 3-13 presents the permeability of Na-bentonite GCLs when permeated with water, methanol, and unleaded gasoline. It was observed that the permeability of Nabentonite to methanol and gasoline was $10^{-8}$ and $10^{-7} \mathrm{~m} / \mathrm{s}$, respectively. Both numbers were 3-4 orders of magnitude higher than the requirement for a GCL liner $\left(10^{-11} \mathrm{~m} / \mathrm{s}\right)$. These reductions in permeability of naturally occurring soil are due to the permeant liquids, methanol and gasoline, which are organic solvents that have a low-dielectric constant. It is well known that non-polar or low-polarity liquids can cause the bentonite particles to flocculate, shrink, and increase the permeability of bentonite significantly (Shackelford et al. 2000).

Table 3-13. Conductivity of GCL (Na-bentonite (100\%)) permeated with water, methanol, and gasoline

\begin{tabular}{|c|c|c|}
\hline Permeant liquid & $\begin{array}{c}\text { Hydraulic } \\
\text { conductivity }(\mathbf{m} / \mathbf{s})\end{array}$ & Porosity \\
\hline Water & $1.7 \times 10^{-11}$ & 0.68 \\
\hline Methanol & $5.4 \times 10^{-8}$ & 0.68 \\
\hline Gasoline & $7.2 \times 10^{-7}$ & 0.67 \\
\hline
\end{tabular}


The permeability of $100 \%$ HDTMA-bentonite to methanol and gasoline was $6.7 \times$ $10^{-9}$ and $1.5 \times 10^{-10} \mathrm{~m} / \mathrm{s}$, respectively, which were around $1-2$ orders of magnitude lower than the hydraulic conductivity of $100 \%$ HDTMA-bentonite to water (Table 3-14). This is due to the presence of organic cations (surfactant) that reduce the polarity of the mineral surface of bentonite, making them organophilic rather than hydrophilic. Moreover, HDTMA-bentonite, which is modified by QACs, has additional spaces for the adsorption of large organic molecules compounds (e.g. gasoline). These organic molecules can strongly sorb to an organic functional group of HDTMA within HDTMA-bentonite interlayers. Therefore, when organoclays are exposed to organic liquids, they swell instead of shrink.

Table 3-14. Conductivity of GCL (HDTMA-bentonite (100\%)) permeated with water, methanol, and gasoline

\begin{tabular}{|c|c|c|}
\hline Permeant liquid & $\begin{array}{c}\text { Hydraulic } \\
\text { conductivity }(\mathbf{m} / \mathbf{s})\end{array}$ & Porosity \\
\hline Water & $4.5 \times 10^{-8}$ & 0.5 \\
\hline Methanol & $6.7 \times 10^{-9}$ & 0.5 \\
\hline Gasoline & $1.5 \times 10^{-10}$ & 0.53 \\
\hline
\end{tabular}

Moreover, the permeability of Na- bentonite GCL with 10\% HDTMA-bentonite to methanol and gasoline was determined. The permeability of 10\% HDTMA-bentonite amended in Na-bentonite GCL was $2.8 \times 10^{-11} \mathrm{~m} / \mathrm{s}$; however, it was increased around 3-4 orders of magnitude when permeated with methanol $\left(2.62 \times 10^{-7}\right)$ and gasoline $\left(2.7 \times 10^{-7}\right.$ $\mathrm{m} / \mathrm{s}$ ). Although 10\% HDTMA-bentonite amendment in a Na-bentonite GCL system can maintain low hydraulic conductivity, it cannot perform efficiently when faced with non- 
polar or low-polarity fluids. Since, the majority of GCL matrix (10\% HDTMA-bentonite $+90 \%$ Na-bentonite) is comprising natural occurring bentonite, which is not compatible with organic liquids. The results of this study comprehensively suggest that $100 \%$ organoclay in a GCL matrix can be effective for decreasing the advection flow of petroleum products and can be used as a secondary liner system for underground storage tanks.

Table 3-15. Conductivity of GCL (Na-bentonite (90\%) + HDTMA-bentonite (10\%) permeated with water, methanol, and gasoline

\begin{tabular}{|c|c|c|}
\hline Permeant liquid & $\begin{array}{c}\text { Hydraulic } \\
\text { conductivity }(\mathbf{m} / \mathbf{s})\end{array}$ & Porosity \\
\hline Water & $2.8 \times 10^{-11}$ & 0.67 \\
\hline Methanol & $2.62 \times 10^{-7}$ & 0.68 \\
\hline Gasoline & $2.7 \times 10^{-7}$ & 0.65 \\
\hline
\end{tabular}




\subsection{Conclusions}

This study was performed to examine the feasibility of using organoclay as an amendment in hydraulic barrier systems, compacted clay liner, and geosynthetic clay liner. The permeability of soil barriers (CCL and GCL) with organoclay amendments were studied using several fluids (e.g. water, methanol, and gasoline). Moreover, the free swelling of the studied soil was examined to aid the interpretation of the permeability test results. The following conclusions are drawn from the study:

1- It was observed that the hydraulic conductivity of compacted silty clayorganobentonite (PM199) mixtures increased with the addition of the organobentonite fraction. This was due to the increased the hydrophobicity of the soils and facilitated the water conduction in soil pores, and this prevailed as the organobentonite fraction increased. Furthermore, the permeability of a mixture

with 50\% PM199 decreased as the permeant liquid switched from water to methanol. Additionally, this study indicated that increased organobentonite fractions had a much less significant impact on the hydraulic conductivity of compacted clays when compared to GCL and uncompacted clays.

2- The obtained results indicated that $10 \%$ of HDTMA bentonite additives had little or no impact on the free swelling of silty clay in water. However, silty clay with HDTMA bentonite showed a much higher swelling potential in gasoline due to the interaction between the organophilic phase in the HDTMA bentonite and non-polar liquid which caused the interlayer expansion of organoclay. When an additional 10\% HDTMA bentonite was added to compacted silty clay, a slight increase in 
hydraulic conductivity (water as the permeant fluid) was observed $\left(5.04 \times 10^{-9} \mathrm{~m} / \mathrm{s}\right.$ to $\left.1.57 \times 10^{-8} \mathrm{~m} / \mathrm{s}\right)$. However, HDTMA bentonite amended silty clay had decreased permeability for gasoline $\left(9.20 \times 10^{-10} \mathrm{~m} / \mathrm{s}\right.$, approximately 1 order of magnitude lower). The decreased permeability was associated with the high swelling potential of the organoclay in organic fluids (i.e. gasoline) which caused the interlayer expansion of organoclay and consequently lead to decreased pore volume of soils admixture under confining stress. Overall, a small fraction of organobentonite additives has limited impact on the hydraulic conductivity of compacted silty clay soil, whereas they may enhance the retention of organic (non-polar) fluids.

3- The hydraulic conductivity of GCL matrix containing $100 \%$ Na-bentonite $(1.7 \times$ $\left.10^{-11} \mathrm{~m} / \mathrm{s}\right)$ or Ca-bentonite $\left(3 \times 10^{-10} \mathrm{~m} / \mathrm{s}\right)$ was much lower compared to $100 \%$ HDTMA-bentonite $\left(4.5 \times 10^{-8} \mathrm{~m} / \mathrm{s}\right)$ in GCL due to hydrophobic characteristics of organobentonite particles. Moreover, GCL amended with low percentages of HDTMA-bentonite (up to $20 \%$ by weight) showed little or no impact on the permeability of the Na-bentonite or Ca-bentonite GCL to water. However, it was observed that the permeability of Na-bentonite or Ca-bentonite GCLs amended with organoclay was decreased significantly when faced with gasoline. This related to the higher chemical compatibility of organoclay to gasoline by reducing the shrinkage and volumetric change. The permeability of 100\% HDTMA-bentonite in GCL matrix was decreased when exposed to nonpolar fluids (gasoline and methanol). The decreased permeability of organoclay is due to the presence of organic cations (surfactant) that reduce the polarity of the mineral surface of bentonite, making them organophilic rather than hydrophilic. Overall, $100 \%$ 
organoclay in GCL matrix can be used as a hydraulic barrier against the advection migration of petroleum contaminants leaking from underground storage tanks. 


\section{RHEOLOGICAL BEHAVIOR OF ORGANOBENTONITE ADDITIVE IN OIL-BASED DRILLING FLUIDS}

\subsection{Introduction}

Drilling fluid (or drilling mud) has been widely used in site investigation, foundation construction and oil production to facilitate drilling and stabilize boreholes. The drilling fluid is composed of a volume of fluid that is pumped by a pump from the surface of the pits through the drilling borehole till reached the bit of drill and then backs to the surface with the cuttings (Figure 4-1) (Darley and Gray 1988). The drilling fluids always remains in contact with the wellbore and the drill throughout the entire drilling operation. The required volume of the drilling fluid usually depends on to the wellbore size and condition, and the rheological properties of drillings fluid.

Drilling fluids should be efficient and reliable under all conditions. The main functions of drilling fluids are those that clean the wellbore by removing drilled cuttings and soils to the surface of the ground, cools down and lubricates the bit of drilling, maintains and supports wellbore stability as the drilling continues, overcomes and controls formation pressure in the wellbore to reduce the risk of wellbore control issues, and minimizes damage to drilling equipment and the environment (Aston et al. 2004; Caenn et al. 2011). 


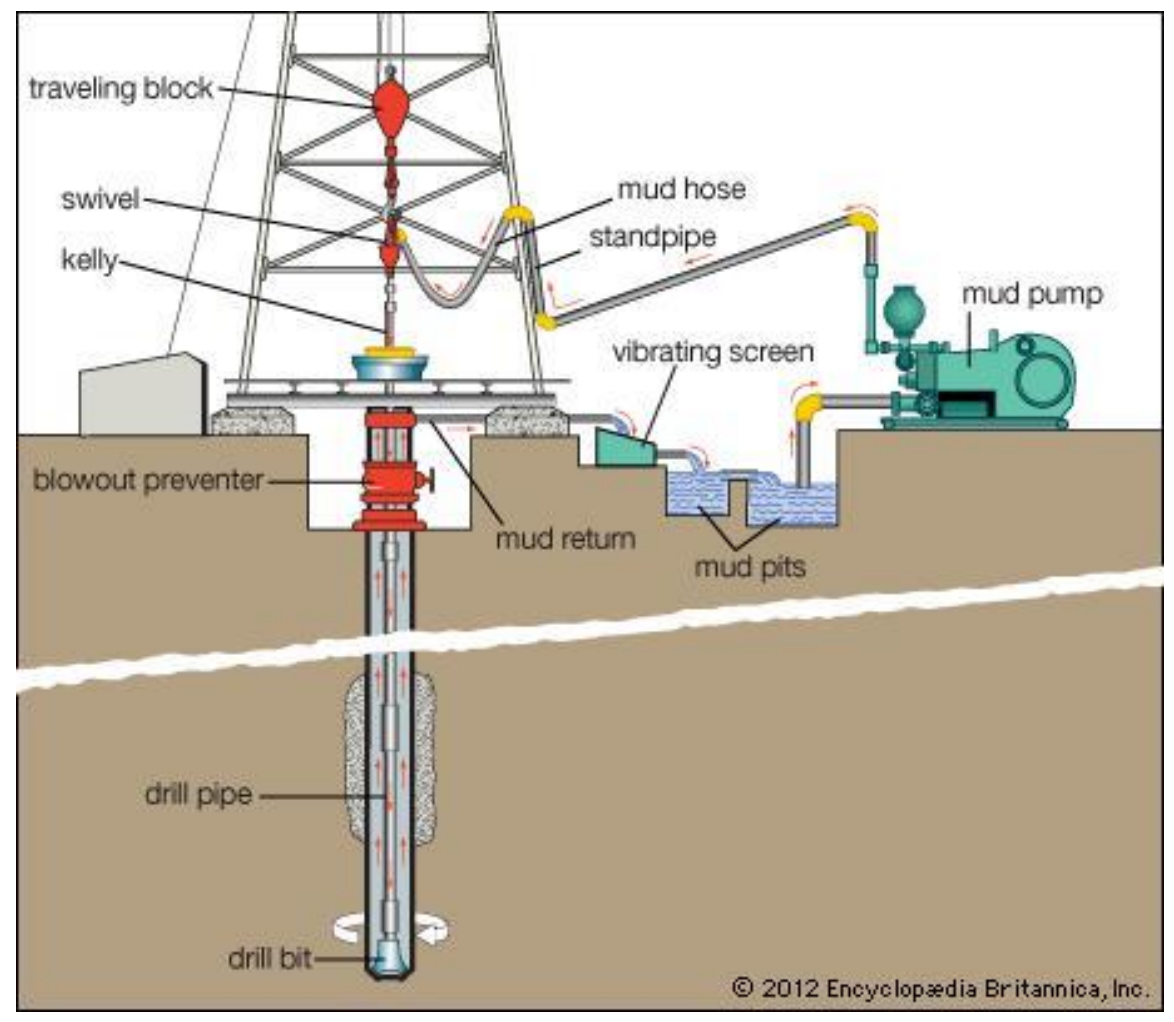

Figure 4-1. The circulation of drilling mud during the drilling of a well (Source:

\section{www.britannica.com)}

Drilling fluid can be divided into two major groups based on their use and composition; water-based fluids and oil-based fluids (Figure 4-2). The selection of the type of drilling fluids is a very important task before drilling wellbore, as it would impact the cost, quality and environmental consequences of drilling (Khodja et al. 2010). Water-based drilling fluid consists of water and fluid loss control agent, and has been widely used to drill about $80 \%$ of the wells. Meanwhile, oil-based fluid is based on diesel or mineral oil with the suspended of polymer, synthetic polymer or modified clay. In global drilling operations, approximately 10 to $15 \%$ of the wells drilled use oil-based drilling fluid (Caenn et al. 2011). 


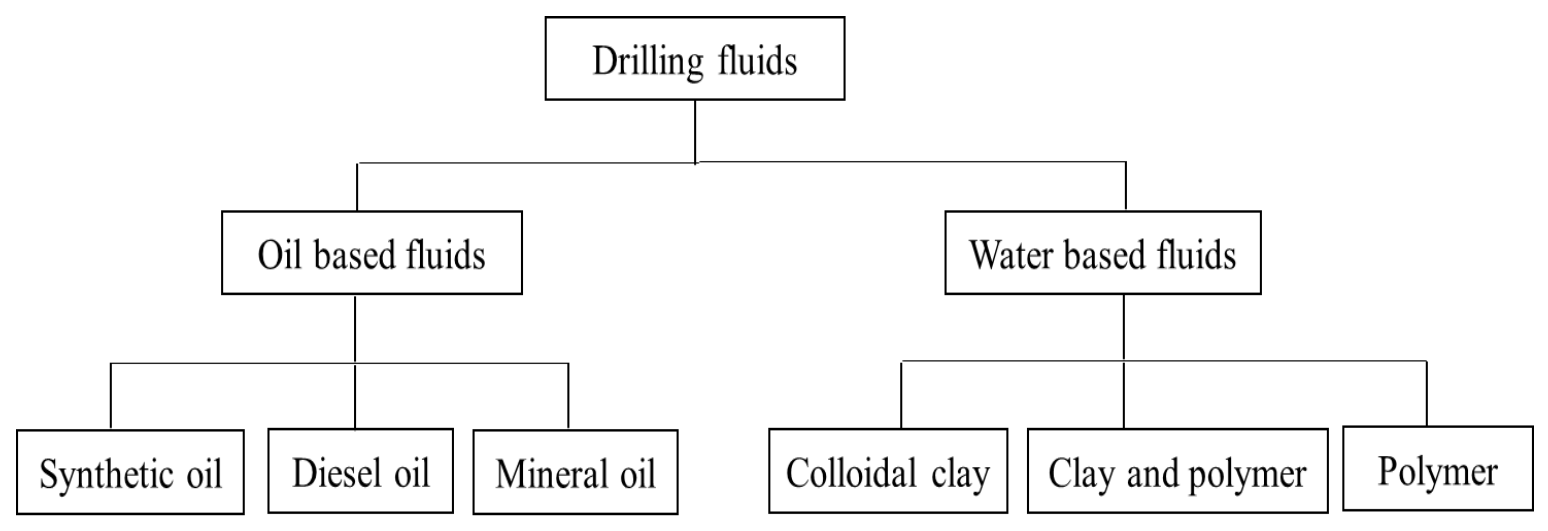

Figure 4-2. Common drilling fluids classification

The based fluid of water-based fluid can be fresh water, distilled water, seawater or brine. Montmorillonite clay (sodium montmorillonite) which is known as a widespread thickening agent for industrial fluid formulations has been widely used as a fluid loss control in the water-based fluid due to its outstanding mechanical and rheological properties. These unique properties of montmorillonite allow them to stabilize the wall of the hole by forming a cake to clean the hole by evacuating the cuttings and to decrease the wear on tools. Moreover, the mud must be used efficiently to limit the consummation of primary material and to reduce the quantity of ultimate waste at once. Also, montmorillonite exhibits high swelling capacity when faced with water, and it can form a stable aqueous suspension for water-based drilling fluids (Darley and Gray 1988).

The rheological behavior of montmorillonite is highly related to several factors such as the type of bentonite, shape, and size of bentonite particles, the exchangeable inorganic ions, and electrostatic properties of the bentonite particles. Based on previous studies, bentonite concentration can be between 2 to $5 \%$ to significantly affect the rheological properties of water-based drilling fluid. Although water-based drilling formulated to meet certain properties as drilling fluids and covered many advantages, when 
itis faced with severe conditions like high temperature and pressure at the borehole, the destruction of water-based fluid properties may happen (Caenn et al. 2011; Khodja et al. 2010).

It is known that the temperature of a borehole increases as the depth increases due to the geothermal gradient. The geothermal gradient will vary depending on the geological conditions, such as the thickness of the earth's crust, thermal conductivity properties of the rocks and geological features such as volcanoes or fault zones. Furthermore, mechanical forces at the drilling bit when it is pushed into the rocks increases temperatures of the environment and the drilling bit. The responsibility of drilling fluids is to reduce the temperature of the drilling bit; otherwise, the drilling string, bit, and also hydraulic motors would fail. Due to the low boiling point of water based drilling fluids, it cannot be used as a drilling fluid for very deep wells where excessively high temperatures and pressures are encountered (Kelessidis et al. 2007).

Moreover, pressure plays an important role in drilling a hole, and it can highly affect the drilling fluids rheological properties. The common types of pressure are hydrostatic pressure, pressure gradient, formation pressure, overburden pressure, pump pressure and bottom hole pressure. Therefore, a drilling fluid's viscosity is directly related to the downhole variations in pressure and temperature and is a very important part of drilling. To overcome these problems, oil-based drilling fluid is a better option compared to water-based fluid in high temperature and pressure applications engineering.

Many scientists suggested oil-based drilling fluids as a promising alternative to overcome certain undesirable features of water-based drilling fluids (Amani et al. 2012). Oil-based drilling fluids have unique properties and characterization such as high thermal 
stability, excellent lubricity, high rate of penetration, wellbore stability, shale inhibition, and high salt resistance in performing of drilling operation (Hermoso et al. 2014; Khodja et al. 2010; Zhang et al. 2003). Therefore, oil-based drilling fluids with outstanding properties and characterization are highly recommended to use as a drilling fluid in offshore wells, high-temperature wells, and geopressured formations.

Organically modified clay, namely as organoclay, is a well-known additive in oilbased drilling fluids (Burgentzlé et al. 2004; Hato et al. 2011; King Jr et al. 2007). Organoclay is commonly prepared from the reaction of smectite-family clays with cationic surfactants (e.g. quaternary ammonium and quaternary phosphonium) through cation exchange. The intercalation of organic surfactant within clay interlayers can change the clay surface from hydrophilic to hydrophobic (organophilic), and also increase the basal spacing of the layers (Ghavami et al. 2017; He et al. 2006; He et al. 2006; Javadi et al. 2016). Organic surfactant bound to the clay surfaces can facilitate the binding of organic molecules to the clay mineral via partitioning and adsorption (Zhao and Burns 2012). Organoclay can be dispersed into a predominate hydrocarbon medium, such as diesel and mineral oils to produce the oil-based drilling fluids. The ease of dispersion is highly affected by the type and concentration of organic surfactant, the polarity of the solvent, and duration and intensity of shearing (Cassagnau 2008; King Jr et al. 2007). Moreover, based on previous studies, organoclay exhibits a remarkable improvement regarding heat resistance in comparison with unmodified clay (He et al. 2005; Xi et al. 2007). Therefore, organoclay can be used as an important rheological control additive in oil-based drilling fluids when they are submitted to the extreme pressure and temperature conditions of the wellbore. 
Few great works have done to examine the rheological behaviors of oil-based drilling fluids when organoclay used as an additive to improve the drilling operations (Benchabane and Bekkour 2006; Bhatt et al. 2013; Herzhaft et al. 2001; King Jr et al. 2007; Minase et al. 2008; Zhong and Wang 2003). They exhibited that rheological properties of organoclay/oil fluids depend on the type of organoclay, size, shape, surface properties, concentration, and medium composition. A recent study by Hermoso et al. (2014) showed that viscous flow behaviors of oil-based drilling fluids with two different type of organoclays as additives at different pressure are strongly influenced by organoclay type and concentration. They also observed that shear-thinning behavior of the organoclays suspensions at different concentration is related to the development of various microstructures, which depend on the type of surfactants within the organoclays. Moreover, Zhuang et al. (2016) investigated on the structure of organo-montmorillonite/oil gels and their viscous flow behaviors under different temperatures. They observed that swelling and gel formation of organoclay dispersion were affected by the interface properties, basal spacing, surfactant loading, and temperature. They also found that the viscosity of organoclay/oil fluids increased with increasing temperature up to $150^{\circ} \mathrm{C}$, while the viscosity of the organoclay dispersions gradually decreased above $150{ }^{\circ} \mathrm{C}$, due to the loss of surfactants within organoclay interlayers.

Although a few studies were conducted to investigate the rheological behavior of oil-based drilling fluid with organoclay additive, less attention has been paid regarding the impact of organoclay concentration and type of organic surfactant on the structure of organoclay/oil fluids. This study aims to examine the microstructure of two organoclays (HDTMA-MMT and PM199) and their impact on the rheological behavior of oil-based 
drilling fluids. Furthermore, superior organoclay was chosen as a promising additive to study the viscosity of the organoclay suspension under high pressure and temperature. Xray diffraction (XRD) test was employed to study the microstructure of organobentonites and organobentonite suspensions in terms of basal spacing. Moreover, a state of the art rheometer (Anton Paar MCR 502) was used to test the rheological behavior of organoclays suspensions under high temperature and pressure. The obtained results are expected to provide the significant information regarding the structure of organoclays suspensions and their viscosity under high temperature and pressure. The findings of this study are aimed to solve drilling operation obstacles such as pressure induced by drilling mud, increasing the drill bit temperature, instability of wellbore wall in drilling operations. 


\subsection{Materials and methods}

\section{Materials}

Two organobentonites, commercially purchased (PM199) and laboratory synthesized (HDTMA modified calcium montmorillonite) were used in this study. A commercial powdered organobentonite PM199 (CETCO Company) was chosen as an organic additive in oil-based drilling fluids due to its high sorptivity of the petroleum hydrocarbons. The PM199 was montmorillonite modified with amine bis(hydrogenated tallow alkyl)dimethyl ammonium surfactant. A commercial diesel oil with a chemical formula of $\mathrm{C}_{12} \mathrm{H}_{23}$ and an average density of $0.838 \mathrm{gr} / \mathrm{cm}^{3}$ was purchased from a Speedway gas station as a base oil to prepare oil-based drilling fluids.

\section{Preparation of organobentonite}

The HDTMA-MMT was synthesized by exchanging naturally occurring $\mathrm{Ca}^{2+}$ cation within Ca-MMT with HDTMA-Br at different CEC concentrations, 50\%, 100\%, and $200 \%$. The procedure of making HDTMA-MMT was as follows: the required amount of HDTMA-Br was added into $1000 \mathrm{~mL}$ distilled water with a temperature of $60{ }^{\circ} \mathrm{C}$ and stirred for 20 minutes. Then the required amount of Ca-MMT was added into the previous dispersion and stirred with a Hamilton Blender for 30 minutes. The suspension was filtered, and the resulting soils were dried in an oven at $60{ }^{\circ} \mathrm{C}$ for 24 hours. The dried soils were milled and sieved with a \#200 sieve. Note that the HDTMA-MMT prepared with 0.5, 1.0, and 2.0 CEC were denoted as HDTMA-MMT(0.5 CEC), HDTMA-MMT(1.0 CEC), and HDTMA-MMT(2.0 CEC). The full procedure of making organobentonite is presented in Chapter 2. The properties of the studied soils are presented in Table 4-1. 
Table 4-1. The physiochemical properties of the studied soils

\begin{tabular}{lccc}
\hline \multicolumn{1}{c}{ Soil } & $\begin{array}{c}\text { Specific } \\
\text { gravity }\end{array}$ & $\begin{array}{c}\text { Specific } \\
\text { surface area } \\
\left(\mathbf{m}^{2} / \mathbf{g}\right)\end{array}$ & $\begin{array}{c}\text { Total } \\
\text { organic } \\
\text { carbon (\%) }\end{array}$ \\
\hline Ca-MMT & 2.58 & 276.3 & 2.73 \\
Na-Bentonite & 2.75 & 628 & - \\
HDTMA-MMT (0.5 CEC) & 2.19 & 215.4 & - \\
HDTMA-MMT (1.0 CEC) & 1.73 & 162.2 & 21.6 \\
HDTMA-MMT (2.0 CEC) & 1.68 & 96.8 & - \\
PM199 & 1.75 & 60.7 & 21.7 \\
\hline
\end{tabular}

\section{Preparation of oil-based fluid and water-based drilling fluids}

The oil-based drilling fluid samples were prepared by pouring the two dried organobentonites, PM199 and HDTMA-MMT (at 1, 3 and 5 by wt\%) into $300 \mathrm{ml}$ of diesel oil at room temperature. Also, the water based fluids were prepared by mixing the Nabentonite with distilled water. The suspensions were mixed for 20 minutes using a high shear mixer. Then the samples were left to age for 24 hours prior to performing the shearing process. Moreover, the 5\% HDTMA-MMT with different surfactant loading, as mentioned in the previous section, was mixed with diesel oil.

\section{Characterization}

X-ray diffraction (XRD) analysis was performed using a Bruker-AXS D8 Discover diffractometer to determine the basal spacing of both the powered studied soils and the two organobentonites (PM199 and HDTMA-MMT(1.0 CEC)) with various concentrations of sorbed diesel oil. The XRD pattern was recorded between $2^{\circ}$ and $20^{\circ}(2 \theta)$ using $\mathrm{CuKa}$ radiation $(\mathrm{n}=1.5406 \AA)$ at a scanning speed of $2^{\circ} / \mathrm{min}$. Then the Bragg's law $(\lambda=2 \mathrm{~d} \sin \theta$, 
where $\lambda$ is a wavelength of the incident wave, $d$ is the basal spacing, and $\theta$ is the scattering angle) was employed to calculate the basal spacing of each soil.

\section{Gel volume}

Gel volume was measured by pouring $100 \mathrm{ml}$ of each suspension into a graduated cylinder with a stopper. The height of a gel formed at the bottom of the cylinder was measured over 24 hours. Note that the gel volumes of 5\% PM199 and 5\% HDTMAMMT(1) was monitored during 48 hours to investigate the impact of time on swelling performances.

\section{Viscosity measurement}

The rheological properties of the fluids were measured using a state of the art rheometer (Anton Paar MCR 502) with a concentric geometry and gap size of $1.13 \mathrm{~mm}$ (Figure 4-3 a). The samples were pre-sheared for $15 \mathrm{~s}$ at a shear rate of $100 \mathrm{~s}^{-1}$ to homogenously mix the dispersions, and then left rest for $15 \mathrm{~s}$ before starting the shearing process. The samples were sheared at a shear rate of 100 to $0.01 \mathrm{~s}^{-1}$ for 10 minutes at a descending flow curve with a constant rate. The corresponding shear stress at each shear rate was measured, and the Bingham model was applied to determine the viscosity and yield stress of each sample.

To investigate the effect of temperature and pressure on the viscosity of the organobentonite suspension, 5\% PM199 suspension was chosen for this study. The suspension was poured into a concentric geometry mold and was heated to 60, 90, 120, and $150^{\circ} \mathrm{C}$ separately for 1 hour before starting the shearing process. For pressure tests, a sealed co-axial cylinder-pressure cell with a gap size of $1.5 \mathrm{~mm}$ was used to measure the viscosity 
of the suspension at the pressures of 0,100 and 200 bars (Figure 4-3 b). The pressure was applied by pumping high-pressure inert gas (Nitrogen) into the cell. Note that the gap size difference between the two concentric cells results in different viscosities, and absolute values were not comparable.

The Bingham model is the most accepted model to fit the viscoelastic behavior of drilling fluids (Chhabra and Richardson 2011). According to the Bingham model: $\tau=\tau_{\mathrm{e}}+$ $\eta_{p \gamma}$, where $\tau_{\mathrm{e}}$ is the extrapolated yield point of the Bingham plastic model $(\mathrm{Pa})$ and $\eta_{\mathrm{p}}$ is the plastic viscosity (Pa.s). The yield point can be defined as the minimum squeezing shear stress needed to force the gel to flow. The plastic viscosity is the slope of the stress-shear rate curves and represents the resistance of material to shearing. All the rheological parameters of the test results were obtained by fitting the data with Bingham model.

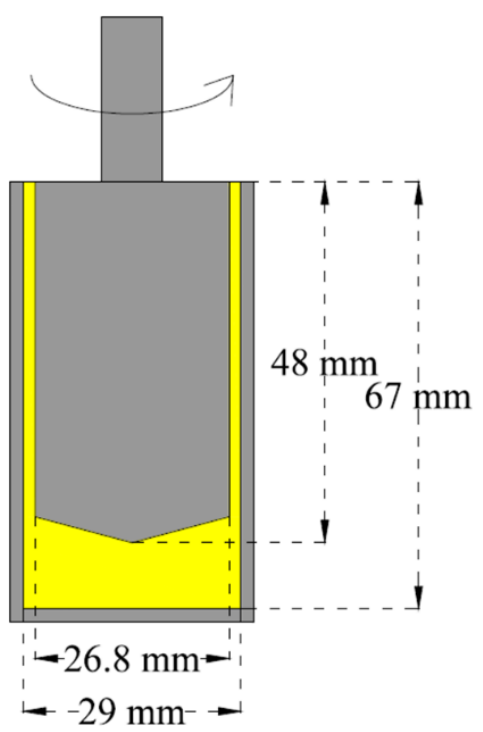

(a)

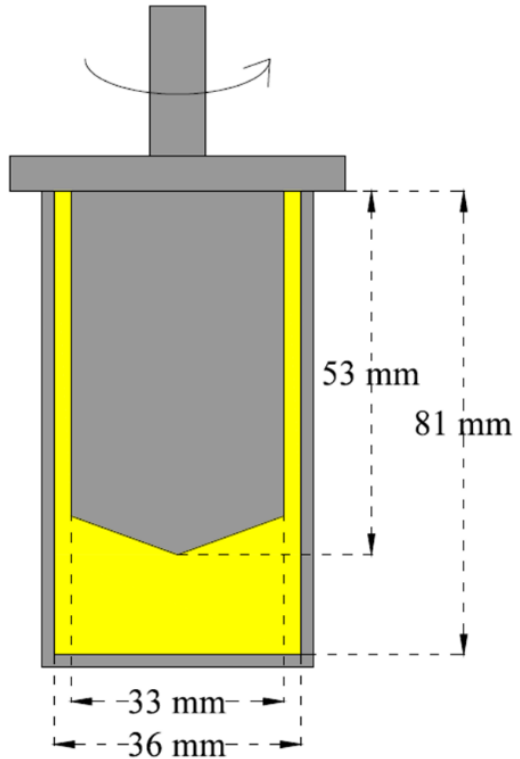

(b)

Figure 4-3. (a) Concentric cylinder geometry (b) Concentric cylinder-pressure cell geometry with cap 


\subsection{Results and discussion}

\subsubsection{X-ray diffraction}

$\mathrm{X}$-ray diffraction is an efficient and powerful technique to interpret/measure the basal spacing of untreated and treated bentonite. The exchange of inorganic cations with the organic cationic surfactant within the montmorillonite interlayers, the expansion of the montmorillonite layers occurs, and can be measured by small angle X-ray diffraction. XRD patterns of Ca-MMT, the surfactant intercalated montmorillonite clays at different surfactant loading, and PM199 are shown in Figure 4-4.

The d-001 or basal spacing of Ca-MMT was $15.06 \AA$, which corresponds to $2 \theta$ of $5.84^{\circ} .50 \%$ and $100 \%$ cation exchange with the HDTMA cationic surfactant caused interlayer expansions ( 2 and $4 \AA$ ) to the measured basal spacings of 17.1 and $19.4 \AA$, respectively. Lagaly (1986) suggested that HDTMA-Br with intercalated aliphatic carbons tend to form layered structures such as lateral monolayers (basal spacing 13-15 A), lateral bilayers (basal spacing 17-19.8 $\AA$ ), and pseudo-trilayers or paraffin monolayers (basal spacing > $22 \AA$ ). Based on this suggestion, it can be proposed that cationic surfactants in HDTMA-MMT with low surfactant loading (0.5 and 1 CEC) form a lateral bilayer structure. It is worth noting that the shape of the perfect straight-chain quaternary ammonium cation (HDTMA-Br) has the appearance of a nail, where the long alkyl carbon chain is the body of the nail and the carbon chain end containing the three methyl groups is the nail-head. The theoretical length of the HDTMA cation is $25 \AA$, and the theoretical height of alkyl chain is $4.0 \AA$, and the nail-head is $5.1 \AA$. It can be hypothesized that the 
HDTMA cations lied flat within the montmorillonite interlayers at the concentration of the HDTMA near to 1 CEC (Ikhtiyarova et al. 2012; Zhu et al. 2003).

When Ca-MMT was intercalated with HDTMA surfactant at high concentration (2.0 CEC), two main peaks were observed in XRD patterns at $2 \theta$ of $2.2^{\circ}$ and $4.48^{\circ}$. These two peaks correspond to the basal spacing of 40.1 (d-001) and 19.7 (d-002) $\AA$, respectively. The intensity of the d-001 was higher than d-002, which suggests that the majority of the HDTMA surfactant (with 2.0 CEC) formed a paraffin type bilayer structure within the montmorillonite interlayers while some of them formed lateral bilayers structure in the interlayers gallery. Overall, this data suggests that the basal spacing of HDTMA-MMT is not uniform at a higher concentration of HDTMA surfactant (2.0 CEC). This can be related to the intercalation process of HDTMA cationic surfactant into the interlayers of montmorillonite. Although most cationic surfactants can penetrate into the interlayers of clay mineral easily, it would be difficult for enough surfactants to penetrate into the interlayers for the purposes of intercalation; therefore different basal spacings were formed. For commercial organobentonite, PM199 with a higher sorption capacity of hydrocarbons of larger sizes, X-ray diffraction patterns indicated that the initial basal spacing of the PM199 was $35.58 \AA$ (Figure 4-4). This suggests a possible paraffin-bilayers surfactant arrangement pattern. 


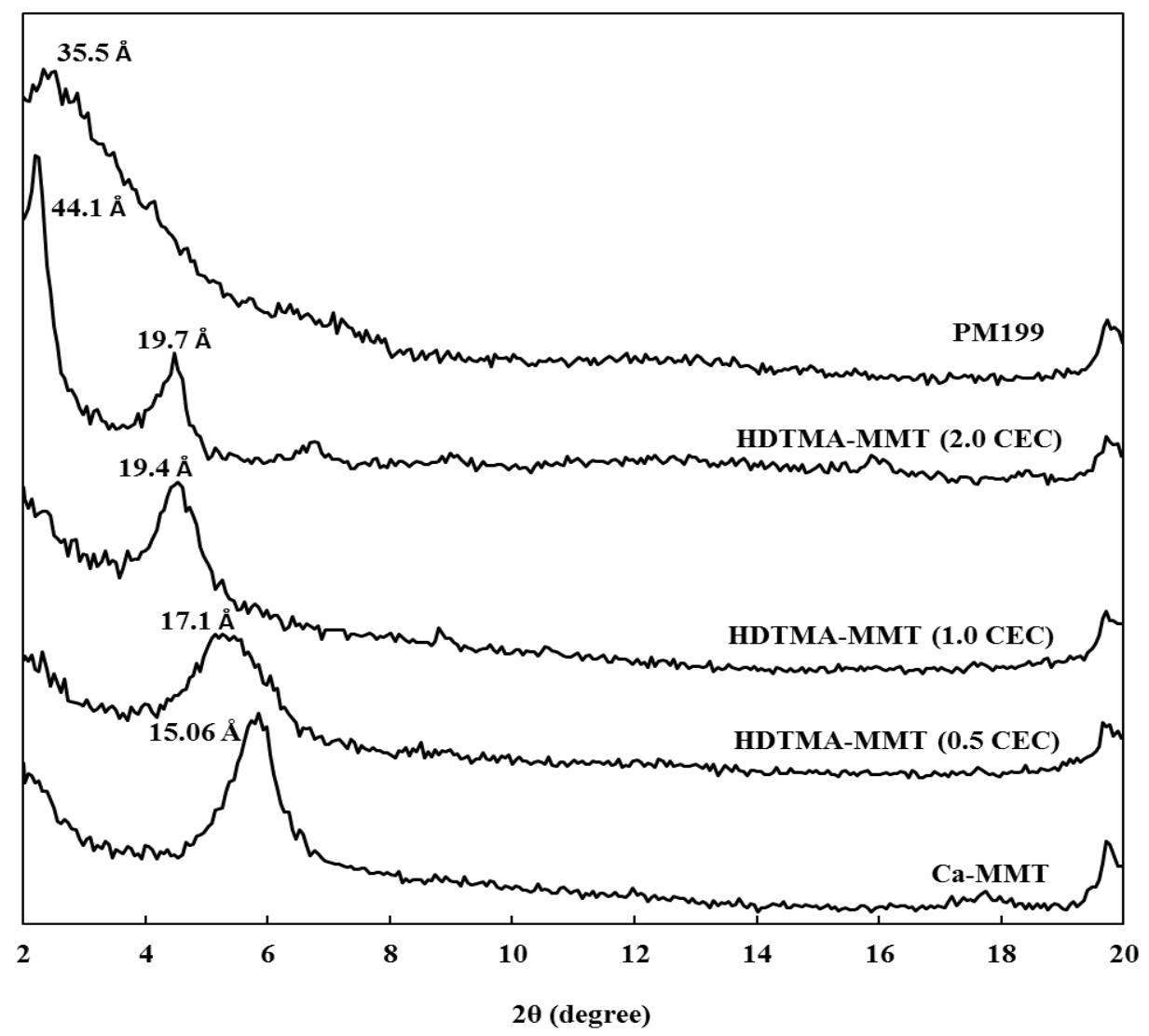

Figure 4-4. XRD patterns of untreated and treated bentonite

The XRD patterns of PM199 and HDTMA-MMT (at different CEC) with various content of sorbed diesel oil are shown in Figure 4-5. The initial basal spacing of the powdered PM199 increased from $35.5 \AA$ to $42 \AA$ after $25 \%$ diesel oil (by weight) was introduced. This occurrence indicated that the diesel oil molecules entered the interlayer galleries of the organobentonite and expanded the interlayers spacing (Figure 4-5 a). It was observed that the basal spacing of the organobentonite increased to $56.6 \AA$ by further increasing the oil content (300\% diesel oil by weight). However, no detectable reflections from montmorillonite lattices were observed in the XRD patterns of PM199 when the diesel oil content more than $400 \%$ in PM199. This suggested that the PM199 was completely exfoliated in the non-polar hydrocarbon medium. This explains why the diesel 
oil molecules intercalated into the interlayer spacing of PM199 and expanded that spacing, consequently reducing the attractive forces between the organobentonite sheets. In other words, dispersing the PM199 in oil solution significantly weakened the forces between the alkyl chains of the surfactants and montmorillonite platelets, resulting in greater disorder in surfactants arrangement within the interlayer of the organobentonite due to interlayer swelling through solvation. The exfoliation of an organobentonite is completely related to the organic chemistry of surfactant (e.g. cationic or anionic, chain length, the quantity of carbon and molecular structure).

In contrast, the basal spacing of HDTMA-MMT with different surfactant loading did not change when different percentages of diesel oil were added (Figure 4-5 b, c and d). These results suggest that the oil molecules could not get into the interlayer space of the HDTMA-MMT as it had a much smaller interlayer spacing when compared with PM199. Eventhough, the HDTMA-MMT with 200\% surfactant loading had the greatest basal spacing (44.1 $\AA \mathrm{d}_{1}$ ), the oil molecules with approximate length of $25 \AA$ could not easily enter the interlayer spacing, as indicated by the minimum increment of basal spacing. This might be related to the larger size of diesel oil molecules as well as the high packing density of HDTMA cations in HDTMA-MMT interlayer. The concept of interactions diesel oil and MMT platelets, the changes of MMT microstructure are shown Figure 4-6.

It is worth mentioning that the surfactant type could play an important role to microstructure of organoclays before and after the sorption of diesel molecules. The comparison between PM199 and HDTMA-MMT (2.0 CEC) suggested that bis(hydrogenated tallow alkyl)dimethyl ammonium surfactant within PM199 interlayers has higher affinity for large organic molecules such as diesel oil in compared with 
hexadecyltrimethylammonium surfactant of HDTMA-MMT. Although an universal model to predict the exfoliation of organobentonite particles in oils still merits examination, this study suggested that the initial basal spacing of 1.5 times of the size of oil molecules would likely to lead to the exfoliation of organobentonite eventually. Additionally, higher affinity of oil molecules towards the surfactants would likely to facilitate the exfoliation as well. Table 4-2 briefly presents the current research on the type of organobentonites which can be used as a promising additive in oil based drilling fluids.

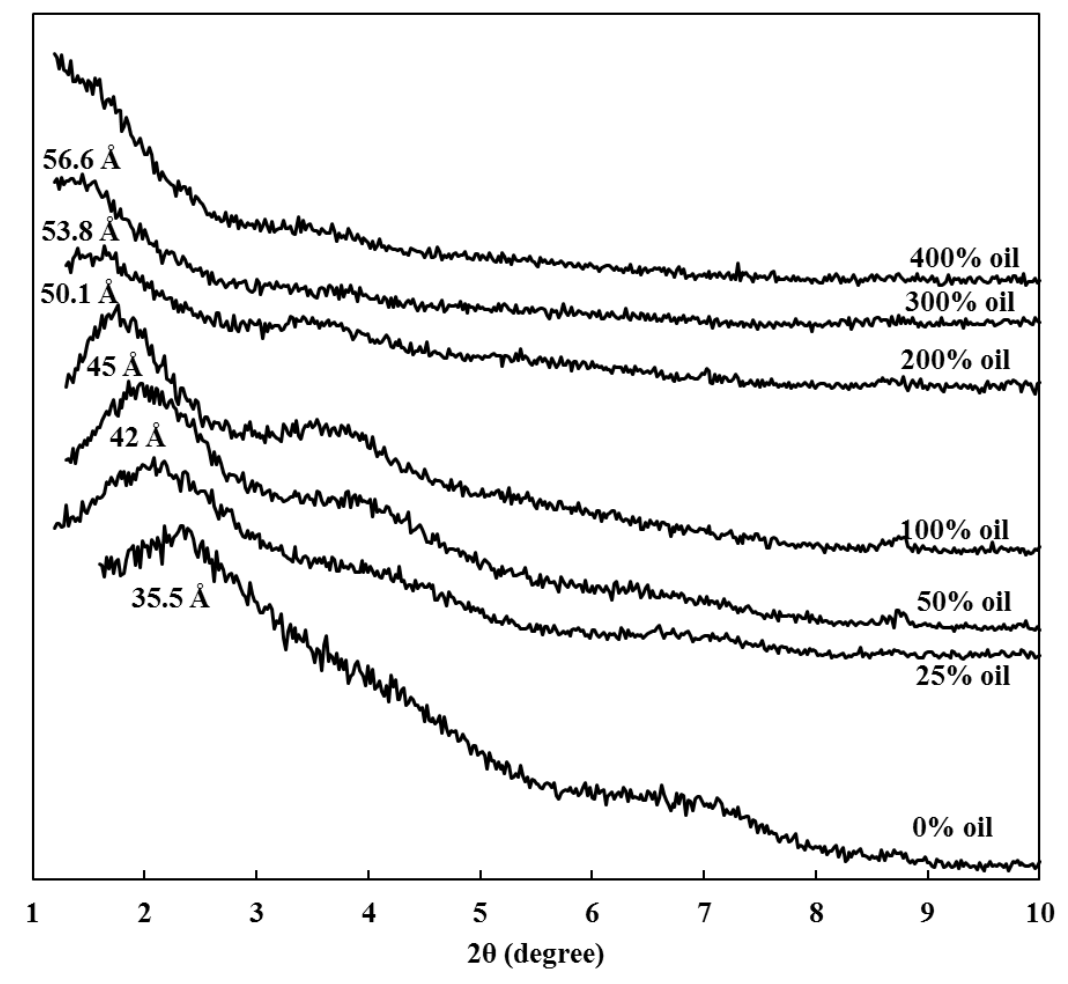

(a) 


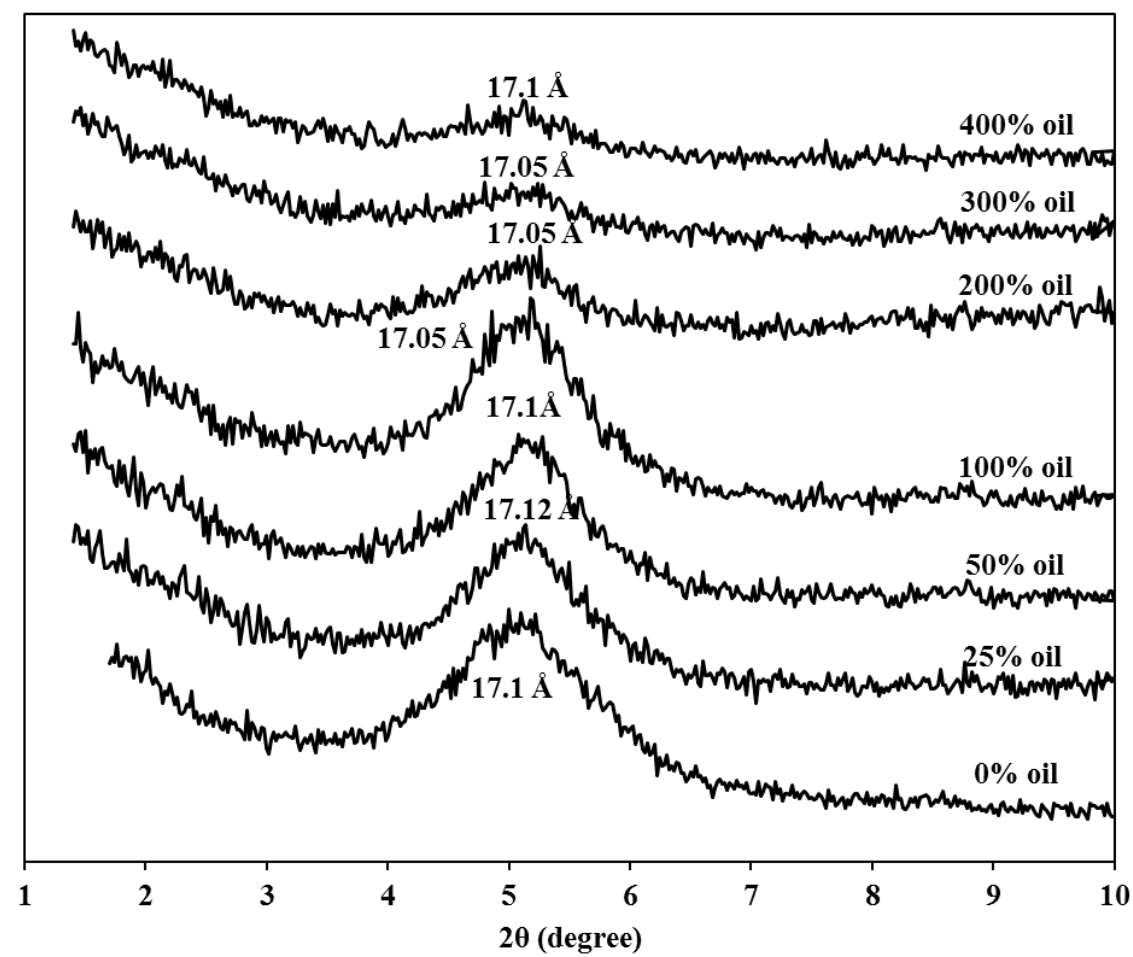

(b)

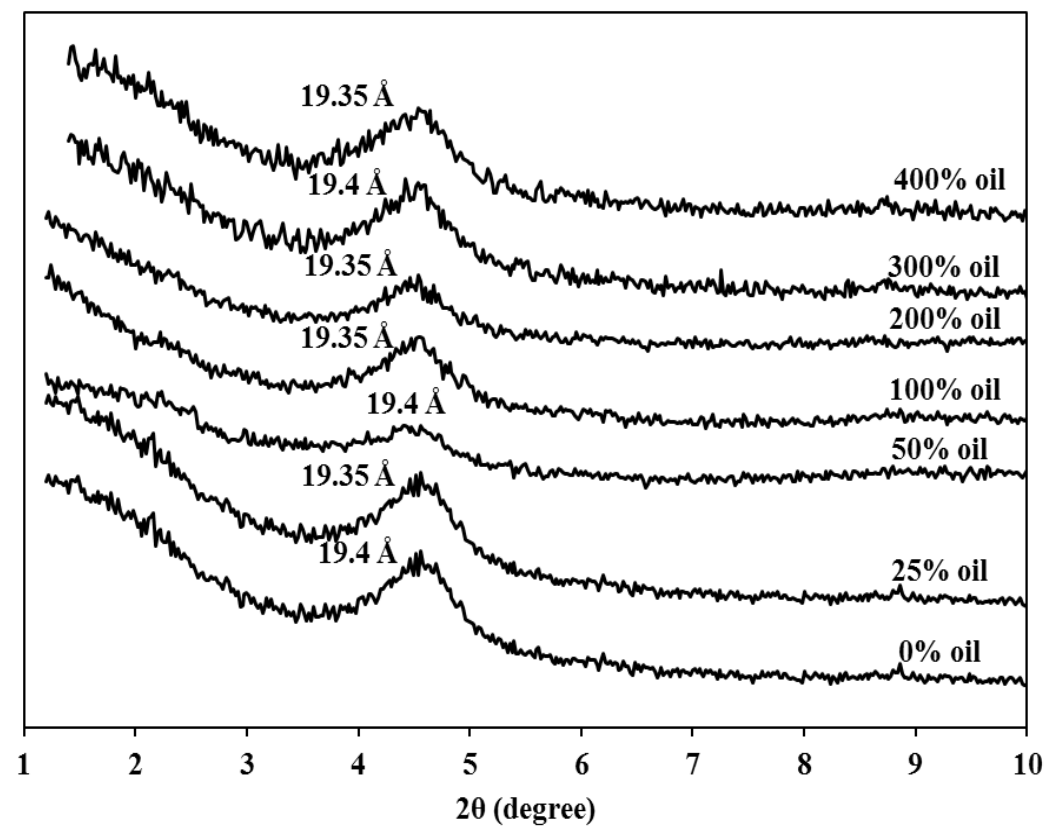

(c) 


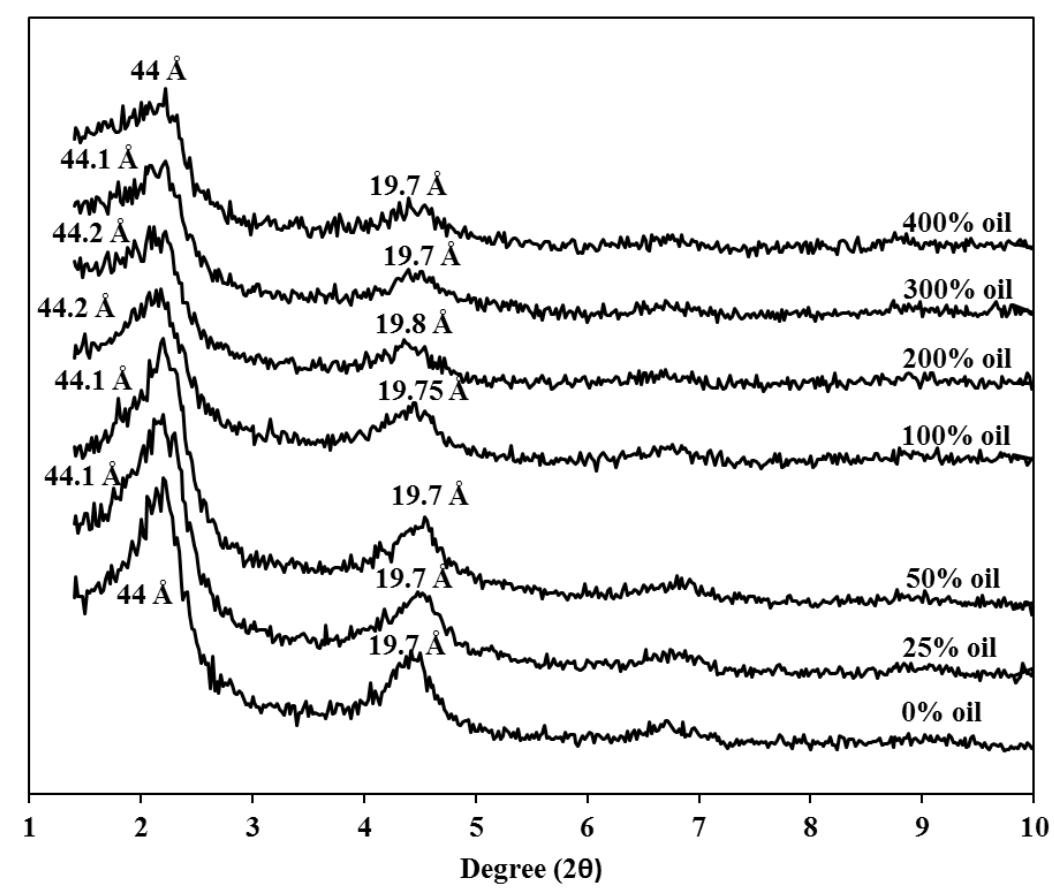

(d)

Figure 4-5. XRD patterns of (a) PM199 and (b) HDTMA-MMT (0.5 CEC) (c) HDTMA-MMT (1.0 CEC) and (d) HDTMA-MMT (2.0 CEC) with various concentration of sorbed diesel oil 


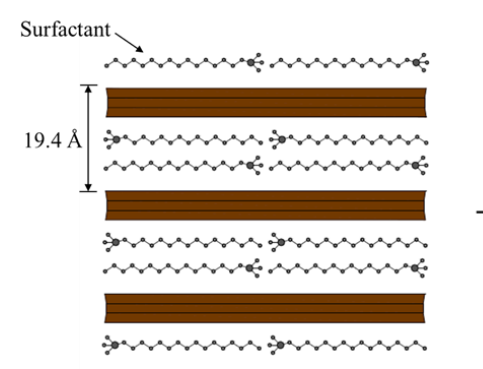

HDTMA-MTT (1.0 CEC) microstructure

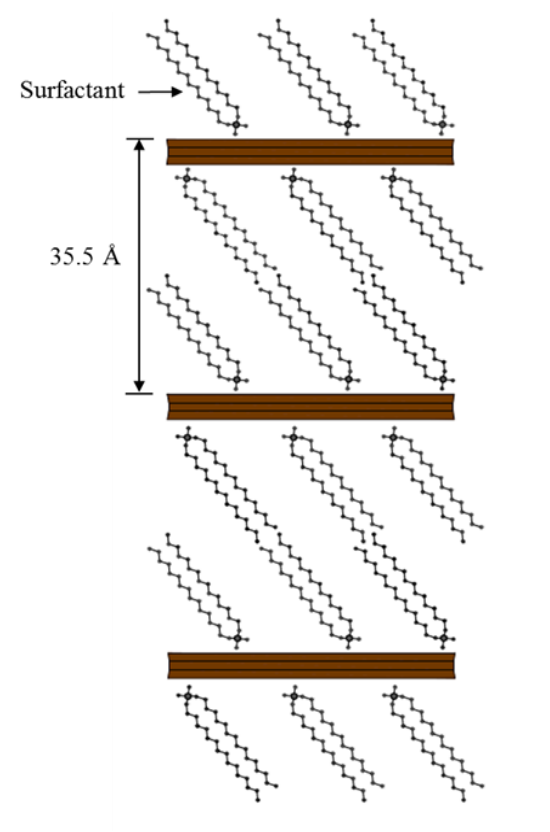

PM199 microstructure

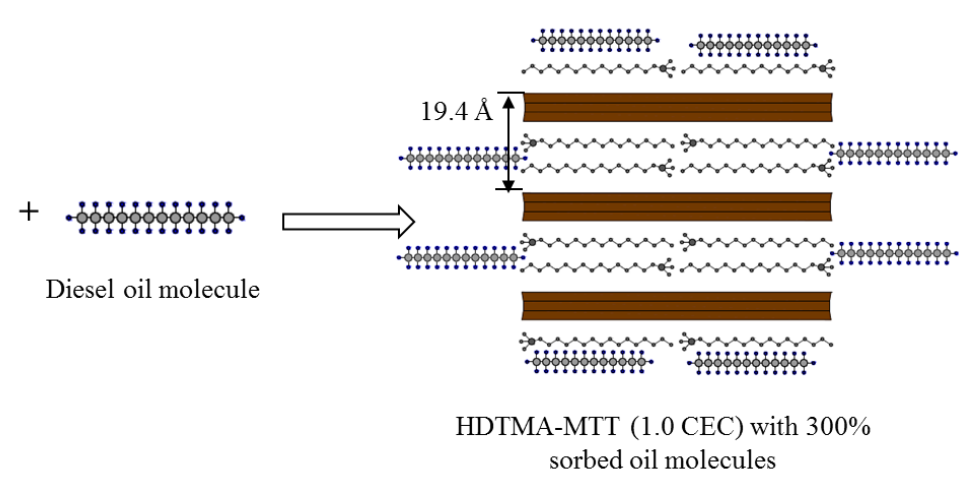

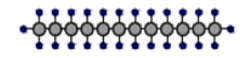

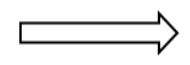

Diesel oil molecule

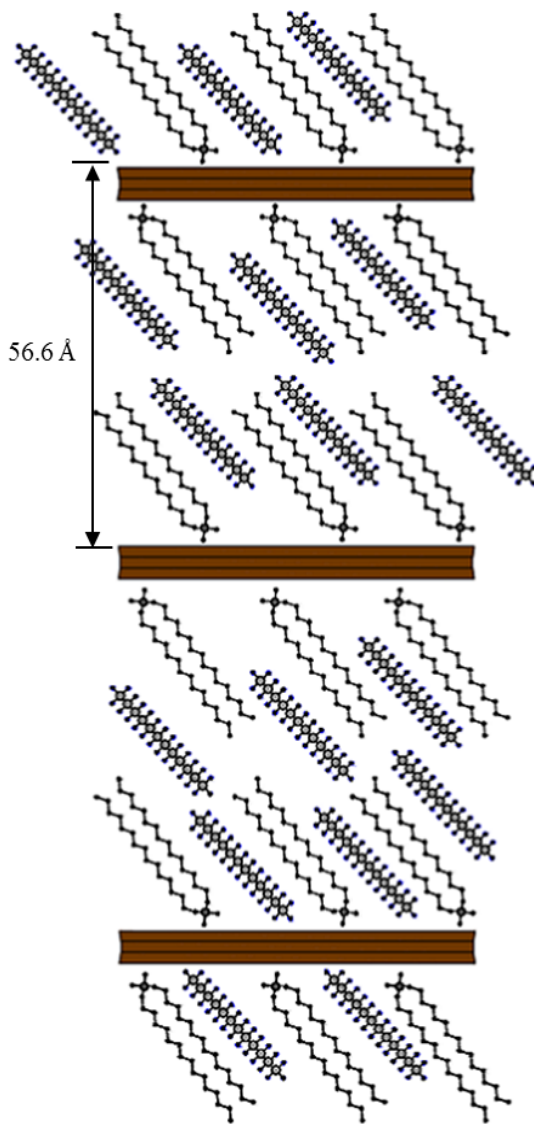

PM199 with $300 \%$ sorbed oil molecules

(a) 


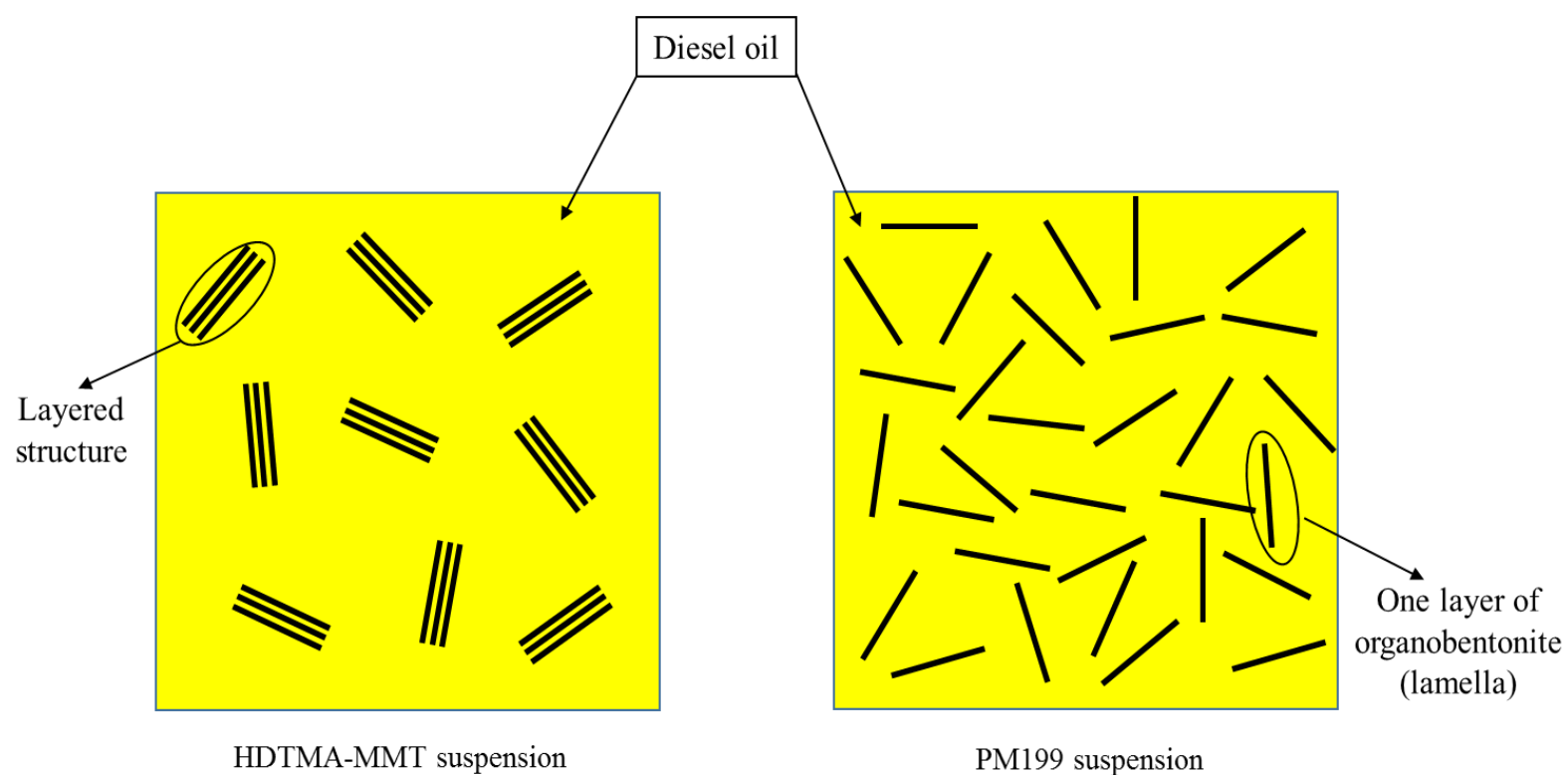

(b)

Figure 4-6. (a) Microstructure of the organobentonites (HDTMA-MMT(1.0 CEC) and PM199) before and after sorption of diesel oil (b) dispersion of two organoclays in oil medium 
Table 4-2. Summary of previous studies on organobentonite/oil-based drilling fluids

\begin{tabular}{|c|c|c|c|c|}
\hline Source & Type of surfactant & Type of base clay & Type of oil & Exfoliation (yes/no) \\
\hline (Zhuang et al. 2016) & Cetyl trimethyl ammonium bromide (CTAB) & Montmorillonite & Diesel oil & Yes \\
\hline \multirow{2}{*}{ (Hermoso et al. 2014) } & dimethyl-dihydrogenated tallow (2M2TA) & \multirow{2}{*}{ Bentonite } & \multirow{2}{*}{ Mineral oil } & \multirow{2}{*}{ yes } \\
\hline & dimethyl- benzyl hydrogenated tallow (2MBHT) & & & \\
\hline \multirow{4}{*}{ (Silva et al. 2014) } & Ultramine 20 (TA20) & Grey clay & \multirow{4}{*}{$\begin{array}{c}\text { Diesel oil } \\
\text { Kerosene } \\
\text { Varsol } \\
\text { Soybean oil }\end{array}$} & \multirow{4}{*}{$\begin{array}{l}\text { Data not shown } \\
\text { (They measured the } \\
\text { swelling potential of } \\
\text { the organoclays) }\end{array}$} \\
\hline & $100 \%$ Active ethoxylated amine TA20 & Light clay & & \\
\hline & Ultramine 50 (TA50) & Dark green clay & & \\
\hline & $100 \%$ Active ethoxylated amine TA50 & bentonite & & \\
\hline \multirow{4}{*}{ (Zhuang et al. 2017) } & lauryl trimethyl ammoniumchloride (C12) & \multirow{4}{*}{ Montmorillonite } & \multirow{4}{*}{ White oil } & No \\
\hline & $\begin{array}{l}\text { octadecyl trimethyl ammonium } \\
\text { chloride (C18-A), }\end{array}$ & & & Yes \\
\hline & $\begin{array}{l}\text { N,N-dimethyl-Noctadecyl } \\
\text { chloride }(\mathrm{C} 18-\mathrm{B})\end{array}$ & & & Yes \\
\hline & $\begin{array}{l}\text { Dimethyl dioctadecyl ammonium chloride } \\
\text { (DC18) }\end{array}$ & & & Yes \\
\hline \multirow[t]{2}{*}{ Our study } & hexadecyltrimethylammonium (HDTMA) & $\begin{array}{c}\text { Calcium } \\
\text { montmorillonite }\end{array}$ & \multirow[t]{2}{*}{ Diesel soil } & No \\
\hline & bis(hydrogenated tallow alkyl)dimethyl ammonium (PM199) & Na-bentonite & & Yes \\
\hline
\end{tabular}




\subsubsection{Gel volume (swelling volume)}

The gel volume values indicated the ability of gel formation and gel stability of organobentonite/oil. The results of gel volume (swelling volume) of PM199 and HDTMAMMT(1.0 CEC) as a function of organobentonite content are shown in Figure 4-7, (a). It can be observed that the gel volume values of both organobentonites increased with the increase of organobentonite content (1-5\%). At each concentration, PM199 exhibited higher swelling capacity in diesel oil compared to the swelling value of HDTMA-MMT. For example, at 5\% concentration of organobentonite, PM199 showed the swelling value of $52 \mathrm{~mL}$, while HDTMA-MMT demonstrated the swelling value of $17 \mathrm{~mL}$. It is important to mention that the swelling capacity of organobentonites in organic solvents was governed by the compatibility between organobentonite and organic solvents. In summary, the PM199 with the highest basal spacing would be the most compatible with diesel oil. In this scenario, a double long alkyl chain surfactant within the PM199 interlayer galleries led to better gel formation.

To clarify the effect of surfactant loading on gel formation, the gel volume of $5 \%$ HDTMA-MMT with different surfactant loading in diesel oil is illustrated in Figure 4-7, (b). The gel volume values of HDTMA-MMT at surfactant loading of $0.5,1$, and 2 CEC were 12, 17, and $25 \mathrm{~mL}$ respectively. By increasing the surfactant loading, the hydrophobicity surface area of organobentonite increased, which resulted in more sorption

of oil onto the surface of organobentonite. The surface hydrophobicity of HDTMA-MMT species varies in the order of 2.0 CEC > 1.0 CEC > 0.5 CEC (refer to Table 4-1). 
Accordingly, the gel volume/swelling ability of HDTMA-MMT increased as a result of increasing the surfactant loading.

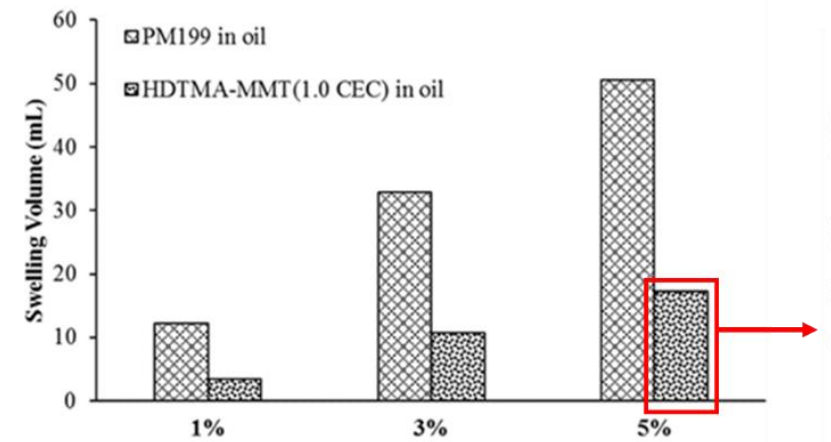

(a)

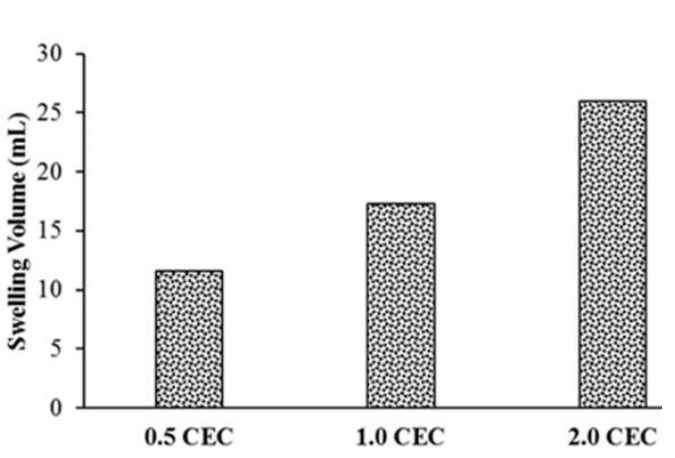

(b)

Figure 4-7. (a) Gel volume of organobentonites as a function of organobentonite concentration (b) gel volume of 5\% HDTMA-MMT as a function of surfactant

\section{loading}

The visual method was employed to analyze the dispersion of the 5\% organobentonites particles (PM199 and HDTMA-MMT(1.0CEC)) in the diesel oil and stability of the prepared organobentonites suspensions within 48 hours, which are depicted in Figure 4-8. The obtained results suggested that both organobentonites could easily disperse in the diesel oil with good uniformity right after the mixing process $(0 \mathrm{~min})$. It was observed that the HDTMA-MMT particles settled down faster than the PM199 particles due to their low interaction with oil molecules. The PM199, with a lower particle density and a higher degree of hydrophobicity had a higher stability in the diesel oil. It is important to mention that the 5\% PM199 suspension created a gel formation, while the 5\% HDTMA-MMT remained in the liquid phase. Overall, it can be derived that the gel volume 
of organobentonite suspension and dispersibility of organobentonite particles were greatly influenced by the surfactant type and basal spacing in accord with the XRD results.

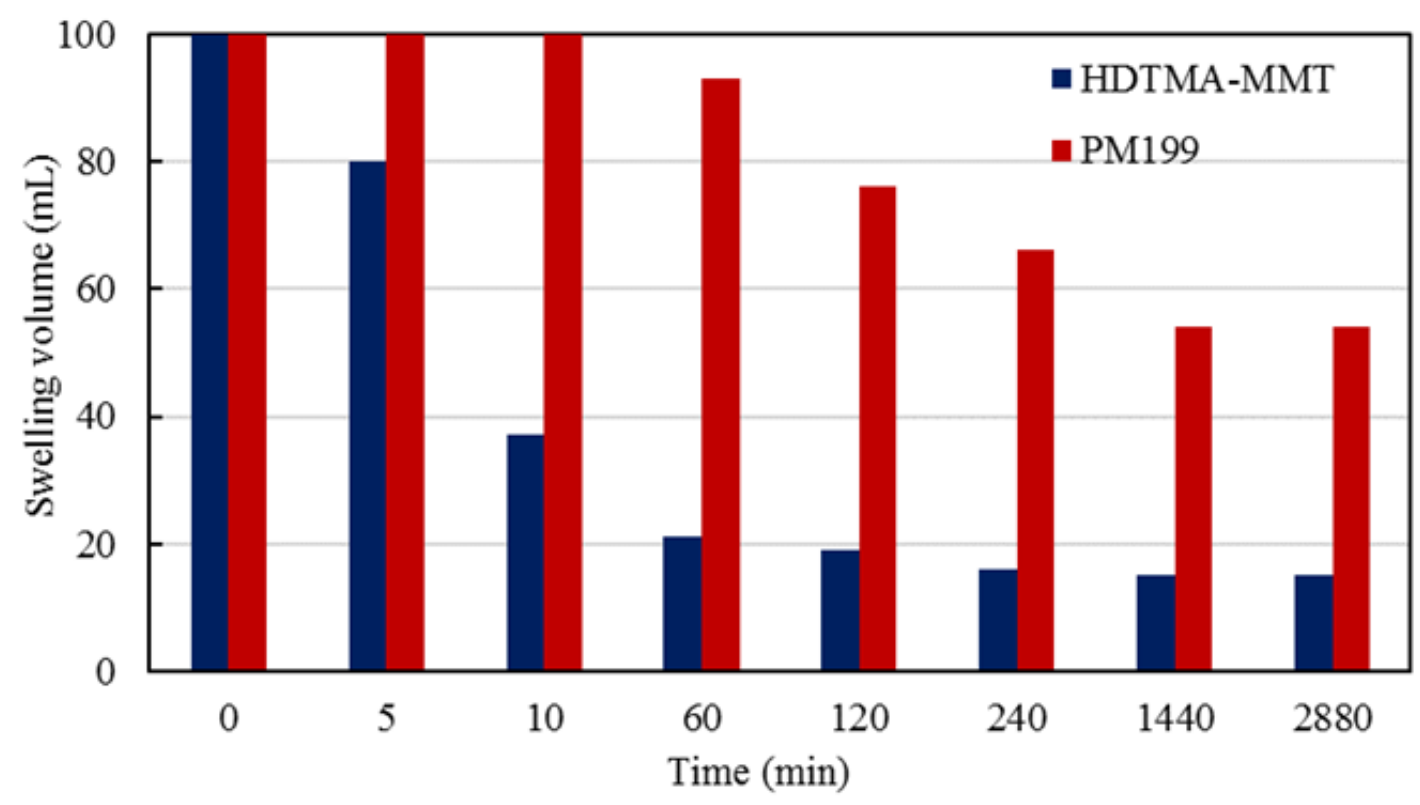

Figure 4-8. Gel volume of 5\% HDTMA-MMT (1 CEC) and PM199 suspensions within 48 hours

\subsubsection{Viscous flow measurement}

Viscous flow behaviors (shear stress vs. shear rate and viscosity vs. shear rate) of the oil-based drilling fluids formulated with PM199 and HDTMA-MMT(1.0 CEC) as a function of organobentonite concentration are graphically presented in Figures 4-9 and 410, respectively. The PM199 suspension at different concentrations (1-5\%) showed a nonNewtonian flow types. The HDTMA-MMT suspension at $1 \%$ concentration displayed a Newtonian flow type; while at higher concentrations (3-5\%), it exhibited non-Newtonian behavior. It was observed that PM199 suspension at any organobentonite concentration (15\%) and HDTMA-MMT suspension at high organobentonite concentrations (3-5\%) 
display a shear thinning behavior. In rheology, the shear thinning behavior is the nonNewtonian behavior of fluids whose viscosity decreases with increasing shear strain. Note that the shear thinning behavior is more apparent as organobentonite concentration increases in the organobentonite suspension matrix.

As it is shown in the Figures 4-9 and 4-10, Bingham's model fits the viscous flow behavior of organobentonite suspension at various organobentonite concentrations (1-5\%) fairly well. The results of Bingham's model parameters for two organobentonite suspensions at different concentrations are listed in Table 4-3. The viscosity of organobentonite suspension increased with increasing organobentonite concentration for both organobentonites, and remarkably for the PM199 suspensions. Typically, flow behavior of organobentonite suspensions is related to the interaction between the cationic surfactant of organobentonite (organophilic ions) and the oil molecules (solvent). Moreover, the viscous flow behavior of organobentonite suspensions is positively related to the based oil and the volume fraction of bentonite in the dispersed system. It is important to mention that any physical and/or chemical interaction between organobentonite molecules and the based oil determined the rheological behavior of the suspension.

The yield point is the main parameter of the Bingham plastic model. Typically, yield point value is used to evaluate the capability of drilling fluid to lift cuttings out of wells during the drilling process. The PM199 suspensions present higher yielding points than HDTMA-MMT suspensions at any organobentonite concentration. The results suggest that the PM199 microstructure has a strong structural network and the platelets of PM199 are somehow strongly attached to the oil molecules. This phenomenon can be related to the high swelling capacity of PM199, which is developed by the interaction 
between the cationic surfactant within the organobentonite interlayers and the diesel oil molecules. However, the HDTMA-MMT at the concentration of 1-5\% showed very low yield stress, indicating that no or very little interaction occurred between the HDTMA surfactant and oil molecules. In other words, the low yield stress of the HDTMA-MMT suspensions indicates less connected formations (aggregated), resulting in easier orientation in the dispersed system.

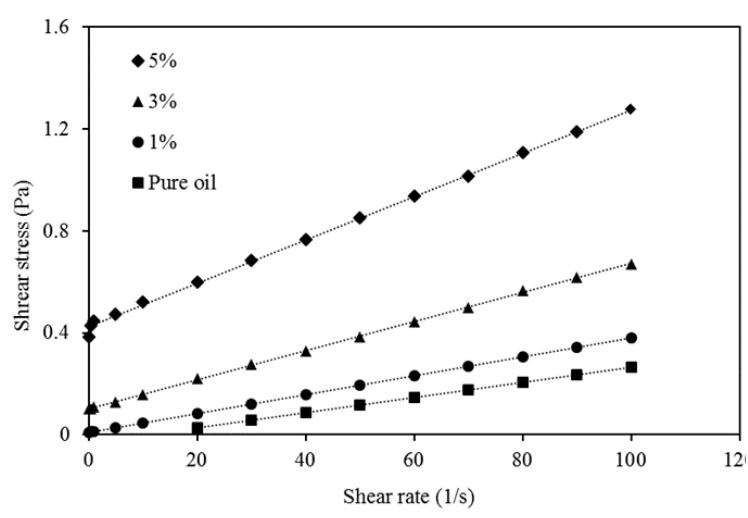

(a)

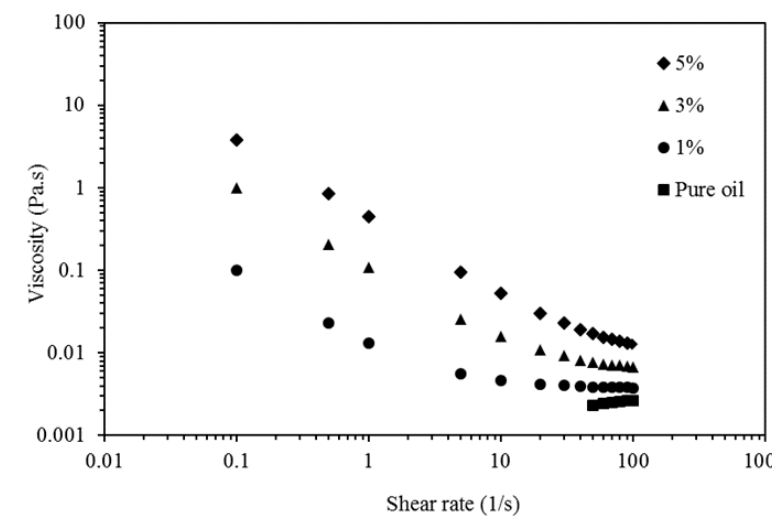

(b)

Figure 4-9. (a) shear stress versus shear rate (b) viscosity versus shear rate of PM199 suspension as a function of PM199 concentration 


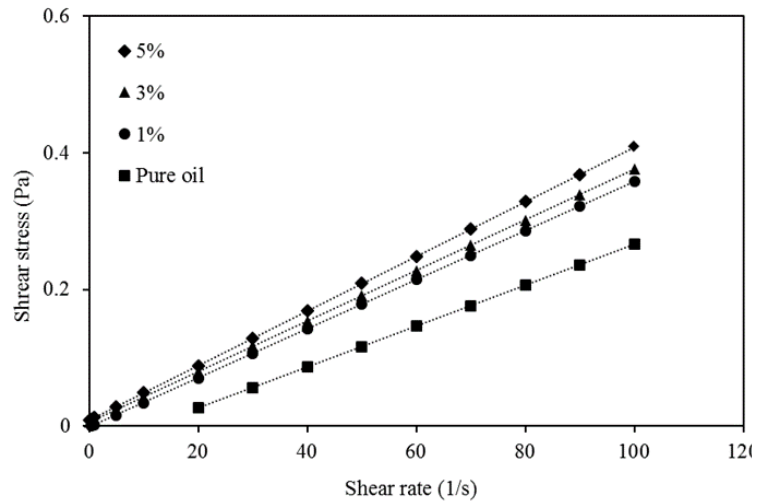

(a)

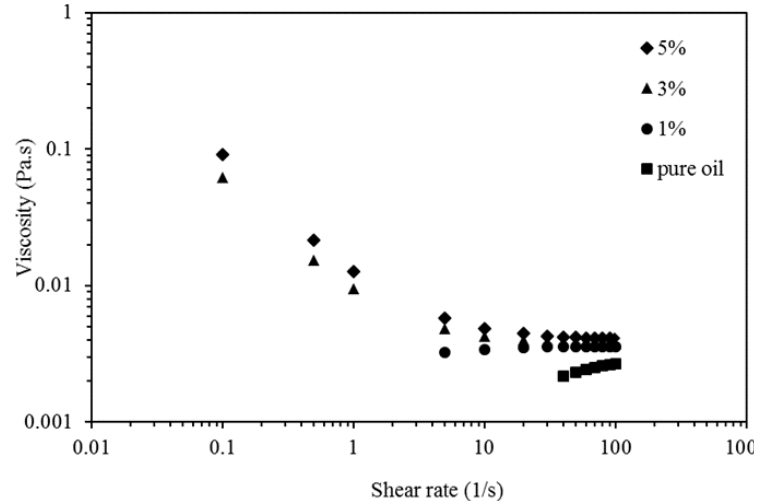

(b)

Figure 4-10. (a) shear stress versus shear rate (b) viscosity versus shear rate of HDTMA-MMT (1.0 CEC) suspension as a function of HDTMA-MMT concentration

Table 4-3. Bingham's parameters for PM199 and HDTMA-MMT(1.0 CEC) suspensions as a function of the organobentonites concentrations

\begin{tabular}{cccc}
\hline & $\boldsymbol{\tau}_{\mathbf{e}}(\mathbf{P a})$ & $\boldsymbol{\eta}_{\mathbf{p}}(\mathbf{P a . s})$ & $\boldsymbol{\eta}_{\mathbf{8 0}}(\mathbf{P a . s})$ \\
\hline Diesel oil & 0 & 0.003 & 0.00339 \\
\hline \multicolumn{4}{c}{ PM199 } \\
$\mathbf{1 \%}$ & 0.0096 & 0.0037 & 0.0037 \\
$\mathbf{3 \%}$ & 0.1001 & 0.0057 & 0.0071 \\
$\mathbf{5 \%}$ & 0.4312 & 0.0084 & 0.014 \\
$\mathbf{1 0 \%}$ & 4.706 & 0.0125 & 0.071 \\
\hline \multicolumn{4}{c}{ HDTMA-MMT } \\
$\mathbf{1 \%}$ & 0 & 0.0036 & 0.00321 \\
$\mathbf{3 \%}$ & 0.0058 & 0.0037 & 0.00412 \\
$\mathbf{5 \%}$ & 0.0087 & 0.004 & 0.00454 \\
$\mathbf{1 0 \%}$ & 0.0336 & 0.0065 & 0.00646 \\
\hline
\end{tabular}

System behavior prediction, particularly in scientific works, leads to an informative decision-making strategy for future studies. The behavior prediction of oil-based drilling fluids as a function of organobentonite can provide valuable information for the engineers who deal with drilling operations. A polynomial curve fitting was employed to fit the 
curves of the viscosity of two organobentonites suspensions (PM199 and HDTMA-MMT) at different concentrations (Figure 4-11). Two unique equations were derived to predict the viscosity of the two organobentonite suspensions as a function of organobentonite concentrations. According to the calculated square root errors $\left(\mathrm{R}^{2}>92 \%\right)$, the two models can be considered reliable models to predict the viscosity of the organobentonite/oil drilling fluids.

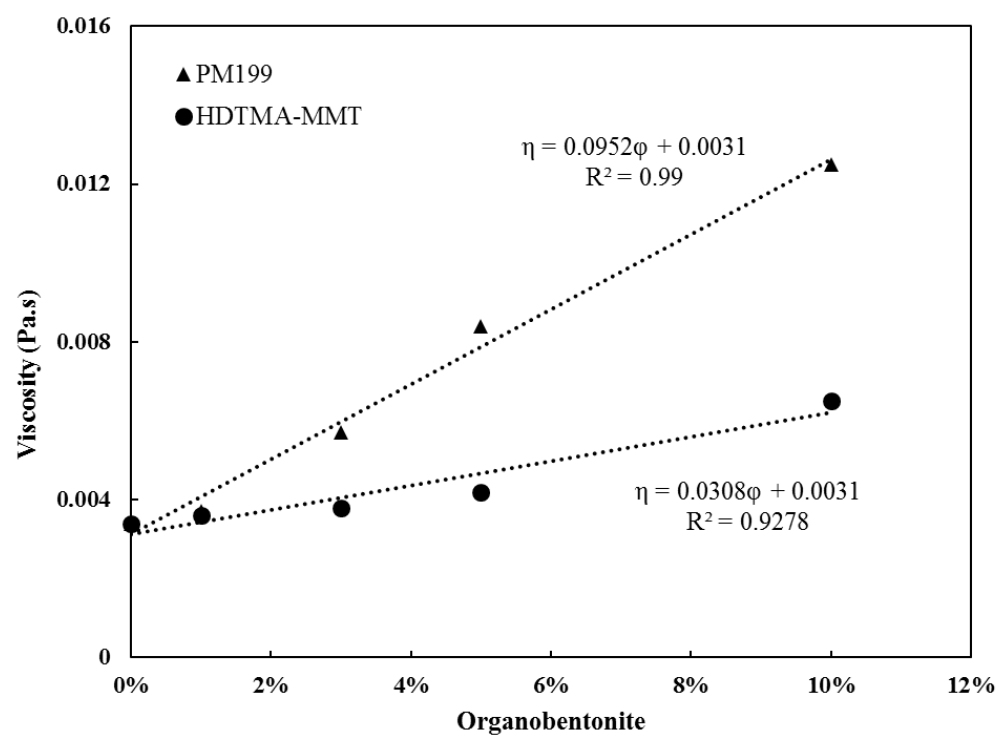

Figure 4-11. The predicted viscosity of PM199 and HDTMA-MMT(1.0 CEC) as a function of organobentonite percentage

The rheological behavior of water-based drilling fluid with Na-bentonite additive was studied to compare the results with oil based drilling fluids. Figure 4-12 shows the shear stress versus shear rate and viscosity versus shear rate relationships for Na-bentonite suspensions at different concentrations ( $1-5 \%$ by weight). The data from the experimental tests are fitted to the Bingham model with correlation coefficients between 0.95 to 0.99 are 
the results are presented in Table 4-4. Bingham's parameters for Na-bentonite suspensions as a function of Na-bentonite concentrations.

It was observed that an increase in the Na-bentonite concentration in water, as would be expected, increased the viscosity of Na-bentonite suspension. Generally, the bentonite concentration will significantly increase all rheological properties (i.e. viscosity and yield stress). It is worth mentioning that the bentonite suspensions tested here exhibited both Newtonian and non-Newtonian behaviors at low and high solid concentration, respectively. Na-bentonite suspension at 3\% concentration and below showed Newtonian behavior without yield stress. However, significant increase in yield stress and viscosity was observed when the solid concentration increase above $5 \%$ bentonite concentration. Also, it is important to mention that the Na-bentonite suspension showed lower viscosity compared to PM199 suspension at 5\% solid concentration or lower. However, at $10 \%$ solid concentration, Na-bentonite suspension showed higher viscosity and yield stress than PM199 suspension (Refer to Tables 4-3 and 4-4).

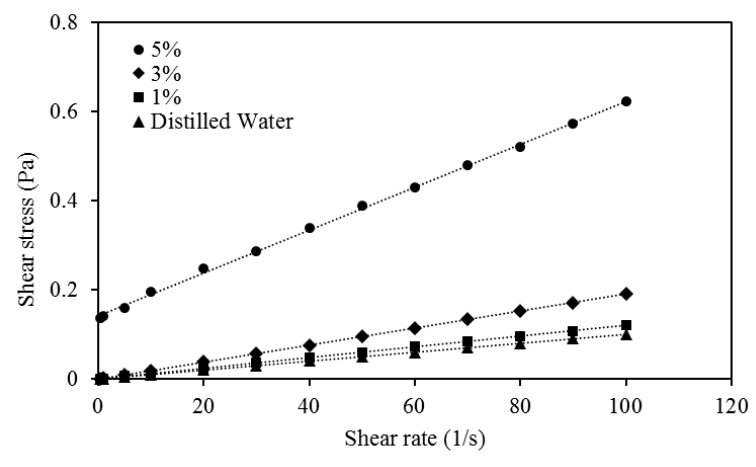

(a)

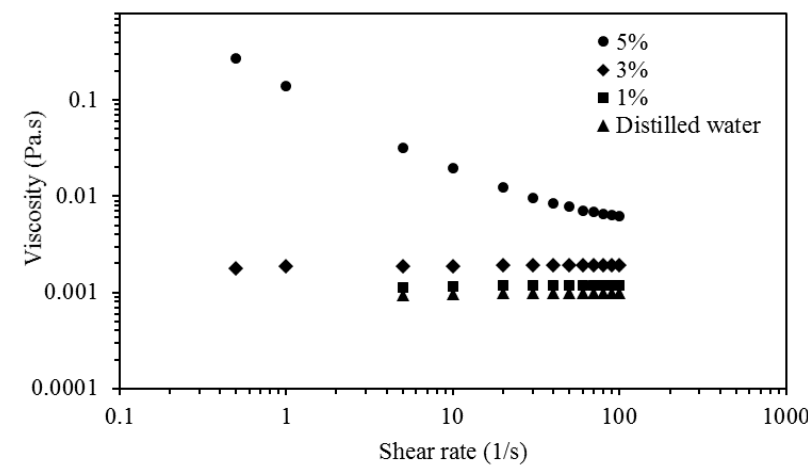

(b)

Figure 4-12. (a) shear stress versus shear rate (b) viscosity versus shear rate of Nabentonite suspension as a function of $\mathrm{Na}$-bentonite concentration 
Table 4-4. Bingham's parameters for Na-bentonite suspensions as a function of Nabentonite concentrations

\begin{tabular}{cccc}
\hline $\begin{array}{c}\text { Solid } \\
\text { concentration }\end{array}$ & $\boldsymbol{\tau}_{\mathbf{e}}(\mathbf{P a})$ & $\boldsymbol{\eta}_{\mathbf{p}}($ Pa.s $)$ & $\boldsymbol{\eta}_{\mathbf{8 0}}$ (Pa.s) \\
\hline Distilled water & 0 & 0.001 & 0.00099 \\
$\mathbf{1 \%}$ & 0 & 0.0012 & 0.0011 \\
$\mathbf{3 \%}$ & 0 & 0.0019 & 0.0018 \\
$\mathbf{5 \%}$ & 0.14 & 0.0041 & 0.0065 \\
$\mathbf{1 0 \%}$ & 4.3 & 0.022 & 0.077 \\
\hline
\end{tabular}

The flow behaviors of HDTMA-MMT suspension as a function of surfactant loading are shown in Figure 4-13. The HDTMA-MMT suspension at different surfactant loadings conform exactly to Bingham's model, and the parameters of the Bingham model are listed in Table 4-5. The viscosity of the 5\% HDTMA-MMT suspension increased with the increase of the HDTMA surfactant loading organobentonite. To compare the viscosity of 5\% PM199 and 5\% HDTMA-MMT (2.0 CEC) suspensions: PM199 with smaller basal spacing (35.5 $\AA$ ) than that of HDTMA-MMT with $200 \%$ surfactant loading (44.1 $\AA$ ) led to a higher viscosity. Therefore, it can be concluded that the large surfactant loading, which results in large interlayer spacing, does not necessarily lead to a higher viscosity. 


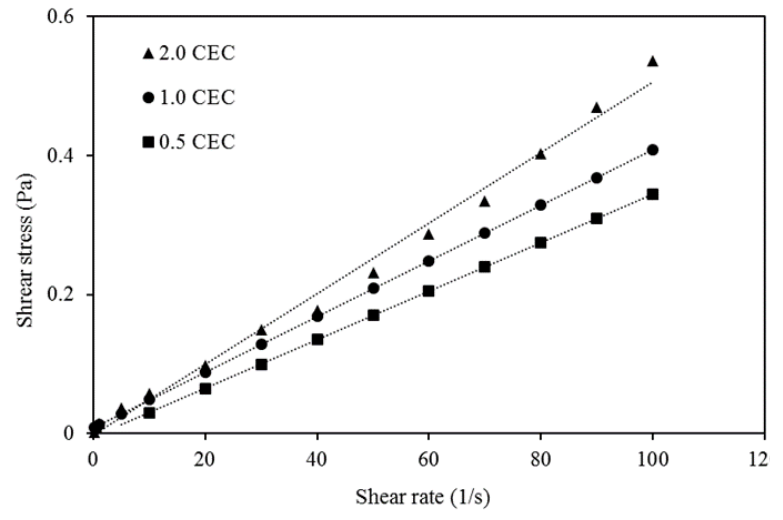

(a)

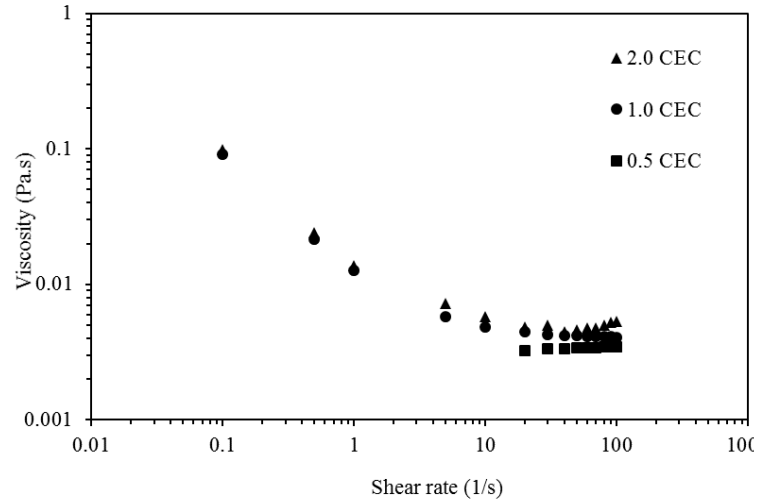

(b)

Figure 4-13. (a) shear stress versus shear rate (b) viscosity versus shear rate of $5 \%$ HDTMA-bentonite suspension as a function of CEC loading

Table 4-5. Bingham's parameters for 5\% HDTMA-MMT suspension as a function of CEC loading

\begin{tabular}{cccc}
\hline & $\boldsymbol{\tau}_{\mathrm{e}}(\mathbf{P a})$ & $\boldsymbol{\eta}_{\mathbf{p}}($ Pa.s $)$ & $\boldsymbol{\eta}_{80}($ Pa.s $)$ \\
\hline $\begin{array}{c}\text { HDTMA-MMT } \\
(\mathbf{0 . 5} \text { CEC) }\end{array}$ & 0 & 0.0035 & 0.00354 \\
$\begin{array}{c}\text { HDTMA-MMT } \\
(\mathbf{1 . 0} \text { CEC) }\end{array}$ & 0.0087 & 0.004 & 0.00454 \\
$\begin{array}{c}\text { HDTMA-MMT } \\
(\mathbf{2 . 0} \text { CEC) }\end{array}$ & 0.0096 & 0.0051 & 0.00545 \\
\hline
\end{tabular}

From the engineering point of view, the impact of temperature and pressure on the viscous flow behavior of oil-based drilling fluid is of key interest for the design of transport operations in the oil drilling industry (Caenn et al. 2011). The viscous flow behavior of 5\% PM199 suspension in diesel oil under different temperatures $\left(25\right.$ to $\left.150{ }^{\circ} \mathrm{C}\right)$ for the shear rate range of 0 to $100 \mathrm{~s}^{-1}$ is graphically illustrated in Figure 4-14.

Bingham's model fits the experimental data fairly well, particularly for the temperature of 25 to $120^{\circ} \mathrm{C}$, compared to that for the high temperature of $150{ }^{\circ} \mathrm{C}$. The 
results of Bingham's parameters are presented in Table 4-6. Overall, Bingham model predicts the viscosity of the organobentonite/oil drilling fluids fairly well. However, it cannot predict the yield stress well. The real yield stress point $\left(\tau_{\mathrm{o}}\right)$ of the organoclay suspension at different temperatures was lower than that of the Bingham model $\left(\tau_{\mathrm{e}}\right)$; therefore, the usefulness of the yield point based on the Bingham plastic model is limited. Overall, the organoclay suspension under different temperatures confirmed to Bingham model at high shear rate, while some deviation emerged at low shear rate. As can be seen from Table 3, the real yield stress of PM199 suspension decreased with increasing temperature up $120^{\circ} \mathrm{C}$, and then increased at the temperature of $150{ }^{\circ} \mathrm{C}$.

The viscosity of the PM199 suspension varied across different temperature ranges. The viscosity of 5\% PM199 suspension decreased when increasing the temperature from 25 to $60{ }^{\circ} \mathrm{C}$ followed by increasing the viscosity from 60 to $150{ }^{\circ} \mathrm{C}$. Two factors were expected to contribute such a trend: (1) the volume expansion of the diesel oil and (2) the sorbed amount of diesel oil by organobentonite. By increasing the temperature from 25 to $60{ }^{\circ} \mathrm{C}$, the expansion of the diesel oil was dominant, which led to overall decreasing in viscosity of the suspension. By increasing the temperature from 60 to $150 \mathrm{C}$, the interaction between organoclays and diesel oil increased which led to higher sorption of diesel oil by organobentonite and consequently increased the viscosity of the suspension. The latter phase was proved by previous studies. However, the first stage of this study that allocates to the temperature between 25 to $60{ }^{\circ} \mathrm{C}$ was not addressed by previous investigations. In summary, raising the temperature of the organobentonite suspension from $60{ }^{\circ} \mathrm{C}$ improved the exfoliation of organobentonite particles in the diesel oil. 


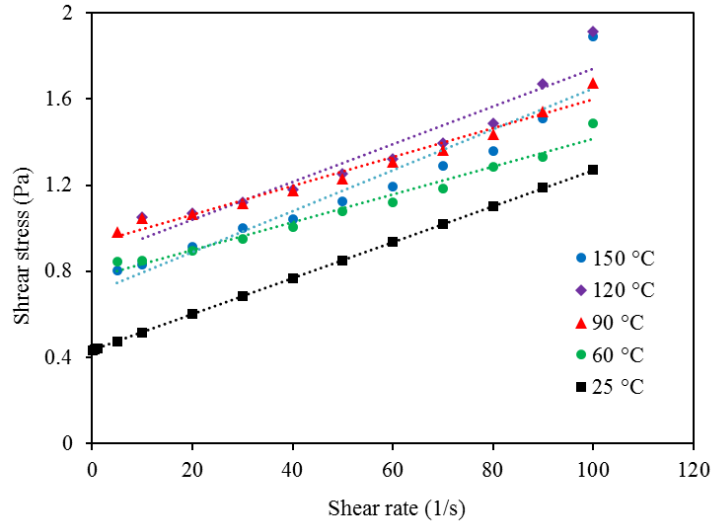

(a)

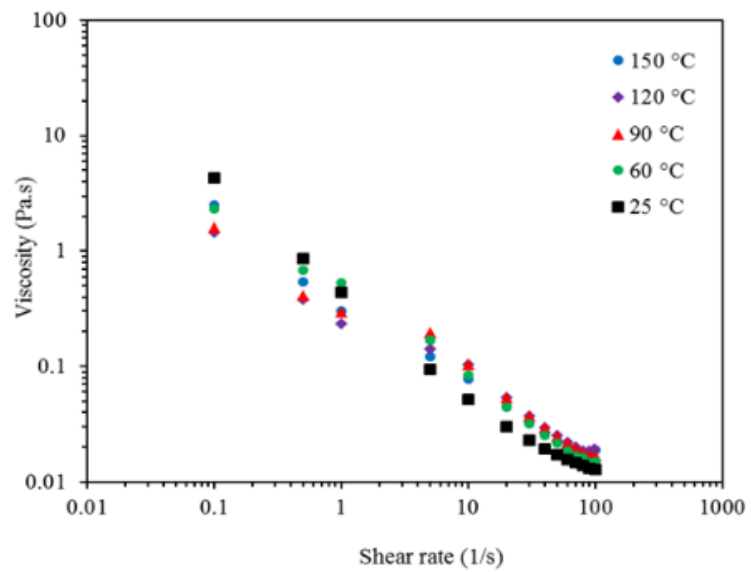

(b)

Figure 4-14. (a) shear stress versus shear rate (b) viscosity versus shear rate of $5 \%$ PM199 suspension as a function of temperature

Table 4-6. Bingham's parameters for $5 \%$ PM199 suspension as a function of temperature

\begin{tabular}{ccccc}
\hline $\begin{array}{c}\text { Temperature } \\
\left({ }^{\mathbf{0}} \mathbf{C}\right)\end{array}$ & $\boldsymbol{\tau}_{\mathbf{o}}(\mathbf{P a})$ & $\boldsymbol{\tau}_{\mathbf{e}}(\mathbf{P a})$ & $\mathbf{\eta}_{\mathbf{p}}(\mathbf{P a . s})$ & $\mathbf{\eta}_{\mathbf{8 0}}(\mathbf{P a . s})$ \\
\hline $\mathbf{2 5}$ & 0.248 & 0.4312 & 0.0084 & 0.0137 \\
$\mathbf{6 0}$ & 0.198 & 0.7676 & 0.0065 & 0.0160 \\
$\mathbf{9 0}$ & 0.153 & 0.929 & 0.0067 & 0.0186 \\
$\mathbf{1 2 0}$ & 0.133 & 0.8622 & 0.0088 & 0.0186 \\
$\mathbf{1 5 0}$ & 0.244 & 0.752 & 0.0106 & 0.0169 \\
\hline
\end{tabular}

The viscous flow curves of 5\% PM199 suspensions as a function of pressure (0200 bar) are shown in Figure 4-15. Figure 4-15 (a) also shows the fitting of Bingham's model to the experimental flow curves. The model fits the viscous flow behavior of the organobentonite in the range of selected pressure fairly well. The Bingham's parameters under different pressures are listed in Table 4-7. The yield stress of organobentonite suspension increased with pressure. The increased yield stress can facilitate the lifting 
cuttings out of the well. It is significant to mention that a drilling fluid with high yield stress can carry cutting better than that of similar fluid with lower yield stress; however, a much higher powered pump is needed to pump the drilling fluid with high yield stress into the well.

The viscosity of organobentonite suspension increased with pressure over the whole range of shear rates. The impact of pressure on the viscosity of organobentonite suspension might be related to the physical alternations that the pressure applies on both oil and organobentonite particles. As the other previous studies mentioned, the impact of pressure on the viscous flow behavior of organobentonite suspension in oil is primarily dependent on the base oil flow properties (Amani et al. 2012; Caenn et al. 2011; Hermoso et al. 2014). In summary, the pressure can significantly affect the viscous flow behavior of organobentonite suspensions.

The obtained results of this study suggest that PM199/oil dispersion containing 5\% organobentonite has fairly well-cutting carrying capacity under high pressure and temperature borehole condition. Although, the yield stress values of organobentonite suspension under severe conditions are high (see TablesTable 4-6 Table 4-7), no excessive powerful pump is required to pump the organobentonite suspension in the range of pressure and temperature tested (Caenn et al. 2011). Thus, PM199 organobentonite having high basal spacing and high hydrophobicity degree can be considered as a superior additive to prepare the oil-based drilling fluid, which can be used in many drilling applications in the studied range of temperature and pressure. 


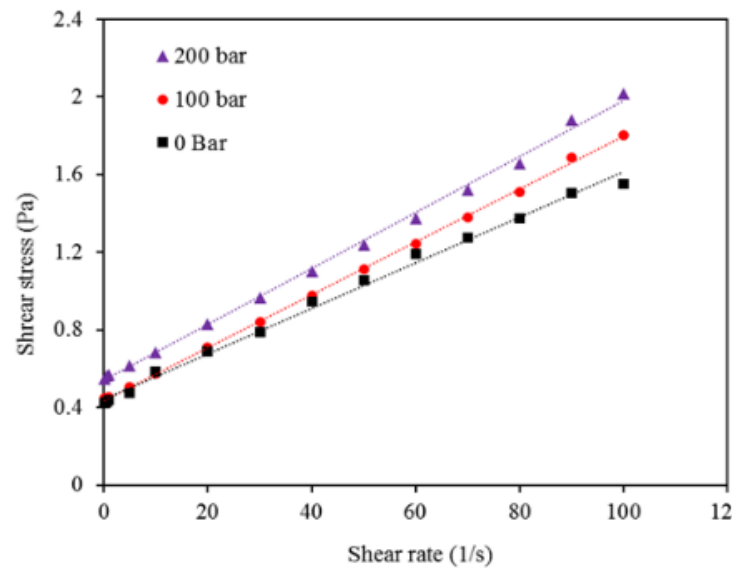

(a)

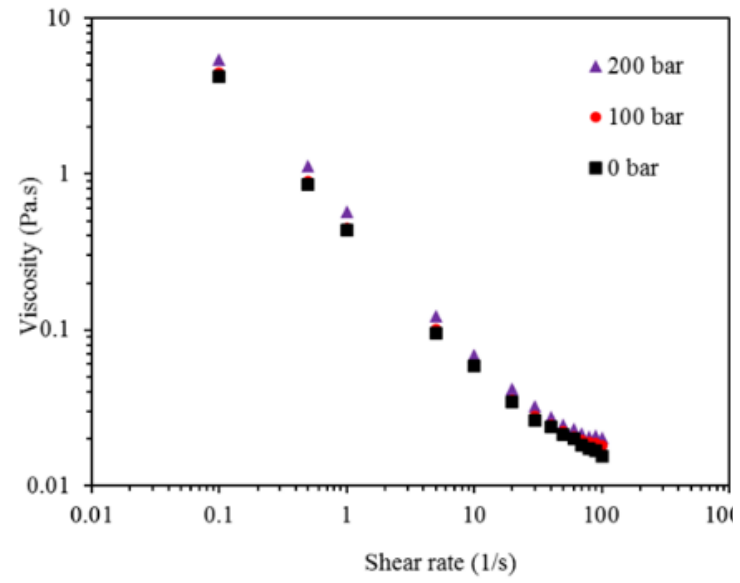

(b)

Figure 4-15. (a) shear stress versus shear rate (b) viscosity versus shear rate of $5 \%$ PM199 suspension as a function of pressure

Table 4-7. Bingham's parameters for 5\% PM199 suspension as a function of pressure

\begin{tabular}{ccccc}
\hline Pressure (bar) & $\boldsymbol{\tau}_{\mathbf{o}}(\mathbf{P a})$ & $\boldsymbol{\tau}_{\mathbf{e}}(\mathbf{P a})$ & $\boldsymbol{\eta}_{\mathbf{p}}(\mathbf{P a . s})$ & $\eta_{\mathbf{8 0}}(\mathbf{P a . s})$ \\
\hline $\mathbf{0}$ & 0.421 & 0.4419 & 0.0117 & 0.0172 \\
$\mathbf{1 0 0}$ & 0.448 & 0.4378 & 0.0136 & 0.019 \\
$\mathbf{2 0 0}$ & 0.548 & 0.5396 & 0.0144 & 0.021 \\
\hline
\end{tabular}




\subsection{Conclusions}

This study was conducted to examine the effect of the two different organoclays (HDTMA-MMT and PM199) on the rheology behavior of the oil-based drilling fluids using rheometer. XRD test was performed to relate the microstructure of the organoclays and organoclay suspensions with their rheology behaviors. Moreover, the impact of the solid concentration, temperature, and pressure on the viscosity of the organoclay suspension was studied by comparison. The following conclusions are drawn:

1- The XRD results showed that HDTMA-MMT with single chain surfactant showed smaller basal spacing (19.4 ̊̊) compared to PM199 with double chains surfactant $(35.5 \AA)$ at the 1.0 CEC surfactant loading. However, increasing the HDTMA cationic surfactant loading caused the expansion of the montmorillonite interlayer space $(2.04 \AA$ for $0.5 \mathrm{CEC}, 4.34 \AA$ for $1.0 \mathrm{CEC}$, and $4.64-29 \AA$ for $2.0 \mathrm{CEC})$. According to Lagaly (1988), the surfactants in HDTMA-MMT at low surfactant loading (0.5 and 1.0 CEC) formed a bilayers structure while it formed a paraffin type bilayers structure within the interlayers of organomontmorillonite at higher surfactant loading (2.0 CEC), which is similar to surfactant arrangement in PM199.

2- The XRD results showed that PM199 had a higher compatibility with diesel oil compared to HDTMA-MMT at different surfactant loading. The acquired results from XRD and swelling volume experiments suggest that the oil molecules can easily penetrate into the PM199 interlayers, resulting in swelling and consequently the exfoliation of PM199. However, HDTMA-MMT presented poor interaction and 
dispersion in diesel oil mixture, and no penetration of the oil molecules into interlayers was observed by XRD. This difference can be associated with the type of organic surfactant, resulting in the prevention of solvation of nonpolar oil molecules into the interlayer space; therefore, oil molecules preferably sorbed on the surface HDTMA-MMT.

3- The viscosity of the organoclays suspension increased by the addition of HDTMAMMT (1.0 CEC) and PM199 to the matrix of oil-based drilling fluid, and the increased viscosity was more noticeable for PM199. The viscous flow curves of the organobentonite dispersions showed that HDTMA-MMT dispersion acted like a Newtonian fluid, while PM199 dispersion exhibited a non-Newtonian fluid behavior which is more desirable for a drilling fluid.

4- The viscosity of 5\% PM199 suspension decreased by increasing the temperature from 25 to $60^{\circ} \mathrm{C}$ followed by increasing the viscosity from 60 to $150{ }^{\circ} \mathrm{C}$. There are two major factors affecting the viscosity of the suspension while the temperature increases: (1) the volume expansion of the diesel oil and (2) the sorption rate of diesel oil by organobentonite. By increasing the temperature from 25 to $60^{\circ} \mathrm{C}$, the expansion of the diesel oil was dominant which led to overall decreasing in viscosity of the suspension. However, by increasing the temperature from 60 to 150 ${ }^{\circ} \mathrm{C}$, the interaction between organoclays and diesel oil increased which led to higher sorption of diesel oil by organobentonite and consequently increasing the viscosity of the suspension.

5- The viscosity of 5\% PM199 suspension increases when the pressure increases over the whole range of shear rates. The effect of pressure on the viscosity of the 
organobentonite dispersion is probably attributed to the physical changes that pressure exerts to the dispersions, not chemical activity between organobentonite and oil molecules. 


\section{CEMENT-ORGANOBENTONITE ADMIXTURES FOR STABILIZATION/SOLIDIFICATION OF PAH- CONTAMINATED SOIL}

\subsection{Introduction}

Contaminations of underground water and soil by organic contaminants are critical environmental issues in most developing and industrialized countries (Sharma and Reddy 2004). Organic contaminants are introduced into the environment through accidental spills or improper disposals of chemicals, coal tars, pesticides and herbicides, chlorinated solvents, degreasers and petroleum products (Sharma and Lewis 1994; Ebrahimi et al. 2016; Mirbagheri et al. 2014). The most common types of organic contaminants found at contaminated sites are hydrocarbons such as gasoline components, chlorinated hydrocarbons, polycyclic aromatic hydrocarbons (PAH), polychlorinated biphenyls, and pesticides. Among the organic contaminates, PAHs are gaining much attention due to their toxicity and continue to be released into the environment (e.g. water and soil) through many human activities related to the combustion of petroleum products (Wilcke 2007). Moreover, they present naturally when they are released from forest fires and volcanoes.

The PAHs are hydrocarbons, organic compounds containing only carbon and hydrogen, which are composed of multiple aromatic rings. According to the United States 
Environmental Protection Agency (USEPA), many of the PAHs are carcinogens or suspected carcinogens (Gehle 2009). Among PAHs compounds, naphthalene and phenanthrene are the most frequently detected organic contaminants in groundwater and soil. In recent studies, it was observed that naphthalene and phenanthrene are produced biologically or generated from the combustion of fossil fuels, in addition to their presence in spills of unburnt petroleum (Aislabie et al. 1999; Becker et al. 2006; Wilcke 2007). The biological production of naphthalene and phenanthrene is related to their release by vegetation fires or volcanic exhalations. The PAHs are persistent and strongly sorbed into soils and sediments thus polluting them. Since the PAHs especially naphthalene and phenanthrene pose serious health problems to humans, remediation of PAH contaminated soils is a critical task for environmental engineers.

Engineers have employed several physical, chemical and biological technolgies as well as the combination of these technologies for several decades to remediate organiccontaminated soils. The soil remediation technologies can be implemented either in-situ or ex-situ. In-situ remediation technologies treat the contaminated soils in place. However, ex-situ remediation technologies involve the excavation of contaminated soil from the site; the treatment can occur on-site, or the contaminated soils can be transported to another location for treatment. Various soil remediation technologies such as soil vapor extraction, selective ion exchange, stabilization/solidification (S/S), thermal desorption, electrokinetic remediation, and bio-remediation can be employed to treat organic contaminated soil (Sharma and Reddy 2004). Among the mentioned remediation technologies, the stabilization/solidification $(\mathrm{S} / \mathrm{S})$ technology has been proven to be an effective and less 
expensive technology to remediate the organic-contaminated soils (Belarbi and Al-Malack 2010; Means et al. 1995; Paria and Yuet 2006; Yilmaz et al. 2003).

Through S/S process, the contaminants are entirely or partially bound to the binder agents using chemical and physical mechanisms, such as adsorption, absorption, chemisorption, precipitation, ion exchange, surface complexation, and microencapsulation. Typically, the stabilization technique refers to a chemical process that essentially converts the contaminants into a less soluble, mobile, or/and toxic form. The solidification technique is a physical process that encapsulates the waste or contaminated soil in a monolithic solid of high structural integrity. Solidification alters the physical properties of contaminated soils. A few examples of the desired alternations are an increase in compressive strength, decrease in hydraulic conductivity, and encapsulation of hazardous constituents. Therefore, $\mathrm{S} / \mathrm{S}$ process refers to both chemically binding and physically trapping the contaminants in soils. The $\mathrm{S} / \mathrm{S}$ technique is typically implemented in place by the injecting or mixing stabilizing/solidifying agents into contaminated soil to immobilize and retain the contaminants and to prevent them from leaching into groundwater.

The degree of efficiency of S/S treatment involves the measurement of physical, engineering and chemical properties of the stabilized/solidified contaminated soils. Typically, the compressive strength test, permeability test, and the Toxicity Characteristics Leaching Process (TCLP) test are the main tests that are performed to evaluate the effectiveness of the S/S technology. The S/S contaminated soil or waste must have adequate strength to be able to support loads of materials placed over them. Typically, for any given solidification and stabilization agent, the stronger the solidified product, the more effective the S/S process (LaGrega et al. 2010). The USEPA has specified the 
minimum required 28 days-unconfined compressive strength (UCS) of a S/S material to be $276 \mathrm{kPa}$ (40 psi) (USEPA 2011). However, in the UK, the minimum 28-days unconfined compressive strength is $690 \mathrm{kPa}$ (100 psi). The USEPA (2011) mentioned that the chosen site remedy must meet a maximum hydraulic conductivity of $10^{-6} \mathrm{~cm} / \mathrm{s}$. Moreover, USEPA specified a target of a $90 \%$ or greater reduction in leachability for the majority of the organic contaminates which includes PAHs, BTEX, and NAPL in organic-contaminated soils.

S/S process highly depends on the type of stabilization agent. Various agents/binders have been introduced in the S/S technology, and they can be divided into two groups: inorganic (cement, lime, fly ash, etc) and organic (polymer, organoclay, etc). Among the suggested agents/binders, several researchers found that the use of cement as a main binder is efficient for the stabilization of hazardous waste and in the remediation of organic or inorganic-contaminated soils. In cement-based S/S process, the contaminated soils are typically mixed with the ordinary Portland cement due to its low cost, relative availability, and well-known hardening reactions. When Portland cement is used, it results in a durable matrix of low permeability and can decrease the release of organic contaminants.

Although, the cement-based S/S process is effective in most cases to remediate contaminated soils and industrial wastes; this process alone is not a very effective technique to remediate the contaminated soils or wastes including a high percentage of organic materials (Karamalidis and Voudrias 2007). The organic compounds in contaminated soils or wastes have a retarding effect on the hydration reactions within cement particles and soils. In other words, the hydration reactions, which are responsible for hardening and 
setting the cementitious binder, may not function properly in the presence of organic contaminants. Therefore, the leaching of organic contaminants from the $\mathrm{S} / \mathrm{S}$ of contaminated soils or wastes treated with Portland cement may occur.

Karamalidis and Voudrias (2007) investigated the feasibility of the cement-based $\mathrm{S} / \mathrm{S}$ process to remediate an oil refinery sludge site. They observed that adding cement to oil refinery sludge comprising of PAHs and alkanes showed higher concentrations in leachates from batch extraction than before S/S process. Furthermore, Leonard and Stegemann (2010) studied the effectiveness of adding Portland cement and carbon fly ash as binders for the improvement of the leachability behavior of petroleum drill cutting. They found that by adding cement alone into samples, some hydrocarbons leached such as PAHs and 2-chloroaniline from the cement-based S/S petroleum drill cutting was increased. However, carbon fly ash addition significantly reduced the leaching hydrocarbon from the S/S products. Yilmaz et al. (2003) investigated the usefulness of Portland cement as a binding agent for $\mathrm{S} / \mathrm{S}$ of hazardous wastes containing toxic metals and organic contaminants. They observed that an effective application of S/S (high shear strength, low permeability and low leaching of organic contaminants) was achieved for most cases. However, they found that leachates from S/S soils contaminated with polychlorinated biphenyls (PCBs) have concentrations above the regulatory limits for the USEPA toxicity characteristic leaching procedure (TCLP). Overall, these studies observed that Portland cement alone is not efficient for the immobilization and stabilization of several common organics contaminants.

Many different types of natural or engineered materials such as carbon fly ash, organoclay, nanotube, and organo-zeolite, have been suggested as potential stabilizers for 
organic contaminated soil or petroleum wastes (Gentry et al. 2014; Hebatpuria et al. 1999; Leonard and Stegemann 2010; Li et al. 2015; Mohebbi et al. 2013). Among the suggested stabilizers, organoclays have been proven to be effective sorbents for organic pollutants(Gentry et al. 2014). Organoclays are synthesized by the ion exchange of natural inorganic interlayer cations (i.e., $\mathrm{Na}^{+}, \mathrm{K}^{+}, \mathrm{Ca}^{2+}$, and $\mathrm{Mg}^{2+}$ ) with certain organic cations such as quaternary ammonium cations (QACs) in the clay's structure. The interaction of an organic surfactant between the clay layers changes the surface properties from hydrophilic (organophobic) to hydrophobic (organophilic). Moreover, the modification of clay with organic molecules results in an increase in the interlayer spacing of clay microstructure and consequently creates new sorption sites (Park et al. 2011; Zhu et al. 2015). Due to their unique sorption capabilities, organoclays have been extensively used for a wide variety of environmental applications (Refer to Chapter 1). Particularly, organoclays become effective sorbents to remove or immobilize the organic pollutant from contaminated soil or water.

The effectiveness of organoclay combined with Portland cement in the stabilizing and solidifying of organic-contaminated soil has been investigated in a few studies. Gentry et al. (2014) evaluated the stabilization and solidification (S/S) treatment of the native sediments (organic-contaminated soils) from selected transects in the Gowanus canal against several constituents of concern, where naphthalene was identified as the key contaminate. They observed that by adding 5-10\% (by dry weight) of Portland cement paired with 1-4\% organoclay to the NAPL-contaminated soil, the unconfined compressive strength of all samples was greater than $345 \mathrm{kPa}(50 \mathrm{psi})$ and hydraulic conductivity was lower than $10^{-6} \mathrm{~cm} / \mathrm{s}$. Moreover, they found that leaching reductions for naphthalene (key 
contaminant) ranged from 89 to $93 \%$ for all mix designs compared to the untreated contaminated soil. In another study, Mohebbi et al. (2013) investigated the effects of the S/S technique on the remediation of cresol-contaminated soil. They used Portland cement (20 and $30 \%$ by dry weight) as a binder and organoclay (15 and $30 \%$ by dry weight) as a stabilizer. They observed that adding Portland cement in combination with modified bentonite to contaminated soil increased the 28-days compressive strength of S/S blocks to a range of 2.44 to $3.08 \mathrm{Mpa}$. Moreover, they stated that efficiency of S/S regarding leaching was about $70 \%$, which was obtained by adding $20 \%$ Portland cement and $30 \%$ organoclay. However, many studies were conducted to investigate the effectiveness of organoclay in removing organic pollutants from contaminated sites (e.g. soil and water). Limited information regarding the effectiveness of organoclay with a combination of Portland cement as S/S agents for stabilizing soils when contaminated with polycyclic aromatic hydrocarbons (PAH) is available. Thus, the fundamental understanding of the function of the organically modified clay as a binding agent of PAH-contaminated soils merits further examination.

The purpose of this chapter was to evaluate the applicability and effectiveness of the stabilization/solidification $(\mathrm{S} / \mathrm{S})$ remediation technology on PAH-contaminated soil. Moreover, the optimum amount of Portland cement and organoclay in immobilizing organic contaminants from contaminated soil has been investigated. Naphthalene and phenanthrene in solid and dissolved phases were selected as PAHs compounds to represent organic contaminants in the soil. Portland cement and organoclay (PM199) were used as solidifier and stabilizer agents for stabilizing and immobilizing naphthalene and phenanthrene in the contaminated soils. The following well-established laboratory tests 
including Unconfined Compressive Strength (UCS), permeability, and Toxicity Characteristics Leaching Procedure (TCLP) were conducted on the S/S contaminated soils. The obtained results proposed that stabilization/solidification is an effective technique for decreasing leaching of contaminated sites and gaining soil with higher strength. 


\subsection{Materials and methods}

\section{Materials}

Soils

The silty clay soil was combined with PAHs to produce the contaminated soil in the lab. Granular organoclay, PM199, was used as a stabilizer agent for contaminated soil. The properties of silty clay and PM199 are presented in Table 5-1.

Table 5-1. The physiochemical properties of the studied soils

\begin{tabular}{|c|c|c|c|}
\hline Properties & $\begin{array}{c}\text { Organobentonite } \\
(\text { PM199) }\end{array}$ & $\begin{array}{c}\text { Natural } \\
\text { Silty Clay }\end{array}$ & Methods \\
\hline Liquid limit (\%) & - & 25.9 & ASTM D4318 - 10 \\
\hline Plastic limit (\%) & - & 21.5 & ASTM D4318 - 10 \\
\hline Plasticity index (\%) & - & 4.4 & ASTM D4318 - 10 \\
\hline $\begin{array}{c}\text { Fraction passed through No. } \\
\text { 200 sieve (\%) }\end{array}$ & 32 & 87 & ASTM D6913 - 04 \\
\hline Specific gravity & 1.75 & 2.62 & ASTM D854 - 14 \\
\hline Specific Surface Area $\left(\mathrm{m}^{2} / \mathrm{g}\right)$ & 62 & 33.5 & Refer to Chapter 2 \\
\hline Total organic carbon $(\%)$ & 21.7 & $<1$ & Refer to Chapter 2 \\
\hline
\end{tabular}

\section{Cement}

Type I Portland cement was obtained from the CEMEX Company. The mean size of the powdered cement particles was $13 \mu \mathrm{m}$. The specific gravity and the specific surface area were 3.15 and $400.8 \mathrm{~m}^{2} / \mathrm{kg}$, respectively. The chemical composition of the Portland cement was listed in Table 5-2. 


\section{Table 5-2. Chemical composition of Portland cement}

\begin{tabular}{|c|c|}
\hline Compound & $(\%)$ \\
\hline $\mathrm{SiO}_{2}$ & 20.49 \\
\hline $\mathrm{Al}_{2} \mathrm{O}_{3}$ & 4.56 \\
\hline $\mathrm{Fe}_{2} \mathrm{O}_{3}$ & 2.82 \\
\hline $\mathrm{CaO}$ & 64.88 \\
\hline $\mathrm{MgO}$ & 2.57 \\
\hline $\mathrm{SO}_{3}$ & 3.17 \\
\hline $\mathrm{Na}_{2} \mathrm{O}$ & 0.16 \\
\hline $\mathrm{K}_{2} \mathrm{O}$ & 0.39 \\
\hline $\mathrm{Na}_{2} \mathrm{O}$ eq & 0.42 \\
\hline $\mathrm{LOI}$ & 1.20 \\
\hline
\end{tabular}

\section{Contaminants}

Two PAHs, naphthalene and phenanthrene were chosen because of their widespread presence in contaminated soil and non-aqueous phase liquids (NAPLs). Naphthalene is an organic compound with the chemical formula of $\mathrm{C}_{10} \mathrm{H}_{8}$. It is the simplest polycyclic aromatic hydrocarbon. Naphthalene can be found in a various range of products such as petroleum products, mothballs, solvents, dyes and wood preservatives, and can be released into the environmental systems. Phenanthrene is another type of $\mathrm{PAH}$, and it is composed of three fused benzene rings with a chemical formula of $\mathrm{C}_{14} \mathrm{H}_{10}$. Phenanthrene has been widely used in the synthesis of dyes, explosives and drugs. The EPA classifies naphthalene and phenanthrene as possibly carcinogenic to humans and animals. Naphthalene and phenanthrene are barley soluble in water, but they are soluble in most low-polarity organic solvents including acetic acid, toluene, ether, heptane, etc. 
Naphthalene and phenanthrene with a purity of $>97 \%$ were purchased from Fisher Scientific and Sigma-Aldrich Companies in crystal form, respectively. The physicochemical properties of naphthalene and phenanthrene are summarized in Table 5-3.

Table 5-3. Physicochemical properties of naphthalene and phenanthrene

\begin{tabular}{|c|c|c|}
\hline Property & Naphthalene & Phenanthrene \\
\hline Physical state & Solid & Solid \\
\hline Chemical formula & $\mathrm{C}_{10} \mathrm{H}_{8}$ & $\mathrm{C}_{14} \mathrm{H}_{10}$ \\
\hline $\begin{array}{c}\text { Molecular weight } \\
(\mathbf{g} / \mathbf{m o l})\end{array}$ & 128.17 & 178.23 \\
\hline Density $\left(\mathbf{g} / \mathbf{c m}^{\mathbf{3}}\right)$ & 1.025 & 1.18 \\
\hline $\begin{array}{c}\text { Solubility at } \mathbf{2 5} \\
{ }^{\circ} \mathbf{C} \\
(\mathbf{m g} / \mathbf{L})\end{array}$ & 31.6 & 1.6 \\
\hline
\end{tabular}

\section{Preparation of contaminated soil}

The target concentrations of naphthalene and phenanthrene in the soil was 2000 and $500 \mathrm{mg} / \mathrm{kg}$ (mass of contaminant/mass of dry soil), respectively. These concentrations were selected based on previous studies (Gentry et al. 2014; López-Vizcaíno et al. 2012; Park et al. 2007). Two groups of contaminated soil samples were prepared under different conditions.

For the first group, the required quantities of naphthalene and phenanthrene to produce the target concentrations were measured. Naphthalene and phenanthrene were completely dissolved in acetone in order to evenly spread out them in the silty clay soil. The solution was then mixed with the required amount of silty clay soil. The mixture was stirred and blended for 20 minutes, until evenly distributed. Afterwards, the mixture was maintained beneath a fume hood for 24 hours $\left(20 \pm 2{ }^{\circ} \mathrm{C}, 95 \%\right.$ humidity $)$. Since some 
portions of the contaminants might have volatilized along with the acetone, a sample of each mixture was taken to measure the initial concentration of naphthalene and phenanthrene in the soil.

For the second group, the required amount of naphthalene and phenanthrene was dissolved in $30 \mathrm{~mL}$ of methanol. Then the solution was introduced to $1 \mathrm{~kg}$ of natural silty clay, and the mixture was stirred for 20 minutes until the solution evenly distributed into the soil. Without any resting time, the contaminated soil was immediately used for the stabilization and solidification treatment.

\section{Stabilization and solidification (S/S) treatment of contaminated soil}

Organoclay as a stabilizer and cement as a solidifier were weighted at the desired amounts to stabilize and solidify the contaminated soil. The testing matrix for the first and second scenarios are presented in Table 5-4. It is important to mention that two control samples with no cement and organoclay were prepared for comparison. The ranges of organoclay and Portland cement amounts were selected based on well-known studies (Botta et al. 2004; Gentry et al. 2014; Mohebbi et al. 2013). Moreover, it is worth noting that adding too much organoclay into the contaminated soil may enhance the soil's stabilization, but it will increase the remediation costs significantly; therefore, finding the optimum amount of organoclay is a fundamental process in $\mathrm{S} / \mathrm{S}$ treatment of contaminated soil. Three soil specimens for each soil combination were prepared. 
Table 5-4. Testing matrix for stabilization and solidification for contaminated soil

(a) group I (b) group II

(a)

\begin{tabular}{|c|c|c|c|}
\hline Sample \# & cement/soil & organoclay/soil & $\begin{array}{c}\text { Mix } \\
\text { identification } \\
\end{array}$ \\
\hline 1 & \multirow{4}{*}{0.05} & 0 & $\mathrm{C}_{5} \mathrm{OC}_{0}$ \\
\hline 2 & & 0.02 & $\mathrm{C}_{5} \mathrm{OC}_{2}$ \\
\hline 3 & & 0.05 & $\mathrm{C}_{5} \mathrm{OC}_{5}$ \\
\hline 4 & & 0.1 & $\mathrm{C}_{5} \mathrm{OC}_{10}$ \\
\hline 5 & \multirow{4}{*}{0.1} & 0 & $\mathrm{C}_{10} \mathrm{OC}_{0}$ \\
\hline 6 & & 0.02 & $\mathrm{C}_{10} \mathrm{OC}_{2}$ \\
\hline 7 & & 0.05 & $\mathrm{C}_{10} \mathrm{OC}_{5}$ \\
\hline 8 & & 0.1 & $\mathrm{C}_{10} \mathrm{OC}_{10}$ \\
\hline 9 & 0 & 0 & control \\
\hline
\end{tabular}

(b)

\begin{tabular}{|c|c|c|c|}
\hline Sample \# & cement/soil & organoclay/soil & $\begin{array}{c}\text { Mix } \\
\text { identification }\end{array}$ \\
\hline $\mathbf{1}$ & \multirow{3}{*}{0.05} & 0 & $\mathrm{C}_{5} \mathrm{OC}_{0}$ \\
\cline { 3 - 4 } $\mathbf{2}$ & & 0.02 & $\mathrm{C}_{5} \mathrm{OC}_{2}$ \\
\hline \multirow{2nnn}{*}{$\mathbf{3}$} & & 0.05 & $\mathrm{C}_{5} \mathrm{OC}_{5}$ \\
\cline { 3 - 4 } & $\mathbf{4}$ & 0.1 & $\mathrm{C}_{5} \mathrm{OC}_{10}$ \\
\hline $\mathbf{5}$ & 0 & 0 & Control \\
\hline
\end{tabular}

For the first group of stabilized soils, the required amount of dried organoclay and cement were added to the naphthalene and phenanthrene contaminated soil (Figure 5-1). The mixture was homogenously mixed with a Hamilton mixer for 10 minutes prior to the 
addition of water. According to the optimum water content and workability, $15 \%$ water content was poured into the mixture. Later, the mixture was mixed for additional 10 minutes. For the second group of stabilized soils, the required amount of cement and organoclay was mixed with $15 \%$ water content to make slurry. Then the slurry was introduced to the contaminated soil and mixed for 10 minutes.

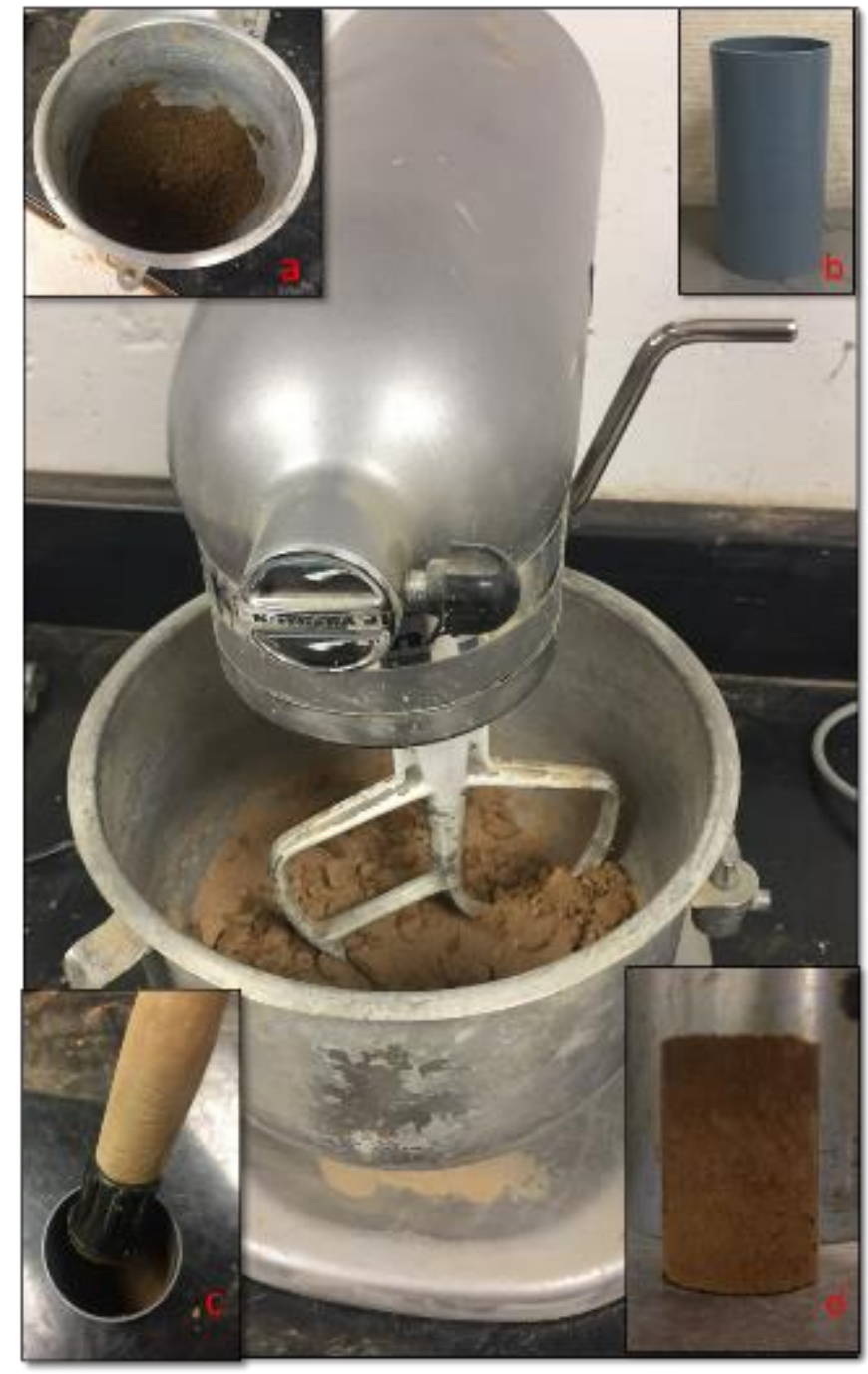

Figure 5-1. Procedure of making S/S specimen

Afterwards, the mixture was cast in three layers into a cylindrical mold with a height and diameter of 4 and 2 inches, respectively. Each layer was compacted by a plastic 
hammer to yield a well-packed mixture. The excess mixture was cleaned out to achieve a flat and smooth surface. Afterwards, the molds were sealed in the plastic bag to avoid any possible carbonation due to air exposure. Initially, the specimens were cured for 24 hours in a humid room. Afterwards, the specimens were gently removed from the molds and were again sealed in a plastic bag and placed in a humid room at a control condition (relative humidity of $95 \pm 2 \%$ and temperature of $20 \pm 2{ }^{\circ} \mathrm{C}$ ) for an additional 27 days curing before testing. Note that the $\mathrm{S} / \mathrm{S}$ treatment process for each soil combination was prepared in triplicate. Figure 5-2 shows the flow diagram of the S/S process used in the tests (group I and II).

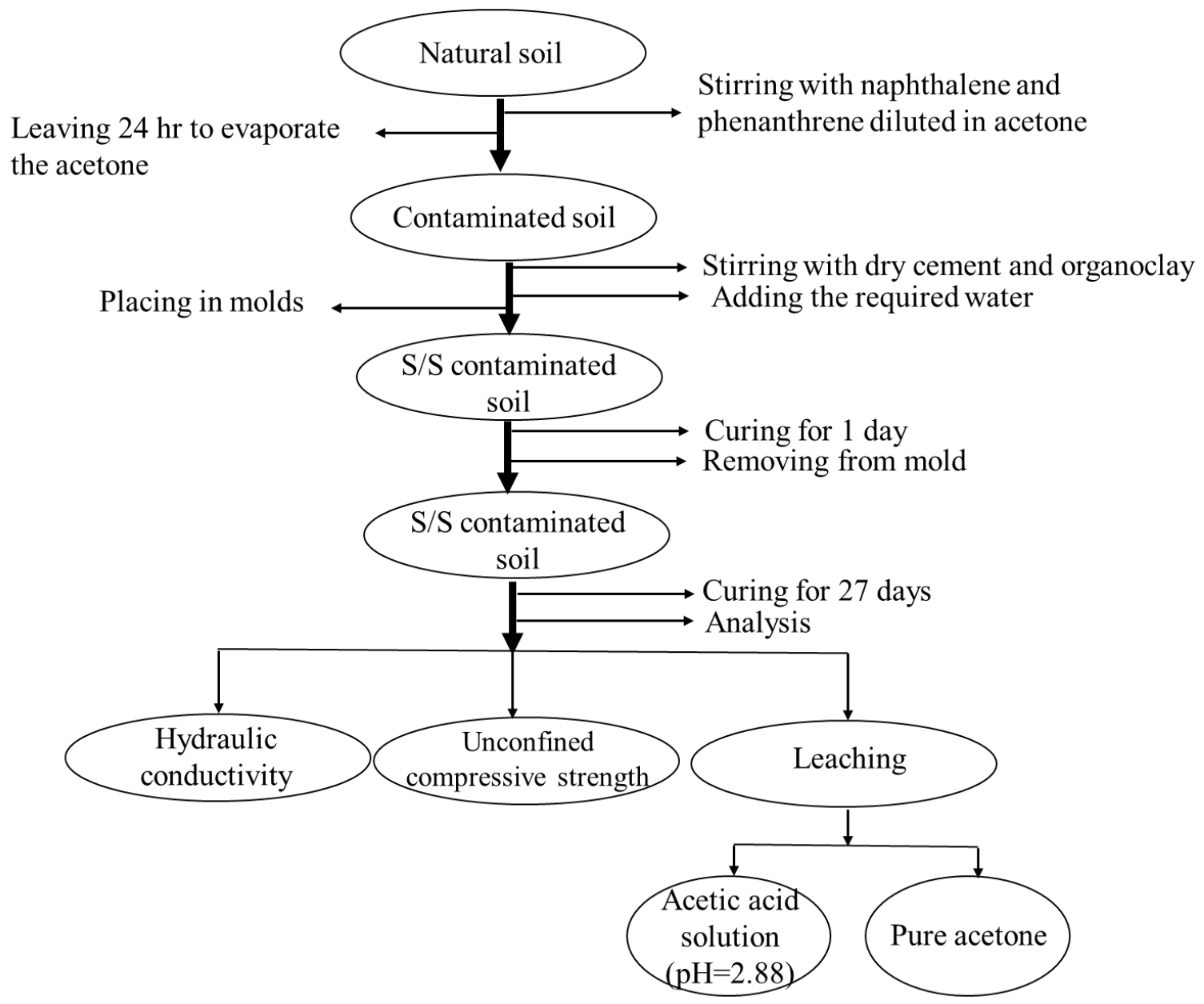

(a) 


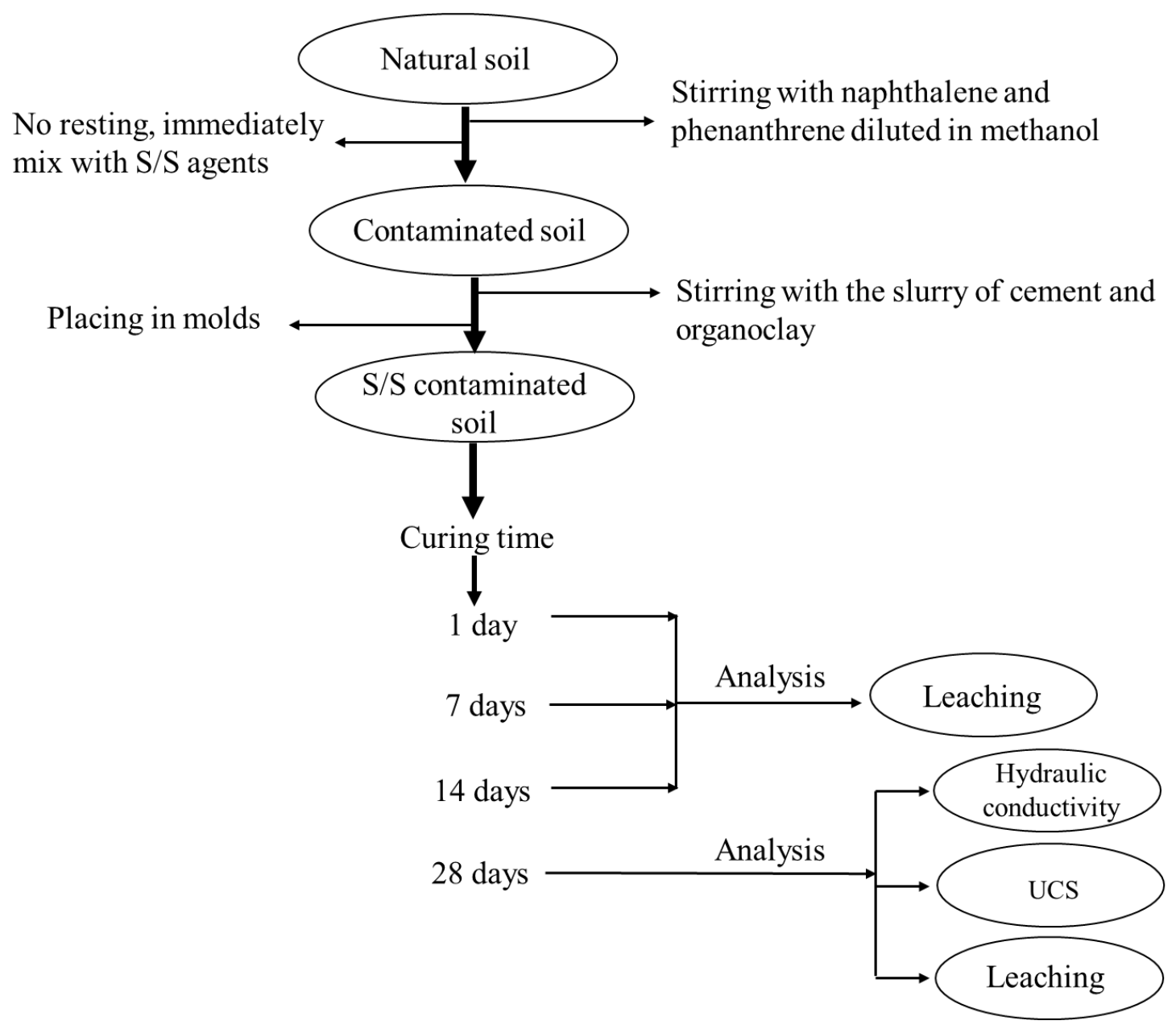

(b)

Figure 5-2. Detailed experimental program of S/S treatment of naphthalene and phenanthrene contaminated soil (a) group I (b) group II

\section{Methods}

\section{Compressive strength test}

The strength test was carried out to evaluate the mechanical performance of the stabilized soils. Strength tests on both unstabilized soil and stabilized soil provide a comparison between the two. Unstabilized waste materials do not show good strength, but by adding cement to contaminated soil, the strength is anticipated to increase significantly. 
The unconfined compressive strength (UCS) test was conducted in accordance with ASTM D2166-06. During the UCS testing, no radial stress is applied to the soil specimen $(\sigma 3=0)$. However, the vertical load is increased rapidly until the soil specimen fails. In this study the UCS was carried out by a triaxial machine (Trautwein Sigma 1 automated load test system), which is equipped with load and deformation data acquisition system.

All S/S soil specimens had a height to diameter (h/d) ratio of 2 (4 and 2 inches, respectively) giving, as recommended by ASTM D2166. The specimens were placed in a triaxial cell, and then the triaxial cell was placed on a triaxial machine to start the shearing the specimens. Note that the rate of loading was chosen as $1.4 \mathrm{~mm} / \mathrm{min}$ according to ASTM D2166. Each mix design sample was tested in replicate for minimizing the potential laboratory errors, which might have occurred in the laboratory. The compressive strength of each sample was noted by taking the average of two replications for each test. Finally, the peak of the strain-stress graph was determined as the compressive strength of the each specimen.

\section{Permeability}

The permeability test has been recommended for evaluating the usefulness of stabilization and solidification process in reducing the leaching of contaminants into the groundwater. In this study, the flexible wall permeameter was used to conduct the hydraulic conductivity tests according to ASTM D5084-10. The falling head, constant tail water elevation method (ASTM 5084-10 method B) with a hydraulic gradient of 20 was used to determine the hydraulic conductivity of $\mathrm{S} / \mathrm{S}$ treated soils. The $\mathrm{S} / \mathrm{S}$ samples were sandwiched between two porous stone and filter papers and then placed in the triaxial permeameter chamber. The samples were surrounded by a latex membrane, which was 
sealed with base and top caps. After that the triaxial cell was assembled, and all valves were connected to the control panel. The procedure of mounting the specimen in the flexible wall permeameter was illustrated in chapter 3 .

The triaxial cell was filled with de-aired water, and the cell pressure was set to 2 psi to confine the membrane against the specimens. The de-aired water was flushed through the specimen, and the hydraulic conductivity was measured. Three hydraulic conductivity measurements were recorded, and the mean values were used as a hydraulic conductivity of the specimen.

The hydraulic conductivity of S/S samples were measured by the following equation:

$$
\begin{aligned}
& K=\frac{a * L}{A * \Delta t} \ln \left(\frac{h_{1}}{h_{2}}\right) \\
& \mathrm{K}=\text { hydraulic conductivity }(\mathrm{m} / \mathrm{s}) \\
& \mathrm{L}=\text { length of specimen }(\mathrm{m}) \\
& \mathrm{a}=\text { cross-sectional area of the reservoir containing the influent liquid }\left(\mathrm{m}^{2}\right) \\
& \mathrm{A}=\text { cross-sectional area of specimen }\left(\mathrm{m}^{2}\right) \\
& \Delta \mathrm{t}=\text { interval time }(\mathrm{s}) \\
& \mathrm{h}_{1}=\text { head loss across the permeameter/specimen at } \mathrm{t}_{1},(\mathrm{~m}) \\
& \mathrm{h}_{2}=\text { head loss across the permeameter/specimen at } \mathrm{t}_{2},(\mathrm{~m})
\end{aligned}
$$




\section{Leaching test}

The effectiveness performance of stabilized and solidified contaminated soil is measured in terms of leaching. Several leaching tests can be conducted to assess the effectiveness of stabilization and solidification treatment in decreasing the leachability. These leaching tests are: the Toxicity characteristics leaching procedure (TCLP) test, the synthetic acid precipitation leach procedure (SPLP) test, the American nuclear society leach test (ANSI/ANS/16.1), the dynamic leach test, etc. The TCLP test method is widely used by many environmental agencies (e.g. EPA) to determine if a contaminated soil is still hazardous or not (Paria and Yuet 2006). TCLP is mainly employed to simulate the leaching potential of contaminated soils or waste materials.

The USEPA (1992) Toxicity Characteristics Leaching Procedure (TCLP), Method 1311, was used to carry out the leaching test in this study. After the required days of curing, the S/S samples were crushed and passed through a $9.5 \mathrm{~mm}$ sieve; to simulate a long-term effect of stabilized/solidified contaminated soil that might breakdown into small particles due to overburden stresses. The $\mathrm{S} / \mathrm{S}$ crushed sample was then mixed with an acetic acid solution with a $\mathrm{pH}$ of 2.88 at a liquid to solid ratio of $(20: 1 \mathrm{~V}: \mathrm{V})$. Note that for the first scenario, the pure acetone was also used to examine the effect of cosolvent in the leaching test. Then the suspension was agitated in a conical glass tube with a mechanical shaker for 18 hours. The solution was filtered through $0.2 \mu \mathrm{m}$ syringe filters, and extracted by hexane. The extracted solutions were tested in the gas chromatography equipped with flame ionization detector (GC-FID) (Clarus 480, Perkin Elmer Co.) to measure the concentration of naphthalene and phenanthrene. 


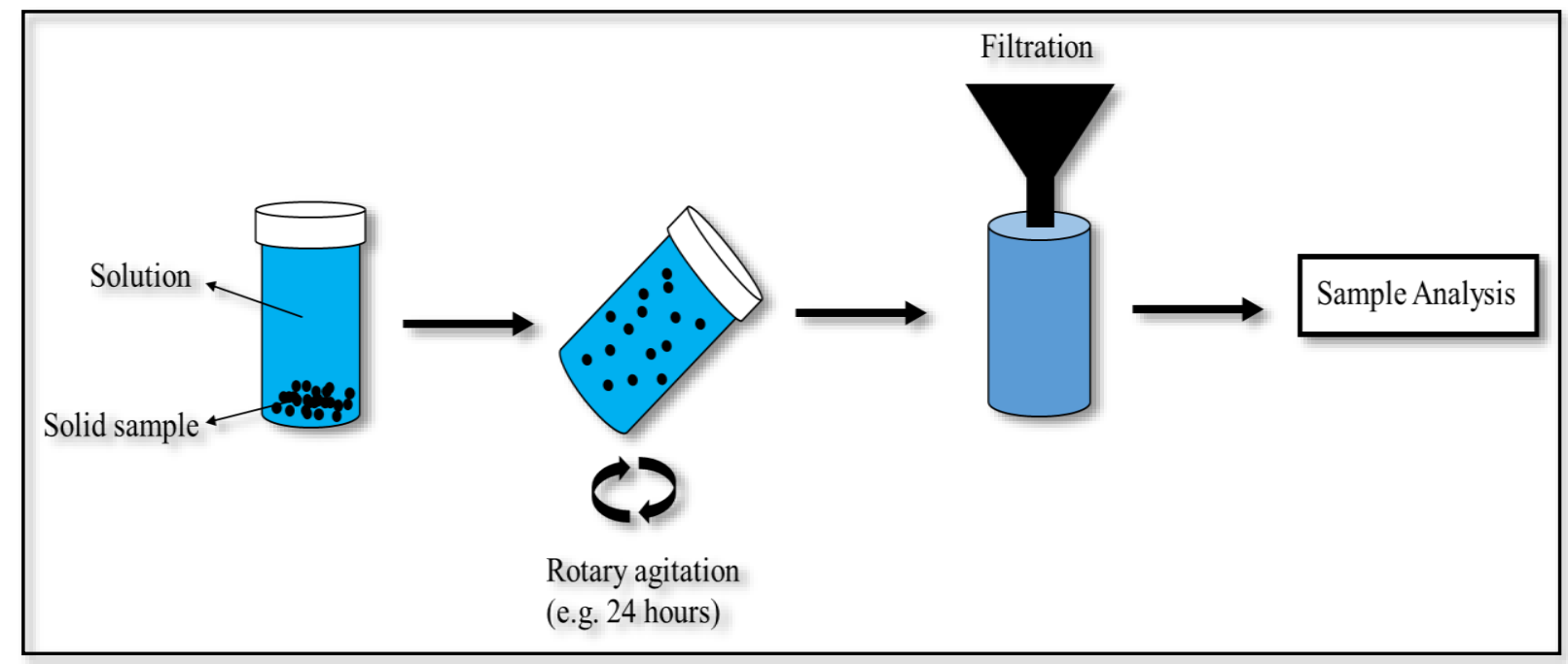

Figure 5-3. Simplified schematic of a batch equilibrium leaching procedure 


\subsection{Results and discussion}

\subsubsection{Stabilized soil group I}

\subsubsection{Unconfined Compressive Strength}

The unconfined compressive strength of 28-days cured solidified and stabilized contaminated soil with a constant percentage of ordinary Portland cement (5 and 10\%, by weight), and varied percentage of organoclay (2, 5, and $10 \%$ by weight) was studied, and the results are summarized in Table 5-5. The dry densities of the S/S samples were in the order of $1.71-1.80 \mathrm{~g} / \mathrm{cm}^{3}$, which shows good uniformity during the mixing.

Table 5-5. Unconfined compressive strength of $S / S$ contaminated soil

\begin{tabular}{|c|c|c|c|}
\hline Mix identification & $\begin{array}{c}\text { Dry density } \\
\left(\mathrm{g} / \mathrm{cm}^{3}\right)\end{array}$ & UCS (psi/kPa) & $\begin{array}{c}\text { Average UCS } \\
(\mathbf{p s i} / \mathbf{k P a})\end{array}$ \\
\hline \multirow{2}{*}{$\mathrm{C}_{5} \mathrm{O}_{0}$} & 1.79 & $205 / 1413$ & \multirow{2}{*}{$212 / 1461$} \\
\hline & 1.76 & $219 / 1509$ & \\
\hline \multirow{2}{*}{$\mathrm{C}_{5} \mathrm{O}_{2}$} & 1.73 & $226 / 1556$ & \multirow{2}{*}{$218 / 1503$} \\
\hline & 1.71 & $210 / 1451$ & \\
\hline \multirow{2}{*}{$\mathrm{C}_{5} \mathrm{O}_{5}$} & 1.74 & $246 / 1694$ & \multirow{2}{*}{$252 / 1737$} \\
\hline & 1.78 & $258 / 1782$ & \\
\hline \multirow{2}{*}{$\mathrm{C}_{5} \mathrm{O}_{10}$} & 1.73 & $259 / 1787$ & \multirow{2}{*}{$265 / 1827$} \\
\hline & 1.74 & $271 / 1872$ & \\
\hline \multirow{2}{*}{$\mathrm{C}_{10} \mathrm{O}_{0}$} & 1.74 & $477 / 3288$ & \multirow{2}{*}{$485 / 3344$} \\
\hline & 1.77 & 493/3399 & \\
\hline \multirow{2}{*}{$\mathrm{C}_{10} \mathrm{O}_{2}$} & 1.76 & $474 / 3271$ & \multirow{2}{*}{$478 / 3295$} \\
\hline & 1.80 & $482 / 3328$ & \\
\hline \multirow{2}{*}{$\mathrm{C}_{10} \mathrm{O}_{5}$} & 1.78 & $506 / 3491$ & \multirow{2}{*}{$502 / 3461$} \\
\hline & 1.74 & $497 / 3432$ & \\
\hline \multirow{2}{*}{$\mathrm{C}_{10} \mathrm{O}_{10}$} & 1.74 & $517 / 3702$ & \multirow{2}{*}{$521 / 3730$} \\
\hline & 1.75 & $526 / 3765$ & \\
\hline \multirow{2}{*}{ Control } & 1.62 & $105 / 723$ & \multirow{2}{*}{$108 / 744$} \\
\hline & 1.65 & $112 / 772$ & \\
\hline
\end{tabular}

It can be observed that the unconfined compressive strength of untreated sample (control sample, with no cement and organoclay addition) was around 108 psi. Moreover, the results exhibited that adding the cement in the mix design of solidified sample resulted 
in higher compressive strengths. When the 5\% cement was introduced into the soil matrix, the strength of the S/S increased from 108 to 212 psi, with an approximately $100 \%$ increase. However, by adding $10 \%$ cement into soil matrix, the strength of S/S increased to $485 \mathrm{psi}$, and a 370\% increase in strength was observed. Typically, with the addition of Portland cement to the contaminated soil, cement coats all the soil particles and binds them together, which yields high density and strength in the soil.

As the weight percent of organoclay increased, a slight increase in the strength of the S/S soils after 28 days curing period was observed. For instance, the strength of the S/S sample with $5 \%$ cement, increased from 212 to 265 psi with a $25 \%$ increase when organoclay content increased from $2 \%$ to $10 \%$. The slight increase in strength might be related to the particle size of organoclay, since the added organoclay had slightly coarser particles compared to the contaminated soil (see table 5-1); therefore, by adding the organoclay into soil matrix, the particles will be well packed with higher density and less void ratio. Moreover, the slight increase of $\mathrm{S} / \mathrm{S}$ specimen could be due to the reduced moisture content of the S/S specimens. According to the obtained results, the strength of solidified samples is primarily associated with the characteristic behavior of the cement additive and its reaction with the contaminated soil.

Interpretation of the results of the UCS test and performance criteria related to the $\mathrm{S} / \mathrm{S}$ process is one of the most significant tasks that must be taken into account. Although different countries have their standards for the minimum compressive strength of $\mathrm{S} / \mathrm{S}$ waste or contaminated soil, USEPA mandated that $\mathrm{S} / \mathrm{S}$ contaminated soils must meet a minimum unconfined compressive strength of $50 \mathrm{psi}(350 \mathrm{kPa})$ at the end of the 28 -day curing period. A comparison between the unconfined compressive strength of S/S soil samples and 
USEPA standard are shown in Figure 5-4. The unconfined compressive strength of all the $\mathrm{S} / \mathrm{S}$ samples were above the 50 psi requirement. Therefore, in terms of the unconfined compressive strength criterion, the addition of $5 \%$ Portland cement into contaminated silty soil can satisfy the UCS requirement.

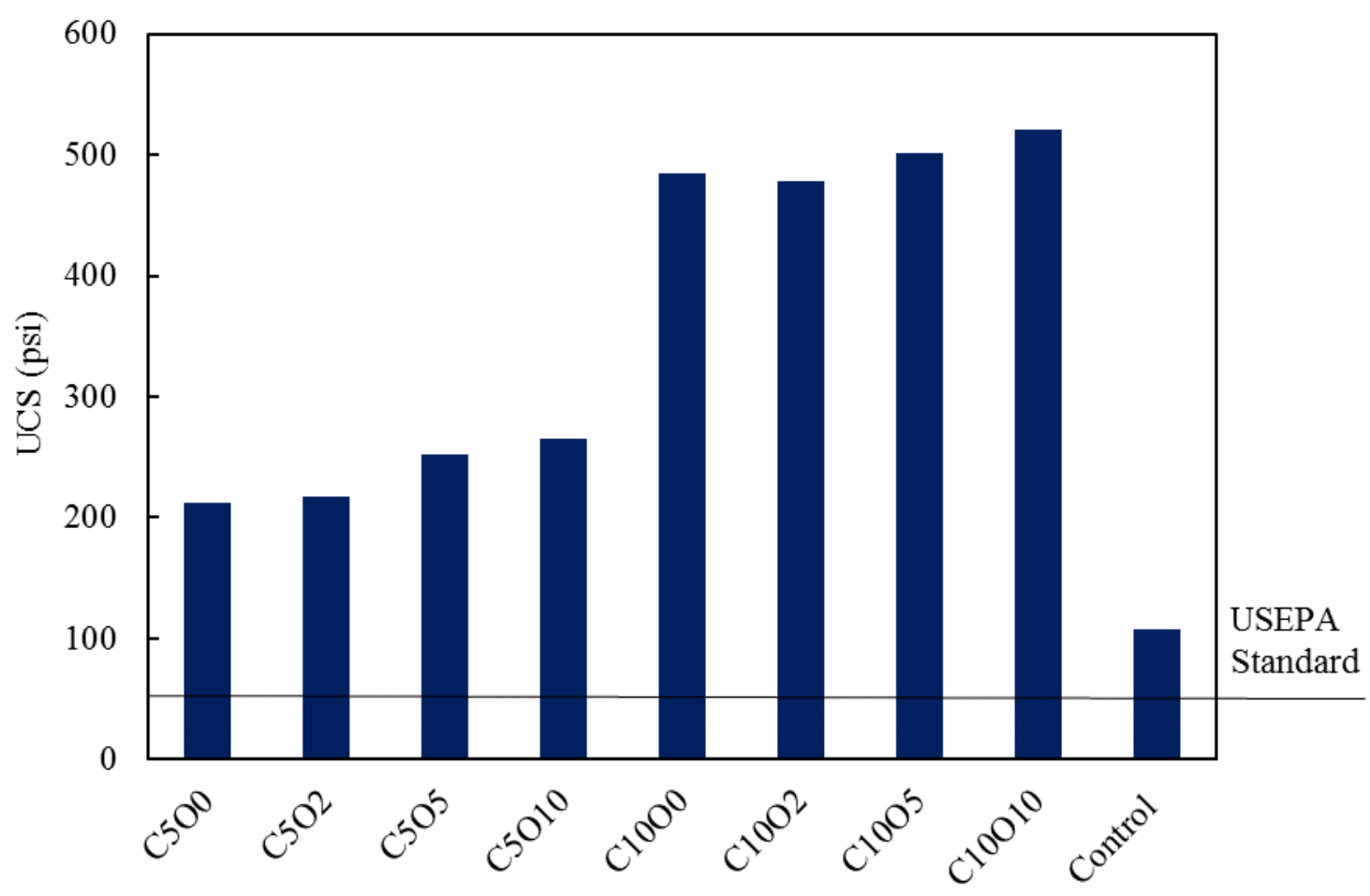

Mix identification

Figure 5-4. Comparison of unconfined compressive strength of $S / S$ samples to

\section{USEPA standard}

\subsubsection{Hydraulic conductivity}

The average hydraulic conductivities of untreated and treated contaminated soils are presented in Table 5-6. Hydraulic conductivity tests were conducted on cylindrical S/S samples at the end of the 28-days curing period. The hydraulic conductivity measurement was repeated three times for each S/S sample to ensure reliable results. The dry density and void ratio of the S/S-treated specimens were on the order of $1.7-1.8 \mathrm{~g} / \mathrm{cm}^{3}$ and $0.46-0.56$, 
respectively. The hydraulic conductivity of the untreated sample was $1.5 \times 10^{-8} \mathrm{~m} / \mathrm{s}$, which is higher than the required hydraulic conductivity at $\mathrm{k} 1 \times 10^{-8} \mathrm{~m} / \mathrm{s}$. It was observed that adding the Portland cement fraction in the soil matrix decreased the hydraulic conductivity of the treated sample. The hydraulic conductivity of S/S sample decreased to $6.2 \times 10^{-9}$ and $1.7 \times 10^{-9}$ when $5 \%$ and $10 \%$ cement were introduced to the samples, respectively.

The measured hydraulic conductivity values for all $\mathrm{S} / \mathrm{S}$ specimens (containing cement and organoclay) were on the order of $10^{-9} \mathrm{~m} / \mathrm{s}$, although a higher organoclay addition into soil matrix resulted in a slightly higher hydraulic conductivity values. This slight increase may be related to the hydrophobic surfactants exchanged onto the organoclay surface, which was able to increase the hydrophobicity of the soil matrix and facilitate the water conduction in soil pores, and this prevailed as the organobentonite fraction increased. Overall, the hydraulic conductivity values of 28-days cured S/S contaminated soils were one order of magnitude lower than the value of $10^{-8} \mathrm{~m} / \mathrm{s}$ regulated by USEPA for solidification and stabilization of the contaminated soil.

Table 5-6. Hydraulic conductivity of S/S contaminated soil

\begin{tabular}{ccc}
\hline Mix identification & Void ratio & $\begin{array}{c}\text { Hydraulic conductivity } \\
(\mathbf{m} / \mathbf{s})\end{array}$ \\
\hline $\mathbf{C}_{\mathbf{5}} \mathbf{O}_{\mathbf{0}}$ & 0.52 & $6.2 \times 10^{-9}$ \\
\hline $\mathbf{C}_{5} \mathbf{O}_{\mathbf{2}}$ & 0.50 & $7.1 \times 10^{-9}$ \\
\hline $\mathbf{C}_{5} \mathbf{O}_{\mathbf{5}}$ & 0.46 & $6.5 \times 10^{-9}$ \\
\hline $\mathbf{C}_{5} \mathbf{O}_{\mathbf{1 0}}$ & 0.48 & $8.8 \times 10^{-9}$ \\
\hline $\mathbf{C}_{\mathbf{1 0}} \mathbf{O}_{\mathbf{0}}$ & 0.52 & $1.7 \times 10^{-9}$ \\
\hline $\mathbf{C}_{\mathbf{1 0}} \mathbf{O}_{\mathbf{2}}$ & 0.51 & $2.5 \times 10^{-9}$ \\
\hline $\mathbf{C}_{\mathbf{1 0}} \mathbf{O}_{\mathbf{5}}$ & 0.49 & $5.6 \times 10^{-9}$ \\
\hline $\mathbf{C}_{\mathbf{1 0}} \mathbf{O}_{\mathbf{1 0}}$ & 0.48 & $6.2 \times 10^{-9}$ \\
\hline $\mathbf{C o n t r o l}$ & 0.59 & $1.5 \times 10^{-8}$ \\
\hline
\end{tabular}




\subsubsection{Leaching}

In addition to the unconfined compressive strength and hydraulic conductivity tests, the effectiveness of the $\mathrm{S} / \mathrm{S}$ process was also assessed by leaching test to determine the amount of contaminants that can be leached from the S/S products. First, the initial concentration of naphthalene and phenanthrene in the soil after evaporation of acetone for each mix design was measured. Secondly, the final concentration of naphthalene and phenanthrene leachate from each mix design after 28 days of curing period was determined by TCLP test using acetic acid solution with $\mathrm{pH}$ of 2.88 and pure acetone. Table 5-7 summarizes the initial concentration of naphthalene and phenanthrene in the contaminated soil after evaporation of the acetone.

The target concentration of naphthalene and phenanthrene in contaminated soil was 2000 and $500 \mathrm{mg} / \mathrm{kg}$. They were dissolved in acetone and mixed with the soil. A sample of each mix design was taken to determine the initial concentration of the contaminants in the soil as a portion of the contaminant may volatilize along with the solvent. After evaporation of acetone, the secondary concentration of naphthalene and phenanthrene was approximately reduced to 1485 and $405 \mathrm{mg} / \mathrm{kg}$, respectively. This means that around 25\% of naphthalene and $20 \%$ of phenanthrene were evaporated along with acetone from the contaminated soil. 
Table 5-7. Initial concentration of naphthalene and phenanthrene before and after evaporation of acetone

\begin{tabular}{|c|c|c|c|c|c|c|}
\hline \multirow{3}{*}{$\begin{array}{c}\text { Mix } \\
\text { identification }\end{array}$} & \multicolumn{3}{|c|}{ Naphthalene } & \multicolumn{3}{|c|}{ Phenanthrene } \\
\hline & \multirow{2}{*}{$\begin{array}{c}\text { Initial } \\
\text { concentration } \\
(\mathbf{m g} / \mathbf{k g})\end{array}$} & \multicolumn{2}{|c|}{$\begin{array}{c}\text { Secondary } \\
\text { concentration }\end{array}$} & \multirow{2}{*}{$\begin{array}{c}\text { Initial } \\
\text { concentration } \\
(\mathrm{mg} / \mathrm{kg})\end{array}$} & \multicolumn{2}{|c|}{$\begin{array}{c}\text { Secondary } \\
\text { concentration }\end{array}$} \\
\hline & & $\mu \mathrm{g} / \mathrm{mL}$ & $\mathrm{mg} / \mathrm{kg}$ & & $\mu \mathrm{g} / \mathrm{mL}$ & $\mathrm{mg} / \mathrm{kg}$ \\
\hline $\mathrm{C}_{5} \mathrm{O}_{0}$ & \multirow{9}{*}{2000} & 73.7 & 1475 & \multirow{9}{*}{500} & 21.1 & 421 \\
\hline $\mathrm{C}_{5} \mathrm{O}_{2}$ & & 74.3 & 1486 & & 20.4 & 408 \\
\hline $\mathrm{C}_{5} \mathrm{O}_{5}$ & & 74.3 & 1486 & & 20.4 & 408 \\
\hline $\mathrm{C}_{5} \mathrm{O}_{10}$ & & 74.3 & 1486 & & 20.4 & 408 \\
\hline $\mathrm{C}_{10} \mathrm{O}_{0}$ & & 75.2 & 1505 & & 21.1 & 421 \\
\hline $\mathrm{C}_{10} \mathrm{O}_{2}$ & & 75.2 & 1505 & & 20.1 & 402 \\
\hline $\mathrm{C}_{10} \mathrm{O}_{5}$ & & 75.2 & 1505 & & 20.1 & 402 \\
\hline $\mathrm{C}_{10} \mathrm{O}_{10}$ & & 73.7 & 1475 & & 20.1 & 402 \\
\hline Control & & 76.1 & 1521 & & 20.75 & 415 \\
\hline
\end{tabular}

The final concentrations of naphthalene and phenanthrene in treated and untreated (control sample) samples after 28-days curing period were measured by TCLP method with two different cosolvent liquids (acetic acid with $\mathrm{pH}=2.88$ and pure acetone). The effect of various treatments on the TCLP naphthalene and phenanthrene concentration was analyzed by a statistical analysis of the data in Table 5-8. Moreover, the leaching reduction of naphthalene and phenanthrene are visually illustrated in Figure 5-5. The final concentration of naphthalene and phenanthrene for the untreated sample (without any cement and organoclay) decreased from $76.1 \mu \mathrm{g} / \mathrm{mL}$ to 60.68 and 20.75 to $17.34 \mu \mathrm{g} / \mathrm{mL}$, respectively, when the acetic acid solution was used as a cosolvent. This slight reduction in naphthalene and phenanthrene concentration (20\% and $16.4 \%$, respectively) may be related to either the compaction of the contaminated soil that trapped the contaminants or the evaporation of the contaminants. When the acetone was used as cosolvent, the higher leachability of naphthalene and phenanthrene (less leachate reduction) was observed due to the higher solubility of the acetone compared to acetic acid solution. 
With the addition of cement into contaminated soil, a high decrease in the amount of naphthalene and phenanthrene leaching from S/S products was resulted. 5\% cement addition reduced the leachability of naphthalene and phenanthrene to 23.23 and $5.15 \mu \mathrm{g} / \mathrm{mL}$ with a leaching reduction of $68.5 \%$ and $73.8 \%$, respectively. However, by adding $10 \%$ cement into contaminated soil, the leaching reduction of naphthalene and phenanthrene was increased to $71.3 \%$ and $78.1 \%$, respectively. The cement $\mathrm{S} / \mathrm{S}$ treatment of contaminated soil resulted in the formation of many cavities containing encapsulated naphthalene and phenanthrene. The results suggest that increasing the amount of cement in the contaminated soil, led to stronger cavities which trapped the contaminants. Therefore, increased amount of cement resulted in a decrease in leaching.

The record of decision (ROD) (USEPA 2011) mandated that the chosen site remedy must meet a target of $90 \%$ or greater reduction in leachability for the most of the site constituents of concern (COC), such as PAHs and BTEX. According to the ROD requirement, cement S/S treatment of PAH-contaminated soil would not satisfy the target reduction of contaminants leaching. Therefore, organoclay with high sorption affinity of organic contaminants was added to the cement-solidified matrix to improve the leachability reduction. The results showed that adding organoclay 2, 5, $10 \%$ (by weight) in the S/S soil samples with a $5 \%$ cement decreased the leaching of naphthalene from $74.3 \mu \mathrm{g} / \mathrm{mL}$ to $5.86,4.68$, and $4.23 \mu \mathrm{g} / \mathrm{mL}$, respectively. Moreover, the leaching of phenanthrene from the solidified and stabilized specimens decreased from $20.4 \mu \mathrm{g} / \mathrm{mL}$ to $1.87,1$, and $0.97 \mu \mathrm{g} / \mathrm{mL}$ when the organoclay percentage increased to 2,5 and $10 \%$, respectively. The results indicated that for each fixed cement content, increasing the organoclay percentage slightly increased the leaching reduction of naphthalene and phenanthrene when either acetic acid 
solution or acetone used as a cosolvent. However, the leaching of naphthalene and phenanthrene were higher when acetone used as a cosolvent. The results stressed out that the organoclay particles sorbed the organic contaminants and consequently reduced the leachate concentration.

Table 5-8. Summary of final concentration of (a) naphthalene and (b) phenanthrene in S/S specimens test by acetone Toxicity Characteristic Leaching Procedure

(a)

\begin{tabular}{|c|c|c|c|}
\hline \multirow{2}{*}{ Mix identification } & \multirow{2}{*}{$\begin{array}{c}\text { Initial } \\
\text { concentration } \\
(\boldsymbol{\mu g} / \mathbf{m L})\end{array}$} & $\begin{array}{c}\text { Leachate concentration }(\boldsymbol{\mu g} / \mathbf{m L}) \\
\text { TCLP by acetic } \\
\text { acid solution }\end{array}$ & TCLP by acetone \\
\hline $\mathbf{C}_{\mathbf{5}} \mathbf{O}_{\mathbf{0}}$ & 73.7 & 23.23 & 28.39 \\
\hline $\mathbf{C}_{\mathbf{5}} \mathbf{O}_{\mathbf{2}}$ & 74.3 & 5.86 & 8.91 \\
\hline $\mathbf{C}_{\mathbf{5}} \mathbf{O}_{\mathbf{5}}$ & 74.3 & 4.68 & 6.61 \\
\hline $\mathbf{C}_{\mathbf{5}} \mathbf{O}_{\mathbf{1 0}}$ & 74.3 & 4.23 & 4.97 \\
\hline $\mathbf{C}_{\mathbf{1 0}} \mathbf{O}_{\mathbf{0}}$ & 75.2 & 21.16 & 25.96 \\
\hline $\mathbf{C}_{\mathbf{1 0}} \mathbf{O}_{\mathbf{2}}$ & 75.2 & 5.41 & 8.57 \\
\hline $\mathbf{C}_{\mathbf{1 0}} \mathbf{O}_{\mathbf{5}}$ & 75.2 & 4.36 & 6.17 \\
\hline $\mathbf{C}_{\mathbf{1 0}} \mathbf{O}_{\mathbf{1 0}}$ & 73.7 & 3.08 & 5.12 \\
\hline $\mathbf{C o n t r o l}$ & 76.1 & 60.68 & 66.54 \\
\hline
\end{tabular}

(b)

\begin{tabular}{|c|c|c|c|}
\hline \multirow{2}{*}{ Mix identification } & \multirow{2}{*}{$\begin{array}{c}\text { Initial } \\
\text { concentration } \\
(\boldsymbol{\mu g} / \mathbf{m L})\end{array}$} & $\begin{array}{c}|c| \\
\text { TCLP by acetic } \\
\text { acid solution }\end{array}$ & TCLP by acetone \\
\cline { 3 - 4 } & 20.5 & 5.15 & 7.22 \\
\hline $\mathbf{C}_{\mathbf{5}} \mathbf{O}_{\mathbf{0}}$ & 20.4 & 1.87 & 2.81 \\
\hline $\mathbf{C}_{\mathbf{5}} \mathbf{O}_{\mathbf{2}}$ & 20.4 & 1.00 & 1.89 \\
\hline $\mathbf{C}_{\mathbf{5}} \mathbf{O}_{\mathbf{5}}$ & 20.4 & 0.97 & 1.61 \\
\hline $\mathbf{C}_{\mathbf{5}} \mathbf{O}_{\mathbf{1 0}}$ & 20.9 & 4.6 & 6.48 \\
\hline $\mathbf{C}_{\mathbf{1 0}} \mathbf{O}_{\mathbf{0}}$ & 20.4 & 1.56 & 2.25 \\
\hline $\mathbf{C}_{\mathbf{1 0}} \mathbf{O}_{\mathbf{2}}$ & 20.2 & 1.00 & 1.53 \\
\hline $\mathbf{C}_{\mathbf{1 0}} \mathbf{O}_{\mathbf{5}}$ & 20.7 & 0.88 & 1.28 \\
\hline $\mathbf{C}_{\mathbf{1 0}} \mathbf{O}_{\mathbf{1 0}}$ & 20.75 & 17.34 & 19.52 \\
\hline $\mathbf{C o n t r o l}$ & & & \\
\hline
\end{tabular}


According to the percent reductions on the cumulative mass release of naphthalene and phenanthrene for different mix design after 28-days curing period, at all the level of organoclay concentration, the target $90 \%$ reduction of naphthalene and phenanthrene leachate concentration was satisfied. Therefore, among the selected range of cement and organoclay, the mix design of $\mathrm{C}_{5} \mathrm{O}_{2}$ ( $5 \%$ cement and $2 \%$ organoclay by weight) surpasses a $90 \%$ reduction in leaching. Thus, $\mathrm{C}_{5} \mathrm{O}_{2}$ was effective mix design, since the both strength and permeability criteria were satisfied.

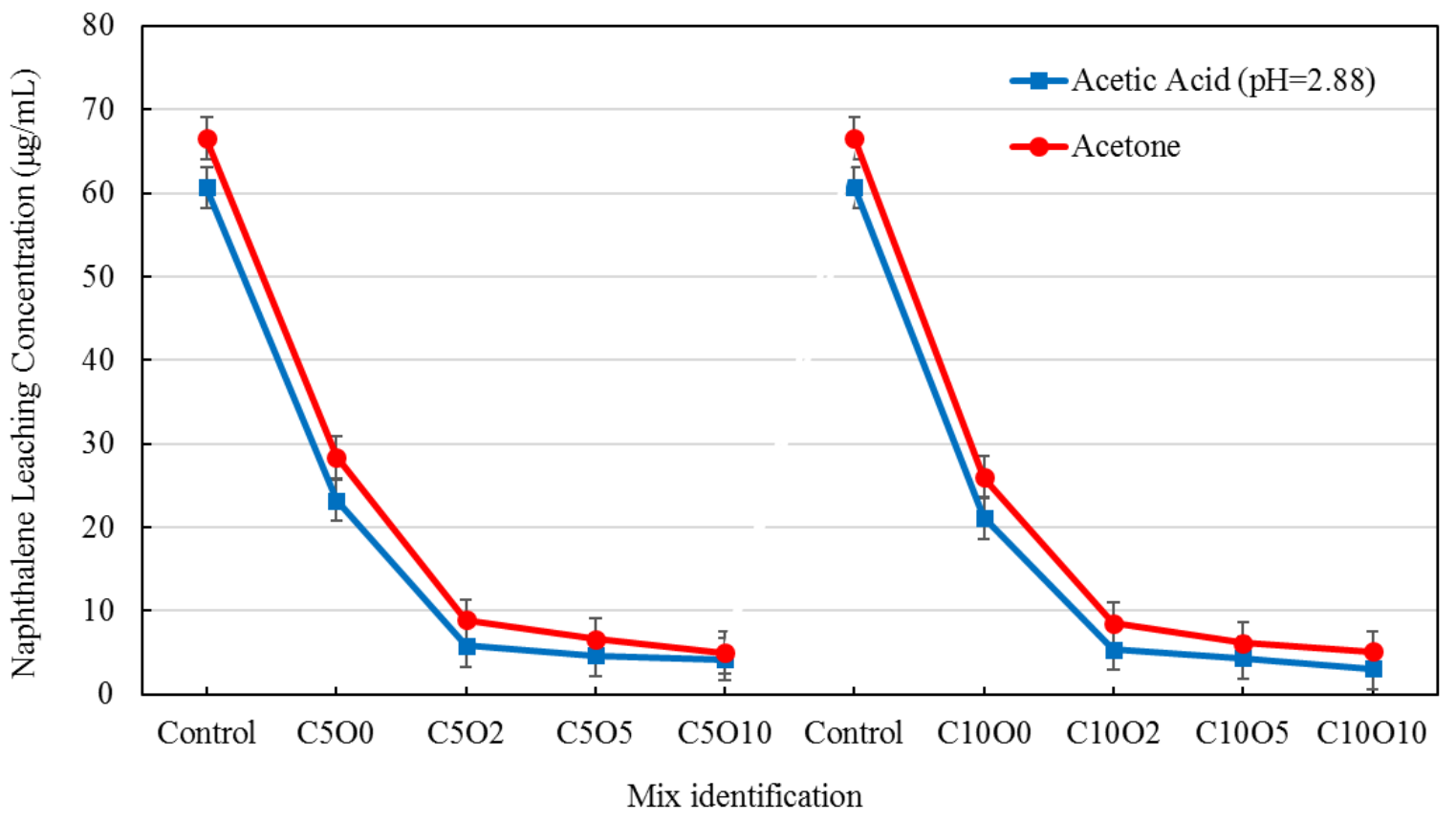

(a) 


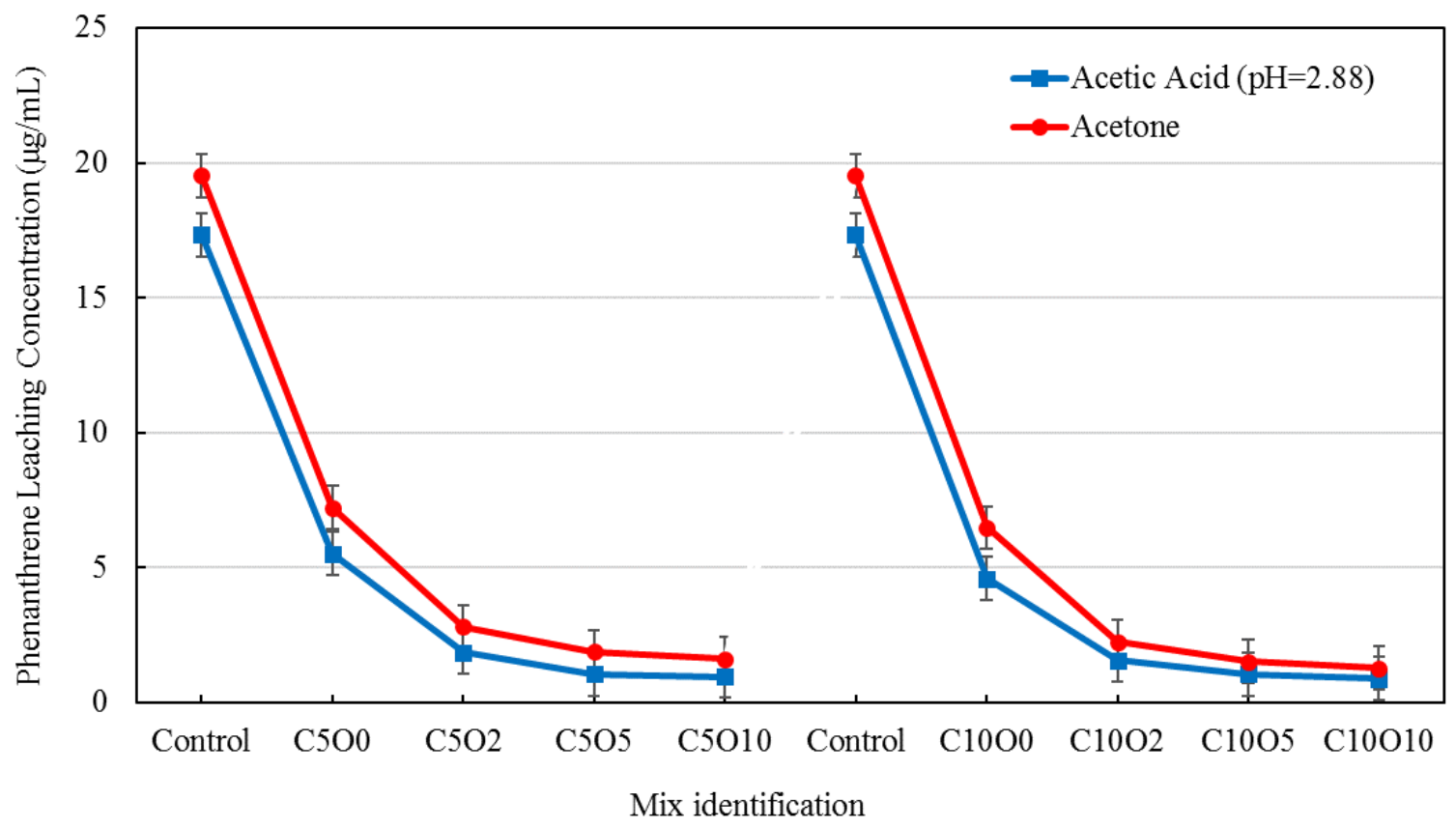

(b)

Figure 5-5. Reduction in (a) naphthalene and (b) phenanthrene mass leaching for each mix design

\subsubsection{Stabilized soil group II}

\subsubsection{Unconfined compressive strength}

Table 5-9 presents the results of the unconfined compressive strength of the solidified and stabilized methanol-contaminated soil. The contaminated soil was solidified by a constant content of Portland cement ( $5 \%$ by weight) and varied percentage of the organoclay (2, 5 and $10 \%$ by weight). The average dry density of the all S/S specimens were in the range of 1.71 to $1.78 \mathrm{~g} / \mathrm{cm}^{3}$. The unconfined compressive strength of the compacted contaminated soil as a control sample was 97 psi. With the addition of 5\% cement into the contaminated soil matrix, the unconfined compressive strength increased up to 207 psi with an average $100 \%$ increase. Moreover, the results showed that introducing organoclay into cement solidified specimens increased the unconfined compressive 
strength of the specimen. The strength increased from 207 to 245 psi with an $18 \%$ increase when the organoclay addition increased from $0 \%$ to $10 \%$. The slight increase in UCS of treated soils is perhaps related to the decrease of contaminated soil and sorption of methanol by the organoclay particles. Overall, all the S/S specimens showed the higher unconfined compressive strength of 50 psi which is mandated by the USEPA (Figure 5-6).

Table 5-9. Unconfined compressive strength of $\mathrm{S} / \mathrm{S}$ contaminated soil

\begin{tabular}{|c|c|c|c|c|}
\hline $\begin{array}{c}\text { Mix } \\
\text { identification }\end{array}$ & $\begin{array}{l}\text { Dry density } \\
\quad\left(\mathrm{g} / \mathrm{cm}^{3}\right)\end{array}$ & $\mathrm{UCS}$ (psi/kPa) & $\begin{array}{c}\text { Average dry } \\
\text { density } \\
\left(\mathrm{g} / \mathrm{cm}^{\mathbf{3}}\right)\end{array}$ & $\begin{array}{c}\text { Average UCS } \\
\quad(\mathbf{p s i} / \mathbf{k P a})\end{array}$ \\
\hline $\mathrm{C}_{5} \mathrm{O}_{0}$ & $\begin{array}{c}1.73 \\
1.7\end{array}$ & $\begin{array}{l}210 / 1448 \\
204 / 1406\end{array}$ & 1.71 & $207 / 1427$ \\
\hline $\mathrm{C}_{5} \mathrm{O}_{2}$ & $\begin{array}{l}1.76 \\
1.74 \\
\end{array}$ & $\begin{array}{l}218 / 1503 \\
206 / 1420 \\
\end{array}$ & 1.73 & $212 / 1461$ \\
\hline $\mathrm{C}_{5} \mathrm{O}_{5}$ & $\begin{array}{l}1.72 \\
1.74\end{array}$ & $\begin{array}{l}215 / 1482 \\
233 / 1606\end{array}$ & 1.73 & $224 / 1544$ \\
\hline $\mathrm{C}_{5} \mathrm{O}_{10}$ & $\begin{array}{l}1.77 \\
1.80\end{array}$ & $\begin{array}{l}254 / 1751 \\
236 / 1627\end{array}$ & 1.78 & $245 / 1689$ \\
\hline Control & $\begin{array}{l}1.65 \\
1.68\end{array}$ & $\begin{array}{c}92 / 634 \\
102 / 703\end{array}$ & 1.66 & $97 / 669$ \\
\hline
\end{tabular}

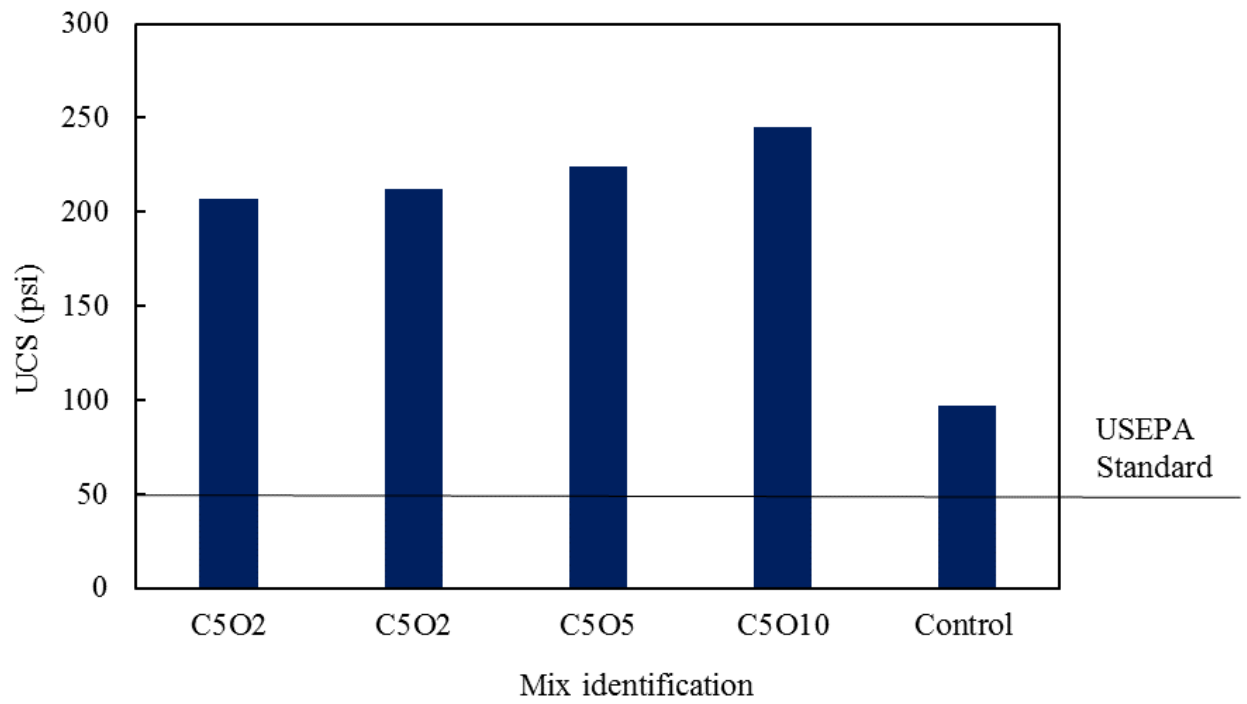

Figure 5-6. Comparison of unconfined compressive strength of $S / S$ samples to

USEPA standard 


\subsubsection{Hydraulic conductivity}

The overall mean hydraulic conductivities of treated contaminated soils with a constant percentage of cement and varied percentage of organoclays, at the end of the 28days curing period, are presented in Table 5-10. The average void ratio of the S/S specimens was in the range of $0.50-0.56$. The hydraulic conductivity results showed that the permeability of contaminated soil decreased from $7 \times 10^{-8}$ to $6.5 \times 10^{-9} \mathrm{~m} / \mathrm{s}$ when $5 \%$ cement was added into the soil. By introducing the organoclay fraction into cement treated soil, the hydraulic conductivity of the samples slightly decreased due to the hydrophobicity characteristics of the organoclay particles. Overall, the hydraulic conductivities of the all $\mathrm{S} / \mathrm{S}$ specimens were in the order of $10^{-9} \mathrm{~m} / \mathrm{s}$, which is lower than the design criteria of $\mathrm{k} 1$ $\times 10^{-8} \mathrm{~m} / \mathrm{s}$, regulated by USEPA for S/S contaminated soil.

Table 5-10. Hydraulic conductivity of $S / S$ contaminated soil

\begin{tabular}{ccc}
\hline Mix identification & Void ratio & $\begin{array}{c}\text { Hydraulic conductivity } \\
(\mathbf{m} / \mathbf{s})\end{array}$ \\
\hline $\mathbf{C}_{5} \mathbf{O}_{\mathbf{0}}$ & 0.54 & $6.5 \times 10^{-9}$ \\
\hline $\mathbf{C}_{5} \mathbf{O}_{\mathbf{2}}$ & 0.52 & $4.3 \times 10^{-9}$ \\
\hline $\mathbf{C}_{5} \mathbf{O}_{5}$ & 0.50 & $8.6 \times 10^{-9}$ \\
\hline $\mathbf{C}_{5} \mathbf{O}_{\mathbf{1 0}}$ & 0.56 & $7.8 \times 10^{-9}$ \\
\hline $\mathbf{C o n t r o l}$ & 0.62 & $7 \times 10^{-8}$ \\
\hline
\end{tabular}

\subsubsection{Leaching}

The results of TCLP leachate naphthalene and phenanthrene of the treated and untreated samples varying with curing time (1, 7, 14 and 28 days) are presented in Table 5-11. TCLP provides a measure of naphthalene and phenanthrene concentrations that leach from the $\mathrm{S} / \mathrm{S}$ products. In the second scenario, just an acetic acid solution with a $\mathrm{pH}$ of 2.88 was used as a cosolvent. Moreover, Figure 5-7 summarizes the percent reductions on the 
mass release of naphthalene and phenanthrene for different mix designs based on different time intervals. The final concentration of naphthalene and phenanthrene leached from the untreated (control) sample slightly decreased with curing time. The initial concentration of naphthalene and phenanthrene was 100 and $25 \mu \mathrm{g} / \mathrm{mL}$ and after 28 days curing period, the naphthalene and phenanthrene concentration reduced to 83.7 and $21.71 \mu \mathrm{g} / \mathrm{mL}$, with $16.3 \%$ and $13.2 \%$ leaching reduction, respectively.

When the $5 \%$ cement $\left(\mathrm{C}_{5} \mathrm{O}_{0}\right)$ was added to the contaminated soil to make a cementsolidified product, the concentration of naphthalene and phenanthrene after 1-day curing period reduced from 100 and $25 \mu \mathrm{g} / \mathrm{mL}$ to 43.8 and $9.82 \mu \mathrm{g} / \mathrm{mL}$, respectively. Further decrease in the naphthalene and phenanthrene concentration was observed at the end of 28 days curing period with the $68.5 \%$ and $71.2 \%$ reduction in leachability, respectively. The results suggest that cement enhance the leachability reduction by encapsulated the contaminants into the cavities area, and as the curing time increase, the stronger cavities area may happen. 
Table 5-11. Summary of final concentration of (a) naphthalene and (b) phenanthrene in S/S specimens test by acetone Toxicity Characteristic Leaching Procedure

(a)

\begin{tabular}{|c|c|c|c|c|c|c|}
\hline \multirow{2}{*}{$\begin{array}{c}\text { Mix } \\
\text { identification }\end{array}$} & \multirow{2}{*}{$\begin{array}{c}\text { Initial } \\
\text { concentration } \\
(\mathrm{mg} / \mathrm{kg}) \text { or }(\mu \mathrm{g} / \mathrm{mL})\end{array}$} & \multicolumn{4}{|c|}{ Final concentration $(\mu \mathrm{g} / \mathrm{mL})$} & \multirow{2}{*}{$\begin{array}{l}\text { Leaching } \\
\text { reduction } \\
\quad(\%)\end{array}$} \\
\hline & & $\begin{array}{c}1 \\
\text { day }\end{array}$ & $\begin{array}{c}7 \\
\text { days }\end{array}$ & $\begin{array}{c}14 \\
\text { days }\end{array}$ & $\begin{array}{c}28 \\
\text { days }\end{array}$ & \\
\hline C5O0 & \multirow{5}{*}{$2000 / 100$} & 43.8 & 39.9 & 37.6 & 31.5 & 68.5 \\
\hline $\mathrm{C5O2}$ & & 21.2 & 18.4 & 15.5 & 9.2 & 90.8 \\
\hline C5O5 & & 20.9 & 17.7 & 14.5 & 7.5 & 92.5 \\
\hline C5O10 & & 15.8 & 13.3 & 11.1 & 5.3 & 94.6 \\
\hline Control & & 91.9 & 90.2 & 86.7 & 83.7 & 16.3 \\
\hline
\end{tabular}

(b)

\begin{tabular}{|c|c|c|c|c|c|c|}
\hline \multirow{2}{*}{$\begin{array}{c}\text { Mix } \\
\text { identificati } \\
\text { on } \\
\end{array}$} & \multirow{2}{*}{$\begin{array}{l}\text { Initial concentration } \\
(\mathrm{mg} / \mathrm{kg}) \text { or }(\mu \mathrm{g} / \mathrm{mL})\end{array}$} & \multicolumn{4}{|c|}{ Final concentration $(\mu \mathrm{g} / \mathrm{mL})$} & \multirow{2}{*}{$\begin{array}{c}\text { Leaching } \\
\text { reduction (\%) }\end{array}$} \\
\hline & & 1 day & $\begin{array}{c}7 \\
\text { days }\end{array}$ & $\begin{array}{c}14 \\
\text { days }\end{array}$ & $\begin{array}{c}28 \\
\text { days }\end{array}$ & \\
\hline C5O0 & \multirow{5}{*}{$500 / 25$} & 9.82 & 9.05 & 7.92 & 7.28 & 71.2 \\
\hline $\mathrm{C5O2}$ & & 6.65 & 5.95 & 4.35 & 2.82 & 88.7 \\
\hline C5O5 & & 6.33 & 5.37 & 4.15 & 2.17 & 91.3 \\
\hline C5O10 & & 5.38 & 4.66 & 3.52 & 1.12 & 95.6 \\
\hline Control & & 23.81 & 23.37 & 22.55 & 21.71 & 13.2 \\
\hline
\end{tabular}

For further improvement of the leachability reduction of $\mathrm{S} / \mathrm{S}$ products, the organoclay at various content alongside with cement was introduced to the organiccontaminated soil. The results indicate that the mix design of $\mathrm{C}_{5} \mathrm{O}_{2}$ reduced the leachability of naphthalene and phenanthrene from 100 and $25 \mu \mathrm{g} / \mathrm{mL}$ to 21.2 and $6.65 \mu \mathrm{g} / \mathrm{mL}$ after 1 day of curing period, respectively. This reduction is related to high sorption affinity of organoclay to organic contaminants. Moreover, the results exhibited that leached naphthalene and phenanthrene amount from the $\mathrm{S} / \mathrm{S}$ products at varying organoclay content 
decreased by increasing curing period. Thus, cement with a combination of organoclay significantly decreased the leachability of naphthalene and phenanthrene from the S/S products. This could be because of either the reactions of cement and contaminated soil that trapped the contaminants or sorption of the organic contaminants by organoclay. Consequently, the better leaching behavior is observed for mix design of $\mathrm{C}_{5} \mathrm{O}_{5}(5 \%$ cement and $5 \%$ organoclay) after 28 days of curing time in terms of satisfying the $90 \%$ reduction in naphthalene and phenanthrene leaching.

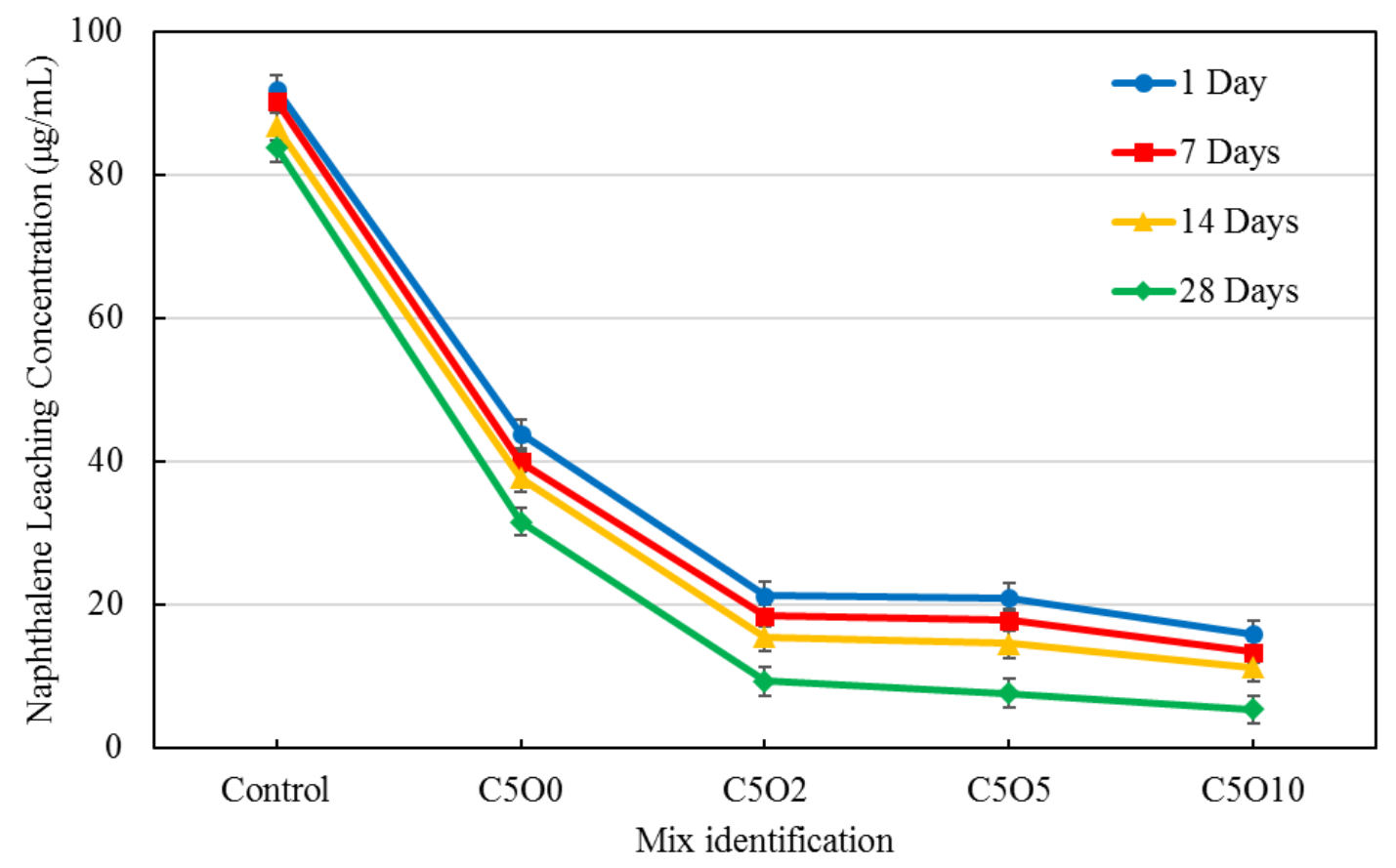

(a) 


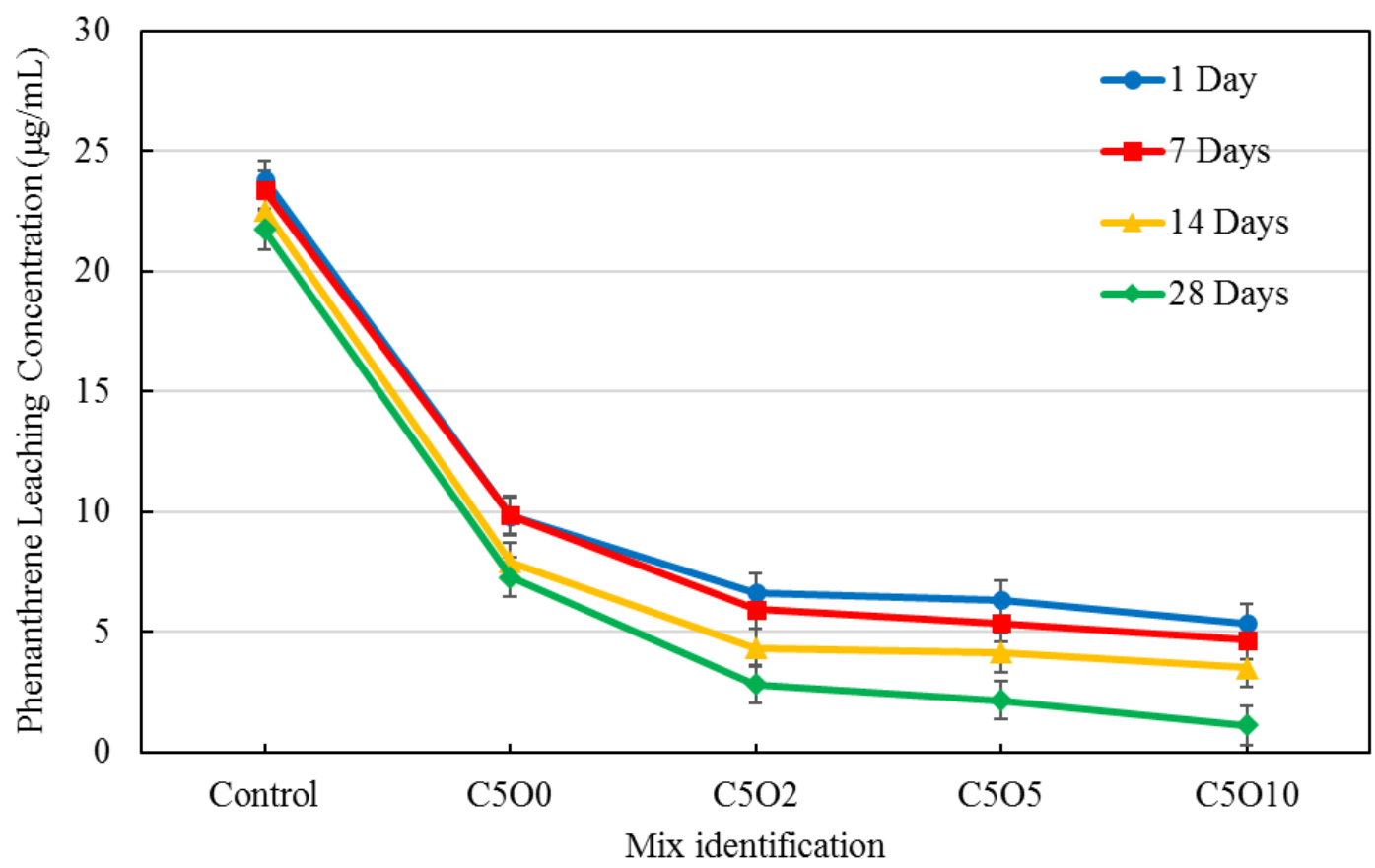

(b)

Figure 5-7. Reduction in (a) naphthalene and (b) phenanthrene mass leaching for each mix design 


\subsection{Conclusions}

The feasibility of using cement and organoclay for the stabilization and solidification (S/S) of the PAHs-contaminated soils was investigated in this chapter. Two polycyclic aromatic hydrocarbon compounds, naphthalene and phenanthrene were introduced to the natural soil as the contaminants. Portland cement at the concentration of 5 and 10\% (by weight) and the organoclay at the concentration of 2, 5 and $10 \%$ (by weight) were used as solidifier and stabilizer agents for stabilizing and immobilizing the naphthalene and phenanthrene in the contaminated soils. Laboratory tests were performed to measure the unconfined compressive strength (UCS) and permeability of the stabilized soils after 28days curing period. Moreover, Toxicity Characteristics Leaching Procedure (TCLP) were conducted on the stabilized soil specimens to investigate the reduction of leached naphthalene and phenanthrene. The significant observations from the current study are:

1- The unconfined compressive strength values of the contaminated soil increased when 5 to $10 \%$ of the weight of the S/S products is mixed with Portland cement. This strength increment is related to the hydration of cement which improves bonding between soil particles.

2- With the addition of the organoclay $(2,5$ and $10 \%$ of $\mathrm{S} / \mathrm{S}$ product weight) in the cement-solidified matrix, the unconfined compressive strength of S/S products slightly increased This increase is associated with the large particle size of organoclay that provides good packing density products. The unconfined compressive strength values of all mix designs were above the standard limit of 50 psi as mandated by USEPA. 
3- The hydraulic conductivity of contaminated soil was higher than the design criteria of $\mathrm{k} 1 \times 10^{-8} \mathrm{~m} / \mathrm{s}$. With the addition of various content of cement ( $5 \%$ and $\left.10 \%\right)$, the hydraulic conductivity of S/S products was one order of magnitude lower than the standard limit. Although, the hydraulic conductivity of the cement-solidified products slightly increased with the addition of organoclay, it was still lower than the required standard.

4- The TCLP results indicated that by just solidifying contaminated soil with cement, the leached naphthalene and phenanthrene decreased by approximately $67-72 \%$ and $72-78 \%$, respectively when acetic acid solution was used as a cosolvent. The decreased leachability of naphthalene and phenanthrene in the cement-solidified matrix was happening with the formation of many cavities containing encapsulated naphthalene and phenanthrene compounds. Increasing the amount of cement resulted in a lower leaching of organic contaminants from S/S products. Moreover, the leaching test results exhibited that when the pure acetone was used as cosolvent, the higher leachability of naphthalene and phenanthrene was observed due to the higher solubility of acetone compared to acetic acid solution.

5- The TCLP results exhibited that for a fixed cement content (5 or 10\%), increasing the organoclay portion (2, 5 and 10\%) increased the leaching reduction of naphthalene and phenanthrene. The results proved that organoclay particles sorbed the organic contaminates and consequently reduced the naphthalene and phenanthrene leachate concentration. Based on the percentage reductions on the cumulative mass release of naphthalene and phenanthrene for different mix design 
after 28-days curing period, at all the levels of organoclay percentage, the required 90\% leaching reductions for the naphthalene and phenanthrene were achieved.

6- The leaching test results indicated that the curing time plays an important role in leaching reduction. For each mix design, the naphthalene and phenanthrene leachate concentration decreased by increasing the curing time of S/S products.

7- The addition of the organoclay as a sorbent with a combination of cement greatly improves the immobilization of naphthalene and phenanthrene in contaminated soil. It was found that among the tested range of cement and organoclay for the S/S contaminated soil $\mathrm{C}_{5} \mathrm{O}_{2}$ was the optimum mix design for natural soil contaminated with solid phase of naphthalene and phenanthrene. While $\mathrm{C}_{5} \mathrm{O}_{5}$ was recognized as the best mix design for the natural soil contaminated with dissolved phase of contaminants. These proposed mixing designs satisfied the unconfined compressive strength, hydraulic conductivity, and leaching reduction requirements that are regulated by the USEPA. It is believed that this study would be quite useful to facilitate the remediation design for PAHs-contaminated soils by using cementorganoclay based solidification and stabilization technique. 


\section{CONCLUSIONS AND RECOMMENDATIONS}

The objectives of this study were described in the introduction (Chapter 1). The first section of this chapter relates the results to those objectives and presents the conclusions reached. The second section makes some recommendations for future studies.

\subsection{Conclusions}

This study focused on the microstructure of organic surfactant modified montmorillonite with enhanced engineering properties (e.g. excellent sorption capacity for organic compounds, high strength, low compressibility, and high swelling and low permeability in non-polar liquid) and their potential use in geoenvironmental engineering applications including hydraulic barriers for organic compounds, rheological control agents for drilling fluid, soil stabilization and contaminated site remediation. In this research, montmorillonites intercalated with two quaternary ammonium surfactants, hexadecyltrimethylammonium (HDTMA+) and bis (hydrogenated tallow alkyl) dimethyl ammonium were used as organoclays.

The organoclay microstructure changes due to the primary sorption (intercalated of organic surfactant within montmorillonite) and the secondary sorption (interaction between the organoclay and organic sorbates) were investigated by laboratory tests including XRD, TEM, SEM, and FT-IR. The SEM results exhibited that the naturally occurring montmorillonite, Ca-MMT, had large aggregated particles with curved edges, and in some 
areas, there were some large flakes. However, it was observed that after the modification of Ca-MMT with HDTMA organic surfactant, the particles of HDTMA-MMT showed a less foliated structure with rough edges, as well as a large number of small flakes.

The obtained results from XRD and TEM indicated that the interlayer spacing of montmorillonite expanded due to consecutive intercalation of surfactant and hydrocarbons (gasoline and naphthalene). The initial basal spacing of HDTMA-MMT and PM199 was 19.44 and $35.58 \AA$, respectively. The results suggested a lateral bilayers surfactant arrangement (basal spacing 17.7-19.8 ), and a paraffin-bilayers surfactant arrangement (basal spacing > $22 \AA$ ) for HDTMA-MMT and PM199, respectively. TEM results exhibited a good uniformity of intercalation and interlayer expansion of the organoclays upon interaction with the organic compounds. XRD and TEM results were in good correlation in terms of basal spacing of organoclays before and after sorption of organic molecules.

The FT-IR spectra of the organoclays demonstrated that the intensity of two bands (Si-O stretching, C-H stretching) increased upon interaction of organic compounds with organoclays, indicating increased interlayer organic carbon content and stronger stretching of siloxane surfaces. Furthermore, the FT-IR results suggested that in PM199, sorption of gasoline hydrocarbons lead to the less-ordered arrangement of surfactant chains and increased bending and torsion of the chains. As a result, stronger interactions were observed between the more "liquidlike" surfactants and organic sorbate molecules in PM199. This explains the ease of sorbate intercalation in PM199 from a perspective at the molecular level. Moreover, further twisting and bending of surfactant chains due to secondary intercalation were observed. The obtained results are expected to provide significant insights into the modified engineering properties (e.g. swelling, permeability, 
strength and compressibility) of intercalated organoclays and their potential applications in waste containment by the earthen barrier (chapter 3), rheological control agents for drilling fluids (chapter 4) and soil stabilization (chapter 5).

The feasibility of using organoclay as an amendment in earthen barriers including compacted clay liner and geosynthetic clay liner was investigated. The obtained results showed that low dosage of organoclay (PM199) additive (less than 30\%) in soil admixtures had limited or no impact on the overall hydraulic conductivity and intrinsic permeability of compacted silty clay soil. The results showed that the hydraulic conductivity and intrinsic permeability of the compacted silty clay-organobentonite mixtures increased as the organobentonite content increased. Moreover, it was observed that the difference between the hydraulic conductivities of compacted natural silty clay $\left(4.6 \times 10^{-9} \mathrm{~m} / \mathrm{s}\right)$ and compacted organobentonite $\left(7.5 \times 10^{-8} \mathrm{~m} / \mathrm{s}\right)$ was only 1 order of magnitude. The increased hydraulic conductivity of the compacted amended soil with organoclay is related to the hydrophobic characteristic of organoclay.

Additionally, the barrier performance of a compacted silty clay and HDTMAbentonite mixture was assessed. Obtained results from one-dimensional swelling test indicated that $10 \%$ of HDTMA-bentonite additive in silty clay had little or no impact on the free swelling of the mixture in water. However, 10\% HDTMA-bentonite amendment in silty clay showed a much higher swelling potential in gasoline due to the interaction between the organophilic phase in the organoclay particles and gasoline. When $10 \%$ HDTMA-bentonite was added to the compacted silty clay, the hydraulic conductivity of the silty clay increased from $5.04 \times 10^{-9} \mathrm{~m} / \mathrm{s}$ to $1.57 \times 10^{-8} \mathrm{~m} / \mathrm{s}$. However, $10 \%$ HDTMAbentonite amended silty clay showed a significant reduction in fluid conductivity when it 
was permeated with gasoline $\left(9.20 \times 10^{-10} \mathrm{~m} / \mathrm{s}\right.$, approximately 1 order of magnitude lower $)$. The combined results suggest that a small fraction of organoclay additives have limited impact on the hydraulic conductivity of amended compacted silty clay, whereas they decreased the fluid conductivity of the mixture when exposed to non-polar organic liquid.

It was observed that the hydraulic conductivity of geosynthetic clay liner (GCL) containing either $100 \%$ Na-bentonite $\left(1.7 \times 10^{-11} \mathrm{~m} / \mathrm{s}\right)$ or Ca-bentonite $\left(3 \times 10^{-10} \mathrm{~m} / \mathrm{s}\right)$ was lower compared to the hydraulic conductivity of $100 \%$ HDTMA-bentonite $\left(4.5 \times 10^{-8} \mathrm{~m} / \mathrm{s}\right)$ in GCL due to the hydration of naturally occurring bentonite. This study suggests that a low concentration of organo-bentonite amendment (up to 20\%) has little or no impact on the hydraulic conductivity of both amended Na-bentonite and Ca-bentonite GCLs. Although 10\% HDTMA-bentonite amendment in a Na-bentonite GCL can maintain low hydraulic conductivity, it cannot perform effectively when faced with non-polar or lowpolarity fluids such as gasoline and methanol. This can be explained as the GCL soil (10\% HDTMA-bentonite $+90 \%$ Na-bentonite) consists natural occurring bentonite, which is not compatible with organic liquids. The results of the fluid conductivity of GCL amended with organoclay suggested that $100 \%$ organoclay in a GCL matrix can be effective for decreasing the advection flow of petroleum products and can be used as a secondary liner system for underground storage tanks.

The rheological behavior of oil-based drilling fluid with organoclay additives (PM199 and HDTMA-MMT) was investigated using a rheometer, and the microstructure of the organoclay gels was examined by the XRD tests. The obtained results from XRD showed that PM199 had a much more dispersed structure in diesel oil compared to HDTMA-MMT. The combined results of XRD and swelling volume experiments 
suggested that the oil molecules easily penetrated into the interlayer of PM199, resulting in particle dispersion and consequently the exfoliation of PM199. However, HDTMAMMT organoclay presented poor interaction and particle dispersion in diesel oil and no intercalation of the oil molecules into interlayers was evidenced by the XRD results. The viscosity of the organoclays suspension increased as the amount of added HDTMA-MMT or PM199 increased, and the increased viscosity was more pronounced for PM199. The viscous flow curves of the organobentonite dispersions showed that HDTMA-MMT-oil behaved like a Newtonian fluid while PM199-oil exhibited a non-Newtonian fluid behavior and seemed more desirable for a drilling fluid.

Additionally, the impact of the temperature $\left(25\right.$ to $\left.150{ }^{\circ} \mathrm{C}\right)$ and pressure $(0$ to 200 bar) on the viscosity of the organoclay-oil suspension (5\% PM199 in diesel oil) was examined. It was observed that the viscosity of 5\% PM199 suspension slightly decreased by increasing the temperature from 25 to $60^{\circ} \mathrm{C}$, and then the viscosity increased when the temperature raised from 60 to $150{ }^{\circ} \mathrm{C}$. There are two major factors affecting the viscosity of the suspension as the temperature increases. The first one is related to the volume expansion of the diesel oil and the second one is the sorption of diesel oil by organobentonite. When the temperature increased from 25 to $60{ }^{\circ} \mathrm{C}$, the expansion of the diesel oil was dominant which led to overall decreasing in viscosity of the suspension. However, when the temperature raised up from 60 to $150{ }^{\circ} \mathrm{C}$, the interaction between organoclays and diesel oil increased which led to higher sorption of diesel oil by organobentonite and consequently increasing the viscosity of the suspension. Moreover, it was found that the viscosity of 5\% PM199 suspension increased when the pressure increased from 0 to 200 bar. The increased in viscosity of organoclay dispersion due to 
increasing the pressure is related to the physical changes that pressure exerts to the dispersions, not chemical activity between organobentonite and oil molecules.

The feasibility of using Portland cement and organobentonite to stabilize and solidify PAH-contaminated soil was examined. It was observed that unconfined compressive strength of the contaminated soil increased when Portland cement $(5 \%$ and $10 \%$ by weight) was introduced to the soil. This increment was related to the hydration of cement, which improved bonding between soil particles. Furthermore, when the organoclay (2, 5 and $10 \%$ by weight) was added to the cement-solidified soils, the unconfined compressive strength of S/S products slightly increased. Also, it was observed that by increasing the cement amount in $\mathrm{S} / \mathrm{S}$ soil, the hydraulic conductivity of $\mathrm{S} / \mathrm{S}$ products decreased to less than $10^{-8} \mathrm{~m} / \mathrm{s}$. However, the hydraulic conductivity of the cementsolidified products slightly increased with the addition of organoclay; it still met the requirement for stabilized soils $\left(10^{-7} \mathrm{~m} / \mathrm{s}\right)$.

The leaching test results indicated that by solidifying contaminated soil with Portland cement only ( 5 and $10 \%$ by weight), the leached naphthalene and phenanthrene from S/S contaminated soil decreased by approximately $67-72 \%$ and $72-78 \%$, respectively. The decreased leachability of naphthalene and phenanthrene in the cement-solidified matrix is associated with the formation of many cavities containing encapsulated naphthalene and phenanthrene compounds. Also, the leaching test results indicated that for a fixed cement content ( 5 or $10 \%$ by wt), increasing the organoclay portion (2, 5 and $10 \%$ by wt) further reduced the leaching of naphthalene and phenanthrene from the contaminated soil by approximately 90 to $95 \%$. It was also observed that the naphthalene and phenanthrene leachate concentration decreased by increasing the curing time of S/S products. Overall, 
the addition of the organoclay as a sorbent with the combination of Portland cement greatly improved the immobilization of naphthalene and phenanthrene in contaminated soil.

\subsection{Recommendations for future studies}

The following specific recommendations are made for additional research to supplement the current study and to provide further insight into the engineering practices of surfactant-clay hybrids.

1- Another study to examine the effect of other petroleum hydrocarbons such as BTEX (benzene, toluene, ethylbenzene and xylene), which are the most common pollutants in environmental systems, on the organoclay interlayer morphology. Moreover, it is recommended to investigate the impact of the microstructure of interlayer surfactants on physical-chemical properties of organoclays including strength, compressibility, and thermal stability.

2- Further research to consider the impact on adsorptivity and hydraulic conductivity of compacted clay barrier when various smaller proportions of organoclay in clay barrier material are employed with the same permeant liquids. This study used $10 \%$ organoclay in the compacted clay materials, and the results satisfy the criterion for the fluid conductivity of CCL when faced with either organic or inorganic liquids. Further studies could investigate using, for example, 3\% and 5\% organoclay in CCL.

3- Another study to investigate the effect of isolating organoclay in a separate layer to reduce its effect on fluid conductivity while continuing to enhance sorptivity of organic liquids. Moreover, this study only investigated the fluid conductivity of 
organoclay amendment when faced with water and gasoline. However, other organic or semi-organic liquids such as diesel oil, ethanol, and landfill leachate as a permeant liquid should be examined.

4- In the rheological behavior of oil-based drilling fluid with organoclay additive, it was found the type of organic surfactant played an important role on the structure of organoclay/oil drilling fluids. Further research could investigate which type of organic surfactant with defined characteristics and proprieties can be used as an effective surfactant to make a promising organic-oil based drilling fluid. Moreover, it is highly recommended that the impacts of higher temperature (higher than 200 ${ }^{\circ} \mathrm{C}$ ), higher shear rate (greater than $100 \mathrm{1} / \mathrm{s}$ ), and different kind of organic oils (e.g. mineral oil) on the rheology of organoclay suspension are investigated in future studies.

5- It was proved that combination of cement and organoclay as solidifier and stabilizer agents to remediate the organic-contaminated soil was highly effective. Still more microstructure level tests such as TEM, XRD, and FT-IR could be conducted to enhance the understanding how cement and organoclay sorbed and encapsulated organic contaminants. 


\section{REFERENCE}

Abood, T. T., Kasa, A. B., and Chik, Z. B. (2007). "Stabilisation of silty clay soil using chloride compounds." Journal of Engineering Science and Technology, 2(1), 102110.

Aislabie, J., Balks, M., Astori, N., Stevenson, G., and Symons, R. (1999). "Polycyclic aromatic hydrocarbons in fuel-oil contaminated soils, Antarctica." Chemosphere, 39(13), 2201-2207.

Alexandre, M., and Dubois, P. (2000). "Polymer-layered silicate nanocomposites: preparation, properties and uses of a new class of materials." Materials Science and Engineering: R: Reports, 28(1), 1-63.

Alkaram, U. F., Mukhlis, A. A., and Al-Dujaili, A. H. (2009). "The removal of phenol from aqueous solutions by adsorption using surfactant-modified bentonite and kaolinite." Journal of Hazardous Materials, 169(1), 324-332.

Amani, M., Al-Jubouri, M., and Shadravan, A. (2012). "Comparative study of using oilbased mud versus water-based mud in HPHT fields." Advances in Petroleum Exploration and Development, 4(2), 18-27.

Aston, M., Alberty, M., McLean, M., De Jong, H., and Armagost, K. "Drilling fluids for wellbore strengthening." Proc., IADC/SPE Drilling Conference, Society of Petroleum Engineers.

Bate, B., Zhao, Q., and Burns, S. (2013). "Impact of organic coatings on frictional strength of organically modified clay." Journal of Geotechnical and Geoenvironmental Engineering, 140(1), 228-236.

Beall, G. W. (2003). "The use of organo-clays in water treatment." Applied Clay Science, 24(1), 11-20. 
Becker, S., Halsall, C. J., Tych, W., Hung, H., Attewell, S., Blanchard, P., Li, H., Fellin, P., Stern, G., and Billeck, B. (2006). "Resolving the long-term trends of polycyclic aromatic hydrocarbons in the Canadian Arctic atmosphere." Environmental science \& technology, 40(10), 3217-3222.

Belarbi, H., and Al-Malack, M. (2010). "Adsorption and stabilization of phenol by modified local clay." International Journal of Environmental Research, 4(4), 855860.

Benchabane, A., and Bekkour, K. (2006). "Effects of anionic additives on the rheological behavior of aqueous calcium montmorillonite suspensions." Rheologica acta, 45(4), 425-434.

Benson, C., Jo, H., and Musso, T. (2015). "Hydraulic Conductivity of Organoclay and Organoclay-Sand Mixtures to Fuels and Organic Liquids." Journal of Geotechnical and Geoenvironmental Engineering, 141(2), 04014094.

Benson, C., Zhai, H., and Wang, X. (1994). "Estimating Hydraulic Conductivity of Compacted Clay Liners." Journal of Geotechnical Engineering, 120(2), 366-387.

Bergaya, F., and Lagaly, G. (2006). "General introduction: clays, clay minerals, and clay science." Developments in clay science, 1, 1-18.

Bergaya, F., and Lagaly, G. (2013). Handbook of clay science, Newnes.

Bhatt, J., Somani, R. S., Mody, H. M., and Bajaj, H. C. (2013). "Rheological study of organoclays prepared from Indian bentonite: effect of dispersing methods." Applied Clay Science, 83, 106-114.

Bonczek, J. L., Harris, W., and Nkedi-Kizza, P. (2002). "Monolayer to bilayer transitional arrangements of hexadecyltrimethylammonium cations on Na-montmorillonite." Clays and Clay Minerals, 50(1), 11-17.

Botta, D., Dotelli, G., Biancardi, R., Pelosato, R., and Sora, I. N. (2004). "Cement-clay pastes for stabilization/solidification of 2-chloroaniline." Waste Management, 24(2), 207-216.

Bouazza, A. (2002). "Geosynthetic clay liners." Geotextiles and Geomembranes, 20(1), 317. 
Bowders, J. J., and Daniel, D. (1987). "Hydraulic Conductivity of Compacted Clay to Dilute Organic Chemicals." Journal of Geotechnical Engineering, 113(12), 14321448.

Broderick, G. P., and Daniel, D. E. (1990). "Stabilizing compacted clay against chemical attack." Journal of Geotechnical Engineering, 116(10), 1549-1567.

Brown, K., Green, J., and Thomas, J. "The influence of selected organic liquids on the permeability of clay liners." Proc., Proc., Land Disposal of Hazardous Waste 9th Annual Research Symp, 114-125.

Budhu, Muni. soil mechanics and foundations, (With CD). John Wiley \& Sons, 2008

Burgentzlé, D., Duchet, J., Gérard, J., Jupin, A., and Fillon, B. (2004). "Solvent-based nanocomposite coatings: I. Dispersion of organophilic montmorillonite in organic solvents." Journal of Colloid and Interface Science, 278(1), 26-39.

Burns, S., Bartelt-Hunt, S., Smith, J., and Redding, A. (2006). "Coupled mechanical and chemical behavior of bentonite engineered with a controlled organic phase." Journal of geotechnical and geoenvironmental engineering, 132(11), 1404-1412.

Burstein, F., Borisover, M., Lapides, I., and Yariv, S. (2008). "Secondary adsorption of nitrobenzene and m-nitrophenol by hexadecyltrimethylammoniummontmorillonite thermo-XRD-analysis." Journal of Thermal Analysis and Calorimetry, 92(1), 35-42.

Caenn, R., and Chillingar, G. V. (1996). "Drilling fluids: State of the art." journal of petroleum science and engineering, 14(3), 221-230.

Caenn, R., Darley, H. C., and Gray, G. R. (2011). Composition and properties of drilling and completion fluids, Gulf professional publishing.

Cassagnau, P. (2008). "Melt rheology of organoclay and fumed silica nanocomposites." Polymer, 49(9), 2183-2196.

Chhabra, R. P., and Richardson, J. F. (2011). Non-Newtonian flow and applied rheology: engineering applications, Butterworth-Heinemann.

Chuang, Y.-H., Liu, C.-H., Tzou, Y.-M., Chang, J.-S., Chiang, P.-N., and Wang, M.-K. (2010). "Comparison and characterization of chemical surfactants and biosurfactants intercalated with layered double hydroxides (LDHs) for removing 
naphthalene from contaminated aqueous solutions." Colloids and Surfaces A: Physicochemical and Engineering Aspects, 366(1), 170-177.

Daniel, D., Shan, H., and Anderson, J. "Effects of partial wetting on the performance of the bentonite component of a geosynthetic clay liner." Proc., Proceedings of Geosynthetics, 1483-1496.

Darley, H. C., and Gray, G. R. (1988). Composition and properties of drilling and completion fluids, Gulf Professional Publishing.

de Paiva, Betega, L., Morales, A. R., and Valenzuela Díaz, F. R. (2008). "Organoclays: Properties, preparation and applications." Applied Clay Science, 42(1-2), 8-24.

de Paiva, L. B., Morales, A. R., and Díaz, F. R. V. (2008). "Organoclays: properties, preparation and applications." Applied Clay Science, 42(1), 8-24.

Delle Site, A. (2001). "Factors affecting sorption of organic compounds in natural sorbent/water systems and sorption coefficients for selected pollutants. A review." Journal of Physical and Chemical Reference Data, 30(1), 187-439.

Di, Y., Iannace, S., Maio, E. D., and Nicolais, L. (2005). "Poly (lactic acid)/organoclay nanocomposites: thermal, rheological properties and foam processing." Journal of Polymer Science Part B: Polymer Physics, 43(6), 689-698.

Dotelli, G., Stampino, P. G., Zampori, L., Sora, I. N., and Pelosato, R. (2008). "Immobilization of organic pollutants in cement pastes admixed with organophilic materials." Waste Management \& Research, 26(6), 515-522.

Ebrahimi, M., Kazemi, H., Mirbagheri, S., and Rockaway, T. D. (2016). "An optimized biological approach for treatment of petroleum refinery wastewater." Journal of Environmental Chemical Engineering, 4(3), 3401-3408.

Esfandiari, A., Nazokdast, H., Rashidi, A.-S., and Yazdanshenas, M.-E. (2008). "Review of polymer-organoclay nanocomposites." Journal of Applied sciences, 8(3), 545561.

Fernandez, F., and Quigley, R. M. (1985). "Hydraulic conductivity of natural clays permeated with simple liquid hydrocarbons." Canadian Geotechnical Journal, 22(2), 205-214.

Gates, W. P., Nefiodovas, A., and Peter, P. (2004). "Permeability of an organo-modified bentonite to ethanol-water solutions." Clays and Clay Minerals, 52(2), 192-203. 
Gehle, K. (2009). Toxicity of polycyclic aromatic hydrocarbons (PAHs), US Department of Health \& Human Services, Public Health Service, Agency for Toxic Substances and Disease Registry.

Gentry, J. L., Niemet, M. R., Grubb, D. G., Bruno, M., Berggren, D. R., and Tsiamis, C. D. (2014). "Gowanus canal superfund site. II: stabilization/solidification of MGPimpacted sediments." Journal of Hazardous, Toxic, and Radioactive Waste, 19(1), C4014004.

Ghavami, M., Zhao, Q., Javadi, S., Jangam, J. S. D., Jasinski, J. B., and Saraei, N. (2017). "Change of organobentonite interlayer microstructure induced by sorption of aromatic and petroleum hydrocarbons - A combined study of laboratory characterization and molecular dynamics simulations." Colloids and Surfaces A: Physicochemical and Engineering Aspects, 520, 324-334.

Gheibi, E., Sasanakul, I., Sanin, M. V., and Puebla, H. (2016). "Effect of temperatures on the dynamic properties of asphaltic core for an earth dam." Geo-Chicago 2016, 272, 266-275.

Gitipour, S., Bowers, M. T., and Bodocsi, A. (1997). "The use of modified bentonite for removal of aromatic organics from contaminated soil." Journal of Colloid and Interface Science, 196(2), 191-198.

Gleason, M. H., Daniel, D. E., and Eykholt, G. R. (1997). "Calcium and sodium bentonite for hydraulic containment applications." Journal of Geotechnical and Geoenvironmental Engineering, 123(5), 438-445.

Guggenheim, S., and Martin, R. (1995). "Definition of clay and clay mineral: joint report of the AIPEA nomenclature and CMS nomenclature committees." Clays and clay minerals, 43(2), 255-256.

Hamdi, N., and Srasra, E. (2013). "Hydraulic conductivity study of compacted clay soils used as landfill liners for an acidic waste." Waste Management, 33(1), 60-66.

Hato, M. J., Zhang, K., Ray, S. S., and Choi, H. J. (2011). "Rheology of organoclay suspension." Colloid and Polymer Science, 289(10), 1119.

He, H., Ding, Z., Zhu, J., Yuan, P., Xi, Y., Yang, D., and Frost, R. L. (2005). "Thermal Charactrization of Surfactant-Modified Montmorillonites." Clays and Clay Minerals, 53(3), 287-293. 
He, H., Frost, R. L., Bostrom, T., Yuan, P., Duong, L., Yang, D., Xi, Y., and Kloprogge, J. T. (2006). "Changes in the morphology of organoclays with HDTMA+ surfactant loading." Applied Clay Science, 31(3), 262-271.

He, H., Yang, D., Yuan, P., Shen, W., and Frost, R. L. (2006). "A novel organoclay with antibacterial activity prepared from montmorillonite and Chlorhexidini Acetas." Journal of colloid and interface science, 297(1), 235-243.

He, H., Zhou, Q., Martens, W. N., Kloprogge, T. J., Yuan, P., Xi, Y., Zhu, J., and Frost, R. L. (2006). "Microstructure of HDTMA+-modified montmorillonite and its influence on sorption characteristics." Clays and Clay Minerals, 54(6), 689-696.

Hebatpuria, V. M., Arafat, H. A., Rho, H. S., Bishop, P. L., Pinto, N. G., and Buchanan, R. C. (1999). "Immobilization of phenol in cement-based solidified/stabilized hazardous wastes using regenerated activated carbon: leaching studies." Journal of hazardous materials, 70(3), 117-138.

Hermoso, J., Martínez-Boza, F., and Gallegos, C. (2014). "Combined Effect of Pressure and Temperature on the Viscous Behaviour of All-Oil Drilling Fluids." Oil \& Gas Science and Technology-Revue d'IFP Energies nouvelles, 69(7), 1283-1296.

Hermoso, J., Martinez-Boza, F., and Gallegos, C. (2014). "Influence of viscosity modifier nature and concentration on the viscous flow behaviour of oil-based drilling fluids at high pressure." Applied Clay Science, 87, 14-21.

Herzhaft, B., Peysson, Y., Isambourg, P., Delepoulle, A., and Abdoulaye, T. "Rheological properties of drilling muds in deep offshore conditions." Proc., SPE/IADC drilling conference, Society of Petroleum Engineers.

Hongping, H., Ray, F. L., and Jianxi, Z. (2004). "Infrared study of HDTMA+ intercalated montmorillonite." Spectrochimica Acta Part A: Molecular and Biomolecular Spectroscopy, 60(12), 2853-2859.

Ikhtiyarova, G., Özcan, A., Gök, Ö., and Özcan, A. (2012). "Characterization of naturaland organo-bentonite by XRD, SEM, FT-IR and thermal analysis techniques and its adsorption behaviour in aqueous solutions." Clay Minerals, 47(1), 31-44.

Javadi, S., Ghavami, M., Zhao, Q., and Bate, B. (2016). "Advection and retardation of nonpolar contaminants in compacted clay barrier material with organoclay amendment." Applied Clay Science. 
Jaynes, W., and Vance, G. (1999). "Sorption of benzene, toluene, ethylbenzene, and xylene (BTEX) compounds by hectorite clays exchanged with aromatic organic cations." Clays and Clay Minerals, 47(3), 358-365.

Jo, H. Y., Benson, C. H., Shackelford, C. D., Lee, J.-M., and Edil, T. B. (2005). "Longterm hydraulic conductivity of a geosynthetic clay liner permeated with inorganic salt solutions." Journal of Geotechnical and Geoenvironmental Engineering, 131(4), 405-417.

Jo, H. Y., Katsumi, T., Benson, C. H., and Edil, T. B. (2001). "Hydraulic conductivity and swelling of nonprehydrated GCLs permeated with single-species salt solutions." Journal of Geotechnical and Geoenvironmental Engineering, 127(7), 557-567.

Kandhal, P. S., and Parker, F. (1998). Aggregate tests related to asphalt concrete performance in pavements, Transportation Research Board.

Karamalidis, A. K., and Voudrias, E. A. (2007). "Cement-based stabilization/solidification of oil refinery sludge: leaching behavior of alkanes and PAHs." Journal of hazardous materials, 148(1), 122-135.

Kelessidis, V. C., Christidis, G., Makri, P., Hadjistamou, V., Tsamantaki, C., Mihalakis, A., Papanicolaou, C., and Foscolos, A. (2007). "Gelation of water-bentonite suspensions at high temperatures and rheological control with lignite addition." Applied clay science, 36(4), 221-231.

Khabiri, M. M., Khishdari, A., and Gheibi, E. (2017). "Effect of tyre powder penetration on stress and stability of the road embankments." Road Materials and Pavement Design, 18(4), 966-979.

Khodja, M., Canselier, J. P., Bergaya, F., Fourar, K., Khodja, M., Cohaut, N., and Benmounah, A. (2010). "Shale problems and water-based drilling fluid optimisation in the Hassi Messaoud Algerian oil field." Applied Clay Science, 49(4), 383-393.

King Jr, H., Milner, S. T., Lin, M. Y., Singh, J. P., and Mason, T. (2007). "Structure and rheology of organoclay suspensions." Physical Review E, 75(2), 021403.

Koerner, R. M. (2012). Designing with geosynthetics, Xlibris Corporation.

Kolstad, D. C. (2000). Compatibility of geosynthetic clay liners (GCLs) with multi-species inorganic solutions, University of Wisconsin--Madison. 
Lagaly, G (1994). "Layer charge determination by alkylammonium ions." Layer charge characteristics of 2: 1 silicate clay minerals 6: 1-46.

Lagaly, G. "Layer charge determination by alkylammonium ions. Pp. 1 À46 in: Layer charge characteristics of 2: 1 silicate clay minerals (AR Mermut, editor)." Proc., CMS Workshop lectures, $495 \mathrm{y} 544$.

Lagaly, G. (1981). "Characterization of clays by organic compounds." CLAY MINER. Clay Miner., 16(1), 1.

Lagaly, G. (1986). "Interaction of alkylamines with different types of layered compounds." Solid State Ionics, 22(1), 43-51.

Lagaly, G., and Dékany, I. (2005). "Adsorption on hydrophobized surfaces: clusters and self-organization." Advances in colloid and interface science, 114, 189-204.

LaGrega, M. D., Buckingham, P. L., and Evans, J. C. (2010). Hazardous waste management, Waveland Press.

Lake, C. B., and Rowe, R. K. (2005). "The 14-year performance of a compacted clay liner used as part of a composite liner system for a leachate lagoon." Geotechnical and Geological Engineering, 23(6), 657-678.

Lan, T., Kaviratna, P. D., and Pinnavaia, T. J. (1995). "Mechanism of clay tactoid exfoliation in epoxy-clay nanocomposites." Chemistry of Materials, 7(11), 21442150.

Lee, J.-M., and Shackelford, C. D. (2005). "Impact of bentonite quality on hydraulic conductivity of geosynthetic clay liners." Journal of Geotechnical and Geoenvironmental Engineering, 131(1), 64-77.

Lee, S. Y., and Kim, S. J. (2002). "Adsorption of naphthalene by HDTMA modified kaolinite and halloysite." Applied Clay Science, 22(1), 55-63.

Lee, S. Y., Cho, W. J., Hahn, P. S., Lee, M., Lee, Y. B., and Kim, K. J. (2005). "Microstructural changes of reference montmorillonites by cationic surfactants." Applied Clay Science, 30(3), 174-180.

Lee, S., Ören, A., Benson, C., and Dovantzis, K. (2012). "Organoclays as Variably Permeable Reactive Barrier Media to Manage NAPLs in Ground Water." Journal of Geotechnical and Geoenvironmental Engineering, 138(2), 115-127. 
Leonard, S. A., and Stegemann, J. A. (2010). "Stabilization/solidification of petroleum drill cuttings: Leaching studies." Journal of hazardous materials, 174(1), 484-491.

Li, J. s., Xue, Q., Wang, P., Li, Z. z., and Du, Y. j. (2015). "Solidification/stabilization of lead-contaminated soil using cement and waste phosphorus slag." Environmental Progress \& Sustainable Energy, 34(4), 957-963.

Li, J., Smith, J. A., and Winquist, A. S. (1996). "Permeability of earthen liners containing organobentonite to water and two organic liquids." Environmental Science \& Technology, 30(10), 3089-3093.

Lo, I. M. C., and Yang, X. Y. (2001). "Use of organoclay as secondary containment for gasoline storage tanks." J. Environ. Eng.-ASCE, 127(2), 154-161.

Lo, I. M. C., Mak, R. K. M., and Lee, C. H. (1997). "Modified Clays for Waste Containment and Pollutant Attenuation." Journal of Environmental Engineering, 123(1), 25-32.

López-Vizcaíno, R., Sáez, C., Cañizares, P., and Rodrigo, M. (2012). "The use of a combined process of surfactant-aided soil washing and coagulation for PAHcontaminated soils treatment." Separation and purification technology, 88, 46-51.

Lorenzetti, R. J., Bartelt-Hunt, S. L., Burns, S. E., and Smith, J. A. (2005). "Hydraulic conductivities and effective diffusion coefficients of geosynthetic clay liners with organobentonite amendments." Geotextiles and Geomembranes, 23(5), 385-400.

Mallakpour, S., and Dinari, M. (2011). "Preparation and characterization of new organoclays using natural amino acids and Cloisite Na+." Applied Clay Science, 51(3), 353-359.

Masooleh, M. S., Bazgir, S., Tamizifar, M., and Nemati, A. (2010). "Adsorption of petroleum hydrocarbons on organoclay." Journal of applied chemical researches, 4(14), 19-25.

Means, J. L. S., Nehring, L. A., Brauning, K. W., Gavaskar, S. E., Sass, A. R., Wiles, B. M., Mashni, C. C., and Charles, I. (1995). The] application of solidification/stabilization to waste materials.

Minase, M., Kondo, M., Onikata, M., and Kawamura, K. (2008). "The viscosity of organic liquid suspensions of trimethyldococylammonium-montmorillonite complexes." Clays and Clay Minerals, 56(1), 49-65. 
Mirbagheri, S. A., Ebrahimi, M., and Mohammadi, M. (2014). "Optimization method for the treatment of Tehran petroleum refinery wastewater using activated sludge contact stabilization process." Desalination and Water Treatment, 52(1-3), 156163.

Mohebbi, M., Gitipour, S., and Madadian, E. (2013). "Solidification/Stabilization of Cresol-Contaminated Soil: Mechanical and Leaching Behavior." Soil and Sediment Contamination: An International Journal, 22(7), 783-799.

Moon, C.-H., Lee, J.-Y., Oh, B.-T., and Choi, S.-I. (2007). "Organically modified lowgrade kaolin as a secondary containment material for underground storage tanks." Environmental Geochemistry and Health : Official Journal of the Society for Environmental Geochemistry and Health, 29(4), 271-280.

Nourmoradi, H., Khiadani, M., and Nikaeen, M. (2012). "Multi-component adsorption of benzene, toluene, ethylbenzene, and xylene from aqueous solutions by montmorillonite modified with tetradecyl trimethyl ammonium bromide." Journal of Chemistry, 2013.

Paria, S., and Yuet, P. K. (2006). "Solidification-stabilization of organic and inorganic contaminants using portland cement: a literature review." Environmental Reviews, 14(4), 217-255.

Park, J.-Y., Lee, H.-H., Kim, S.-J., Lee, Y.-J., and Yang, J.-W. (2007). "Surfactantenhanced electrokinetic removal of phenanthrene from kaolinite." Journal of hazardous materials, 140(1), 230-236.

Park, Y., Ayoko, G. A., and Frost, R. L. (2011). "Application of organoclays for the adsorption of recalcitrant organic molecules from aqueous media." Journal of Colloid and Interface Science, 354(1), 292-305.

Park, Y., Ayoko, G. A., and Frost, R. L. (2011). "Characterisation of organoclays and adsorption of p-nitrophenol: environmental application." Journal of colloid and interface science, 360(2), 440-456.

Pavia, D., Lampman, G., Kriz, G., and Vyvyan, J. (2008). Introduction to spectroscopy, Cengage Learning.

Rao, S., Thyagaraj, T., and Thomas, H. (2006). "Swelling of compacted clay under osmotic gradients." Geotechnique, 56(10), 707-713. 
Redding, A., Burns, S., Upson, R., and Anderson, E. (2002). "Organoclay sorption of benzene as a function of total organic carbon content." Journal of Colloid and Interface Science, 250(1), 261-264.

Richards, S., and Bouazza, A. (2007). "Phenol adsorption in organo-modified basaltic clay and bentonite." Applied Clay Science, 37(1), 133-142.

Rowe, R. K. (2001). Geotechnical and geoenvironmental engineering handbook, Springer Science \& Business Media.

Rowe, R. K., Quigley, R. M., Brachman, R. W., Booker, J. R., and Brachman, R. (2004). Barrier systems for waste disposal facilities, Spon press.

Ruhl, J. L., and Daniel, D. E. (1997). "Geosynthetic clay liners permeated with chemical solutions and leachates." Journal of Geotechnical and Geoenvironmental Engineering, 123(4), 369-381.

Sanchez-Martin, M., Rodriguez-Cruz, M., Andrades, M., and Sanchez-Camazano, M. (2006). "Efficiency of different clay minerals modified with a cationic surfactant in the adsorption of pesticides: influence of clay type and pesticide hydrophobicity." Applied Clay Science, 31(3), 216-228.

Santamarina, J., Klein, K., Wang, Y., and Prencke, E. (2002). "Specific surface: determination and relevance." Canadian Geotechnical Journal, 39(1), 233-241.

Schampera, B., Tunega, D., Šolc, R., Woche, S., Mikutta, R., Wirth, R., Dultz, S., and Guggenberger, G. (2016). "External surface structure of organoclays analyzed by transmission electron microscopy and X-ray photoelectron spectroscopy in combination with molecular dynamics simulations." Journal of Colloid and Interface Science, 478, 188-200.

Shackelford, C. D., Benson, C. H., Katsumi, T., Edil, T. B., and Lin, L. (2000). "Evaluating the hydraulic conductivity of GCLs permeated with non-standard liquids." Geotextiles and Geomembranes, 18(2), 133-161.

Shackelford, C. D., Sevick, G. W., and Eykholt, G. R. (2010). "Hydraulic conductivity of geosynthetic clay liners to tailings impoundment solutions." Geotextiles and Geomembranes, 28(2), 149-162.

Shan, H., and Daniel, D. "Results of laboratory tests on a geotextile/bentonite liner material." Proc., Proceedings Geosynthetics, 517e535. 
Sharma, H. D., and Lewis, S. P. (1994). Waste containment systems, waste stabilization, and landfills: design and evaluation, John Wiley \& Sons.

Sharma, H. D., and Reddy, K. R. (2004). Geoenvironmental engineering: site remediation, waste containment, and emerging waste management technologies, John Wiley \& Sons, Inc.

Sheng, G., and Boyd, S. A. (2000). "Polarity effect on dichlorobenzene sorption by hexadecyltrimethylammonium-exchanged clays." Clays and Clay Minerals, 48(1), 43-50.

Silva, I., Sousa, F., Menezes, R., Neves, G., Santana, L., and Ferreira, H. (2014). "Modification of bentonites with nonionic surfactants for use in organic-based drilling fluids." Applied Clay Science, 95, 371-377.

Smith, J. A., Bartelt-Hunt, S. L., and Burns, S. E. (2003). "Sorption and permeability of gasoline hydrocarbons in organobentonite porous media." Journal of Hazardous Materials, 96(1), 91-97.

Soule, N. M., and Burns, S. E. (2001). "Effects of organic cation structure on behavior of organobentonites." Journal of Geotechnical and Geoenvironmental Engineering, 127(4), 363-370.

Sun, D. a., Cui, H., and Sun, W. (2009). "Swelling of compacted sand-bentonite mixtures." Applied Clay Science, 43(3), 485-492.

Sun, Z., Park, Y., Zheng, S., Ayoko, G. A., and Frost, R. L. (2013). "XRD, TEM, and thermal analysis of Arizona Ca-montmorillonites modified with didodecyldimethylammonium bromide." Journal of colloid and interface science, $408,75-81$.

Upson, R., and Burns, S. (2006). "Sorption of nitroaromatic compounds to synthesized organoclays." Journal of colloid and interface science, 297(1), 70-76.

USEPA (2011). "Record of decision, operable unit 1, quanta resources OU1, Edgewater, New Jersey."New York.

Vaia, R. A., Teukolsky, R. K., and Giannelis, E. P. (1994). "Interlayer structure and molecular environment of alkylammonium layered silicates." Chemistry of Materials, 6(7), 1017-1022. 
Wang, X.-p., Huang, A.-m., Jia, D.-m., and Li, Y.-m. (2008). "From exfoliation to intercalation — changes in morphology of HNBR/organoclay nanocomposites." European Polymer Journal, 44(9), 2784-2789.

Wen, X., He, H., Zhu, J., Jun, Y., Ye, C., and Deng, F. (2006). "Arrangement, conformation, and mobility of surfactant molecules intercalated in montmorillonite prepared at different pillaring reagent concentrations as studied by solid-state NMR spectroscopy." Journal of colloid and interface science, 299(2), 754-760.

Wilcke, W. (2007). "Global patterns of polycyclic aromatic hydrocarbons (PAHs) in soil." Geoderma, 141(3), 157-166.

Xi, Y., Frost, R. L., He, H., Kloprogge, T., and Bostrom, T. (2005). "Modification of Wyoming montmorillonite surfaces using a cationic surfactant." Langmuir, 21(19), 8675-8680.

Xi, Y., Mallavarapu, M., and Naidu, R. (2010). "Preparation, characterization of surfactants modified clay minerals and nitrate adsorption." Applied Clay Science, 48(1), 92-96.

Xi, Y., Zhou, Q., Frost, R. L., and He, H. (2007). "Thermal stability of octadecyltrimethylammonium bromide modified montmorillonite organoclay." Journal of Colloid and Interface Science, 311(2), 347-353.

Xie, W., Gao, Z., Pan, W.-P., Hunter, D., Singh, A., and Vaia, R. (2001). "Thermal degradation chemistry of alkyl quaternary ammonium montmorillonite." Chemistry of Materials, 13(9), 2979-2990.

Yang, X., and Lo, I. (2004). "Flow of Gasoline through Composite Liners." Journal of Environmental Engineering, 130(8), 886-890.

Yariv, S., and Cross, H. (2001). Organo-clay complexes and interactions, CRC Press.

Yilmaz, O., Ünlü, K., and Cokca, E. (2003). "Solidification/stabilization of hazardous wastes containing metals and organic contaminants." Journal of environmental engineering, 129(4), 366-376.

Zhang, L.-M., Jahns, C., Hsiao, B. S., and Chu, B. (2003). "Synchrotron SAXS/WAXD and rheological studies of clay suspensions in silicone fluid." Journal of colloid and interface science, 266(2), 339-345. 
Zhao, Q., and Burns, S. E. (2012). "Microstructure of single chain quaternary ammonium cations intercalated into montmorillonite: A molecular dynamics study." Langmuir, 28(47), 16393-16400.

Zhao, Q., and Burns, S. E. (2012). "Molecular dynamics simulation of secondary sorption behavior of montmorillonite modified by single chain quaternary ammonium cations." Environmental science \& technology, 46(7), 3999-4007.

Zhao, Q., Choo, H., Bhatt, A., Burns, S. E., and Bate, B. (2016). "Review of the fundamental geochemical and physical behaviors of organoclays in barrier applications." Applied Clay Science.

Zhong, Y., and Wang, S.-Q. (2003). "Exfoliation and yield behavior in nanodispersions of organically modified montmorillonite clay." Journal of Rheology, 47(2), 483-495.

Zhou, L., Chen, H., Jiang, X., Lu, F., Zhou, Y., Yin, W., and Ji, X. (2009). "Modification of montmorillonite surfaces using a novel class of cationic gemini surfactants." Journal of colloid and interface science, 332(1), 16-21.

Zhou, Q., Frost, R. L., He, H., and Xi, Y. (2007). "Changes in the surfaces of adsorbed para-nitrophenol on HDTMA organoclay-The XRD and TG study." Journal of colloid and interface science, 307(1), 50-55.

Zhou, Q., Frost, R. L., He, H., Xi, Y., and Liu, H. (2007). "Adsorbed para-nitrophenol on HDTMAB organoclay-A TEM and infrared spectroscopic study." Journal of colloid and interface science, 307(2), 357-363.

Zhou, Q., Frost, R. L., He, H., Xi, Y., and Zbik, M. (2007). "TEM, XRD, and thermal stability of adsorbed paranitrophenol on DDOAB organoclay." Journal of colloid and interface science, 311(1), 24-37.

Zhou, Q., Zhu, R., Parker, S. C., Zhu, J., He, H., and Molinari, M. (2015). "Modelling the effects of surfactant loading level on the sorption of organic contaminants on organoclays." RSC Advances, 5(58), 47022-47030.

Zhu, J., He, H., Guo, J., Yang, D., and Xie, X. (2003). "Arrangement models of alkylammonium cations in the interlayer of HDTMA+ pillared montmorillonites." Chinese Science Bulletin, 48(4), 368-372.

Zhu, L., Li, Y., and Zhang, J. (1997). "Sorption of organobentonites to some organic pollutants in water." Environmental science \& technology, 31(5), 1407-1410. 
Zhu, R., Chen, Q., Zhou, Q., Xi, Y., Zhu, J., and He, H. (2016). "Adsorbents based on montmorillonite for contaminant removal from water: a review." Applied Clay Science, 123, 239-258.

Zhu, R., Zhou, Q., Zhu, J., Xi, Y., and He, H. (2015). "Organo-clays as sorbents of hydrophobic organic contaminants: sorptive characteristics and approaches to enhancing sorption capacity." Clays and Clay Minerals, 63(3), 199-221.

Zhuang, G., Zhang, H., Wu, H., Zhang, Z., and Liao, L. (2017). "Influence of the surfactants' nature on the structure and rheology of organo-montmorillonite in oilbased drilling fluids." Applied Clay Science, 135, 244-252.

Zhuang, G., Zhang, Z., Fu, M., Ye, X., and Liao, L. (2015). "Comparative study on the use of cationic-nonionic-organo-montmorillonite in oil-based drilling fluids." Applied Clay Science, 116, 257-262.

Zhuang, G., Zhang, Z., Sun, J., and Liao, L. (2016). "The structure and rheology of organomontmorillonite in oil-based system aged under different temperatures." Applied Clay Science, 124, 21-30. 


\section{CURRICULUM VITAE}

NAME: Mohammad Ghavami

ADDRESS: Department of Civil and Environmental Engineering, University of Louisville, 40208

EDUCATION

\begin{tabular}{|c|c|c|}
\hline \multirow[t]{2}{*}{ Ph.D. } & 2013-2017 & $\begin{array}{l}\text { Civil and Environmental Engineering, University } \\
\text { of Louisville }\end{array}$ \\
\hline & & $\begin{array}{l}\text { Specialization: Geotechnical and } \\
\text { Geoenvironmental Engineering }\end{array}$ \\
\hline MSc. & 2011-2013 & $\begin{array}{l}\text { Civil Engineering, The National University of } \\
\text { Malaysia (University Kebangsaan Malaysia) } \\
\text { Specialization: Geotechnical and } \\
\text { Geoenvironmental Engineering }\end{array}$ \\
\hline PUBLI & 2006-2010 & $\begin{array}{l}\text { Civil Engineering, Islamic Azad University- } \\
\text { Ghaemshahr- Iran }\end{array}$ \\
\hline
\end{tabular}

Peer-Reviewed Journal Papers

(1) Ghavami, M., Zhao, Q., Javadi, S., Dilip, J., Jasinski, J. B., Saraei, N., (2017) "Change of Organobentonite Interlayer Microstructure Induced by Sorption of Aromatic and Petroleum Hydrocarbons - A Combined Study of Laboratory Characterization and Molecular Dynamics Simulations". Colloids and Surfaces A Physicochemical and Engineering Aspects, 520, 324-334

(2) Javadi, S., Ghavami, M., Zhao, Q., Bate, B., (2016) “Advection and Retardation of Non-Polar Contaminants in Compacted Clay Barrier Material with Organoclay Amendment". Applied Clay Science;, DOI:10.1016/j.clay.2016.10.041

(3) Behnampour, A., Akbari, O. A., Safaei, M. R., Ghavami, M., Marzban, A., Shabani. Zarringhalam. M., Mashayekhi. R., (2017). "Analysis of Heat Transfer and Nanofluid Fluid Flow in Microchannels with Trapezoidal, Rectangular and Triangular Shaped Ribs". Physica E: Low-dimensional Systems and Nanostructures, 91, 15-31 
(4) Yousefi, D., Ghavami, M., Javadi, S., (2016) "Impact of Landfill Leachate Transport on Physiochemical Properties of Underlying Soil. A Case Study", Environmental Monitoring and Assessment (Under review)

(5) Bashirnezhad, M., Safaei, M. R.., Ghavami, M., (2016) "Experimental Investigations of Nanofluids Convective Heat Transfer Under Laminar Flows: A Review" The Journal of Molecular Liquids (Under review)

\section{Conference Proceedings}

(1) Ghavami, M., Javadi, S., Zhao, Q., (2016) "Laboratory Characterization of the Saturated Conductivities of Compacted Clay-Organobentonite Mixtures" GeoChicago, Chicago, USA, 458-467

(2) Javadi, S., Abdollahian, S., Zhao, Q., Ghavami, M., Rockaway, T., (2016) "Effectiveness of Heavy Metal Removal in Urban Permeable Pavement Systems". Geo-Chicago, Chicago, USA, 22-31

(3) Javadi, S., Ghavami, M., Zhao, Q., (2017) "Sorption and Transport of Benzene through Organoclay Amended Geosynthetic Clay Liners (GCL)". Geotechnical Frontiers, Orlando, FL, 86-96

(4) Shooshpasha, S., Afzali Rad, M., Ghavami, M., Kamalijoo, H., (2011) "Study on Bearing Capacity of Pile in Liquefiable and Unliquefiable Soil Layers". GeoFrontiers Congress, Dallas, Texas, USA, 3716-3725

(5) Shooshpasha, S., Afzali Rad, M., Ghavami, M., Kamalijoo, H., (2010) "Evaluation of Static and Dynamic Methods for Determining the Bearing Capacity of the Driven Pipe Piles". 4th International Conference on Geotechnical Engineering and Soil Mechanics, Tehran, Iran 